UNIVERSIDADE DE SÃO PAULO

FACULDADE DE FILOSOFIA, LETRAS E CIÊNCIAS HUMANAS

DEPARTAMENTO DE GEOGRAFIA

PROGRAMA DE PÓS-GRADUAÇÃO EM GEOGRAFIA FÍSICA

MÁRCIO GREYCK GUIMARÃES CORREA

DINÂMICA HIDROCLIMÁTICA E O FENÔMENO ENOS NA BACIA HIDROGRÁFICA DO RIO PIQUIRI-PR

Versão Corrigida 
LOMBADA

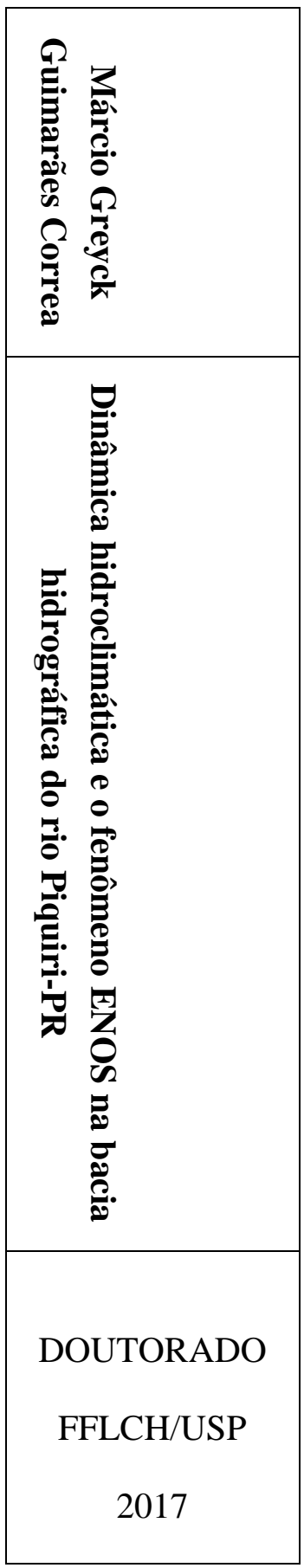




\section{DINÂMICA HIDROCLIMÁTICA E O FENÔMENO ENOS NA BACIA HIDROGRÁFICA DO RIO PIQUIRI-PR}

Tese apresentada ao Programa de Pós-Graduação em Geografia Física da Faculdade de Filosofia, Letras e Ciências Humanas da Universidade de São Paulo como parte dos requisitos para obtenção do título de Doutor em Ciências (Geografia Física).

Orientador: Prof. Dr. Emerson Galvani

\section{Versão Corrigida}

Prof. Dr. Emerson Galvani I 
2017

Ficha Catalográfica 
CORREA, M. G. G. Dinâmica hidroclimática e o fenômeno ENOS na bacia hidrográfica do rio Piquiri-PR. Tese apresentada à Faculdade de Filosofia, Letras e Ciências Humanas da Universidade de São Paulo para obtenção do título de Doutor em Ciências (Geografia Física)

Aprovado em

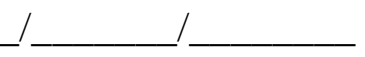

Banca examinadora

Prof. Dr. Emerson Galvani (Orientador)

Instituição: Universidade de São Paulo - USP

Assinatura:

Julgamento:

Prof. Dr. José Bueno Conti

Instituição: Universidade de São Paulo - USP

Assinatura:

Julgamento:

Prof. Dra. Maria Elisa Siqueira Silva

Instituição: Universidade de São Paulo - USP

Assinatura:

Julgamento:

Prof. Dra. Leila Limberger

Instituição: Universidade Estadual do Oeste do Paraná - UNIOESTE

Assinatura:

Julgamento:

Prof. Dr. Paulo Roberto Moraes

Instituição: Pontifícia Universidade Católica de São Paulo - PUC

Assinatura:

Julgamento: 


\section{Agradecimentos}

Foram quatro anos dedicados à realização de um sonho, encerro mais uma etapa da minha vida acreditando que o fim deste trabalho novos caminhos e desafios me aguardam para o futuro, mas não poderia deixar de agradecer a aqueles que estiveram e fizeram parte dessa longa jornada.

Agradeço ao Prof. Dr. Emerson Galvani pela orientação do trabalho, pelos conselhos e cobranças acadêmicas que tanto ajudaram na minha formação profissional e pessoal. Um exemplo de dedicação e profissionalismo ao qual me espelharei por toda a vida.

Aos meus pais (Artur e Seleide), por me apoiarem e acreditarem nos meus sonhos, serei sempre grato pela confiança, pela onipresença, pelo vosso amor.

Aos amigos e companheiros da pós-graduação e do Laboratório de Climatologia e Bioclimatologia - LCB, pelo apoio, pela ajuda, pelo companheirismo.

Ao Centro de Estatística Aplicada CEA-USP pela iniciativa de ajudar aos estudantes da instituição nas análises estatísticas de suas pesquisas, especialmente à Prof. Dra. Airlane Pereira Alencar, os alunos Msc. Orlando Yesid Esparza Albarracin, Fernando Poliano Tarouco Corrêa Filho e Raul de Holanda Campos.

Ao Prof. Dr. Fernando Nadal Junqueira Villela e à Prof. Dra. Maria Elisa Siqueira Silva do Programa de Pós-graduação em Geografia Física - USP pelas contribuições científicas durante o processo de qualificação do trabalho.

Ao Programa de Pós-graduação em Geografia Física pela oportunidade de cursar o doutorado numa instituição de prestígio como a Universidade de São Paulo - USP.

Ao Conselho Nacional de Desenvolvimento Científico e Tecnológico (CNPq) pelo financiamento por meio da bolsa de pesquisa, esse tipo de fomento é de extrema importância a todos nós pós-graduandos do país. 
Ao Instituto das Águas do Paraná, Agência Nacional de Águas e Bureau of Meteorology - National Climate Centre da Austrália pela disponibilização dos dados necessários para o desenvolvimento desta pesquisa.

Ao Programa de Aperfeiçoamento de Ensino (PAE) da Faculdade de Filosofia, Letras e Ciências Humanas - USP pela experiência de poder participar do estágio e auxílio à docência no Departamento de Geografia.

A todos os amigos que tive a honra de conhecer durante todos esses anos de vida acadêmica morando em São Paulo, em especial à Grace, Beatriz, Miguel, Aline, Diego, Renato Macchia, Renato de Abreu, Marina e Jessyca, os guardarei para sempre no meu coração.

À todos vocês, muito obrigado! 


\section{Resumo}

Esta tese apresenta um estudo hidroclimático para a bacia hidrográfica do rio Piquiri-Pr, o trabalho desenvolve-se sob a égide sistêmica e a bacia hidrográfica entendida como unidade de análise da paisagem é a delimitação espacial escolhida para fornecer respostas à hipótese norteadora da pesquisa. O objetivo da pesquisa é compreender como ocorre a dinâmica hidroclimática na bacia em questão, para isso considera-se a precipitação pluviométrica e a vazão fluvial como elementos dinamizadores do sistema e o El Niño Oscilação Sul (ENOS) como o responsável por influenciar a variabilidade temporal desses elementos. Para isso buscou-se descrever estatisticamente a precipitação e a vazão fluvial, os dados de 41 postos pluviométricos foram fornecidos pelo Instituto das Águas do Paraná e os dados de três postos fluviométricos pela Agência Nacional de Águas (ANA) no período de 1976 a 2010. Por meio da correlação linear procurou-se explicar as relações existentes entre a precipitação pluviométrica e a vazão fluvial, calculou-se a evapotranspiração e o coeficiente de escoamento da bacia hidrográfica. Determinou-se a influência do ENOS na precipitação e na vazão fluvial utilizando-se dos dados do Índice de Oscilação Sul (IOS) disponibilizados pelo Bureau of Meteorology - National Climate Centre da Austrália, a partir da correlação entre as variáveis e a aplicação do modelo GAMLSS (Modelos aditivos generalizados para posição, escala e forma) buscou-se explicar a participação do ENOS na variabilidade temporal da precipitação pluviométrica e da vazão. Com o desenvolvimento da pesquisa conclui-se que a vazão não é apenas resultante da precipitação, mas os processos de evapotranspiração e infiltração também influenciam na sua variabilidade. Com relação à influência do fenômeno ENOS, as correlações mostraram que o IOS influencia a precipitação e a vazão na bacia hidrográfica do rio Piquiri, com maior confiança, de um a três meses de defasagem, o modelo GAMLSS mostrou-se satisfatório para a determinação da influência do IOS nas variáveis precipitação e vazão.

\section{Palavras-chave}

Hidroclimatologia, Bacia Hidrográfica, Índice de Oscilação Sul, Precipitação pluviométrica, Vazão fluvial. 


\begin{abstract}
This thesis presents a hydroclimatic study for the Piriqui watershed, Paraná State, Brazil. The study was developed under a systemic approach, and the watershed, understood as the unit of analysis of the landscape, was the spatial limit chosen to provide responses to the hypothesis guiding the research. The objective was to investigate the hydroclimatic dynamics of the watershed in question, considering precipitation and river flow as elements dynamizing the system and the El Niño Southern Oscillation (ENSO) as responsible for influencing the temporal variability of these elements. To this end, precipitation and river flow were described statistically. Data from 41 rain gauge stations in the period from 1976 to 2010 were provided by Instituto das Águas do Paraná and the river flow datas were provided by National Water Agency (Agência Nacional de Águas - ANA). Using linear correlation analysis, we explained the relationships existing between precipitation and river flow and calculated the evapotranspiration and the runoff coefficient of the drainage basin. The influence of ENSO on precipitation and river flow was determined using data from the Southern Oscillation Index (SOI) provided by the Bureau of Meteorology - National Climate Centre of Australia. The correlation between the variables and the application of the GAMLSS model allowed us to explain the participation of ENOS in the temporal variability of precipitation and flow. Through the development of the research, we concluded that the river flow results not only from precipitation, but the processes of evapotranspiration and infiltration may interfere with its variability. With respect to the influence of the ENSO phenomenon, the correlations revealed that SOI influences the precipitation and flow in the Piquiri watershed, with greater reliability with a delay of one to three months, and the GAMLSS model showed to be satisfactory for determining the influence of SOI on the precipitation and river flow variables.
\end{abstract}

\title{
Keywords
}

Hydroclimatology, Watershed, Southern Oscillation Index, Precipitation, River Flow. 


\section{LISTA DE ABREVIATURAS E SIGLAS}

ENOS El Niño Oscilação Sul

SEMA Secretaria Estadual do Meio Ambiente

CCMs Complexos Convectivos de Mesoescala

ZCAS Zona de Convergência do Atlântico Sul

JBN Jatos de Baixos Níveis

ANA Agência Nacional de Águas

ETP Evapotranspiração Potencial

C Coeficiente de Escoamento Superficial

P Precipitação Pluviométrica

Q Vazão Fluvial

TSM Temperatura da Superfície do Mar

IOS Índice de Oscilação Sul

EM El Niño

LN La Niña

GAMLSS Modelos Aditivos Generalizados para Posição, Escala e Forma

MLG Modelos Lineares Generalizados

MAG Modelos Aditivos Generalizados 


\section{LISTA DE FIGURAS}

FiguRA 1: MAPA DE LOCALIZAÇÃo DA BACIA HIDROGRÁFICA DO RIO PIQUIRI-PR. ............................................. 26

FIGURA 2: FLUXOGRAMA DOS PROCEDIMENTOS E TÉCNICAS UTILIZADOS NA PESQUISA. ........................................ 34

FIGURA 3: LOCALIZAÇÃO DOS POSTOS PLUVIOMÉTRICOS DO INSTITUTO DAS ÁGUAS DO PARANÁ COM SEUS RESPECTIVOS RAIOS DE ABRANGÊNCIA NA BACIA HIDROGRÁFICA DO RIO PIQUIRI-PR. ................................... 38

Figura 4: PLUVIÔMETRO VILLE DE PARIS UTILIZADO NA COLETA DA PRECIPITAÇÃo PluVIOMÉTRICA NA REDE DE

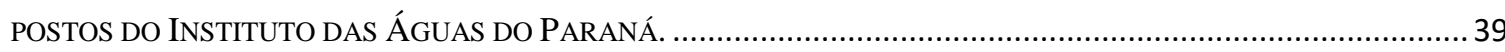

FIGURA 5: DESVIOS DE PRECIPITAÇão E LINHA DE TENDÊNCIA ANUAL PARA A BACIA HIDROGRÁFICA DO RIO

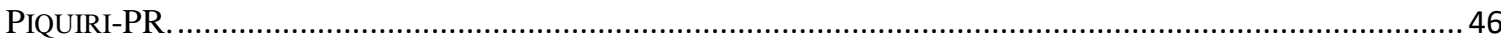

FIGURA 6: DESVIOS DE PRECIPITAÇÃO E LINHA DE TENDÊNCIA SAZONAL PARA A BACIA HIDROGRÁFICA DO RIO PIQUIRI-PR

FIGURA 7: DESVIOS DE PRECIPITAÇÃO E LINHA DE TENDÊNCIA MENSAL PARA A BACIA HIDROGRÁFICA DO RIO PIQUIRI-PR.

FIGURA 8: HISTOGRAMA DE FREQUÊNCIA DOS TOTAIS DE PRECIPITAÇÃO ANUAL PARA A BACIA HIDROGRÁFICA DO RIO PIQUIRI-PR.

FIGURA 9: HISTOGRAMA DE FREQUÊNCIA DOS TOTAIS DE PRECIPITAÇÃO SAZONAL PARA A BACIA HIDROGRÁFICA DO RIO PIQUIRI-PR.

Figura 10: PAISAGENS HIDROLÓGICAS GENERALIZADAS, (A) VALE DE MONTANHA; (B) ÁREAS PLANAS E DESÉRTICAS; (C) Platôs E ALTAS PlANíCIES; (D) VALE FLUVIAL; (E) TERRENOS COSTEIROS; (F) TERRENOS DE HUMMOCKY

FigURA 11: MAPA HIPSOMÉTRICO COM TRÊS PERFIS TRANSVERSAIS NO ALTO, MÉDIO E BAIXO CURSO DO RIO PIQUIRI.

FIGURA 12: FOTOGRAFIA DE TRECHO DO RIO PIQUIRI SOBRE A PONTE NA PR-486 (ASSIS CHATEAUBRIAND BRASILÂNDIA DO SUL) VISADA PARA OESTE.

Figura 13 - LOCALIZAÇÃo dOS POSTOS FLUVIOMÉTRICOS DA AGÊNCIA NACIONAL DE ÁGUAS (ANA) NA baCia HIDROGRÁFICA DO RIO PIQUIRI-PR.

FIGURA 14: ESQUEMA EXPLICATIVO DE INSTALAÇÃO DO LINIMENTO DA AGÊNCIA NACIONAL DE ÁGUAS (ANA).60

FiguRA 15: DESVIO DE VAZÃo ANUAL E LINHA DE TENDÊNCIA ANUAL PARA O POSTO BALSA STA. MARIA DA BACIA HIDROGRÁFICA DO RIO PIQUIRI-PR...

FIGURA 16: DESVIO DE VAZÃO SAZONAL E LINHA DE TENDÊNCIA SAZONAL PARA O POSTO BALSA STA. MARIA DA BACIA HIDROGRÁFICA DO RIO PIQUIRI-PR.

Figura 17: DESVIO DE VAZÃo MENSAL E LINHA DE TENDÊNCIA MENSAL PARA O POSTO BALSA STA. MARIA DA BACIA HIDROGRÁFICA DO RIO PIQUIRI-PR.

FigURA 18: ÁREA DE CAPTAÇÃO DETERMINADA PELA ÁREA DE DRENAGEM DE CADA POSTO FLUVIOMÉTRICO NA BACIA HIDROGRÁFICA DO RIO PIQUIRI.

FIGURA 19: BOXPLOTS E AUTOCORRELAÇÃO DA PRECIPITAÇÃO PLUVIOMÉTRICA PARA AS TRÊS ÁREAS DE DRENAGEM DA BACIA HIDROGRÁFICA DO RIO PIQUIRI

FIGURA 20: BOXPLOTS E AUTOCORRELAÇ̃̃O PARCIAL DA VAZÃO FLUVIAL PARA AS TRÊS ÁREAS DE DRENAGEM DA BACIA HIDROGRÁFICA DO RIO PIQUIRI.

FIGURA 21: GRÁFICOS DE DISPERSÃO E AUTOCORRELAÇÃO CRUZADA ENTRE PRECIPITAÇÃO E VAZÃO NA BACIA HIDROGRÁFICA DO RIO PIQUIRI-PR

Figura 22: AUTOCORRELAÇ̃̃o CRUZADA ENTRE VAZÃO E PRECIPITAÇÃO COM DEFASAGEM PARA O POSTO DE BALSA STA. MARIA A3.

FIGURA 23: GRÁFICO DE DISPERSÃO ENTRE VAZ̃̃o E PRECIPITAÇÃO DEFASADA EM UM MÊS PARA O POSTO DE BALSA STA. MARIA A3.

FigURA 24: DISTRIBUIÇÃO TEMPORAL DA PRECIPITAÇÃO PLUVIOMÉTRICA E DA VAZ̃̃o FLUVIAL PARA A BACIA DO RIO PIQUIRI-PR.

FigURA 25: REGIÕES CONSIDERADAS PARA DETERMINAÇÃO DE ANOMALIAS DE TEMPERATURA DA SUPERFICIE DO MAR (TSM) NO OCEANO PACÍFICO. 
FIGURA 26: LOCALIZAÇÃO DAS ÁREAS CONSIDERADAS PARA A MENSURAÇÃO DO ÍNDICE DE OSCILAÇÃO SUL

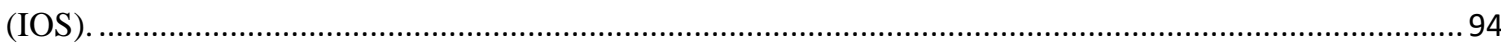

FIGURA 27: COMPARAÇÃO ENTRE ANOMALIAS DE TSM (REGIÃO NIÑO 3.4) E IOS. ........................................... 95

FIGURA 28: MODELO EXPLICATIVO DA OCORRÊNCIA DO ENOS EM SUA FASE POSITIVA E NEGATIVA SOBRE O

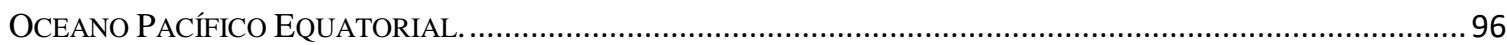

FIGURA 29: GRÁFICOS DE DISPERSÃO E AUTOCORRELAÇÃO COM DEFASAGEM ENTRE PRECIPITAÇÃO, VAZÃO E IOS PARA ÁREA 1- GUAMPARÁ NA BACIA HIDROGRÁFICA DO RIO PIQUIRI-PR .......................................................... 105

FIGURA 30: GRÁFICOS DE DISPERSÃO E AUTOCORRELAÇÃO COM DEFASAGEM ENTRE PRECIPITAÇÃO, VAZÃO E IOS

PARA ÁREA 2- PORTO GUARANI NA BACIA HIDROGRÁFICA DO RIO PIQUIRI-PR ............................................. 106

FIGURA 31: GRÁFICOS DE DISPERSÃO E AUTOCORRELAÇÃO COM DEFASAGEM ENTRE PRECIPITAÇÃO, VAZÃO E IOS PARA ÁREA 3- BALSA SANTA MARIA NA BACIA HIDROGRÁFICA DO RIO PIQUIRI-PR ..................................... 107

Figura 32: ANÁLISE DE RESÍDUOS DO MODELO GAMLSS DUPLO COM RESPOSTA GAMA GENERALIZADA AJUSTADO PARA A VARIÁVEL PRECIPITAÇÃO EM A1 - GUAMPARÁ. …………………………………..... 108

FIGURA 33: ANÁLISE DE RESÍDUOS DO MODELO GAMLSS DUPLO COM RESPOSTA GAMA GENERALIZADA AJUSTADO PARA A VARIÁVEL PRECIPITAÇÃO EM A2 - PORTO GUARANI. ....................................................... 109

FIGURA 34: ANÁLISE DE RESÍDUOS DO MODELO GAMLSS DUPLO COM RESPOSTA GAMA GENERALIZADA AJUSTADO PARA A VARIÁVEL PRECIPITAÇÃO EM A3 - BALSA SANTA MARIA.

FIGURA 35: ANÁLISE DE RESÍDUOS DO MODELO DE REGRESSÃO LINEAR AJUSTADO PARA A VAZÃO COM TRANSFORMAÇÃO LOGARÍTMICA NA VARIÁVEL RESPOSTA E AUTO-CORRELAÇÃO NOS RESÍDUOS PARA A1GUAMPARÁ.

FIGURA 36: ANÁLISE DE RESÍDUOS DO MODELO DE REGRESSÃO LINEAR AJUSTADO PARA A VAZÃO COM TRANSFORMAÇÃO LOGARÍTMICA NA VARIÁVEL RESPOSTA E AUTO-CORRELAÇÃO NOS RESÍDUOS PARA A2PORTO GUARANI.

FIGURA 37: ANÁLISE DE RESÍDUOS DO MODELO DE REGRESSÃO LINEAR AJUSTADO PARA A VAZÃO COM TRANSFORMAÇÃO LOGARÍTMICA NA VARIÁVEL RESPOSTA E AUTO-CORRELAÇÃO NOS RESÍDUOS PARA A3BALSA SANTA MARIA.

FIGURA 38: VALORES AJUSTADOS PREDITOS E VALORES OBSERVADOS PELO MODELO DE REGRESSÃO COM RESÍDUOS AUTO CORRELACIONADOS PARA VAZÃO PARA A3 - BALSA SANTA MARIA. 


\section{LISTA DE TABELAS}

TABEla 1- POSTOS PLUVIOMÉTRICOS DO INSTITUTO DAS ÁGUAS DO PARANÁ PARA A BACIA HIDROGRÁFICA DO RIO PIQUIRI-PR.

TABELA 2- COEFICIENTE DE DETERMINAÇÃO PARA OS 41 POSTOS PLUVIOMÉTRICOS NA BACIA HIDROGRÁFICA DO RIO PIQUIRI.

TABELA 3- ESTATÍSTICA DESCRITIVA DA PRECIPITAÇÃO PLUVIOMÉTRICA MÉDIA PARA A BACIA HIDROGRÁFICA DO RIO PIQUIRI DE 1976 A 2010

TABELA 4- COEFICIENTE DE DETERMINAÇÃO PARA OS POSTOS FLUVIOMÉTRICOS DA ANA NA BACIA HIDROGRÁFICA DO RIO PIQUIRI-PR

TABELA 5- ESTATÍSTICA DESCRITIVA DA VAZÃO FLUVIAL MÉDIA PARA A BACIA HIDROGRÁFICA DO RIO PIQUIRI DE 1976 A 2010.

TABELA 6 - ESTATÍSTICA DESCRITIVA DA VAZÃO FLUVIAL SAZONAL MÉDIA PARA A BACIA HIDROGRÁFICA DO RIO PIQUIRI DE 1976 A 2010.

TABELA 7 - ESTATÍSTICA DESCRITIVA DA VAZÃO FLUVIAL MENSAL MÉDIA PARA O POSTO FLUVIOMÉTRICO DE GUAMPARÁ NA BACIA HIDROGRÁFICA DO RIO PIQUIRI DE 1976 A 2010.

TABELA 8 - ESTATÍSTICA DESCRITIVA DA VAZÃO FLUVIAL MENSAL MÉDIA PARA O POSTO FLUVIOMÉTRICO DE PTO. GUARANI NA BACIA HIDROGRÁFICA DO RIO PIQUIRI DE 1976 A 2010.

TABELA 9- ESTATÍ́STICA DESCRITIVA DA VAZÃO FLUVIAL MENSAL MÉDIA PARA O POSTO FLUVIOMÉTRICO DE BALSA STA. MARIA NA BACIA HIDROGRÁFICA DO RIO PIQUIRI DE 1976 A 2010.

TABELA 10 - CORRELAÇÃo (R) ENTRE PRECIPITAÇÃO MÉDIA (P) E VAZÃO (Q) ANUAL, SAZONAL E MENSAL......... 77

TABELA 11 - BALANÇO HÍDRICO CLIMATOLÓGICO ANUAL PARA O PERÍODO DE 1976 A 2010 PARA BACIA HIDROGRÁFICA DO RIO PIQUIRI-PR

TABELA 12 - PARÂMETROS AJUSTAdOS PARA A MODELAGEM DA MÉdiA DA PRECIPITAÇÃO NO MODELO GAMLSS COM RESPOSTA GAMA GENERALIZADA PARA A1 - GUAMPARÁ.

TABELA 13 - PARÂMETROS AJUSTADOS PARA A MODELAGEM DA MÉDIA DA PRECIPITAÇÃO NO MODELO GAMLSS COM RESPOSTA GAMA GENERALIZADA PARA A2 - PORTO GUARANI 111

TABEla 14- PARÂMETROS AJUSTADOS PARA A MODELAGEM DA MÉDIA DA PRECIPITAÇÃO NO MODELO GAMLSS COM RESPOSTA GAMA GENERALIZADA PARA A3 - BALSA SANTA MARIA 111

TABELA 15- PARÂMETROS AJUSTADOS PARA A MODELAGEM DA VARIÂNCIA DA PRECIPITAÇÃO NO MODELO GAMLSS COM RESPOSTA GAMA GENERALIZADA PARA A1 - GUAMPARÁ.

TABELA 16- PARÂMETROS AJUSTADOS PARA A MODELAGEM DA VARIÂNCIA DA PRECIPITAÇÃO NO MODELO GAMLSS COM RESPOSTA GAMA GENERALIZADA PARA A2 - PORTO GUARANI. 112

TABELA 17 - PARÂMETROS AJUSTADOS PARA A MODELAGEM DA VARIÂNCIA DA PRECIPITAÇÃO NO MODELO GAMLSS COM RESPOSTA GAMA GENERALIZADA PARA A3 - BALSA SANTA MARIA 113

TABELA 18 - PARÂMETROS AJUSTADOS PARA O MODELO DE REGRESSÃO LINEAR COM ERROS CORRELACIONADOS PARA VAZÃO DA A1 - GUAMPARÁ COM TRANSFORMAÇÃO LOGARÍTMICA 118

TABELA 19 - PARÂMETROS AJUSTADOS PARA O MODELO DE REGRESSÃO LINEAR COM ERROS CORRELACIONADOS PARA VAZÃO DA A2 - PORTO GUARANI COM TRANSFORMAÇÃO LOGARÍTMICA. 119

TABELA 20 - PARÂMETROS AJUSTADOS PARA O MODELO DE REGRESSÃO LINEAR COM ERROS CORRELACIONADOS PARA VAZÃO DA A3 - BALSA SANTA MARIA COM TRANSFORMAÇÃO LOGARÍTMICA 


\section{SUMÁRIO}

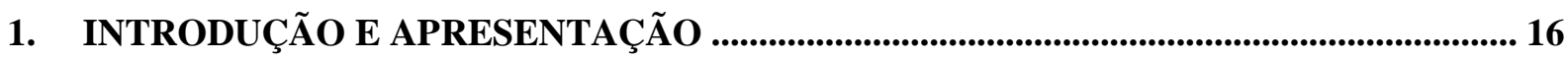

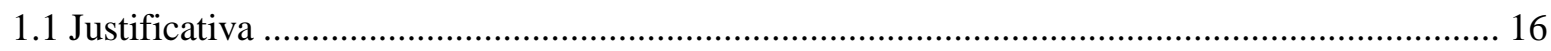

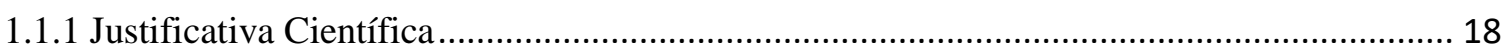

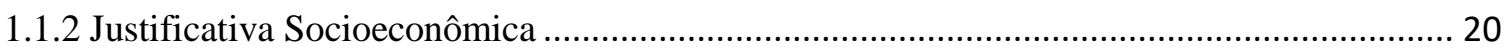

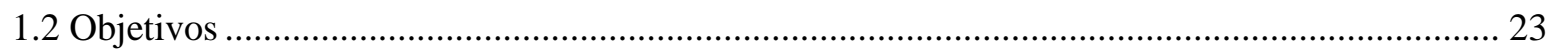

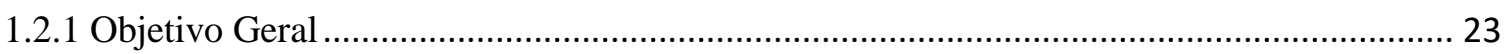

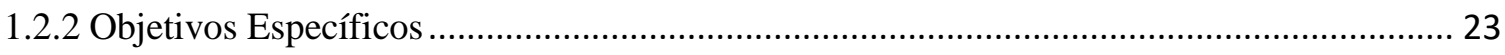

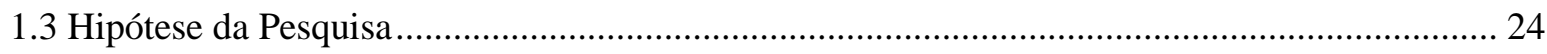

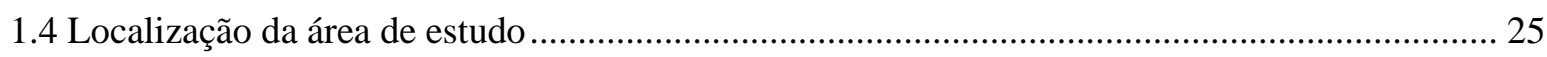

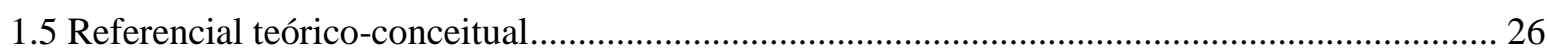

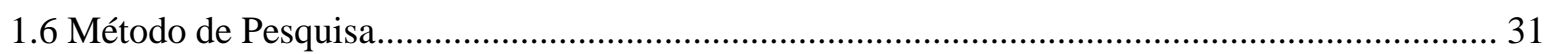

\section{PARTE I - PRECIPITAÇÃO PLUVIOMÉTRICA DA BACIA HIDROGRÁFICA DO}

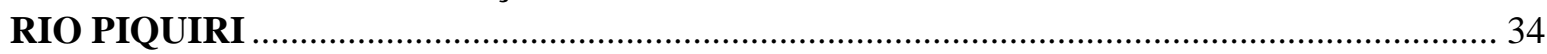

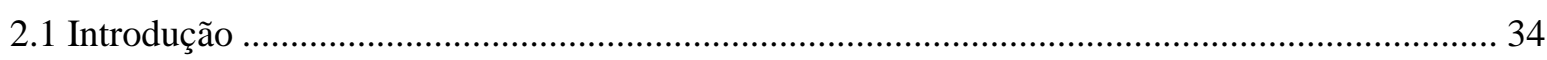

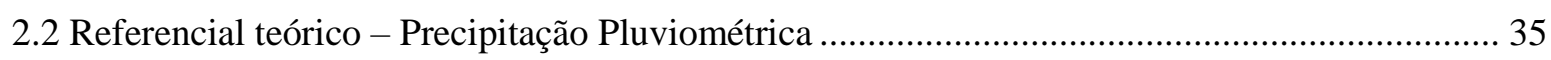

2.3 Procedimentos metodológicos: Precipitação Pluviométrica ...................................................... 36

2.3.1 Escolha e análise da consistência dos dados de precipitação ............................................... 36

2.3.2 Análise estatística dos dados de precipitação ......................................................................... 41

2.4 Análise e discussão dos resultados da precipitação....................................................................... 42

2.4.1 Estatística descritiva da precipitação pluviométrica............................................................. 42

2.4.2 Desvio e tendência da precipitação pluviométrica .................................................................. 45

2.4.3 Análise da frequência dos totais pluviométricos .................................................................... 48

2.5 Considerações sobre a precipitação pluviométrica ...................................................................... 50

3. PARTE II - VAZÃo FLUVIAL DA BACIA HIDROGRÁFICA DO RIO PIQUIRI.......... 52

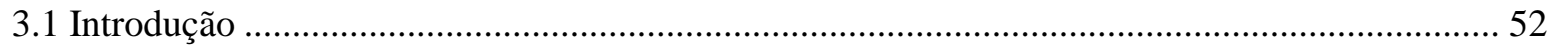

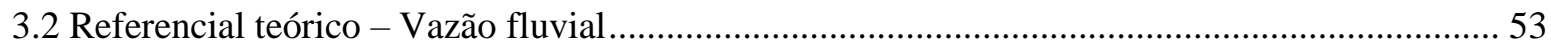

3.2.1 Características hidrogeomorfológicas da bacia hidrográfica do rio Piquiri .......................... 56

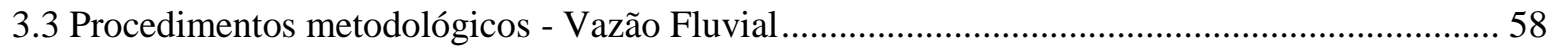

3.3.1 Escolha e análise da consistência dos dados de vazão ........................................................ 58

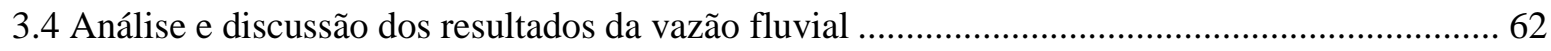

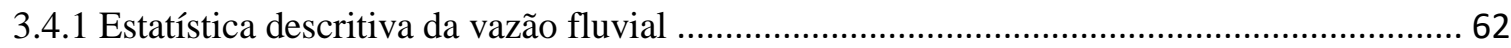




\section{PARTE III - CORRELAÇÃO ENTRE PRECIPITAÇÃO E VAZÃO NA BACIA}

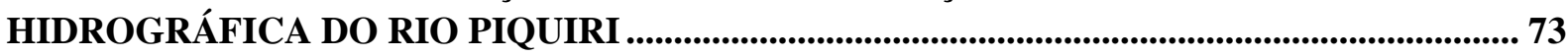

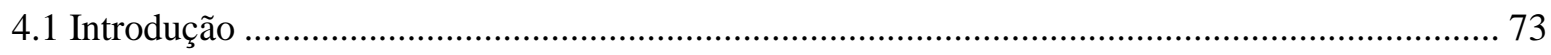

4.2 Procedimentos metodológicos: Correlação precipitação e vazão ................................................ 73

4.2.1 Estatística para a análise de série temporal ……................................................................ 75

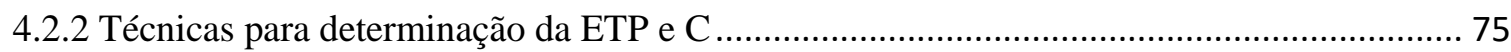

4.3 Análise e discussão dos resultados da correlação entre precipitação e a vazão .......................... 77

4.3.1 Boxplots e autocorrelação de precipitação e vazão para as três áreas de drenagem.............. 77

4.3.1 Processos de evapotranspiração (ETP) e coeficiente de escoamento (C) ............................ 86

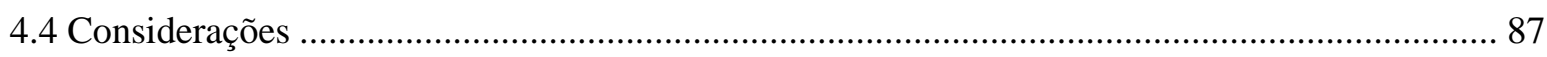

\section{PARTE IV - EL NIÑO OSCILAÇÃO SUL E A BACIA HIDROGRÁFICA DO RIO}

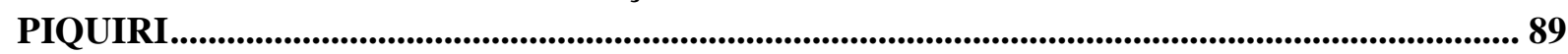

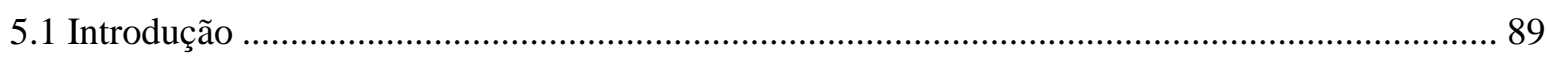

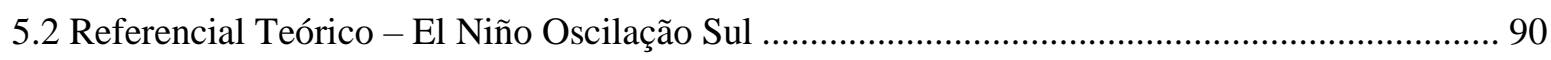

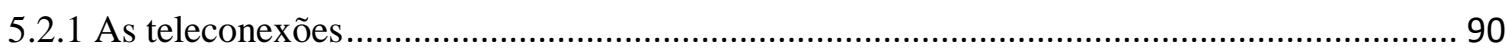

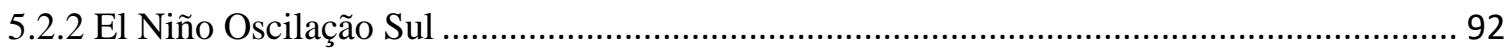

5.3 Procedimentos Metodológicos: Correlação ENOS, Precipitação e Vazão fluvial ........................ 97

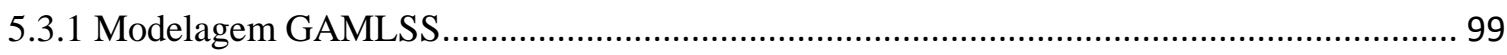

5.4 Análise e discussão dos resultados da correlação entre ENOS, precipitação e vazão fluvial ... 103

5.4.1 Modelo inferencial para Precipitação.................................................................................. 108

5.4.2 Modelo inferencial para Vazão ……………….......................................................... 114

5.5 Considerações sobre ENOS na bacia hidrográfica do rio Piquiri............................................ 120

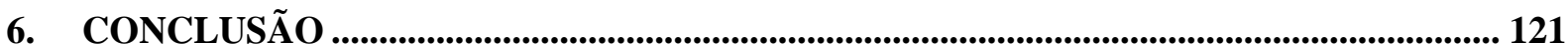

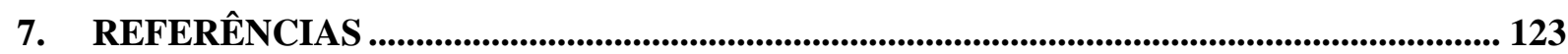




\section{INTRODUÇÃO E APRESENTAÇÃO}

A água é um elemento essencial para a perpetuação da vida na Terra e para o desenvolvimento das atividades humanas. Shelton (2009) explica que apesar da abundância de água no planeta, apenas uma pequena parte está disponível para o uso da sociedade em forma de água doce, além das disparidades existentes quanto à sua distribuição na superfície

terrestre. É através dos processos físicos do ciclo hidrológico que a água é redistribuída naturalmente entre os oceanos, terra e atmosfera.

De acordo com Tundisi (2003), aproximadamente $47 \mathrm{mil} \mathrm{km}^{3}$ de água é drenada para os oceanos pelos rios no mundo. O problema é que essa drenagem não é uniforme na superfície do planeta, a distribuição natural da água é desigual e causa problemas de disponibilidade nos continentes, países e regiões. A distribuição também não é homogênea durante o ano, causando desequilíbrios e ações diversificadas de gerenciamento dos recursos hídricos para melhor enfrentar os períodos de excesso ou escassez de água.

Para Shelton (2009), o clima é a força motora do ciclo hidrológico, as interações entre a precipitação, evapotranspiração, intercepção, percolação, armazenamento de umidade do solo, águas subterrâneas, escoamento, vazão, entre outros processos, são objetos de estudo da hidroclimatologia, responsável por fornecer uma ampla perspectiva de análise dos problemas que envolvem os recursos hídricos.

A disponibilidade e variabilidade da água disponível nos reservatórios, rios, lagos e lençóis freáticos são comandadas pela variabilidade da precipitação. A precipitação é resultante da atuação de diferentes sistemas atmosféricos e das interações decorrentes entre a atmosfera e o oceano. 
Perturbações climáticas podem estar associadas à forçantes que repercutem na variabilidade dos principais padrões da circulação atmosférica de grande escala, Ambrizzi (2003). Uma dessas perturbações é o fenômeno El Nino Oscilação Sul (ENOS), responsável por alterar os padrões de circulação global da atmosfera e influenciar o clima de várias regiões do globo, inclusive o Brasil.

Estudos feitos por Harzallah et al. (1996) indicam a participação do oceano Atlântico e Pacífico na variabilidade interanual das chuvas sobre o nordeste brasileiro na definição dos períodos mais secos em contraposição aos mais úmidos, assim como Espinozza Villar et al. (2009) também correlacionaram a distribuição das chuvas com a dinâmica dos oceanos e suas decorrências na dinâmica atmosférica na bacia hidrográfica do rio Amazonas.

A bacia hidrográfica é uma importante unidade de análise da paisagem, onde a água é o elemento responsável por dinamizar os processos naturais; é na bacia hidrográfica que o ciclo hidrológico pode ser melhor compreendido a partir dos processos de precipitação e escoamento da água.

Faz-se necessário entender não apenas o funcionamento da variabilidade da precipitação pluviométrica, mas também sua relação em conformidade com outros elementos da paisagem, que podem responder direta ou indiretamente a essa variabilidade, nesse sentido, buscou-se com o desenvolvimento desta pesquisa incluir a vazão fluvial como objeto de análise, com a finalidade de compreender as relações hidroclimáticas (precipitação pluviométrica, vazão fluvial e ENOS) na bacia hidrográfica do rio Piquiri.

Esta tese apresenta-se estruturada em quatro partes, cada parte apresenta uma análise detalhada dos elementos considerados fundamentais (objetos de estudo) para o desenvolvimento da pesquisa, desta forma tem-se na "Parte I - Precipitação Pluviométrica" 
uma análise estatística descritiva em escala anual, sazonal e mensal, desvios, tendência e frequência da precipitação para a bacia hidrográfica do rio Piquiri.

$\mathrm{Na}$ “Parte II - Vazão Fluvial”, apresenta-se a estatística descritiva em escala anual, sazonal e mensal para os três postos fluviométrico utilizados na pesquisa (Guampará, Porto Guarani e Balsa Santa Maria), para a "Parte III - Análise Integrada de Precipitação e Vazão" optou-se por realizar uma análise de correlação linear entre as duas variáveis estudadas com emprego de análises estatísticas e métodos de avaliação como o cálculo de evapotranspiração e o coeficiente de escoamento.

A "Parte IV - Correlação com o El Niño Oscilação Sul” faz-se uma correlação estatística entre a precipitação, vazão e o Índice de Oscilação Sul com a finalidade de mostrar a participação do fenômeno do aquecimento das águas superficiais do Oceano Pacífico na distribuição temporal da chuva e da vazão na bacia hidrográfica do rio Piquiri.

\subsection{Justificativa}

\subsubsection{Justificativa Científica}

Os estudos hidroclimáticos apontam para uma visão sistêmica do funcionamento dos fenômenos e processos naturais. Compreender os mecanismos atuantes na dinâmica das bacias hidrográficas é essencial para o desenvolvimento desta área do conhecimento, sendo a climatologia uma área do conhecimento fundamental nesse processo.

Os estudos de correlação entre dois ou mais fenômenos tem se tornado cada vez mais frequentes em climatologia, a natureza interdisciplinar da Geografia tem dado suporte aos 
pesquisadores para que possam buscar cada vez mais metodologias e técnicas de análise que corroborem para o desenvolvimento de suas pesquisas.

Esta pesquisa desenvolve-se sob a égide interdisciplinar, partindo-se de pressupostos teóricos geográficos busca-se nas bases de disciplinas como a climatologia, geomorfologia, hidrografia, meteorologia, estatística e matemática, procedimentos que permitam analisar de forma integrada os fenômenos aqui propostos a serem entendidos.

Shelton (2009) evidencia que a água é o elemento principal dos estudos hidroclimáticos, sendo considerada como o fator de entrada de energia e matéria no sistema hidrográfico e responsável por desencadear uma série de processos naturais, precipitação, infiltração e escoamento, dinamizados pelo ciclo hidrológico.

A vazão fluvial é uma das resultantes da entrada de água no sistema hidrográfico por meio da precipitação. A compreensão da sua dinâmica e funcionamento é essencial para explicar a dinâmica hídrica da bacia hidrográfica sendo o fenômeno El Niño Oscilação Sul (ENOS) responsável por parte da variabilidade da precipitação e da vazão fluvial em bacias hidrográficas.

O fenômeno ENOS pode causar variações na dinâmica climática e estar relacionado à períodos prolongados de excesso de chuva que causam alagamentos, deslizamentos e cheias dos rios. Estão também associados a longos períodos de seca que trazem sérios riscos ao abastecimento hídrico, causando deficiência hídrica e sérios danos socioambientais, como constatado por Nery (2005), Molion e Bernardo (2000), Limberger e Silva (2016).

De acordo com Grimm et al. (2000) o setor sul do Brasil apresenta um forte sinal resposta aos períodos de EN e LN. A bacia hidrográfica do rio Piquiri está localizada numa região de transição climática entre o clima tropical e o clima subtropical, como apresentado 
por Correa (2013). Esta pesquisa pode trazer contribuições singulares na compreensão da participação do fenômeno ENOS numa bacia hidrográfica localizada em uma zona de transição climática.

\subsubsection{Justificativa Socioeconômica}

A bacia hidrográfica do rio Piquiri está localizada numa importante região agrícola do estado do Paraná, a área da bacia abrange 69 municípios do centro-oeste do estado, que em sua maioria são importantes produtores de grãos. O quadro 1 mostra todos os municípios que estão localizados na bacia hidrográfica do rio Piquiri, com um total de 1,5 milhão de habitantes e uma produção agrícola total de mais de 2,2 bilhões de reais, de acordo com o IBGE.

Quadro 1 - População total e produção agrícola total por município da bacia hidrográfica do rio Piquiri-PR

\begin{tabular}{c|c|c}
\hline Município & População Total & Prod. Agrícola Total (Milhões R\$) \\
\hline \hline Altamira do Paraná & 4.306 & $\mathrm{R} \$ 5.842,00$ \\
\hline Alto Piquiri & 20.516 & $\mathrm{R} \$ 6.985,00$ \\
\hline Altônia & 10.179 & $\mathrm{R} \$ 25.596,00$ \\
\hline Anahy & 2.874 & $\mathrm{R} \$ 7.246,00$ \\
\hline Araruna & 13.419 & $\mathrm{R} \$ 24.660,00$ \\
\hline Assis Chateaubriand & 33.025 & $\mathrm{R} \$ 104.605,00$ \\
\hline Boa Esperança & 4.568 & $\mathrm{R} \$ 36.895,00$ \\
\hline Boa Ventura de São Roque & 6.554 & $\mathrm{R} \$ 25.527,00$ \\
\hline Braganey & 5.735 & $\mathrm{R} \$ 34.860,00$ \\
\hline Brasilândia do Sul & 3.209 & $\mathrm{R} \$ 23.954,00$ \\
\hline Cafelândia & 14.662 & $\mathrm{R} \$ 29.723,00$ \\
\hline Cafezal do Sul & 4.290 & $\mathrm{R} \$ 2.825,00$ \\
\hline Campina da Lagoa & 15.394 & $\mathrm{R} \$ 50.918,00$ \\
\hline Campina do Simão & 4.076 & $\mathrm{R} \$ 6.226,00$ \\
\hline Campo Bonito & 4.407 & $\mathrm{R} \$ 20.428,00$ \\
\hline Campo Mourão & 87.194 & $\mathrm{R} \$ 59.441,00$ \\
\hline Cantagalo & 12.952 & $\mathrm{R} \$ 24.355,00$ \\
\hline Cascavel & 286.205 & $\mathrm{R} \$ 108.507,00$ \\
\hline Catanduvas & 10.202 & $\mathrm{R} \$ 22.753,00$ \\
\hline
\end{tabular}




\begin{tabular}{|c|c|c|}
\hline Cianorte & 69.958 & $\mathrm{R} \$ 26.345,00$ \\
\hline Corbélia & 16.312 & $\mathrm{R} \$ 46.912,00$ \\
\hline Cruzeiro do Oeste & 20.416 & $\mathrm{R} \$ 7.875,00$ \\
\hline Diamante do Sul & 3.510 & $\mathrm{R} \$ 4.962,00$ \\
\hline Farol & 3.472 & $\mathrm{R} \$ 26.305,00$ \\
\hline Formosa do Oeste & 7.541 & $\mathrm{R} \$ 21.286,00$ \\
\hline Francisco Alves & 6.418 & $\mathrm{R} \$ 18.786,00$ \\
\hline Goioerê & 29.018 & $\mathrm{R} \$ 50.019,00$ \\
\hline Goioxim & 7.503 & $\mathrm{R} \$ 29.114,00$ \\
\hline Guaraniaçu & 14.582 & $\mathrm{R} \$ 23.584,00$ \\
\hline Guarapuava & 167.328 & $\mathrm{R} \$ 134.457,00$ \\
\hline Ibema & 6.066 & $\mathrm{R} \$ 8.839,00$ \\
\hline Iguatu & 2.234 & $\mathrm{R} \$ 6.454,00$ \\
\hline Iporã & 14.981 & $\mathrm{R} \$ 31.453,00$ \\
\hline Iracema do Oeste & 2.578 & $\mathrm{R} \$ 9.268,00$ \\
\hline Janiópolis & 6.532 & $\mathrm{R} \$ 23.015,00$ \\
\hline Jesuítas & 9.001 & $\mathrm{R} \$ 19.151,00$ \\
\hline Juranda & 7.641 & $\mathrm{R} \$ 42.873,00$ \\
\hline Laranjal & 6.360 & $\mathrm{R} \$ 4.530,00$ \\
\hline Laranjeiras do Sul & 30.777 & $\mathrm{R} \$ 24.318,00$ \\
\hline Luiziana & 7.315 & $\mathrm{R} \$ 74.015,00$ \\
\hline Mamborê & 13.961 & $\mathrm{R} \$ 88.944,00$ \\
\hline Mariluz & 10.224 & $\mathrm{R} \$ 29.599,00$ \\
\hline Maripá & 5.684 & $\mathrm{R} \$ 35.379,00$ \\
\hline Marquinho & 4.981 & $\mathrm{R} \$ 5.095,00$ \\
\hline Mato Rico & 3.818 & $\mathrm{R} \$ 7.524,00$ \\
\hline Moreira Sales & 12.606 & $\mathrm{R} \$ 29.286,00$ \\
\hline Nova Aurora & 11.866 & $\mathrm{R} \$ 60.103,00$ \\
\hline Nova Cantu & 7.425 & $\mathrm{R} \$ 17.393,00$ \\
\hline Nova Laranjeiras & 11.241 & $\mathrm{R} \$ 9.870,00$ \\
\hline Nova Santa Rosa & 7.626 & $\mathrm{R} \$ 13.987,00$ \\
\hline Palmital & 14.865 & $\mathrm{R} \$ 13.325,00$ \\
\hline Palotina & 28.683 & $\mathrm{R} \$ 95.830,00$ \\
\hline Perobal & 5.653 & $\mathrm{R} \$ 13.685,00$ \\
\hline Pérola & 10.208 & $\mathrm{R} \$ 2.532,00$ \\
\hline Pitanga & 32.638 & $\mathrm{R} \$ 90.660,00$ \\
\hline Quarto Centenário & 4.856 & $\mathrm{R} \$ 44.581,00$ \\
\hline Rancho Alegre D'Oeste & 2.847 & $\mathrm{R} \$ 31.874,00$ \\
\hline Roncador & 11.537 & $\mathrm{R} \$ 38.833,00$ \\
\hline Santa Maria do Oeste & 11.500 & $\mathrm{R} \$ 28.316,00$ \\
\hline São Jorge do Patrocínio & 6.041 & $\mathrm{R} \$ 2.290,00$ \\
\hline Tapejara & 14.598 & $\mathrm{R} \$ 5.062,00$ \\
\hline Terra Roxa & 16.759 & $\mathrm{R} \$ 60.887,00$ \\
\hline
\end{tabular}




\begin{tabular}{c|c|c}
\hline Toledo & 119.313 & $\mathrm{R} \$ 108.614,00$ \\
\hline Tuneiras do Oeste & 8.695 & $\mathrm{R} \$ 19.580,00$ \\
\hline Tupãssi & 7.997 & $\mathrm{R} \$ 42.665,00$ \\
\hline Turvo & 13.811 & $\mathrm{R} \$ 12.665,00$ \\
\hline Ubiratã & 21.558 & $\mathrm{R} \$ 72.456,00$ \\
\hline Umuarama & 100.676 & $\mathrm{R} \$ 10.138,00$ \\
\hline Xambrê & 6.012 & $\mathrm{R} \$ 1.315,00$ \\
\hline \hline Total & $\mathbf{1 . 5 1 0 . 9 8 9}$ & $\mathbf{R} \$ \mathbf{2 . 2 4 7 . 3 9 5 , 0 0}$ \\
\hline \hline
\end{tabular}

Fonte: IBGE - Censo Demográfico 2010 e Censo Agropecuário 2007.

Org.: Márcio Greyck Guimarães Correa, 2017.

De acordo com a SEMA (2010) a demanda hídrica da Bacia do Piquiri é de aproximadamente $3000 \mathrm{~L} / \mathrm{s}$, dos quais $52 \%$ provém de mananciais superficiais e $48 \%$ de mananciais subterrâneos. Os setores que mais usam a água da bacia são: abastecimento público com $36 \%$; indústrias $23 \%$; agricultura $11 \%$; pecuária $31 \%$ e a mineração com menos de $1 \%$.

A disponibilidade dos recursos hídricos é essencial para a economia dos municípios da região, a agricultura possui uma dependência indireta da água, uma vez que a estrutura fundiária e a organização do espaço agrário da bacia hidrográfica do Piquiri (predominantemente pequenas propriedades) não faz uso de irrigação, por isso a agricultura aparece com apenas $11 \%$ no consumo de agua nos dados apresentados anteriormente. Portanto, a variabilidade das chuvas é um fator determinante para a manutenção da produção agrícola dessas áreas.

Conhecer a influência do fenômeno ENOS na distribuição da precipitação pluviométrica e na dinâmica hídrica do rio Piquiri tem um importante peso socioeconômico para estes municípios, uma vez que traz as possibilidades de adaptação e planejamento dos órgãos competentes. 


\subsection{Objetivos}

\subsubsection{Objetivo Geral}

Esta pesquisa tem por objetivo principal compreender as interações hidroclimáticas entre a precipitação pluvial, a vazão fluvial e o fenômeno El Niño Oscilação Sul na bacia hidrográfica do rio Piquiri-PR no período entre 1976 e 2010.

\subsubsection{Objetivos Específicos}

- Analisar por meio da estatística descritiva os dados de precipitação pluvial e de vazão fluvial em diferentes escalas temporais: anual, sazonal e mensal.

- Calcular a correlação linear entre a precipitação pluvial e a vazão fluvial.

- Determinar a defasagem temporal entre a precipitação pluvial e a vazão fluvial mensal.

- Calcular a evapotranspiração e o coeficiente de escoamento na bacia hidrográfica do rio Piquiri.

- Determinar a defasagem temporal entre os dados mensais de IOS, precipitação pluvial e a vazão fluvial.

- Propor um modelo de regressão linear que explique a influência do IOS na precipitação e na vazão fluvial da bacia hidrográfica do rio Piquiri. 
- Relacionar o fenômeno ENOS com a variabilidade da precipitação pluvial e da vazão fluvial.

\subsection{Hipótese da Pesquisa}

Fenômenos como o El Niño Oscilação Sul podem causar excessos de precipitação no sul do Brasil em sua fase positiva, assim como redução considerável no volume de chuva em sua faze negativa, como descrito por Nery (2005) e Coelho et al. (2002).

Entende-se que a variabilidade climática comandada por fenômenos de escala global, como ENOS, condicionam regionalmente as condições climáticas, Karoly (1989) e Ambrizzi (2003). Portanto, a configuração conjunta destes fenômenos de escalas diversas podem representar um incremento de energia e matéria substancial na bacia hidrográfica do rio Piquiri-PR.

O fenômeno ENOS influencia o clima da América do Sul de forma diferenciada, como demonstrado por Grimm et al. (2000) e Coelho et al. (2002) que identificaram uma correlação negativa entre EN e precipitação no norte e nordeste do Brasil, e incremento na precipitação pluvial no centro-sul do país.

Considerando a área localizada em uma zona de transição climática entre o clima tropical e subtropical, como apontado por Correa (2013), este trabalho embasa-se na hipótese de que o fenômeno de escala global, ENOS, influencia na variabilidade temporal da precipitação pluviométrica e da vazão fluvial, representando significativas variações na dinâmica hidrológica da bacia hidrográfica do Piquiri.

Um questionamento norteador da pesquisa seria se existe relação entre ENOS, precipitação pluviométrica e vazão fluvial numa bacia hidrográfica caracterizada como área 
de transição climática tropical-subtropical? E se esta relação existir, quais seriam suas decorrências na variabilidade hidroclimática da área de estudo?

\subsection{Localização da área de estudo}

A bacia hidrográfica do rio Piquiri localiza-se na região centro-oeste do estado do Paraná, entre as latitudes de $23^{\circ} 00^{\prime} \mathrm{S}$ e $25^{\circ} 30^{\prime} \mathrm{S}$, e ,longitudes $52^{\circ} 00^{\prime} \mathrm{W}$ e $55^{\circ} 30^{\prime} \mathrm{W}$, como pode-se observar na Figura 1. O rio Piquiri é afluente da margem esquerda do rio Paraná e tem sua nascente na região centro-sul do estado na localidade do Paiquerê, município de Campina do Simão. O rio Piquiri percorre aproximadamente $485 \mathrm{~km}$ até sua foz no rio Paraná, na divisa dos municípios de Altônia e Terra Rocha, SEMA (2010).

A área de drenagem de toda a bacia é de aproximadamente $24700 \mathrm{~km}^{2}$ (cerca de $12 \%$ da área total do estado do Paraná) e limita-se ao norte e a leste com a bacia hidrográfica do rio Ivaí, ao sul com a bacia hidrográfica do rio Iguaçu e a oeste o rio Piquiri tem sua foz junto ao rio Paraná. 


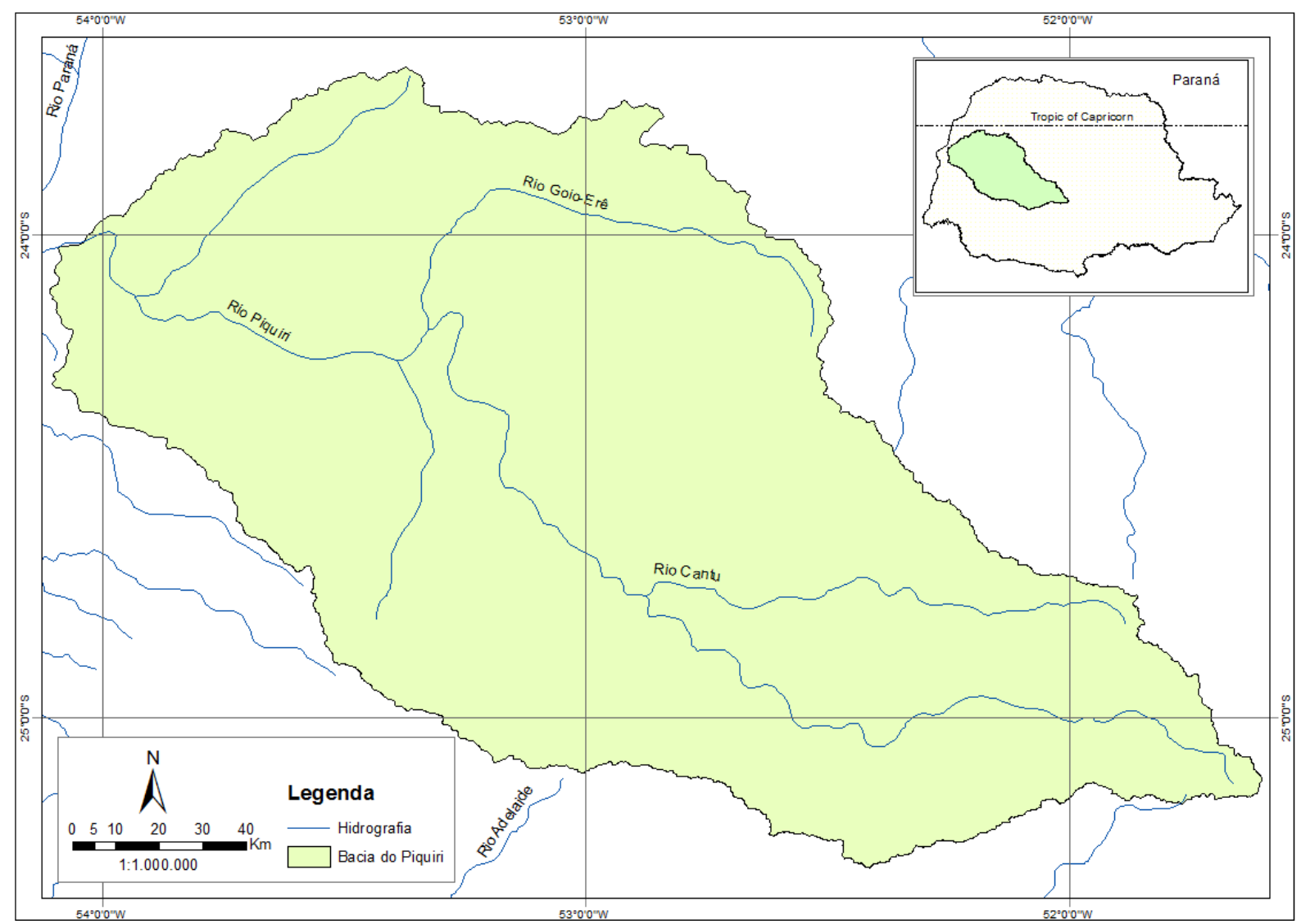

Figura 1: Mapa de localização da bacia hidrográfica do rio Piquiri-PR.

Org.: Márcio Greyck Guimarães Correa, 2017.

\subsection{Referencial Teórico-conceitual}

No início do século XX o conhecimento científico atingiu um elevado nível de desenvolvimento tecnológico. De acordo com Von Bertalanffy (2010) as novas descobertas científicas proporcionaram o advento de novas concepções teóricas em diversas áreas do conhecimento bem como sua categorização em várias disciplinas e especialidades, entre as novas correntes teóricas, a Teoria Geral dos Sistemas obteve significativo êxito ao introduzir noções de sistemas, hierarquias, funcionamento e interdependência.

Von Bertalanffy (2010) discute a busca incansável em formular uma teoria que explicasse fenômenos até então não compreendidos ou não explicados pela ciência, ao 
conceituar sistemas como um complexo de elementos em interação e com certo grau de organização que procura atingir algum objetivo ou finalidade. Ele torna possível a teorização do funcionamento de muitos fenômenos naturais, explicações físicas e matemáticas, e um grande desenvolvimento na área de comunicações e cibernética. É baseada nas concepções de sistemas naturais abertos que a ecologia firma-se como importante disciplina ao implementar o conceito de ecossistema. Nas ciências da Terra, a Geomorfologia (Chorley, 1964) e a Meteorologia (Thompson, 1961) vão se apropriar do conceito de sistemas naturais abertos, tratando-o como uma generalização da teoria física da termodinâmica e da cinética.

Christopherson (2012) apresenta, em linhas gerais, os sistemas naturais como sistemas abertos, ou seja, não são autocontidos, com entrada e saída de fluxos de energia e matéria, nesses sistemas naturais as partes funcionam de maneira inter-relacionadas dando características especificas a cada subsistema.

O planeta Terra é um sistema natural aberto em termos de troca de energia, recebe energia solar e libera energia térmica para o espaço. Essa energia que a Terra recebe, pode se transformar em diferentes formas de energia no seu percurso até a superfície terrestre, (cinética, potencial, química ou mecânica) e é responsável por movimentar a atmosfera e os oceanos.

Em termos de matéria física e recursos, Christopherson (2012) explica que o sistema terrestre funciona como um sistema fechado, isolado do ambiente circundante, o espaço. Existe na verdade uma pequena troca de matéria com a saída mínima de alguns gases da atmosfera terrestre e a entrada de alguns meteoros e poeiras cósmicas, mas que não altera o funcionamento sistêmico do planeta. É baseado nessas concepções sistêmicas de funcionamento do planeta que o uso dos recursos naturais tem sido cada vez mais discutido nos dias atuais. 
Christofoletti (1990) ao utilizar a teoria dos sistemas na Geografia, explica que a organização espacial é uma unidade integrada composta de diversos elementos que interagem por meio de fluxos de energia e matéria. É na Geografia Física que essa teoria se expande e solidifica-se ao propor um estudo geossistêmico. Para tanto deve-se retornar aos primórdios da Geografia moderna e a assimilação de tais teorias e conceitos no ambiente acadêmico geográfico, e destacar as obras de Chorley (1964), Sotchava (1977), Tricart (1977), Bertrand e Beroutchachvili (1978) bem como a contribuição dessas obras para a compreensão dos sistemas naturais numa ótica geográfica.

Bertrand e Beroutchachvili (1978, p. 05) explicam o geossistema ao evidenciar o sistema geográfico ou sistema territorial natural e enfatizam:

O geossistema serve para designar um "sistema geográfico natural homogêneo associado a um território". Ele se caracteriza por uma morfologia, isto é, pelas estruturas espaciais verticais (os geohorizontes), e horizontais (os geofácies): um funcionamento, que engloba o conjunto de transformações dependentes da energia solar ou gravitacional, dos ciclos da água, dos biogeociclos, assim como dos movimentos das massas de ar e dos processos de geomorfogênese: um comportamento específico, isto é, para as mudanças de estado que intervêm no geossistema em uma dada sequência temporal.

Diferentemente do ecossistema, um estudo geossistêmico não prioriza nenhuma abordagem, a visão mais ampla do geossistema permite o estudo de estruturas e mecanismos em nível global e é a própria hierarquia natural dos elementos que determina a prioridade da análise. O geossistema compreende os componentes bióticos, abióticos e antrópicos, dentro de uma perspectiva vertical e horizontal, o que o torna de extrema complexidade analítica. 
A complexidade analítica geossistêmica ainda não foi superada nos dias atuais, uma pesquisa geossistêmica envolve uma série de elementos e uma interdisciplinaridade tal que os centros de pesquisa e universidades ainda enfrentam problemas de ordem técnica para promover seus estudos em plenitude.

Esta pesquisa situa-se nessa visão limitada descrita anteriormente, mas são as concepções sistêmicas a base conceitual para a análise aqui proposta, uma visão ampla do conceito de paisagem permite analisar o objeto de pesquisa sem desvincular-se da análise geográfica, em outras palavras, antes de ser uma pesquisa climatológica, trata-se de uma pesquisa geográfica munida de uma base conceitual-teórica da Geografia.

Com o passar do tempo as concepções sistêmicas se apoderaram do conhecimento sobre o funcionamento natural do planeta. Na Geografia não poderia ser diferente, e os estudos em Geografia Física apresentam uma ampla variedade de pesquisas voltadas para o geossistema e a análise da paisagem.

A paisagem passou a ser um importante recorte espacial de análise geográfica devido sua natureza integradora. O estudo da paisagem se desenvolve concomitantemente aos estudos geossistêmicos, e segundo Monteiro (1974, s/n.), a paisagem é uma:

Entidade espacial delimitada segundo um nível de resolução do geógrafo (pesquisador) a partir dos objetivos centrais da análise, de qualquer modo, sempre resultante da integração dinâmica, portanto instável, dos elementos de suporte e cobertura (físicos, biológicos e antrópicos) expressa em partes delimitáveis infinitamente mas individualizadas através das relações entre elas que organizam um todo complexo (Sistema), verdadeiro conjunto solidário e único, em perpétua evolução. 
Os estudos realizados por Monteiro $(1974,2001)$ aproximaram a visão geossistêmica aos conceitos climáticos. Ao abordar a paisagem como um conjunto dinâmico de elemento em evolução ele abre uma discussão dentro da Geografia, especialmente na Climatologia, da análise momentânea dos elementos do clima, até então apenas utilizado na meteorologia. A inserção da análise rítmica e a noção de ritmo climático pressuposto anteriormente por Sorre (1951) marcam uma nova fase nos estudos climatológicos em âmbito nacional.

Por outro lado, outros campos do conhecimento geográfico também se desenvolviam sob a égide do conhecimento sistêmico. A Geomorfologia traz importantes discussões acerca do funcionamento da paisagem, especialmente, sobre as bacias hidrográficas.

Uma das unidades de análise da paisagem mais utilizadas nos estudos geográficos é a bacia hidrográfica. Para Rodrigues e Adami (2005, p. 147-148) a bacia hidrográfica é:

[...] um sistema que compreende um volume de materiais, predominantemente sólidos e líquidos, próximos à superfície terrestre, delimitado interna e externamente por todos os processos que, a partir do fornecimento de água pela atmosfera, interferem no fluxo de matéria e de energia de um rio ou de uma rede de canais fluviais. Inclui, portanto, todos os espaços de circulação, armazenamento, e de saídas de água e do material por ela transportado, que mantêm relações com esses canais.

Concebida a bacia hidrográfica como unidade de análise da paisagem, esta pesquisa se aproxima das concepções hidroclimatológicas. A água é o principal elemento estudado no desenvolvimento da tese, na sua condição de precipitação e escoamento superficial (vazão fluvial).

Langbein (1967) definiu a hidroclimatologia como o estudo da influência do clima sobre a água disponível na superfície terrestre e considerou a precipitação e a 
evapotranspiração como elementos essenciais para esta área do conhecimento. No contexto das ciências modernas, Shelton (2009) elucida que o desenvolvimento das técnicas de estudo apontam para uma visão mais abrangente da hidroclimatologia, inclui a climatologia e a hidrologia como áreas do conhecimento essenciais para compreender o funcionamento do transporte de umidade entre a atmosfera e a superfície, o ciclo hidrológico.

Shelton (2009) considera a bacia hidrográfica como uma importante escala de análise dos fenômenos hidroclimáticos, o clima impulsiona o ciclo hidrológico, e a variabilidade dos elementos climáticos são a premissa de todo estudo hidroclimatológico. O autor define o ciclo hidrológico como o movimento da água nos subsistemas do sistema climático.

De acordo com Silveira (2001), o ciclo hidrológico em escala global pode ser considerado fechado, mas quando analisado em escalas inferiores do sistema terrestre ele passa a ser compreendido como um ciclo aberto. Através da evaporação e evapotranspiração o vapor de água chega até a atmosfera, acumula-se, condensa, forma as nuvens, e retorna à superfície em forma de precipitação. Ao atingir a superfície terrestre a precipitação associa-se às condições morfológicas das vertentes (declividade, estrutura geológica e pedológica, cobertura e uso da terra) e é escoada para as áreas mais baixas, até encontrar os rios.

\subsection{Método de Pesquisa}

O desenvolvimento da pesquisa parte da observação dos dados de precipitação, vazão e IOS, preconizando o uso do método experimental dedutivo. De acordo com Rampazzo (2010), o ponto de partida do método dedutivo é o antecedente, ou seja, acontecimentos já 
conhecidos formulam a hipótese da pesquisa. Considerando a hipótese levantada nessa pesquisa, parte-se da premissa que o fenômeno ENOS influencia as condições climáticas em diferentes regiões do globo, logo, espera-se que o clima sobre a bacia hidrográfica do rio Piquiri também seja influenciado por este fenômeno. Para averiguar se a hipótese é verdadeira ou não, busca-se metodologias que melhor possa explica-la.

Nesta pesquisa utiliza-se de dados distribuídos temporalmente, e de acordo com Ehlers (2005), uma série temporal constitui uma coleção de observações sequenciais ao longo do tempo. Uma das características mais importantes dos dados em séries temporais de processos físicos é que as observações vizinhas são dependentes, portanto a ordem dos dados é essencial.

A sequência da série temporal utilizada nesta pesquisa é do tipo contínua “discretizada", de forma que, os valores de precipitação e vazão registrados em intervalos de tempo, foram em seguida, acumulados na escala mensal, sazonal e anual.

Nas primeiras duas partes do texto apresentam-se métodos e técnicas descritivas da série temporal da precipitação pluviométrica e da vazão fluvial, são apresentados por meio da representação gráfica a distribuição temporal das variáveis ao longo dos anos, estações do ano e meses.

Nas duas últimas partes do texto, buscou-se por meio de modelo probabilísticos de autocorrelação parcial correlacionar, fazer inferências sobre as variáveis precipitação, vazão e IOS.

A seguir apresenta-se cada etapa metodológica realizada durante a pesquisa através de um fluxograma, Figura 2. Cada etapa mostrada no fluxograma está detalhadamente descrita nas seções de procedimentos metodológicos de cada parte da tese. 


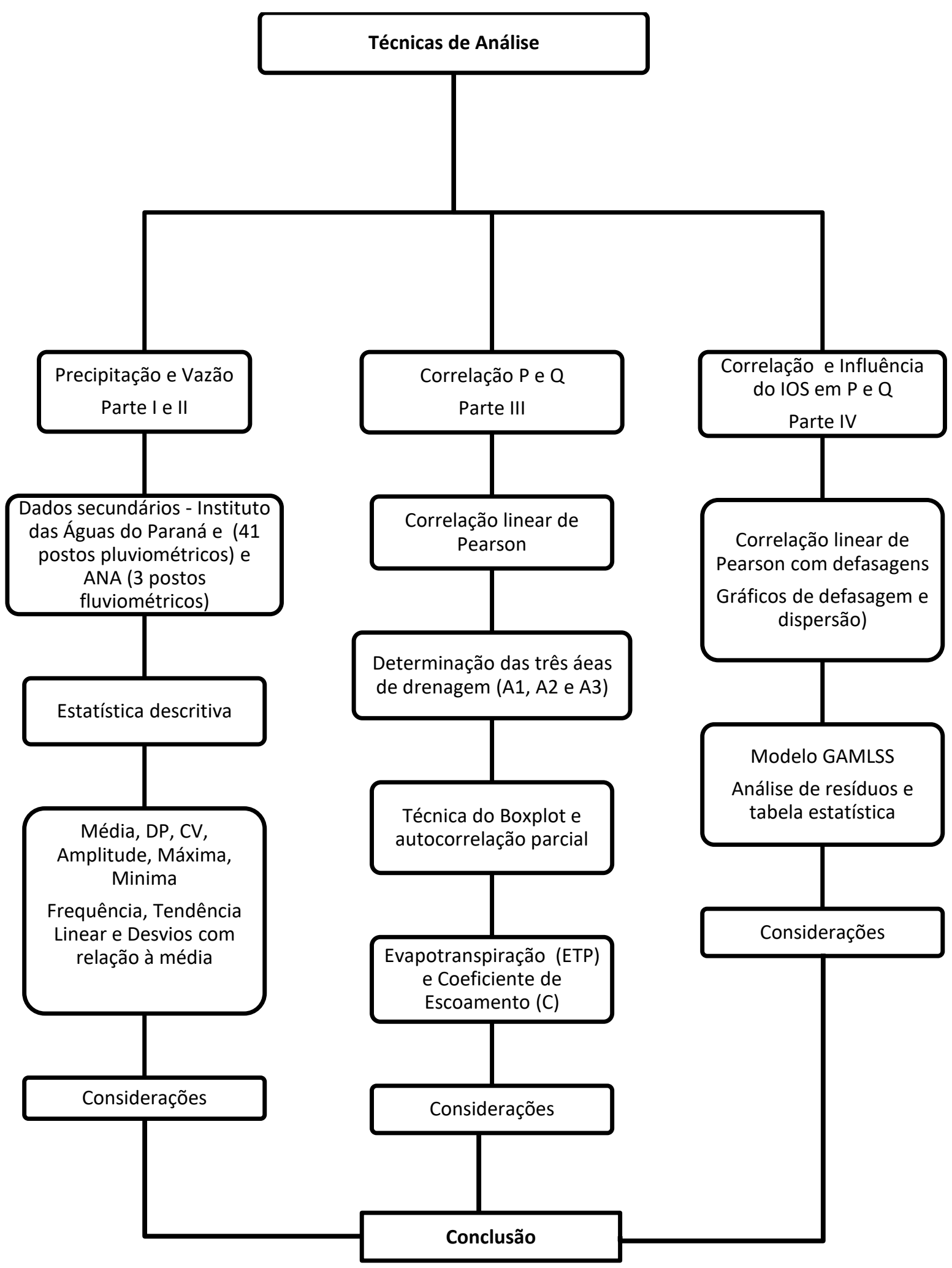


Figura 2: Fluxograma dos procedimentos e técnicas utilizados na pesquisa.

Org.: Márcio Greyck Guimarães Correa, 2017.

\section{PARTE I - PRECIPITAÇÃO PLUVIOMÉTRICA DA BACIA HIDROGRÁFICA DO RIO PIQUIRI}

\subsection{Introdução}

Os estudos climáticos buscam explicar, em grande parte, de forma dinâmica como os elementos do clima interagem com a superfície terrestre, a precipitação é um dos elementos climáticos mais estudados devido à sua importância para as atividades humanas, como a agricultura, planejamento urbano, abastecimento de água, entre outros.

A precipitação pluviométrica é um elemento de destaque nos estudos hidroclimatológicos pois representa o input de energia e matéria na bacia hidrográfica. A variabilidade temporal da precipitação é o objeto principal de análise aqui proposto.

A região sul do Brasil apresenta singularidades climáticas que a diferencia do restante do país, isso porque apresenta características climáticas subtropicais, marcadas pela sazonalidade térmica entre o verão e o inverno e pela distribuição relativamente regular da precipitação ao longo do ano, com diminuição nos meses invernais, conforme já identificado por Köppen (1948).

A análise da distribuição e variabilidade temporal e espacial da precipitação pluviométrica em bacias hidrográficas é ideal para a compreensão da dinâmica pluvial de uma região. No estado do Paraná vários estudos já abordaram a variabilidade da precipitação em bacias hidrográficas, com destaque para os estudos de Baldo (2006) que considera a bacia hidrográfica do rio Ivaí, de Zandonadi (2013) na bacia hidrográfica do rio Paraná, de Azevedo 
(2006) na bacia hidrográfica do rio Iguaçu, de Terassi (2015) nas bacias hidrográficas do rio Pirapó, Paranapanema III e IV, e, de Correa (2013) para a bacia hidrográfica do rio Piquiri.

\subsection{Referencial teórico - Precipitação Pluviométrica}

A precipitação de acordo com Bertoni e Tucci (2001) é entendida como toda água que atinge a superfície terrestre, proveniente da atmosfera. A precipitação pode ser observada em diferentes formas, como neblina, chuva, granizo, saraiva, orvalho, geada e neve, sendo a chuva (precipitação pluviométrica) a mais comum. Mendonça e Danni-Oliveira (2007) explicam que a precipitação pluviométrica é medida em milímetros $(\mathrm{mm})$ e refere-se à quantidade de água (altura) coletada por um pluviômetro ou pluviógrafo.

A distribuição da precipitação pluviométrica no tempo e no espaço vem sendo discutida no âmbito acadêmico com exaustão, principalmente sob o ponto de vista amplo da variabilidade climática, esta entendida com uma variação dos elementos do clima ao longo de uma determinada escala espaço-temporal, Sant'Anna Neto (1998) e Nunes (2009).

A análise quantitativa da variabilidade da chuva é uma importante ferramenta para o conhecimento climático das mais diversas regiões do globo. As variações sazonais e interanuais da precipitação auxiliaram na compreensão da dinâmica do clima, a presença ou a ausência da chuva e os desdobramentos decorrentes. Rowell et al. (1995) demonstraram a importância dos oceanos (variações da temperatura da superfície do mar) e das características da superfície continental na distribuição e variabilidade sazonal das chuvas no norte da África, implicando em longos períodos de seca intercalado por eventos de precipitação pluviométrica, o que define características singulares à aquela região. 
No Brasil a sazonalidade da chuva sempre foi muito importante e presente nos estudos climatológicos, desde os trabalhos de Monteiro (1968, 1969), Nimer (1979), Conti (1975; 1995), Sant'Anna Neto (1995) que buscaram explicar a gênese das chuvas sobre o Brasil, os sistemas atmosféricos atuantes, a orografia e a análise rítmica como procedimento de compreensão sobre a sucessão dos tipos de tempo.

\subsection{Procedimentos metodológicos: Precipitação Pluviométrica}

\subsubsection{Escolha e análise da consistência dos dados de precipitação}

Para a análise da precipitação utilizou-se de dados secundários de precipitação pluviométrica do Instituto das Águas do Paraná, ao qual se escolheu uma quantidade representativa de 41 postos pluviométricos na bacia hidrográfica do rio Piquiri, com série histórica de 35 anos entre 1976 e 2010, como pode-se observar na Tabela 1.

Tabela 1- Postos pluviométricos do Instituto das Águas do Paraná para a bacia hidrográfica do rio Piquiri-PR.

\begin{tabular}{c|c|c|c}
\hline \hline Posto & Código ANEEL & Município & Altitude $(\mathrm{m})$ \\
\hline \hline 1 & 2352026 & Tuneiras do Oeste & 459 \\
\hline 2 & 2353002 & Mariluz & 320 \\
\hline 3 & 2353005 & Xambrê & 412 \\
\hline 4 & 2353006 & Mariluz & 345 \\
\hline 5 & 2353016 & Pérola & 438 \\
\hline 6 & 02353047 & Cafezal do Sul & 384 \\
\hline 7 & 2451010 & Santa Maria do Oeste & 900 \\
\hline 8 & 02451021 & Santa Maria do Oeste & 929 \\
\hline 9 & 2452000 & Altamira do Paraná & 360 \\
\hline 10 & 2452001 & Ubiratã & 320 \\
\hline 11 & 2452009 & Ubiratã & 509 \\
\hline 12 & 2452010 & Janiópolis & 350 \\
\hline 13 & 2452011 & Campina da Lagoa & 618 \\
\hline 14 & 2452012 & Altamira do Paraná & 650 \\
\hline 15 & 2452015 & Roncador & 723 \\
\hline 16 & 02452016 & Palmital & 890 \\
\hline
\end{tabular}




\begin{tabular}{|c|c|c|c|}
\hline 17 & 2452019 & Laranjal & 741 \\
\hline 18 & 02452029 & Farol & 582 \\
\hline 19 & 02452033 & Juranda & 513 \\
\hline 20 & 2452035 & Mamborê & 650 \\
\hline 21 & 2452040 & Mamborê & 638 \\
\hline 22 & 02453000 & Iporã & 270 \\
\hline 23 & 2453001 & Ubiratã & 310 \\
\hline 24 & 2453008 & Alto Piquiri & 427 \\
\hline 25 & 2453009 & Alto Piquiri & 430 \\
\hline 26 & 2453010 & Formosa do Oeste & 370 \\
\hline 27 & 2453012 & Corbélia & 696 \\
\hline 28 & 02453013 & Iguatu & 730 \\
\hline 29 & 2453014 & Campo Bonito & 700 \\
\hline 30 & 2453016 & Goioerê & 497 \\
\hline 31 & 2453030 & Assis Chateaubriand & 501 \\
\hline 32 & 2453037 & Nova Aurora & 544 \\
\hline 33 & 2453047 & Maripá & 394 \\
\hline 34 & 2453048 & Nova Santa Rosa & 341 \\
\hline 35 & 2453050 & Brasilândia do Sul & 396 \\
\hline 36 & 2453052 & Francisco Alves & 302 \\
\hline 37 & 2453056 & Cascavel & 602 \\
\hline 38 & 2551009 & Campina do Simão & 1056 \\
\hline 39 & 2552006 & Guaraniaçu & 920 \\
\hline 40 & 2552008 & Marquinho & 872 \\
\hline 41 & 02552019 & Laranjeiras do Sul & 785 \\
\hline
\end{tabular}

Org.: Márcio Greyck Guimarães Correa, 2017.

A Organização Meteorológica Mundial (WMO,1994), diz que para se determinar a densidade mínima de postos pluviométricos para a análise climatológica deve-se considera as características de relevo, tipo de clima, geologia e sistemas atmosféricos predominantes e determinou que a densidade mínima de postos pluviométricos para áreas planas no interior do continente é de $575 \mathrm{~km}^{2}$. Baseando-se nessa determinação estimou-se o raio médio de abrangência de 13,5 km para cada posto pluviométrico do Instituto das Águas do Paraná utilizados na pesquisa, Figura 3. 


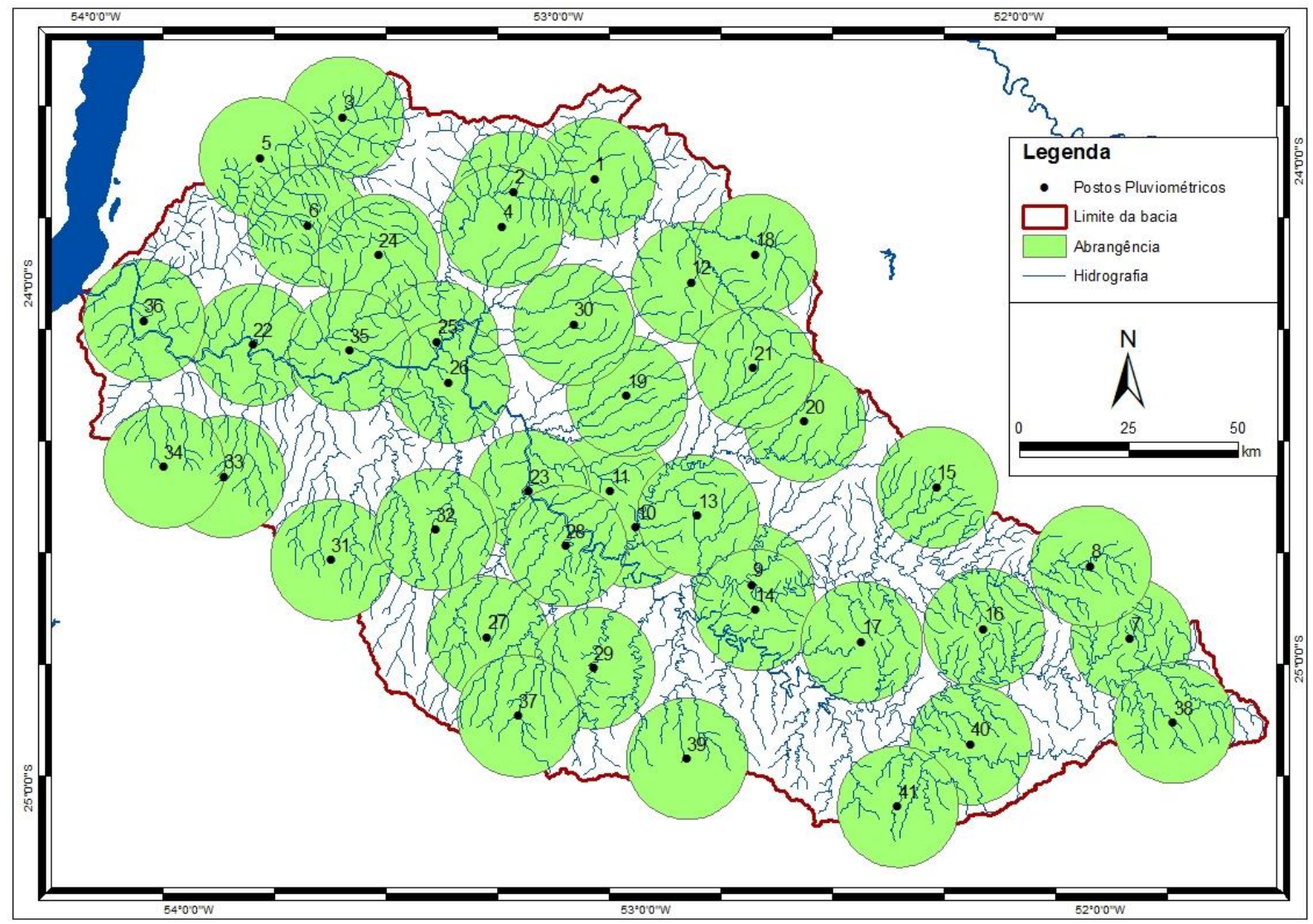

Figura 3: Localização dos postos pluviométricos do Instituto das Águas do Paraná com seus respectivos raios de abrangência na bacia hidrográfica do rio Piquiri-PR.

Org.: Márcio Greyck Guimarães Correa, 2017.

Os postos pluviométricos do Instituto das Águas do Paraná são responsáveis por coletar a água da chuva por meio do pluviômetro ordinário Ville de Paris. Segundo VarejãoSilva (2006) este tipo de pluviômetro possui um reservatório para a água da chuva e na parte inferior existe uma torneira de drenagem que permite ao observador fazer a leitura através de um copo graduado. A Figura 4 mostra o funcionamento do pluviômetro Ville de Paris e as fotos indicam o pluviômetros utilizado para a coleta de água. Trata-se do pluviômetro do posto 31 localizado no município de Assis Chateaubriand. 


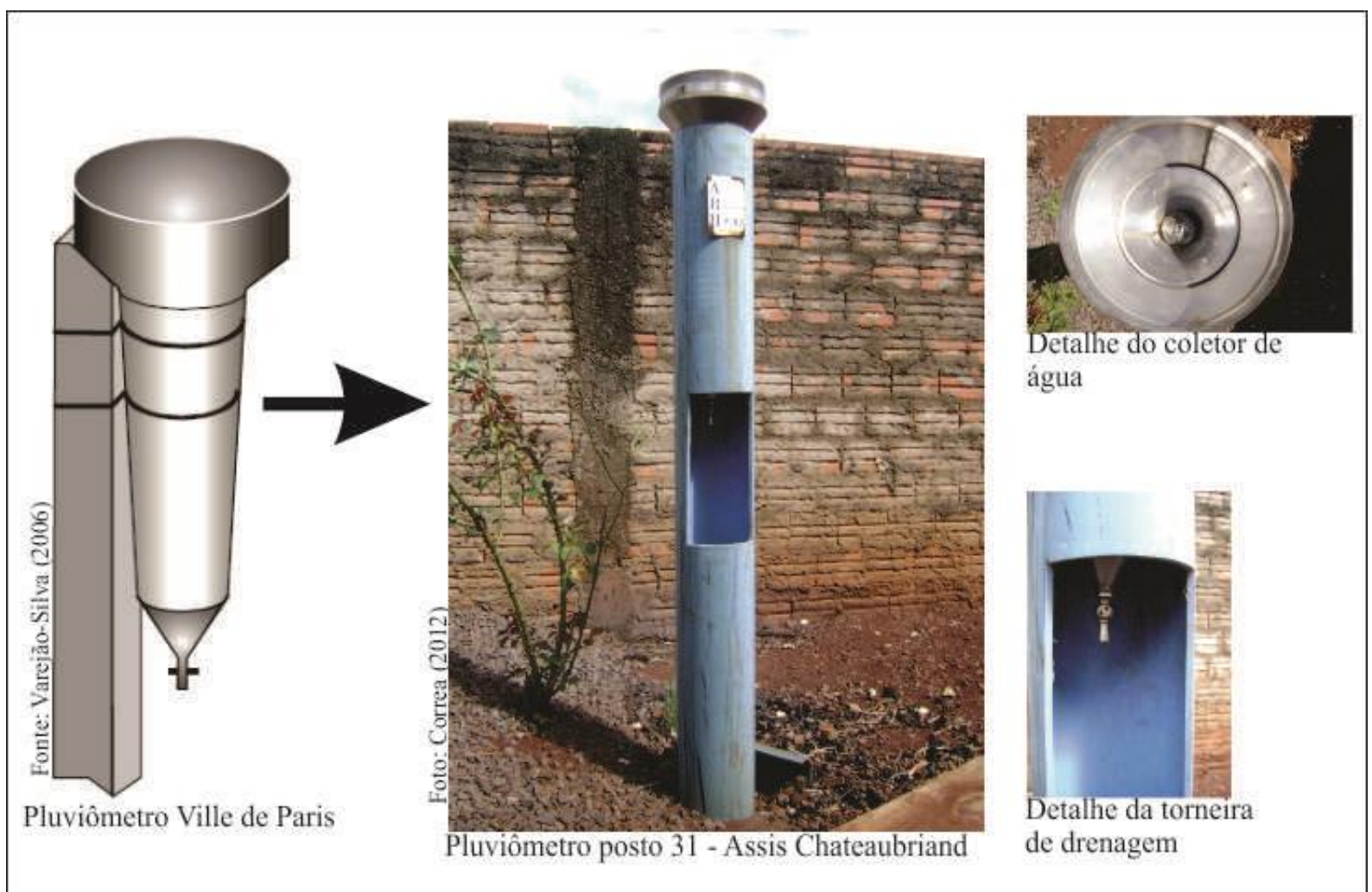

Figura 4: Pluviômetro Ville de Paris utilizado na coleta da precipitação pluviométrica na rede de postos do Instituto das Águas do Paraná.

Fonte: Correa (2013)

O banco de dados do Instituto das Águas do Paraná apresentou uma pequena falha de consistência de $0,11 \%$, essas falhas foram preenchidas de acordo com o método da média aritmética, onde segundo Bertoni e Tucci (2001), por este método admite-se que todos os pluviômetros têm o mesmo peso, e o cálculo é feito com base nos valores medidos. A seguir apresenta-se a fórmula do cálculo da média aritmética utilizada para sanar as falhas do banco de dados (equação 1).

$$
\mathrm{Pm}=1 / n \cdot \sum P i
$$

$\mathrm{P} m=$ precipitação média na área em mm;

$\mathrm{P} i=$ precipitação média do i-nésimo pluviômetro;

$n=$ número total de pluviômetros. 
Averiguou-se a consistência dos dados de cada posto de coleta por meio do coeficiente de determinação $\left(\mathrm{r}^{2}\right)$ que segundo Bertoni e Tucci (2001) indica a consistência de um banco de dados a partir da análise de uma base de comparação. Quanto mais próximo de 0 menor a correlação linear entre as variáveis, quanto mais próximo de 1 maior a correlação, cuja formula apresenta-se a seguir ( equação 2).

$$
R^{2}=\frac{\left(s_{x y}\right)^{2}}{s_{x x} s_{y y}}
$$

$\mathrm{R}^{2}=$ Coeficiente de determinação;

$\mathrm{S}_{x y}=$ Variância entre $x$ e $y$;

Calculou-se o coeficiente de determinação para os 41 postos pluviométricos e suas respectivas precipitações mensais no período de 35 anos e comparou-se à média mensal de toda a série histórica com a finalidade de identificar o grau de correlação e consistência dos dados coletados. Os resultados de $\mathrm{r}^{2}$ podem ser observados na tabela 2 , onde o menor coeficiente de determinação foi de 0,85 e o maior 0,99 . Empregando o teste $\mathrm{t}$ student todos os 41 postos resultaram em correlação significativa ao nível de 95\%, demonstrando que nenhum posto pluviométrico apresentou valores discrepantes de precipitação.

Tabela 2- Coeficiente de determinação para os 41 postos pluviométricos na bacia hidrográfica do rio Piquiri.

\begin{tabular}{c|c|c|c}
\hline Posto Pluv. & Coef. Det. $\left(\mathbf{r}^{\mathbf{2}}\right)$ & Posto Pluv. & Coef. Det. $\left(\mathbf{r}^{\mathbf{2}}\right)$ \\
\hline $\mathbf{1}$ & 0,93 & $\mathbf{2 2}$ & 0,97 \\
\hline $\mathbf{2}$ & 0,95 & $\mathbf{2 3}$ & 0,98 \\
\hline $\mathbf{3}$ & 0,93 & $\mathbf{2 4}$ & 0,97 \\
\hline $\mathbf{4}$ & 0,96 & $\mathbf{2 5}$ & 0,96 \\
\hline $\mathbf{5}$ & 0,92 & $\mathbf{2 6}$ & 0,94 \\
\hline $\mathbf{6}$ & 0,92 & $\mathbf{2 7}$ & 0,97 \\
\hline $\mathbf{7}$ & 0,90 & $\mathbf{2 8}$ & 0,96 \\
\hline $\mathbf{8}$ & 0,91 & $\mathbf{2 9}$ & 0,95 \\
\hline $\mathbf{9}$ & 0,92 & $\mathbf{3 0}$ & 0,97 \\
\hline $\mathbf{1 0}$ & 0,95 & $\mathbf{3 1}$ & 0,96 \\
\hline
\end{tabular}




\begin{tabular}{l|l|l|l}
\hline $\mathbf{1 1}$ & 0,96 & $\mathbf{3 2}$ & 0,99 \\
\hline $\mathbf{1 2}$ & 0,96 & $\mathbf{3 3}$ & 0,96 \\
\hline $\mathbf{1 3}$ & 0,96 & $\mathbf{3 4}$ & 0,94 \\
\hline $\mathbf{1 4}$ & 0,98 & $\mathbf{3 5}$ & 0,95 \\
\hline $\mathbf{1 5}$ & 0,97 & $\mathbf{3 6}$ & 0,94 \\
\hline $\mathbf{1 6}$ & 0,91 & $\mathbf{3 7}$ & 0,93 \\
\hline $\mathbf{1 7}$ & 0,98 & $\mathbf{3 8}$ & 0,85 \\
\hline $\mathbf{1 8}$ & 0,96 & $\mathbf{3 9}$ & 0,96 \\
\hline $\mathbf{1 9}$ & 0,97 & $\mathbf{4 0}$ & 0,91 \\
\hline $\mathbf{2 0}$ & 0,89 & $\mathbf{4 1}$ & 0,94 \\
\hline $\mathbf{2 1}$ & 0,97 & & \\
\hline
\end{tabular}

Org.: Márcio Greyck Guimarães Correa, 2017.

\subsubsection{Análise estatística descritiva dos dados de precipitação}

A análise dos dados foi feita através da estatística descritiva, de forma a indicar sua variabilidade nas escalas anual, sazonal e mensal.

De acordo com Downing e Clark (2000), o desvio padrão que segundo é importante para ter-se a noção do grau de dispersão dos valores em relação ao valor médio, e o coeficiente de variação utilizado para fazer comparações em termos relativos, expressa a variabilidade de cada conjunto de dados normalizada em relação à média, em porcentagem. Essa estatística foi utilizada para descrever os dados nas escalas temporais anual, sazonal e mensal.

Determinou-se ainda a média aritmética como uma medida de tendência central. Os valores máximos e mínimos, a amplitude, que expressas a diferença entre os valores máximos (Vmax) e os valores mínimos (Vmin).

Buscou-se no desenvolvimento da pesquisa demonstrar a variabilidade da precipitação em torno dos valores médios, para isso calculou-se o desvio de precipitação em relação à média, gerando gráficos de desvio de precipitação anual, sazonal e mensal para toda a série 
histórica. Esses gráficos indicam ainda a linha de tendência linear dos dados analisados no período de 35 anos.

De acordo com Goossens e Berger (1986) a tendência climática é considerada uma mudança do clima, determinada pelo acréscimo ou decréscimo contínuo da variável climático ao longo de um período. A mudança climática abrupta é uma mudança abrupta e permanente, durante o período de registro, de um valor médio para outro.

Existem testes matemáticos que podem ser utilizados para indicar a tendência de uma série de dados, para os estudos aqui propostos, a linha de tendência linear foi acrescentada aos gráficos de desvio de precipitação com relação a média, apesar de ser uma metodologia estatística mais simples, é a mais indicada para análises de séries temporais e suficientes para os objetivos propostos nessa pesquisa.

Os gráficos foram feitos a partir dos desvios de precipitação com relação à média, pois de acordo com Galvani (2011) esse tipo de representação facilita a visualização da variabilidade dos dados em torno da média.

O histograma de frequência relativa foi utilizado para analisar a frequência dos intervalos de precipitação, sendo assim, produziu-se os histogramas de frequência na escala anual, sazonal e mensal.

\subsection{Análise e discussão dos resultados da precipitação}

\subsubsection{Estatística descritiva da precipitação pluviométrica}

A bacia hidrográfica do rio Piquiri apresenta uma precipitação média anual de 1761,9 mm, na série histórica analisada (1976-2010) dos 41 postos pluviométricos considerados para 
a pesquisa. $\mathrm{O}$ ano mais chuvoso foi $1983 \mathrm{com}$ um total de $2558,7 \mathrm{~mm}$ e o ano menos chuvoso foi 1988 com $1256,7 \mathrm{~mm}$, ou seja, no ano mais seco da série histórica choveu 49,1\% a menos que no ano mais chuvoso (1302,0 $\mathrm{mm}$ de amplitude), como pode-se observar na tabela 4.

Sazonalmente a precipitação pluviométrica apresenta um coeficiente de variação superior ao observado anualmente, o outono e o inverno apresentam maior coeficiente de variação, desvio padrão e amplitude com relação ao verão e a primavera, como se pode observar na tabela 4. Em valores médios a primavera e o verão apresentam-se como os mais chuvosos enquanto outono e inverno como menos chuvosos.

O mês com maior precipitação registrada na média histórica para a bacia hidrográfica do rio Piquiri é outubro $(192,2 \mathrm{~mm})$, com a menor média registrada é agosto $(81,3 \mathrm{~mm})$. Os meses invernais apresentam maior coeficiente de variação, sendo maio (67,5\%), junho $(65,8 \%)$, julho $(62,1 \%)$ e agosto $(76,4 \%)$, a maior amplitude ocorre no mês de maio $(424,7$ mm) e a menor em março $(202,1 \mathrm{~mm})$, como mostra a tabela 3.

Tabela 3- Estatística descritiva da precipitação pluviométrica média para a bacia hidrográfica do rio Piquiri de 1976 a 2010.

\begin{tabular}{c|c|c|c|c|c|c}
\hline \hline Período & $\begin{array}{c}\text { Média } \\
(\mathbf{m m})\end{array}$ & $\begin{array}{c}\text { D.P. } \\
(\mathbf{m m})\end{array}$ & $\begin{array}{c}\text { C.V. } \\
(\mathbf{\%})\end{array}$ & $\begin{array}{c}\text { Máxima } \\
(\mathbf{m m})\end{array}$ & $\begin{array}{c}\text { Mínima } \\
(\mathbf{m m})\end{array}$ & $\begin{array}{c}\text { Amplitude } \\
(\mathbf{m m})\end{array}$ \\
\hline \hline 1976-2010 & 1761,9 & 273,4 & 20 & 2558,7 & 1256,7 & 1302,0 \\
\hline \hline Verão & 469,7 & 110,2 & 23 & 670,2 & 253,7 & 416,5 \\
\hline Outono & 422,3 & 161,0 & 38 & 922,6 & 151,4 & 771,2 \\
\hline Inverno & 326,3 & 144,9 & 44 & 635,7 & 23,1 & 612,6 \\
\hline Primavera & 543,6 & 131,4 & 24 & 845,0 & 255,9 & 589,1 \\
\hline \hline Jan & 186,2 & 77,7 & 41,2 & 366,9 & 43,3 & 323,6 \\
\hline Fev & 157,9 & 67,7 & 42,9 & 302,6 & 26,1 & 276,5 \\
\hline Mar & 125,6 & 47,4 & 37,7 & 252,8 & 50,7 & 202,1 \\
\hline Abr & 134,5 & 76,5 & 56,9 & 393,6 & 9,7 & 383,9 \\
\hline Mai & 169,3 & 114,3 & 67,5 & 440,4 & 15,7 & 424,7 \\
\hline Jun & 118,5 & 78,0 & 65,8 & 331,9 & 5,2 & 326,7 \\
\hline Jul & 97,4 & 60,5 & 62,1 & 250,2 & 6,2 & 244,0 \\
\hline Ago & 81,3 & 62,1 & 76,4 & 219,0 & 1,5 & 217,5 \\
\hline
\end{tabular}




\begin{tabular}{c|c|c|c|c|c|c}
\hline Set & 147,6 & 84,3 & 57,1 & 359,2 & 11,1 & 348,1 \\
\hline Out & 192,2 & 84,8 & 44,1 & 467,0 & 62,7 & 404,3 \\
\hline Nov & 165,0 & 72,8 & 44,1 & 390,9 & 45,8 & 345,1 \\
\hline Dez & 186,4 & 82,5 & 44,2 & 470,9 & 64,7 & 406,2 \\
\hline
\end{tabular}

Org.: Márcio Greyck Guimarães Correa, 2017.

O coeficiente de variação indica a variabilidade normalizada em relação à média da precipitação, ou seja, entre os meses de abril a setembro a oscilação da precipitação é maior que durante os meses de outubro a março, da mesma forma que durante o outono e o inverno a oscilação da precipitação é maior que durante a primavera e o verão.

Com relação à dinâmica atmosférica predominante sobre a região sul do Brasil, e consequentemente sobre a bacia hidrográfica do rio Piquiri, Reboita et. al (2010) ao realizar uma caracterização do regime de chuvas da América do Sul, identificou a região sul do Brasil, sul do Paraguai e Uruguai (R4) como uma área de elevados totais pluviométricos, principalmente as áreas do oeste da região sul do Brasil na divida com o Paraguai, segundo a autora, os valores de precipitação nessa área variam de $1750-2100 \mathrm{~mm}$ por ano e dentre os principais sistemas atmosféricos atuantes destacam-se os deslocamento dos sistemas frontais, ciclones e frentes frias, junto às as características frontogenéticas que a região apresenta, a presença dos complexos convectivos de mesoescala (CCMs), sistemas de circulação local, e a Zona de Convergência do Atlântico Sul (ZCAS).

De acordo com Nery (2005), durante o verão observa-se em baixos níveis um escoamento de norte-noroeste (jato) proveniente da encosta leste dos Andes que se prolonga até a região sudeste do Brasil, responsável por transportar umidade da região amazônica para a região central, sul e Sudeste do Brasil. O acoplamento desses jatos à umidade proveniente do Oceano Atlântico e aos sistemas frontais favorecem a formação da ZCAS, que são responsáveis por trazer aumento das chuvas principalmente entre a primavera e o verão. 
Durante o período do inverno o avanço constante dos sistemas frontais e das massas de ar de origem polar (sistemas de alta pressão), faz com que as temperaturas diminuam em toda a região sul do Brasil, Reboita et. al (2010) discute que no sul do Brasil ocorre no mínimo a atuação de 4 sistemas frontais por mês no inverno, que podem ter adentrado ou se formado na região, estes sistemas causam chuvas generalizadas na zona de contraste térmico formada por uma banda de nebulosidade (frente fria). A permanência da alta pressão sobre o Brasil inibe a atuação dos processos convectivos e os jatos direcionados da região amazônica perdem intensidade, favorecendo a diminuição da chuva sobre boa parte do Brasil, inclusive sobre o sul do país.

\subsubsection{Desvio e tendência da precipitação pluviométrica}

Analisando a Figura 5 nota-se os desvios de precipitação ao longo dos 35 anos da série histórica que o maior desvio positivo registrado foi em 1983 (796,2 mm) e o maior desvio negativo foi em 1988 (-505,8 mm), anos apontado anteriormente como o mais e o menos chuvoso, respectivamente. Observa-se que 51,4\% dos anos apresentaram desvios negativos de precipitação e 48,6\% de desvios positivos, a reta de tendência linear apresenta-se nula para os desvios de precipitação anual. 


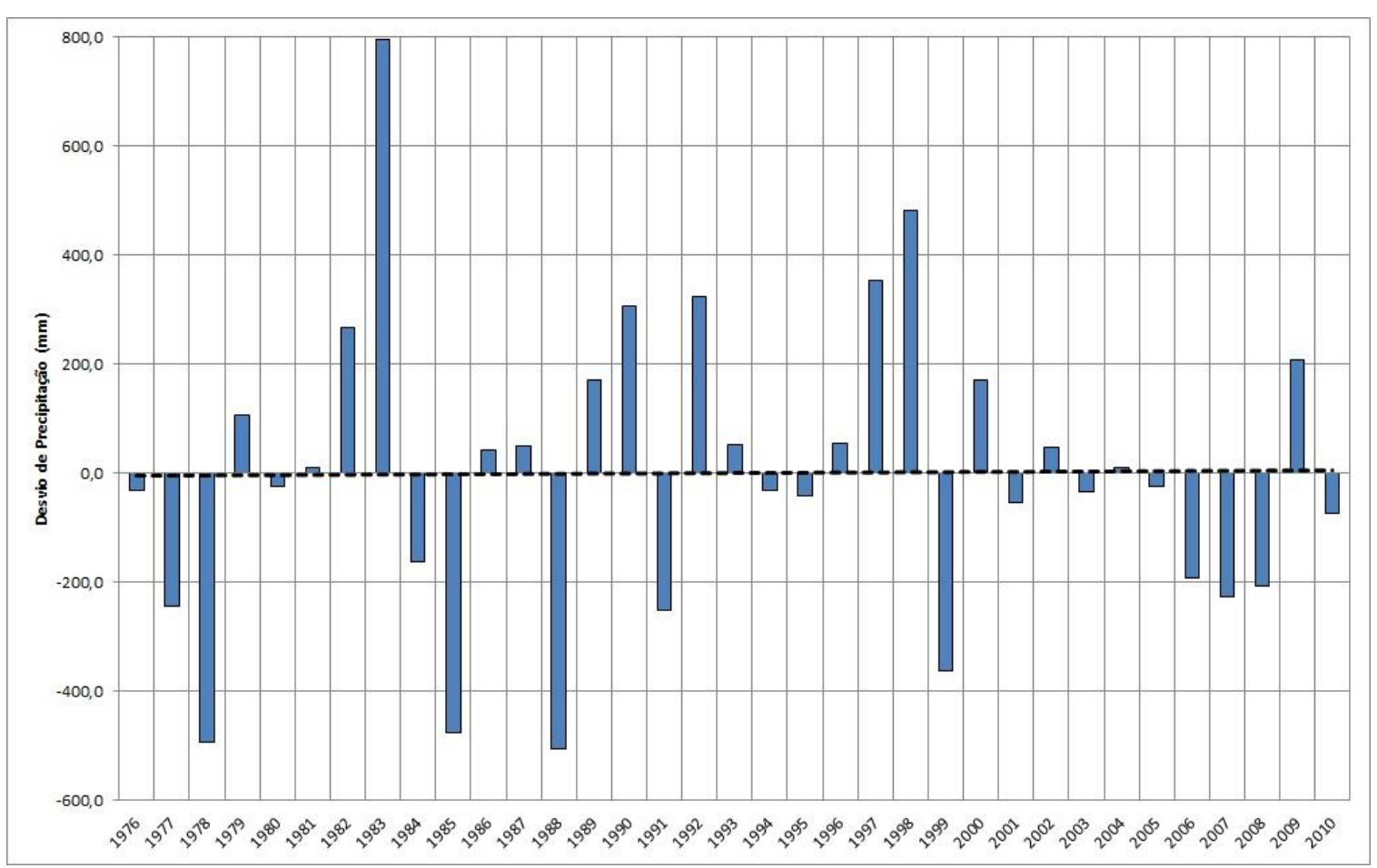

Figura 5: Desvios de precipitação e linha de tendência anual para a bacia hidrográfica do rio Piquiri-PR. Org.: Márcio Greyck Guimarães Correa, 2017.

A figura 6 mostra os desvios de precipitação sazonal ao longo dos anos, nota-se que o maiores desvio do verão foram 1996 (200,5 mm) e 1978 (-216,0 mm). No outono foi 1983 $(500,4 \mathrm{~mm})$ e $1978(-270,9 \mathrm{~mm})$ para o inverno teve-se os maiores desvios no ano de 1990 $(300,7 \mathrm{~mm})$ e $1988(-302,8 \mathrm{~mm})$. Na primavera os maiores desvios foram em 1981 (301,7 $\mathrm{mm})$ e em $1985(-287,3 \mathrm{~mm})$.

Durante o verão e a primavera a reta de tendência indica aumento dos desvios de precipitação ao longo da série histórica analisada, diminuição dos desvios no outono e estabilidade no inverno. 

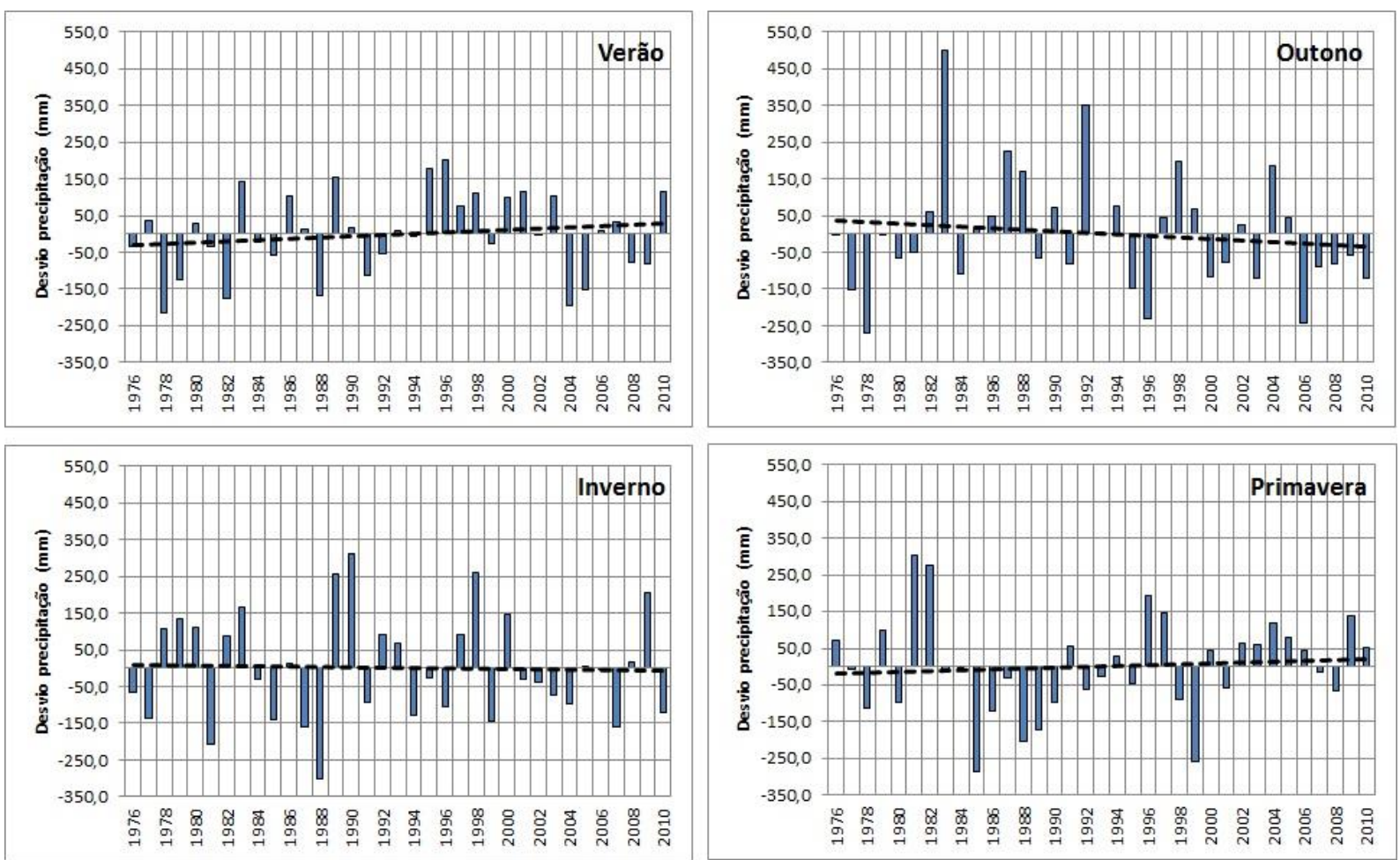

Figura 6: Desvios de precipitação e linha de tendência sazonal para a bacia hidrográfica do rio Piquiri-PR.

Org.: Márcio Greyck Guimarães Correa, 2017.

Proporcionalmente o período do verão apresenta mais desvios positivos que negativos, com $46,6 \%$ de desvios negativos e $51,4 \%$ de desvios positivos, nas outras três estações ocorre o inverso, sendo que os desvios negativos correspondem a 54,3\%, e os desvios positivos 45,7\%. A sazonalidade da precipitação não apresenta-se tão marcante como em áreas de clima tropical, indicando uma regime sazonal subtropical das chuvas para a bacia hidrográfica do rio Piquiri

Analisando a figura 7 com os desvios de precipitação para cada mês ao longo da série histórica, observa-se tendência de aumento dos desvios positivos para janeiro e outubro e tendência de aumento dos desvios negativos para maio, junho e dezembro. Para os demais meses os desvios tendem a se manter estáveis.

A amplitude dos desvios é menor entre os meses de março, junho, julho e agosto e maior em maio, setembro, outubro e dezembro. O limite inferior máximo dos desvios 
negativos é de -153,6 mm (maio, 2006) e o limite superior máximo de 284,5 mm (dezembro, 1981). Destaca-se a quantidade de desvios positivos elevados para o mês de maio acima de 200 mm (3 ocorrências) e desvios negativos próximos a -150mm (5 ocorrências).

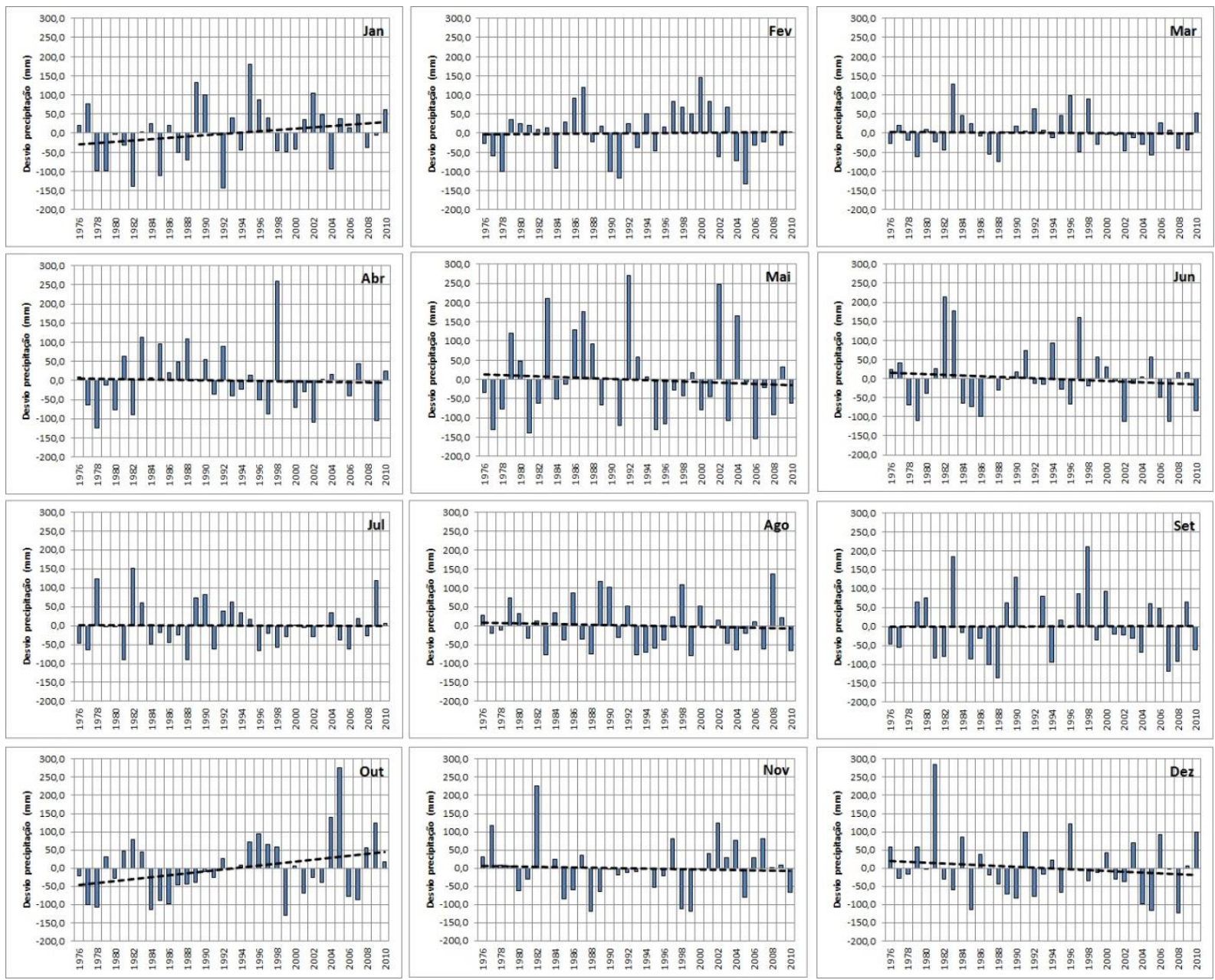

Figura 7: Desvios de precipitação e linha de tendência mensal para a bacia hidrográfica do rio Piquiri-PR. Org.: Márcio Greyck Guimarães Correa, 2017.

\subsubsection{Análise da frequência dos totais pluviométricos}

Observando a Figura 8, da frequência dos totais anuais da precipitação nota-se que a maior frequência ocorre nos intervalos entre 1600 a $2000 \mathrm{~mm}$ (22 anos), seguido dos 
intervalos com menos de 1600 mm (10 anos) e com menor frequência os intervalos com mais de $2000 \mathrm{~mm}(2$ anos).

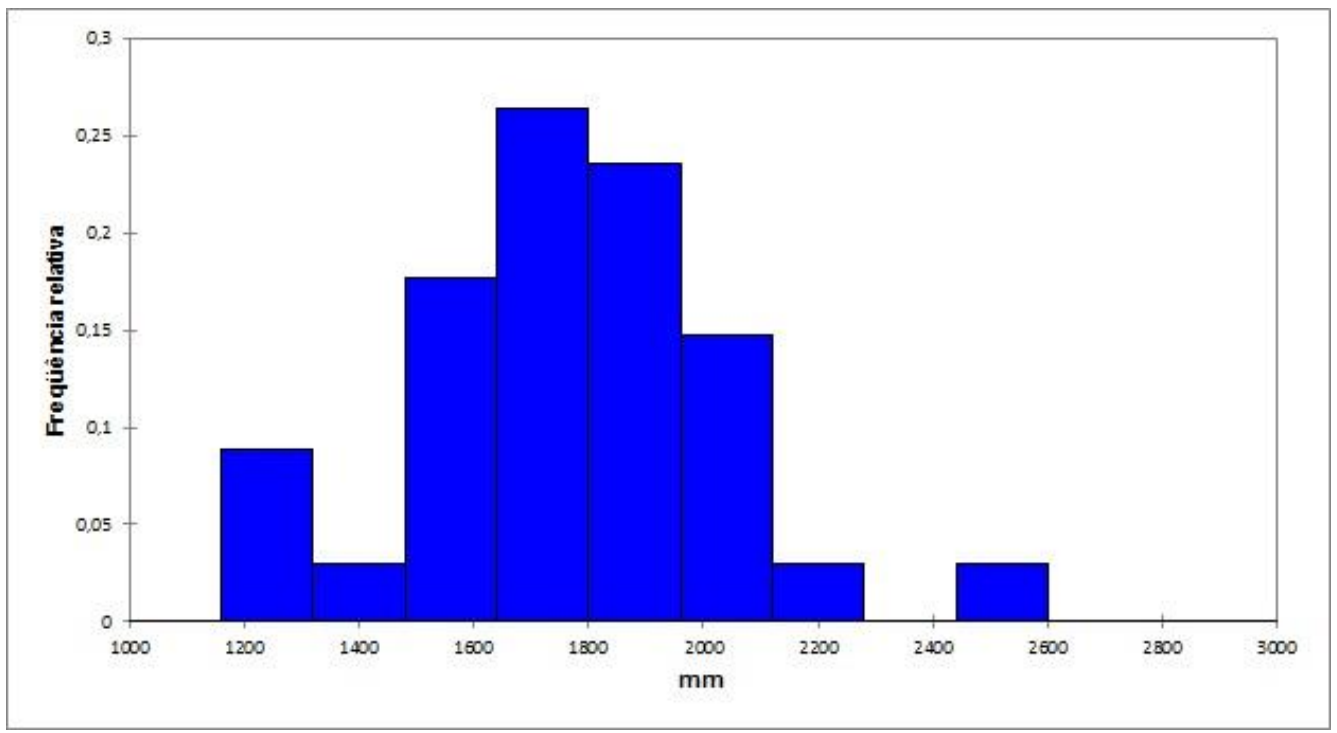

Figura 8: Histograma de frequência dos totais de precipitação anual para a bacia hidrográfica do rio Piquiri-PR. Org.: Márcio Greyck Guimarães Correa, 2017.

O histograma de frequência, Figura 9, mostra que durante o verão ocorre maior frequência de precipitação nos intervalos entre 400 e 600 mm, no outono a maior frequência de precipitação fica de 300 a $500 \mathrm{~mm}$. Para o inverno os intervalos de precipitação que ocorrem com maior frequência é 200 a 300 mm, na primavera a maior frequência ocorre de 400 a $700 \mathrm{~mm}$.

Os intervalos de frequência mostram a importância dos sistemas atmosféricos na variabilidade sazonal da precipitação pluviométrica da bacia hidrográfica do rio Piquiri. Como apresentado anteriormente, a atuação dos sistemas frontais durante o outono e o inverno corrobora para a diminuição dos valores de precipitação mais frequentes, enquanto durante a primavera e o verão, o acoplamento dos sistemas frontais com os processos 
convectivos resultantes do aquecimento da atmosfera e da umidade proveniente da Amazônia e do Oceano Atlântico favorece o aumento dos valores pluviométricos e sua frequência.
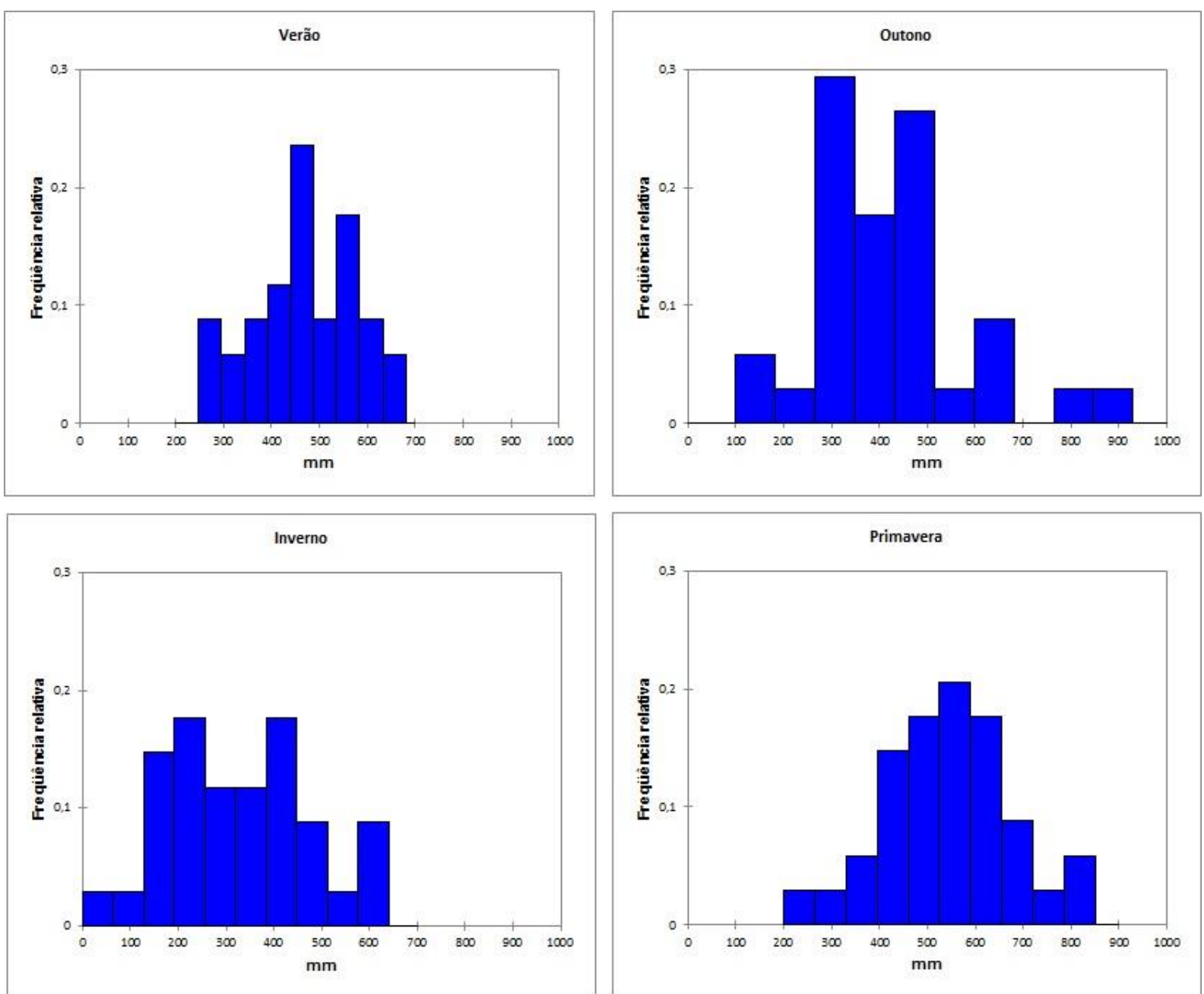

Figura 9: Histograma de frequência dos totais de precipitação sazonal para a bacia hidrográfica do rio PiquiriPR.

Org.: Márcio Greyck Guimarães Correa, 2017.

\subsection{Considerações sobre a precipitação pluviométrica}

A bacia hidrográfica do rio Piquiri apresenta uma precipitação média anual de 1761,9 mm, sendo que o ano mais chuvoso foi 1983 e o ano menos chuvoso foi 1988 , com $49,1 \%$ a menos de chuva que no ano mais chuvoso, a primavera e o verão apresentam-se como os mais 
chuvosos enquanto outono e inverno como menos chuvosos e com maior coeficiente de variação, desvio padrão e amplitude. $\mathrm{O}$ mês com maior precipitação registrada na média histórica para a bacia hidrográfica do rio Piquiri é outubro, com a menor média registrada é agosto.

Temporalmente percebe-se que a variabilidade mensal é mais expressiva que a variabilidade sazonal e anual. A diferença é de $20,7 \%$ de variação na distribuição das chuvas entre as estações e os meses, e de 33,3\% entre a distribuição anual e a mensal. Observa-se uma escala crescente de variabilidade temporal da precipitação pluviométrica anual para sazonal para mensal.

A frequência dos intervalos de maior e menor precipitação pode indicar a presença de fenômenos atmosféricos de menor ou maior frequência. As condições médias da atmosfera com os sistemas de maior frequência, como os sistemas frontais, Zona de Convergência do Atlântico Sul, bloqueios atmosféricos, entre outros, podem explicar os intervalos de precipitação mais frequentes. 


\section{PARTE II - VAZÃO FLUVIAL DA BACIA HIDROGRÁFICA DO RIO PIQUIRI}

\subsection{Introdução}

De acordo com Shelton (2009) a vazão é uma fonte de informação valiosa para entender como ocorre a interação entre o sistema climático e o sistema hidrológico, explica que a precipitação produz um aumento na vazão média dos rios, enquanto que períodos de seca e diminuição da precipitação resultam em uma diminuição da vazão fluvial. Portanto, a vazão fluvial é entendida nesta pesquisa como uma importante variável hidrológica para compreender a dinâmica hidroclimática da bacia hidrográfica do rio Piquiri.

Estudos que consideram a vazão fluvial como uma variável resposta das condições climáticas de uma bacia hidrográfica foram realizados por Zandonadi (2013) que investigou a atuação dos sistemas atmosféricos produtores da precipitação pluviométrica sobre a bacia hidrográfica do rio Paraná e a vazão fluvial como uma variável resposta e concluiu que na escala anual, as variações da precipitação resultaram em variações na vazão das usinas consideradas no estudo.

A variabilidade da vazão também é um importante indicador dos riscos de inundação das planícies fluviais, segundo Tucci (2001, p.621) "quando a precipitação é intensa a quantidade de água que chega simultaneamente ao rio pode ser superior à sua capacidade de drenagem" o que resulta na inundação das áreas ribeirinhas, os problemas gerados pelas inundações são os mais diversos, e a gravidade depende do nível de ocupação da área e a frequência com que ocorrem as inundações. 
No caso da bacia hidrográfica do rio Piquiri, por ser essencialmente uma área agrícola, a inundações afetam principalmente a produção de grãos, e as populações que vivem na proximidade da várzea.

Esta parte da tese é dedicada a explicar a dinâmica do escoamento fluvial da bacia hidrográfica do rio Piquiri, considerando-se três postos fluviométricos da Agencia Nacional de Águas (ANA), buscou-se analisar estatisticamente a variável hidroclimática da vazão fluvial. Apresenta-se uma analise da estatística descritiva para os posto de Guampará, Porto Guarani e Balsa Santa Maria na escala temporal anual, sazonal e mensal. Por fim, faz-se uma analise dos desvios de vazão com relação à media e a linha de tendência linear para o posto de Balsa Santa Maria.

\subsection{Referencial teórico - Vazão fluvial}

Winter (2001) propõe uma visão integradora da paisagem levando em conta o ciclo hidrológico, a estrutura geológica e geomorfológica como condicionantes do que ele chama de "hydrologic landscapes", para o autor, que considera a paisagem em sua visão funcional, ao entender os processos de precipitação, infiltração, escoamento e evaporação da água na superfície terrestre e suas decorrências com a estrutura geológica e geomorfológica é possível criar parâmetros de explicação e funcionamento da paisagem. $\mathrm{O}$ autor apresenta uma classificação de "hydrologic landscapes" de acordo com o tipo de interação entre a água e a superfície (infiltração e escoamento), como áreas de praia, vales entre montanhas e áreas planas ou planálticas, e serve para explicar as mais diferentes hipóteses sobre o movimento da água em bacias hidrográficas. . 
A água da chuva ao atingir a superfície terrestre segue por gravidade para as áreas mais baixas do relevo, o que caracteriza o sistema de escoamento da água. Winter (2001) apresenta a complexidade desses sistemas de escoamento e infiltração nas diferentes paisagens hidrológicas, como pode-se observar na Figura 10.
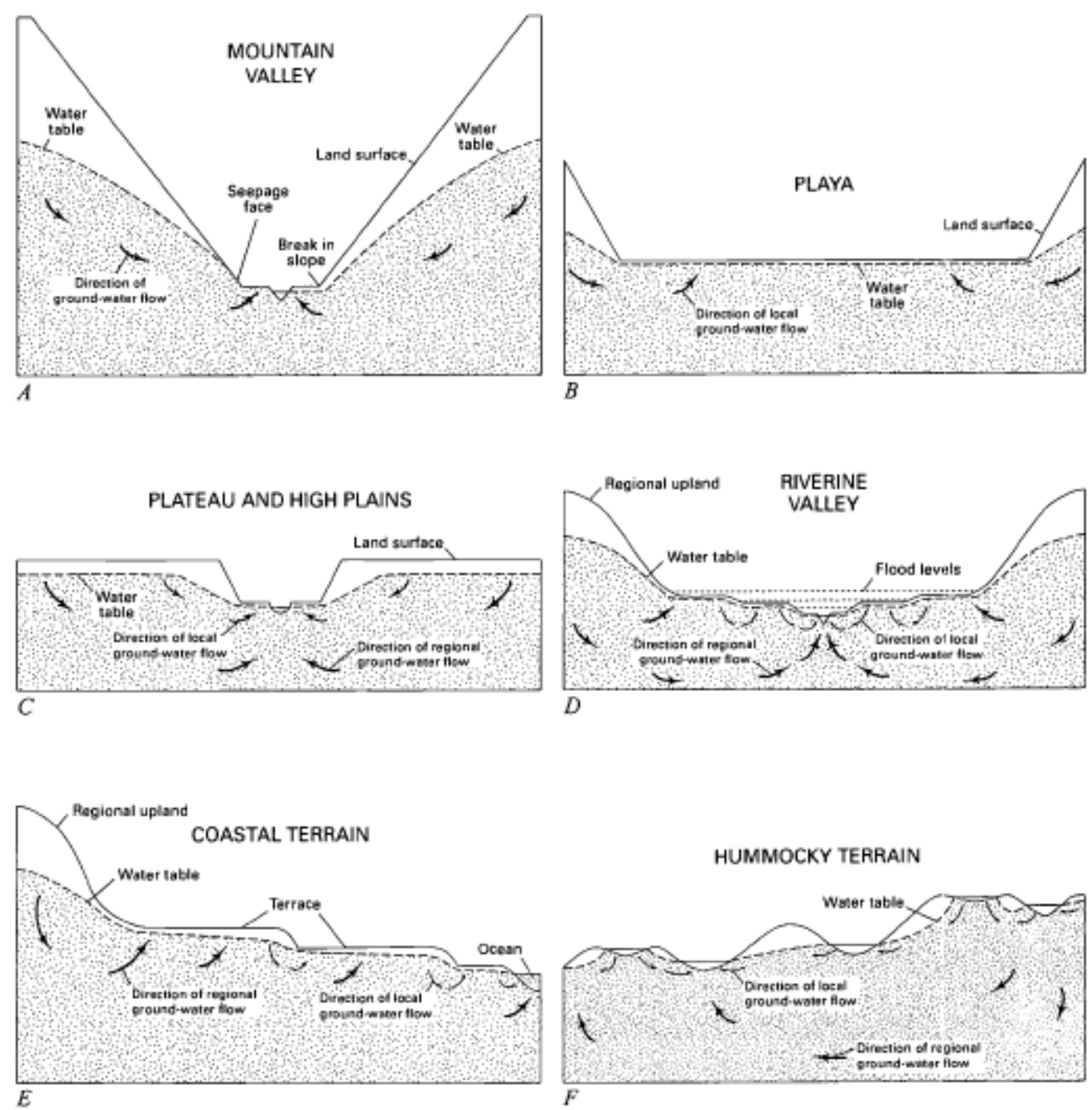

Figura 10: Paisagens hidrológicas generalizadas, (A) vale de montanha; (B) áreas planas e desérticas; (C) platôs e altas planícies; (D) vale fluvial; (E) terrenos costeiros; (F) terrenos de hummocky ${ }^{1}$.

Fonte: Winter (2001).

\footnotetext{
${ }^{1}$ Hummochy: Estratificação cruzada diagnóstica dos processos ligados às tempestades, que ocorre em uma camada com granodecrescência e espessamento ascendentes, em cuja base podem estar concentrados fósseis. A laminação interna manifesta-se por ondulações truncantes, normalmente com mergulhos suaves. Existem tendências das ondulações aumentarem o espaçamento entre as cristas, no sentido ascendente, ao mesmo tempo que diminuem sua altura. $\mathrm{O}$ espaçamento entre as cristas de ondulações deve ser superior a $1 \mathrm{~m}$, sendo que abaixo deste valor pode ser utilizado o termo microhummocky.

Acesso em 08 de julho de 2015 < http://www.mineropar.pr.gov.br/modules/glossario/conteudo.php?conteudo=H>
} 
O lençol freático sofre alteração no seu nível de acordo com as características da morfologia do relevo, bem como o escoamento superficial e a infiltração da água.

Observando na Figura 10 (A e D) nota-se as condições hidrológicas e geomorfológicas encontradas na bacia hidrográfica do rio Piquiri, onde o vale fluvial sofre inundações frequentes, dependendo do volume e da intensidade da precipitação, com o canal fluvial extrapolando para toda a planície. Próximo ao canal do rio observa-se a conectividade do mesmo com o lençol freático, e a presença de chuvas durante o ano todo como apontado por Correa (2013), o que concerne uma característica perene ao rio Piquiri.

A entrada de água no sistema bacia hidrográfica por meio da precipitação pluviométrica dinamiza não apenas os processos de infiltração e escoamento subsuperficial, mas também os processos superficiais, como a erosão e transporte de massa e altera significativamente o volume escoado pelo canal do rio.

O escoamento, segundo Tucci (2001, p. 373), “é o deslocamento da água na superfície da bacia, nos rios, canais e reservatórios, é uma das parcelas mais importantes do ciclo hidrológico". O escoamento pode ser representado quantitativamente por meio de variáveis como a vazão, a profundidade e a velocidade.

De acordo com Shelton (2009) a vazão é o escoamento da água em um canal natural, como resultante da precipitação que cai em uma área a montante do ponto de referência, portanto, a vazão fluvial é resultante de toda a água captada pela bacia hidrográfica proveniente da precipitação pluviométrica, e por se tratar de uma medida volumétrica em um intervalo de tempo especifico, usualmente utiliza-se a unidade de medida volume/tempo $\left(\mathrm{m}^{3} / \mathrm{s}\right)$. 


\subsubsection{Características hidrogeomorfológicas da bacia hidrográfica do rio Piquiri}

Geologicamente a área da bacia do rio Piquiri encontra-se, de acordo com Maack (1981), numa zona transitória entre as rochas eruptivas básicas do derrame do Trapp (basalto) a Formação Caiuá (arenito). O basalto abrange setores mais elevados (com mais de $800 \mathrm{~m}$ ) ao no sudeste até setores mais baixos sul e sudoeste da bacia (200m até $700 \mathrm{~m})$, enquanto o arenito ocupada uma área menor e mais baixa (entre $200 \mathrm{~m}$ e $500 \mathrm{~m}$ ) ao norte da bacia.

Essa configuração geológica confere à bacia do rio Piquiri a predominância de planaltos, que se estendem por toda a extensão da bacia hidrográfica, com exceção da planície fluvial localizada próximo a foz do rio Piquiri junto ao rio Paraná, a altimetria varia entre 200 m nas regiões mais baixas, próximo ao rio Paraná e ao norte da bacia de predomínio do Arenito, podendo ultrapassar $1000 \mathrm{~m}$ em direção ao sul e sudeste, área de predomínio do basalto.

Nota-se por meio de três perfis transversais, Figura 11 a variação da altimetria no alto curso, médio curso e baixo curso. No perfil 3, do alto curso, o rio Piquiri escoa em uma altitude que varia entre $800-900 \mathrm{~m}$, isso faz com que a velocidade do escoamento seja maior, no perfil 1 e 2 do médio-baixo curso, o rio escoa a uma altitude média de 200-300 m, o que faz com a velocidade do escoamento seja menor, uma vez que o canal do rio atravessa uma região de relevo mais baixo e menor declividade. 


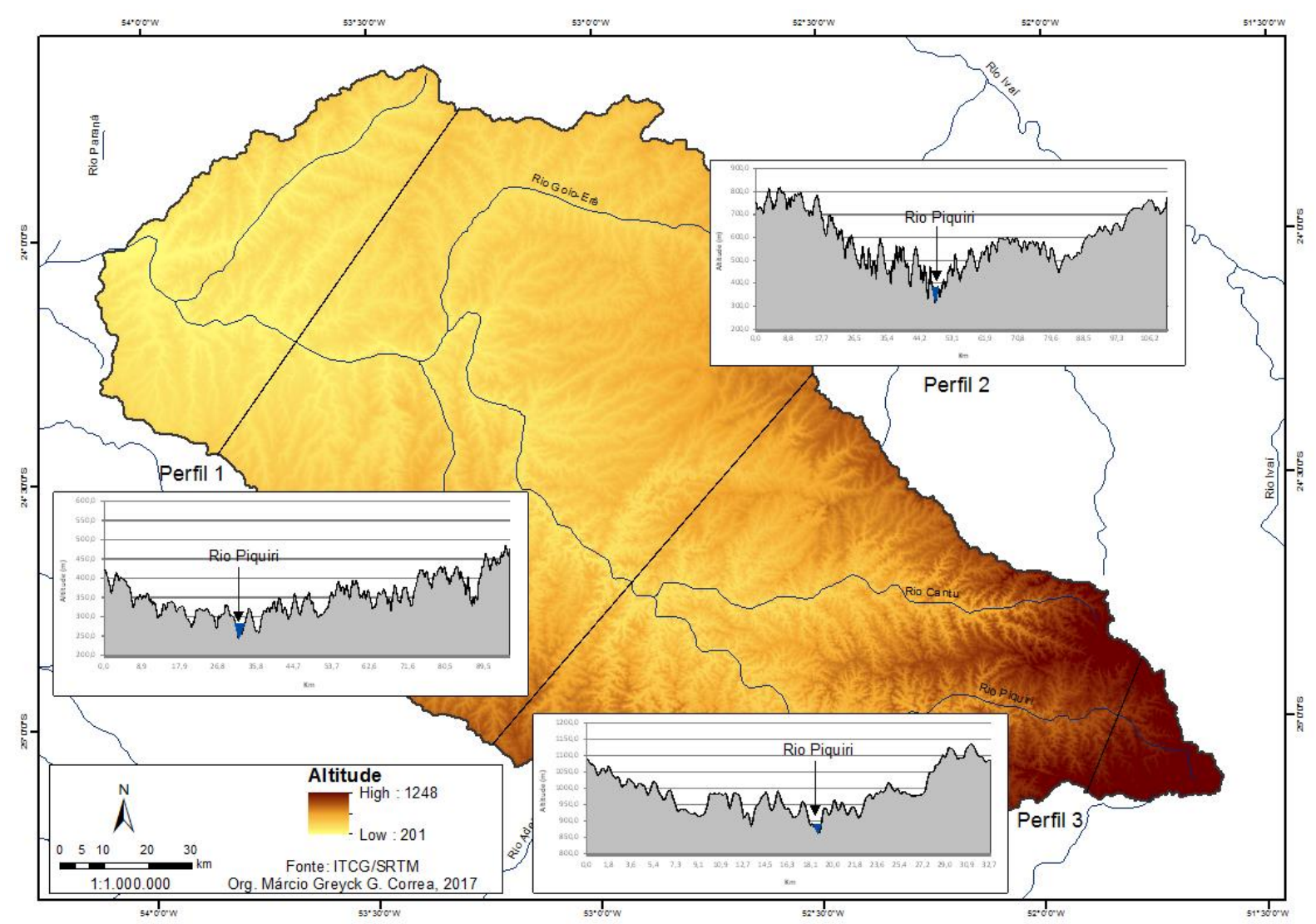

Figura 11: Mapa hipsométrico com três perfis transversais no alto, médio e baixo curso do rio Piquiri. Org.: Márcio Greyck Guimarães Correa, 2017.

Segundo Aguiar (2009) a bacia hidrográfica do rio Piquiri apresenta 54,6\% da sua área com declividade entre 6-20\% (suave ondulado a ondulado forte), essas classes de declividade necessitam de manejo adequado e práticas de conservação mais complexas, o rio Piquiri tem seu canal sobre uma estrutura geológica resultante da formação Serra Geral com rochas magmáticas e relevo suavemente ondulado o que concerne uma característica sinuosa no canal, principalmente em seu baixo curso, Figura 12. 


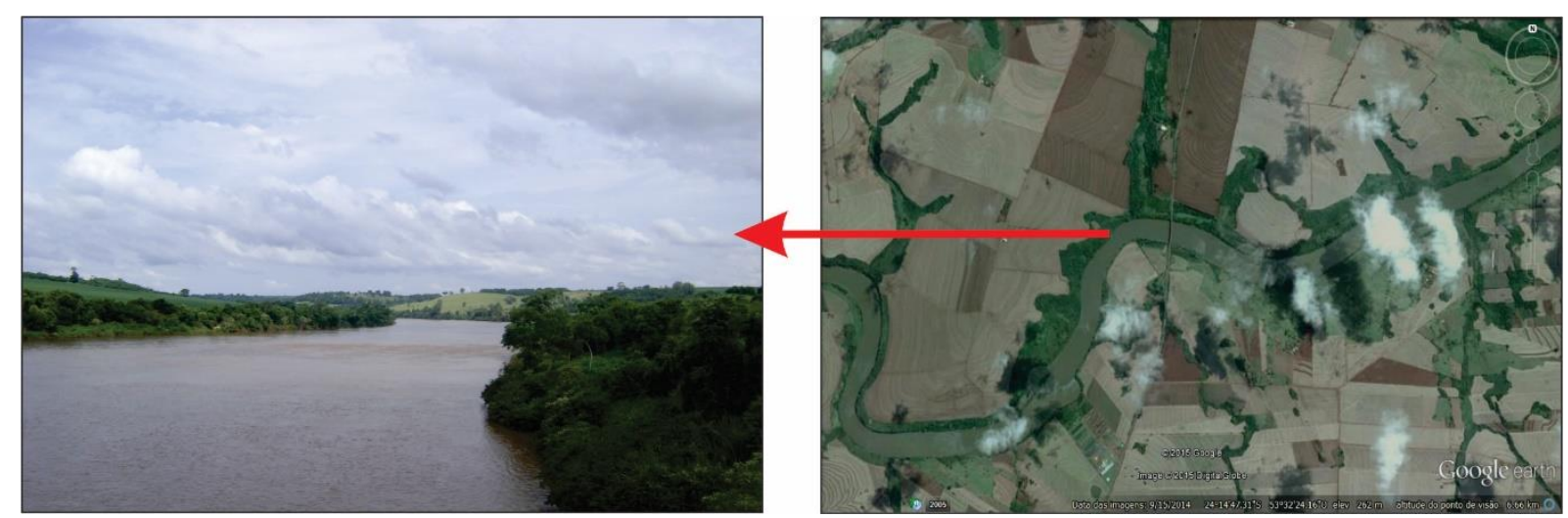

Figura 12: Fotografia de trecho do rio Piquiri sobre a ponte na PR-486 (Assis Chateaubriand - Brasilândia do Sul) visada para oeste.

Org.: Márcio Greyck Guimarães Correa, 2017.

De acordo com a hierarquização de canais de drenagem proposta por Strahler (1952) e aplicada à bacia hidrográfica do rio Piquiri por Aguiar (2009) a bacia caracteriza-se por ser de $7^{\mathrm{a}}$ ordem. Sendo os principais afluentes do rio Piquiri: rio Cantu, Goio-Erê e Goio-Gang da margem direita e rio do Cobre e São Pedro da margem esquerda.

\subsection{Procedimentos metodológicos - Vazão Fluvial}

\subsubsection{Escolha e análise da consistência dos dados de vazão}

Os dados de vazão fluvial foram obtidos junto a Agência Nacional de Águas (ANA), para o desenvolvimento da pesquisa optou-se por utilizar três postos fluviométricos escolhidos de acordo com a localização geográfica e a série histórica disponível, sendo assim escolheu-se o posto fluviométrico de Guampará localizado a montante do canal principal do rio Piquiri, Porto Guarani no médio curso do canal e Balsa Santa Maria no baixo curso, Figura 13. 


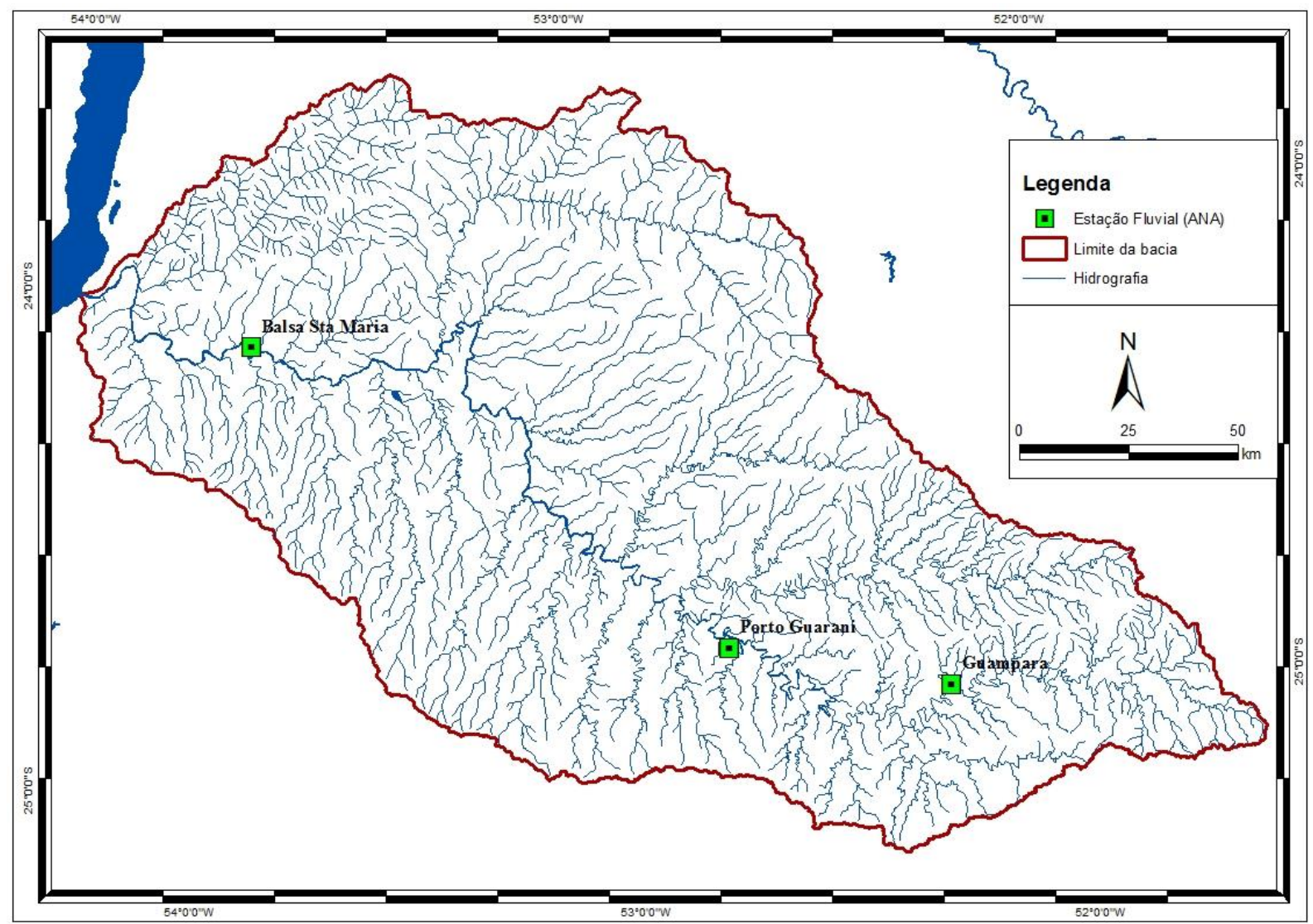

Figura 13 - Localização dos postos fluviométricos da Agência Nacional de Águas (ANA) na bacia hidrográfica do rio Piquiri-PR.

Org.: Márcio Greyck Guimarães Correa, 2017.

A coleta da vazão é feita pelo método convencional de medição de cotas, de acordo com Chevallier (2001, p. 497), este método de coleta consiste em “colocar uma régua vertical e observar com regularidade o nível". A régua é chamada de linímetro e é nivelada com referencia a um datum. Os linímetros são geralmente feitos de metal ou madeira, com uma régua graduada.

A Figura 14 mostra exemplos de linímetros instalados pela Agencia Nacional de Águas, de acordo com ANA (2011), normalmente usa-se réguas numeradas de $2 \mathrm{em} 2 \mathrm{~cm}$, sendo os espaços intermediários indicados por traços. 


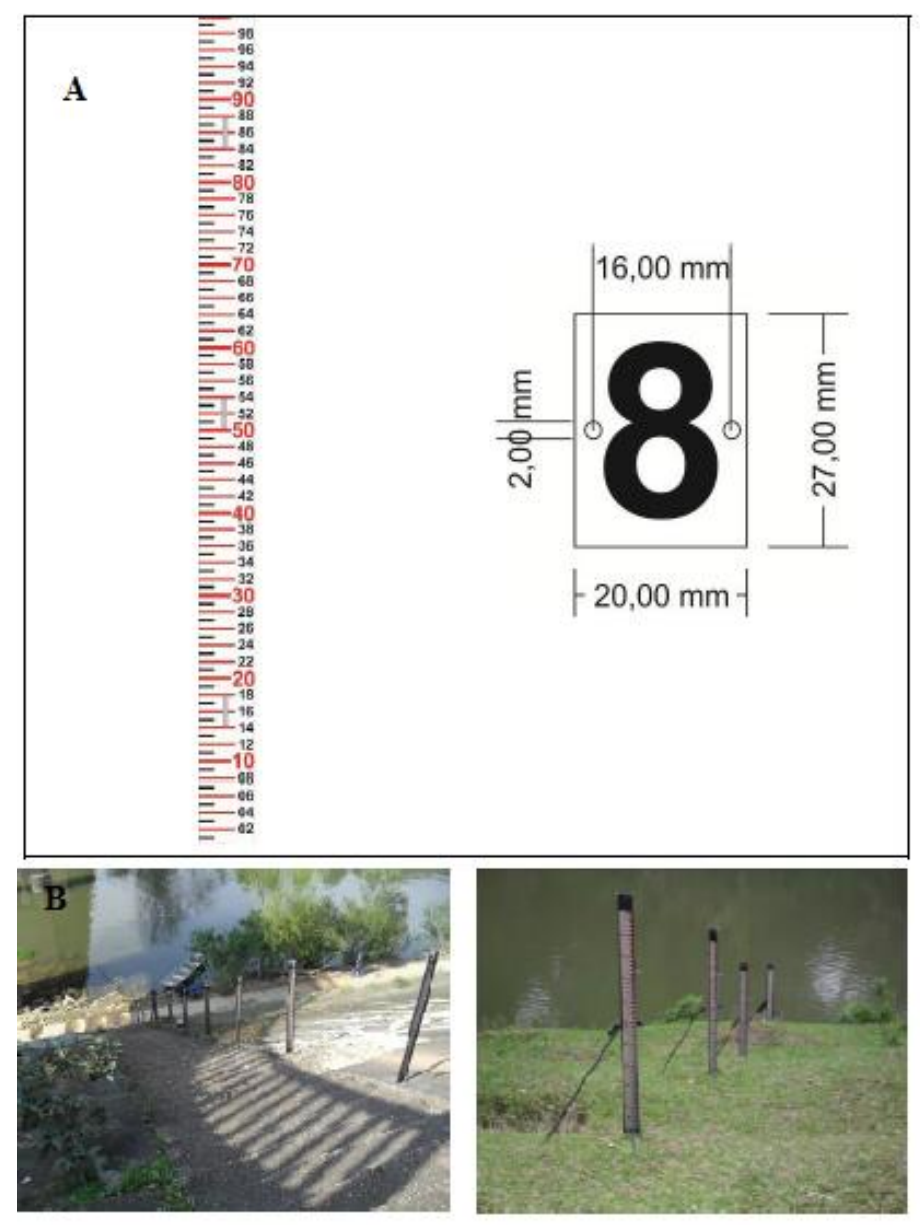

Figura 14: Esquema explicativo de instalação do linimento da Agência Nacional de Águas (ANA). Fonte: Orientações para elaboração do relatório de instalação de estações hidrométricas - ANA, 2011 Org.: Márcio Greyck Guimarães Correa, 2017.

A estação de Guampará está instalada na margem direita do rio Piquiri, junto à ponte da estrada que liga Palmital a Marquinhos e 250m a montante da foz do rio Jaguatirica. Tem as margens bem definidas até a profundidade correspondente a leitura de régua de $7 \mathrm{~m}$. Ambas as margens apresentam inclinação média, de constituição argilosa e leito rochoso. A série histórica de Guampará corresponde ao período de 1984 à 2010.

De acordo com a ANA a estação fluviométrica Porto Guarani localiza-se na margem direita do rio Piquiri, com 4 lances de réguas de 2 metros, sendo: A RN2 com cota 10872mm e a RN3 com cota $6510 \mathrm{~mm}$. Os lances de régua estão fixados em cimento e a seção de medição localiza-se a 50 metros a jusante da balsa. 
A estação de Balsa Santa Maria está instalada com réguas de madeira, na margem esquerda do rio, em três lances, todos com $2 \mathrm{~m}$ cada, fixados em esteios de ferro. A RN 1 com cota $4284 \mathrm{~mm}$ - em placa de metal. A RN 2 com cota $3702 \mathrm{~mm}$ - em placa de metal, as condições de instalação é em leito arenoso com margens de terra e ponto inicial na margem esquerda com largura média de $200 \mathrm{~m}$.

Porto Guarani e Balsa Santa Maria tem uma série histórica de 1976 à 2010. Os dados escolhidos não apresentaram falhas e para testar a consistência do mesmo também se realizou o cálculo do coeficiente de determinação baseando-se nas médias mensais de cada posto fluviométrico e a média geral da vazão fluvial do rio Piquiri, tabela 4.

Tabela 4- Coeficiente de determinação para os postos fluviométricos da ANA na bacia hidrográfica do rio Piquiri-PR.

\begin{tabular}{c|c|c}
\hline \hline Posto Fluviométrico & Área de Drenagem $\left(\mathbf{k m}^{2}\right)$ & Coef. Det. $\left(\mathbf{R}^{\mathbf{2}}\right)$ \\
\hline \hline Guampara & 1690 & 0,78 \\
\hline Porto Guarani & 4160 & 0,96 \\
\hline Balsa Santa Maria & 20900 & 0,98 \\
\hline
\end{tabular}

Org.: Márcio Greyck Guimarães Correa, 2017.

Assim como na análise dos dados de precipitação, optou-se por realizar a estatística descritiva (média, desvio padrão, coeficiente de variação, máxima, mínima e amplitude) da vazão fluvial para os três postos fluviométricos na escala anual, sazonal e mensal.

A análise mais detalhada na escala mensal foi realizada apenas para o posto Balsa Santa Maria por ser mais representativo e ter uma área de drenagem maior. 


\subsection{Análise e discussão dos resultados da vazão fluvial}

\subsubsection{Estatística descritiva da vazão fluvial}

A bacia hidrográfica do rio Piquiri apresenta uma vazão média de $6101,1 \mathrm{~m}^{3} \cdot \mathrm{s}^{-1}$, na estação hidrométrica Balsa Santa Maria, segundo o Instituto das Águas do Paraná², e o rio principal tem características perenes, devido à disponibilidade de chuvas ao longo do ano todo.

Como se pode observar na tabela 6 à medida que se caminha nas estações da montante para a jusante (Guampará para Balsa Sta. Maria) os valores médios de vazão, desvio padrão, máxima, mínima e a amplitude sofrem acréscimos, resultante da dinâmica natural do incremento de corpos hídricos de menor ordem ao rio principal e aumento da área de drenagem pelo mesmo. O coeficiente de variação indica uma variação em torno de $30 \%$ para ambas as estações.

Tabela 5- Estatística descritiva da vazão fluvial média para a bacia hidrográfica do rio Piquiri de 1976 a 2010.

\begin{tabular}{c|c|c|c|c|c|c}
\hline $\begin{array}{c}\text { Posto } \\
\text { Fluviométrico }\end{array}$ & $\begin{array}{c}\text { Méd. } \\
\left(\mathrm{m}^{3} \mathrm{~s}^{-1}\right)\end{array}$ & $\begin{array}{c}\text { D.P. } \\
\left(\mathrm{m}^{3} \mathrm{~s}^{-1}\right)\end{array}$ & C.V. & $\begin{array}{c}\text { Máx. } \\
\left(\mathrm{m}^{3} \mathrm{~s}^{-1}\right)\end{array}$ & $\begin{array}{c}\text { Mín. } \\
\left(\mathrm{m}^{3} \mathrm{~s}^{-1}\right)\end{array}$ & $\begin{array}{c}\text { Amp. } \\
\left(\mathrm{m}^{3} \mathrm{~s}^{-1}\right)\end{array}$ \\
\hline \hline Guampará & 618,1 & 182,4 & $29,5 \%$ & 1012,5 & 282,1 & 730,3 \\
\hline Pto. Guarani & 1410,7 & 488,3 & $34,6 \%$ & 2741,8 & 566,6 & 2175,1 \\
\hline Balsa Sta. Maria & 6101,1 & 1997,1 & $32,7 \%$ & 12254,0 & 2663,0 & 9591,0 \\
\hline
\end{tabular}

Org.: Márcio Greyck Guimarães Correa, 2017.

Sazonalmente no posto fluviométrico de Guampará a vazão fluvial é maior no outono $\left(175,1 \mathrm{~m}^{3} \cdot \mathrm{s}^{-1}\right)$, em Pto. Guarani e Balsa Sta. Maria é na primavera $\left(411,0 \mathrm{~m}^{3} \mathrm{~s}^{-1}\right.$ e $1763,3 \mathrm{~m}^{3} \mathrm{~s}$

\footnotetext{
${ }^{2}$ Bacias Hidrográficas do Paraná: Uma série histórica - Instituto das Águas do Paraná. Disponivel em < http://www.aguasparana.pr.gov.br/arquivos/File/BACIAS/piquiri.pdf> acesso em 18 de agosto/2015.
} 
$\left.{ }^{1}\right)$. A vazão é menor em Guampará e Pto. Guarani durante o verão $\left(136,7 \mathrm{~m}^{3} \mathrm{~s}^{-1} \mathrm{e} 302,3 \mathrm{~m}^{3} \mathrm{~s}^{-1}\right)$ e para Balsa Sta. Maria é durante o inverno $\left(1389,5 \mathrm{~m}^{3} \mathrm{~s}^{-1}\right)$, tabela 6 .

O coeficiente de variação e o desvio padrão mostra maior variabilidade no outono e inverno e menor variabilidade para o verão e primavera para Pto. Guarani e Balsa Sta. Maria, para Guampará os maiores coeficientes de variação são observados no inverno e no verão, e os menores no outono e na primavera, como pode-se observar na tabela 6 .

Para o posto Guampará o verão com maior vazão registrada na série histórica foi o de $1995\left(278,9 \mathrm{~m}^{3} \mathrm{~s}^{-1}\right)$ e a menor em $1991\left(33,1 \mathrm{~m}^{3} \mathrm{~s}^{-1}\right)$, o outono com maior vazão foi o de 1987 $\left(425,0 \mathrm{~m}^{3} \mathrm{~s}^{-1}\right)$ e menor em $2006\left(33,5 \mathrm{~m}^{3} \mathrm{~s}^{-1}\right)$, o inverno com maior vazão foi o de $1990(486,4$ $\left.\mathrm{m}^{3} \mathrm{~s}^{-1}\right)$ e com a menor vazão foi o de $1996\left(44,2 \mathrm{~m}^{3} \mathrm{~s}^{-1}\right)$, a primavera de 1997 foi a que registrou maior vazão $\left(341,5 \mathrm{~m}^{3} \mathrm{~s}^{-1}\right)$ e a menor em $1988\left(27,1 \mathrm{~m}^{3} \mathrm{~s}^{-1}\right)$.

Para a estação de Pto. Guarani o verão com maior vazão foi $1995\left(701,4 \mathrm{~m}^{3} \mathrm{~s}^{-1}\right)$ e a menor vazão em $1978\left(40,3 \mathrm{~m}^{3} \mathrm{~s}^{-1}\right)$, o outono que registrou a maior vazão foi o do ano de 1983 $\left(1064,2 \mathrm{~m}^{3} \mathrm{~s}^{-1}\right)$ e a menor também em $1978\left(27,1 \mathrm{~m}^{3} \mathrm{~s}^{-1}\right)$, o inverno com maior vazão foi em $1990\left(904,6 \mathrm{~m}^{3} \mathrm{~s}^{-1}\right)$ e a menor vazão em $1977\left(66,4 \mathrm{~m}^{3} \mathrm{~s}^{-1}\right)$ e a primavera com maior vazão registrada na série histórica foi a de $1982\left(944,4 \mathrm{~m}^{3} \mathrm{~s}^{-1}\right)$ e a menor vazão registrada foi em $1988\left(37,6 \mathrm{~m}^{3} \mathrm{~s}^{-1}\right)$.

Para a estação fluvial Balsa Sta. Maria observa-se que o verão com maior vazão registrada foi em $2001\left(2570,6 \mathrm{~m}^{3} \mathrm{~s}^{-1}\right)$ e a menor em $1978\left(564,0 \mathrm{~m}^{3} \mathrm{~s}^{-1}\right)$, no outono a maior vazão foi em $1983\left(4157,0 \mathrm{~m}^{3} \mathrm{~s}^{-1}\right)$ e a menor em $1978\left(289,0 \mathrm{~m}^{3} \mathrm{~s}^{-1}\right)$, no inverno a maior vazão registrada também foi em $1983\left(3160,0 \mathrm{~m}^{3} \mathrm{~s}^{-1}\right)$ e menor em $1977\left(464,0 \mathrm{~m}^{3} \mathrm{~s}^{-1}\right)$ e na primavera a maior vazão registrada foi em $1982\left(3359,0 \mathrm{~m}^{3} \mathrm{~s}^{-1}\right)$ e a menor em $1988\left(370,7 \mathrm{~m}^{3} \mathrm{~s}^{-1}\right)$. 
Tabela 6 - Estatística descritiva da vazão fluvial sazonal média para a bacia hidrográfica do rio Piquiri de 1976 a 2010.

\begin{tabular}{c|c|c|c|c|c|c|c}
\hline $\begin{array}{c}\text { Posto } \\
\text { Fluviométrico }\end{array}$ & Estação & $\begin{array}{c}\text { Méd. } \\
\left(\mathrm{m}^{3} \mathrm{~s}^{-1}\right)\end{array}$ & $\begin{array}{c}\text { D.P. } \\
\left(\mathrm{m}^{3} \mathrm{~s}^{-1}\right)\end{array}$ & C.V. & $\begin{array}{c}\text { Máx. } \\
\left(\mathrm{m}^{3} \mathrm{~s}^{-1}\right)\end{array}$ & $\begin{array}{c}\text { Mín. } \\
\left(\mathrm{m}^{3} \mathrm{~s}^{-1}\right)\end{array}$ & $\begin{array}{c}\text { Amp. } \\
\left(\mathrm{m}^{3} \mathrm{~s}^{-1}\right)\end{array}$ \\
\hline \hline \multirow{4}{*}{ Guampará } & Ver. & 136,7 & 71,2 & $52,1 \%$ & 278,9 & 33,1 & 245,8 \\
\cline { 2 - 8 } & Out. & 175,1 & 88,5 & $50,5 \%$ & 425,0 & 33,5 & 391,5 \\
\cline { 2 - 8 } & Inv. & 142,0 & 95,7 & $67,4 \%$ & 486,4 & 44,2 & 442,2 \\
\cline { 2 - 8 } & Prim. & 164,2 & 75,1 & $45,7 \%$ & 341,5 & 27,1 & 314,4 \\
\hline \hline \multirow{4}{*}{ Pto. Guarani } & Ver. & 302,3 & 178,7 & $59,1 \%$ & 701,4 & 40,3 & 661,1 \\
\cline { 2 - 8 } & Out. & 366,9 & 229,5 & $62,5 \%$ & 1064,2 & 27,1 & 1037,2 \\
\cline { 2 - 8 } & Inv. & 330,5 & 217,5 & $65,8 \%$ & 904,6 & 66,4 & 838,2 \\
\cline { 2 - 8 } & Prim. & 411,0 & 209,4 & $51,0 \%$ & 944,4 & 37,6 & 906,8 \\
\hline \hline \multirow{3}{*}{ Balsa Sta. Maria } & Ver. & 1420,0 & 573,1 & $40,4 \%$ & 2570,6 & 564,0 & 2006,6 \\
\cline { 2 - 8 } & Out. & 1528,3 & 851,5 & $55,7 \%$ & 4157,0 & 289,0 & 3868,0 \\
\cline { 2 - 8 } & Inv. & 1389,5 & 736,9 & $53,0 \%$ & 3160,0 & 464,0 & 2696,0 \\
\cline { 2 - 7 } & Prim. & 1763,3 & 796,7 & $45,2 \%$ & 3359,0 & 370,7 & 2988,3 \\
\hline
\end{tabular}

Org.: Márcio Greyck Guimarães Correa, 2017.

Em linhas gerais nota-se maior relação com a distribuição temporal da vazão fluvial entre os postos de Pto. Guarani e Balsa Sta. Maria, destaca-se a vazão do outono e inverno de 1983 com os maiores valores medidos na série histórica e o verão e outono de 1978 com os menores valores medidos de vazão fluvial, resultados que coincidem com os períodos mais chuvosos e menos chuvosos para a bacia hidrográfica do rio Piquiri.

O posto de Guampará se diferencia dos outros dois na variabilidade sazonal, sendo que neste, o verão e o inverno são os períodos com maior oscilação e não o outono e o inverno, como observado nos outros dois postos fluviométricos, isso pode ser explicado pela diferença altimétricas existente na bacia hidrográfica, que condiciona as características térmicas e pluviométricas da área, como demonstrado por Correa (2013) e Correa e Galvani (2016) e que resulta em diferenciações de variabilidade da vazão fluvial sazonal. 
A tabela 7 apresenta os cálculos estatísticos da vazão fluvial mensal para o posto de Guampara e nota-se que a maior média de vazão é no mês de outubro $\left(70,6 \mathrm{~m}^{3} \mathrm{~s}^{-1}\right)$, em outubro também é registrado os maiores valores médios de precipitação, e a menor média no mês de março $\left(32,0 \mathrm{~m}^{3} \mathrm{~s}^{-1}\right)$, enquanto para a precipitação agosto é o mês com menor média de precipitação, o coeficiente de variação e a amplitude indicam uma elevada variabilidade para todos os meses.

Tabela 7 - Estatística descritiva da vazão fluvial mensal média para o posto fluviométrico de Guampará na bacia hidrográfica do rio Piquiri de 1976 a 2010.

\begin{tabular}{c|c|c|c|c|c|c}
\hline Mês & $\begin{array}{c}\text { Méd. } \\
\left(\mathrm{m}^{3} \mathrm{~s}^{-1}\right)\end{array}$ & $\begin{array}{c}\text { D.P. } \\
\left(\mathrm{m}^{3} \mathrm{~s}^{-1}\right)\end{array}$ & C.V. & $\begin{array}{c}\text { Máx. } \\
\left(\mathrm{m}^{3} \mathrm{~s}^{-1}\right)\end{array}$ & $\begin{array}{c}\text { Mín. } \\
\left(\mathrm{m}^{3} \mathrm{~s}^{-1}\right)\end{array}$ & $\begin{array}{c}\text { Amp. } \\
\left(\mathrm{m}^{3} \mathrm{~s}^{-1}\right)\end{array}$ \\
\hline \hline Jan & 50,5 & 38,8 & $76,8 \%$ & 204,1 & 10,0 & 194,1 \\
\hline Fev & 54,3 & 35,4 & $65,2 \%$ & 136,1 & 12,4 & 123,8 \\
\hline Mar & 32,0 & 19,2 & $60,0 \%$ & 83,7 & 7,4 & 76,4 \\
\hline Abr & 41,3 & 37,4 & $90,6 \%$ & 193,7 & 8,0 & 185,6 \\
\hline Mai & 70,6 & 66,7 & $94,5 \%$ & 282,0 & 8,1 & 273,9 \\
\hline Jun & 63,2 & 42,4 & $67,1 \%$ & 166,7 & 7,1 & 159,7 \\
\hline Jul & 51,9 & 32,2 & $62,0 \%$ & 150,4 & 5,5 & 144,9 \\
\hline Ago & 39,5 & 37,3 & $94,4 \%$ & 186,8 & 8,4 & 178,4 \\
\hline Set & 50,6 & 49,9 & $98,6 \%$ & 182,9 & 9,0 & 173,9 \\
\hline Out & 74,9 & 56,4 & $75,3 \%$ & 228,0 & 9,0 & 218,2 \\
\hline Nov & 44,5 & 24,6 & $55,2 \%$ & 102,8 & 6,2 & 96,7 \\
\hline Dez & 44,9 & 29,8 & $66,3 \%$ & 107 & 6,8 & 100,2 \\
\hline Org.
\end{tabular}

Org.: Márcio Greyck Guimarães Correa, 2017.

Para o posto fluviométrico de Guampará observa-se que para janeiro a maior vazão registrada foi em $1995\left(204,1 \mathrm{~m}^{3} \mathrm{~s}^{-1}\right)$ e a menor em $1986\left(10,0 \mathrm{~m}^{3} \mathrm{~s}^{-1}\right)$, em fevereiro a maior vazão foi em $1997\left(136,1 \mathrm{~m}^{3} \mathrm{~s}^{-1}\right)$ e a menor em $1991\left(12,4 \mathrm{~m}^{3} \mathrm{~s}^{-1}\right)$, no mês de março a maior vazão fluvial registrada foi em $1996\left(83,7 \mathrm{~m}^{3} \mathrm{~s}^{-1}\right)$ e a menor também em $1991\left(7,4 \mathrm{~m}^{3} \mathrm{~s}^{-1}\right)$, para abril a máxima em $1998\left(193,7 \mathrm{~m}^{3} \mathrm{~s}^{-1}\right)$ e a mínima em $2005\left(8,0 \mathrm{~m}^{3} \mathrm{~s}^{-1}\right)$, em maio a máxima vazão registrada foi em $1987\left(282,0 \mathrm{~m}^{3} \mathrm{~s}^{-1}\right)$ e a mínima em $2006\left(8,1 \mathrm{~m}^{3} \mathrm{~s}^{-1}\right)$. 
Em junho a máxima vazão foi registrada no ano de $1992\left(166,7 \mathrm{~m}^{3} \mathrm{~s}^{-1}\right)$ e a mínima em $2006\left(7,1 \mathrm{~m}^{3} \mathrm{~s}^{-1}\right)$, para julho a máxima foi em $1990\left(150,4 \mathrm{~m}^{3} \mathrm{~s}^{-1}\right)$ e a mínima também em 2006 $\left(5,5 \mathrm{~m}^{3} \mathrm{~s}^{-1}\right)$, agosto a máxima registrada foi em $1990\left(186,8 \mathrm{~m}^{3} \mathrm{~s}^{-1}\right)$ e a mínima também em $2006\left(8,4 \mathrm{~m}^{3} \mathrm{~s}^{-1}\right)$, no mês de setembro a maior vazão registrada foi no ano de $1998\left(182,9 \mathrm{~m}^{3} \mathrm{~s}^{-}\right.$ ${ }^{1}$ ) e a menor em $2010\left(9,0 \mathrm{~m}^{3} \mathrm{~s}^{-1}\right)$, outubro a maior vazão foi em $2005\left(228,0 \mathrm{~m}^{3} \mathrm{~s}^{-1}\right)$ e a menor em $2007\left(9,8 \mathrm{~m}^{3} \mathrm{~s}^{-1}\right)$, para novembro a máxima vazão foi em $2004\left(102,8 \mathrm{~m}^{3} \mathrm{~s}^{-1}\right)$ e mínima em $1999\left(6,2 \mathrm{~m}^{3} \mathrm{~s}^{-1}\right)$ e em dezembro a máxima foi no ano de $1984\left(107,0 \mathrm{~m}^{3} \mathrm{~s}^{-1}\right)$ e a mínima em $1988\left(6,8 \mathrm{~m}^{3} \mathrm{~s}^{-1}\right)$.

Para o posto fluviométrico de Pto. Guarani o mês que apresenta a maior vazão média é outubro $\left(170,6 \mathrm{~m}^{3} \mathrm{~s}^{-1}\right)$ e o mês com menor média de vazão é março $\left(69,6 \mathrm{~m}^{3} \mathrm{~s}^{-1}\right)$, a variabilidade é muito alta especialmente no trimestre março, abril, maio e setembro, com o coeficiente de variação passando de $100 \%$ para abril, isso porque o desvio padrão é maior que a média mensal, fato que também pode ser observado na amplitude entre a máxima e a mínima vazão registrada para cada mês, tabela 8 .

Tabela 8 - Estatística descritiva da vazão fluvial mensal média para o posto fluviométrico de Pto. Guarani na bacia hidrográfica do rio Piquiri de 1976 a 2010.

\begin{tabular}{c|c|c|c|c|c|c}
\hline Mês & $\begin{array}{c}\text { Méd. } \\
\left(\mathrm{m}^{3} \mathrm{~s}^{-1}\right)\end{array}$ & $\begin{array}{c}\text { D.P. } \\
\left(\mathrm{m}^{3} \mathrm{~s}^{-1}\right)\end{array}$ & $\mathbf{C . V} \cdot$ & $\begin{array}{c}\text { Máx. } \\
\left(\mathrm{m}^{3} \mathrm{~s}^{-1}\right)\end{array}$ & $\begin{array}{c}\text { Mín. } \\
\left(\mathrm{m}^{3} \mathrm{~s}^{-1}\right)\end{array}$ & $\begin{array}{c}\text { Amp. } \\
\left(\mathrm{m}^{3} \mathrm{~s}^{-1}\right)\end{array}$ \\
\hline Jan & 116,4 & 102,9 & $88,4 \%$ & 559,8 & 13,9 & 545,9 \\
\hline Fev & 116,3 & 88,8 & $76,4 \%$ & 369,6 & 8,4 & 361,2 \\
\hline Mar & 69,6 & 62,6 & $90,0 \%$ & 289,1 & 8,9 & 280,2 \\
\hline Abr & 85,5 & 99,2 & $116,0 \%$ & 566,8 & 4,9 & 561,9 \\
\hline Mai & 147,9 & 138,8 & $93,9 \%$ & 506,6 & 9,2 & 497,5 \\
\hline Jun & 133,6 & 99,7 & $74,7 \%$ & 450,7 & 13,9 & 437,7 \\
\hline Jul & 125,1 & 97,8 & $78,2 \%$ & 385,2 & 11,4 & 373,8 \\
\hline Ago & 81,4 & 65,7 & $80,7 \%$ & 285,1 & 19,1 & 266,0 \\
\hline Set & 124,0 & 114,7 & $92,5 \%$ & 367,9 & 12,0 & 355,9 \\
\hline Out & 170,6 & 125,9 & $73,8 \%$ & 492,6 & 14,3 & 478,3 \\
\hline Nov & 118,0 & 96,2 & $81,6 \%$ & 499,0 & 11,3 & 487,7 \\
\hline Dez & 122,4 & 100,2 & $81,9 \%$ & 472,4 & 7,4 & 465,1 \\
\hline Org.
\end{tabular}

Org.: Márcio Greyck Guimarães Correa, 2017. 
No posto fluviométrico Pto. Guarani nota-se que em janeiro a máxima vazão registrada foi em $1995\left(559,8 \mathrm{~m}^{3} \mathrm{~s}^{-1}\right)$ e a mínima em $1991\left(13,9 \mathrm{~m}^{3} \mathrm{~s}^{-1}\right)$, em fevereiro a máxima foi em $2001\left(369,6 \mathrm{~m}^{3} \mathrm{~s}^{-1}\right)$ e a mínima em $1978\left(8,4 \mathrm{~m}^{3} \mathrm{~s}^{-1}\right)$, para março a maior vazão foi registrada no ano de $1983\left(289,1 \mathrm{~m}^{3} \mathrm{~s}^{-1}\right)$ e a menor em $1978\left(8,9 \mathrm{~m}^{3} \mathrm{~s}^{-1}\right)$, em abril a maior vazão foi em $1998\left(566,8 \mathrm{~m}^{3} \mathrm{~s}^{-1}\right)$ e a menor vazão também em $1978\left(4,9 \mathrm{~m}^{3} \mathrm{~s}^{-1}\right)$, no mês de maio a máxima registrada foi no ano de $1987\left(506,6 \mathrm{~m}^{3} \mathrm{~s}^{-1}\right)$ e a menor em $1978\left(9,2 \mathrm{~m}^{3} \mathrm{~s}^{-1}\right)$.

Para o mês de junho a máxima vazão registrada foi no ano de $1983\left(450,7 \mathrm{~m}^{3} \mathrm{~s}^{-1}\right)$ e a mínima no ano de $1978\left(13,0 \mathrm{~m}^{3} \mathrm{~s}^{-1}\right)$, em julho a máxima foi em $1983\left(385,2 \mathrm{~m}^{3} \mathrm{~s}^{-1}\right)$ e a mínima em $2006\left(11,4 \mathrm{~m}^{3} \mathrm{~s}^{-1}\right)$, para o mês de agosto a máxima foi em $1990\left(285,1 \mathrm{~m}^{3} \mathrm{~s}^{-1}\right)$ e a mínima em $1996\left(19,1 \mathrm{~m}^{3} \mathrm{~s}^{-1}\right)$, para setembro a maior vazão foi registrada no ano de 1998 (367,9 $\left.\mathrm{m}^{3} \mathrm{~s}^{-1}\right)$ e a menor vazão no ano de $1988\left(12,0 \mathrm{~m}^{3} \mathrm{~s}^{-1}\right)$, em outubro a maior vazão foi em $2005\left(492,6 \mathrm{~m}^{3} \mathrm{~s}^{-1}\right)$ e a menor vazão em $1885\left(14,3 \mathrm{~m}^{3} \mathrm{~s}^{-1}\right)$, para o mês de novembro a máxima foi registrada no ano de $1982\left(499,0 \mathrm{~m}^{3} \mathrm{~s}^{-1}\right)$ e a mínima em $1999\left(11,3 \mathrm{~m}^{3} \mathrm{~s}^{-1}\right)$ e para o mês de dezembro a máxima vazão foi no ano de $1981\left(472,4 \mathrm{~m}^{3} \mathrm{~s}^{-1}\right)$ e a mínima em $1985\left(7,4 \mathrm{~m}^{3} \mathrm{~s}^{-1}\right)$.

A tabela 9 apresenta os cálculos estatísticos para o posto fluviométrico de Balsa Sta. Maria, observa-se que a maior vazão média mensal ocorre também em outubro $\left(643,1 \mathrm{~m}^{3} \mathrm{~s}^{-1}\right)$ assim como nos postos Guampará e Pto. Guarani e menor em março $\left(383,9 \mathrm{~m}^{3} \mathrm{~s}^{-1}\right)$ também o mesmo observado nos outros postos. O coeficiente de variação é menor se comparado aos outros postos, indicando menor variabilidade da vazão fluvial para o posto Balsa Sta. Maria, abril, maio e setembro são os meses com maior variabilidade.

Tabela 9- Estatística descritiva da vazão fluvial mensal média para o posto fluviométrico de Balsa Sta. Maria na bacia hidrográfica do rio Piquiri de 1976 a 2010.

\begin{tabular}{c|c|c|c|c|c|c}
\hline Mês & $\begin{array}{c}\text { Méd. } \\
\left(\mathrm{m}^{3} \mathrm{~s}^{-1}\right)\end{array}$ & $\begin{array}{c}\text { D.P. } \\
\left(\mathrm{m}^{3} \mathrm{~s}^{-1}\right)\end{array}$ & C.V. & $\begin{array}{c}\text { Máx. } \\
\left(\mathrm{m}^{3} \mathrm{~s}^{-1}\right)\end{array}$ & $\begin{array}{c}\text { Mín. } \\
\left(\mathrm{m}^{3} \mathrm{~s}^{-1}\right)\end{array}$ & $\begin{array}{c}\text { Amp. } \\
\left(\mathrm{m}^{3} \mathrm{~s}^{-1}\right)\end{array}$ \\
\hline Jan & 533,3 & 294,7 & $55,3 \%$ & 1658,1 & 139,0 & 1519,1 \\
\hline
\end{tabular}




\begin{tabular}{c|c|c|c|c|c|c}
\hline Fev & 502,8 & 237,2 & $47,2 \%$ & 1171,1 & 173,0 & 998,1 \\
\hline Mar & 383,9 & 223,0 & $58,1 \%$ & 1280,0 & 137,0 & 1143,0 \\
\hline Abr & 394,9 & 304,2 & $77,2 \%$ & 1846,2 & 96,8 & 1749,4 \\
\hline Mai & 582,8 & 411,0 & $70,5 \%$ & 1718,2 & 95,8 & 1622,4 \\
\hline Jun & 551,3 & 344,9 & $62,6 \%$ & 1708,0 & 96,4 & 1611,6 \\
\hline Jul & 499,6 & 289,9 & $59,8 \%$ & 1357,0 & 113,7 & 1243,3 \\
\hline Ago & 393,3 & 220,3 & $56,0 \%$ & 901,9 & 117,3 & 784,5 \\
\hline Set & 496,5 & 360,2 & $72,6 \%$ & 1294,2 & 118,8 & 1175,4 \\
\hline Out & 643,1 & 428,6 & $66,6 \%$ & 1749,4 & 134,3 & 1625,2 \\
\hline Nov & 555,5 & 310,5 & $55,9 \%$ & 1436,0 & 124,0 & 1312,0 \\
\hline Dez & 564,8 & 299,4 & $53,0 \%$ & 1527,0 & 93,3 & 1433,7 \\
\hline Org:
\end{tabular}

Org.: Márcio Greyck Guimarães Correa, 2017.

No mês de janeiro a maior vazão foi registrada no ano de $1995\left(1658,1 \mathrm{~m}^{3} \mathrm{~s}^{-1}\right)$ e a menor em $1986\left(139,0 \mathrm{~m}^{3} \mathrm{~s}^{-1}\right)$, para fevereiro a maior foi no ano de $2001\left(1171,1 \mathrm{~m}^{3} \mathrm{~s}^{-1}\right)$ e a menor em $1978\left(173,0 \mathrm{~m}^{3} \mathrm{~s}^{-1}\right)$, para março a máxima registrada foi no ano de 1983 (1280,0 $\left.\mathrm{m}^{3} \mathrm{~s}^{-1}\right)$ e a mínima em $1978\left(137,0 \mathrm{~m}^{3} \mathrm{~s}^{-1}\right)$, em abril a máxima foi em $1998\left(1846,2 \mathrm{~m}^{3} \mathrm{~s}^{-1}\right)$ e a mínima em $1978\left(96,8 \mathrm{~m}^{3} \mathrm{~s}^{-1}\right)$, para o mês de maio a máxima vazão foi no ano de 1992 $\left(1718,2 \mathrm{~m}^{3} \mathrm{~s}^{-1}\right)$ e a mínima também foi em $1978\left(95,8 \mathrm{~m}^{3} \mathrm{~s}^{-1}\right)$, para junho a máxima foi em $1983\left(1708,0 \mathrm{~m}^{3} \mathrm{~s}^{-1}\right)$ e a mínima em $1978\left(96,4 \mathrm{~m}^{3} \mathrm{~s}^{-1}\right)$.

No mês de julho a maior vazão foi em $1983\left(1357,0 \mathrm{~m}^{3} \mathrm{~s}^{-1}\right)$ e a menor em $2006(113,7$ $\left.\mathrm{m}^{3} \mathrm{~s}^{-1}\right)$, agosto a maior foi em $1990\left(901,9 \mathrm{~m}^{3} \mathrm{~s}^{-1}\right)$ e menor também em $2006\left(117,3 \mathrm{~m}^{3} \mathrm{~s}^{-1}\right)$, para setembro a maior vazão foi registrada no ano de $1998\left(1294,2 \mathrm{~m}^{3} \mathrm{~s}^{-1}\right)$ e a menor vazão no ano de $2007\left(118,8 \mathrm{~m}^{3} \mathrm{~s}^{-1}\right)$, para outubro a maior foi em $2005\left(1749,4 \mathrm{~m}^{3} \mathrm{~s}^{-1}\right)$ e a menor também em $2007\left(134,3 \mathrm{~m}^{3} \mathrm{~s}^{-1}\right)$, em novembro a maior vazão foi no ano de $1982\left(1436,0 \mathrm{~m}^{3} \mathrm{~s}^{-1}\right)$ e a menor no ano de $1988\left(124,0 \mathrm{~m}^{3} \mathrm{~s}^{-1}\right)$ e em dezembro a máxima foi em $1981\left(1527,0 \mathrm{~m}^{3} \mathrm{~s}^{-1}\right)$ e a mínima foi em $1985\left(93,3 \mathrm{~m}^{3} \mathrm{~s}^{-1}\right)$.

\subsubsection{Desvio e tendência da vazão fluvial para o posto Balsa Santa Maria}


Observando a Figura 15, nota-se que anualmente no posto fluviométrico de Balsa Sta. Maria os desvios positivos possuem uma amplitude maior que os desvios negativos, sendo o maior desvio positivo em 1983 e o maior desvio negativo em 1978.

A linha de tendência mostra estabilidade dos desvios de vazão para a série histórica analisada.

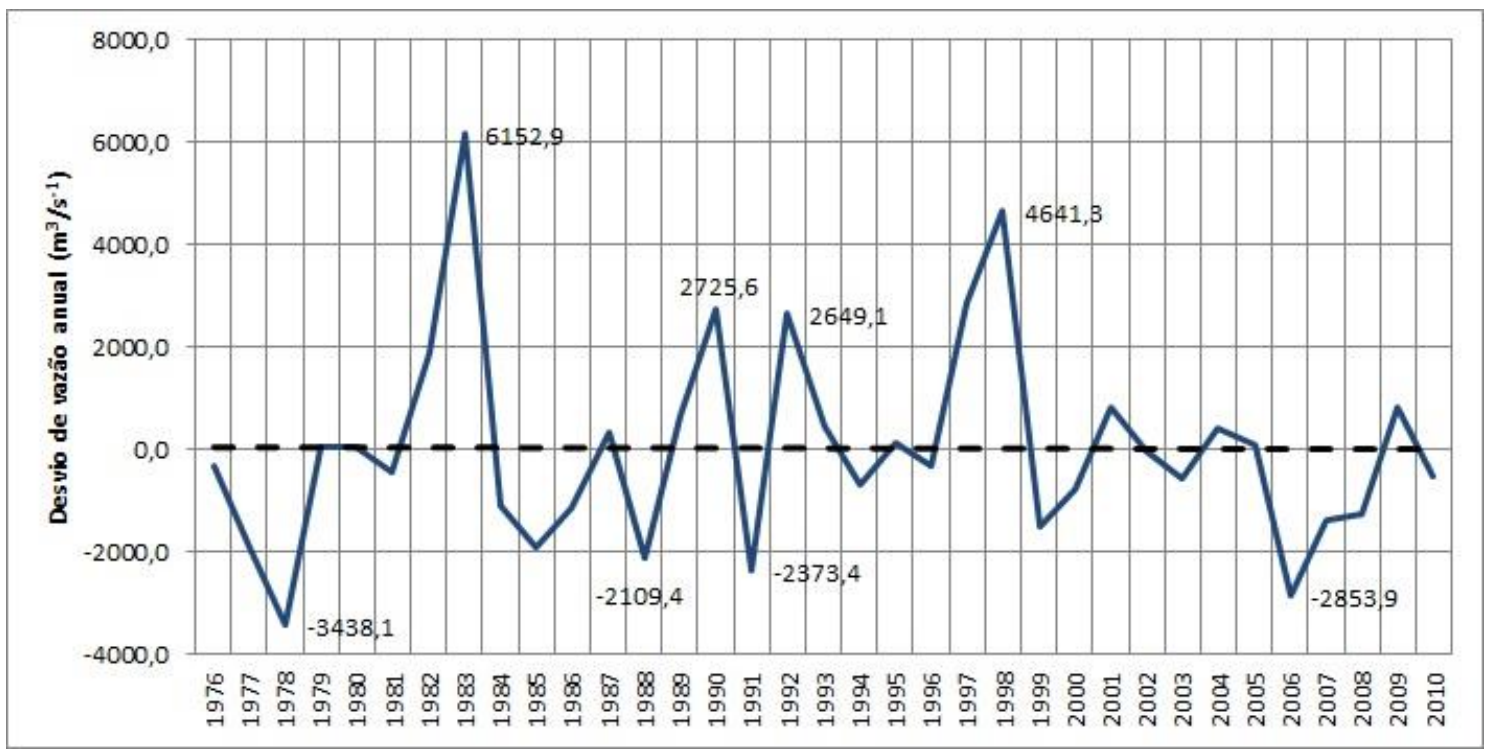

Figura 15: Desvio de vazão anual e linha de tendência anual para o posto Balsa Sta. Maria da bacia hidrográfica do rio Piquiri-PR.

Org.: Márcio Greyck Guimarães Correa, 2017.

A Figura 16 mostra os desvios de vazão sazonal e pode-se observar que durante o verão a amplitude entre os maiores e os menores desvios é menos pronunciado, ao contrário do outono e da primavera.

A linha de tendência linear mostra aumento durante o verão e a primavera e diminuição no outono e inverno dos desvios de vazão. 

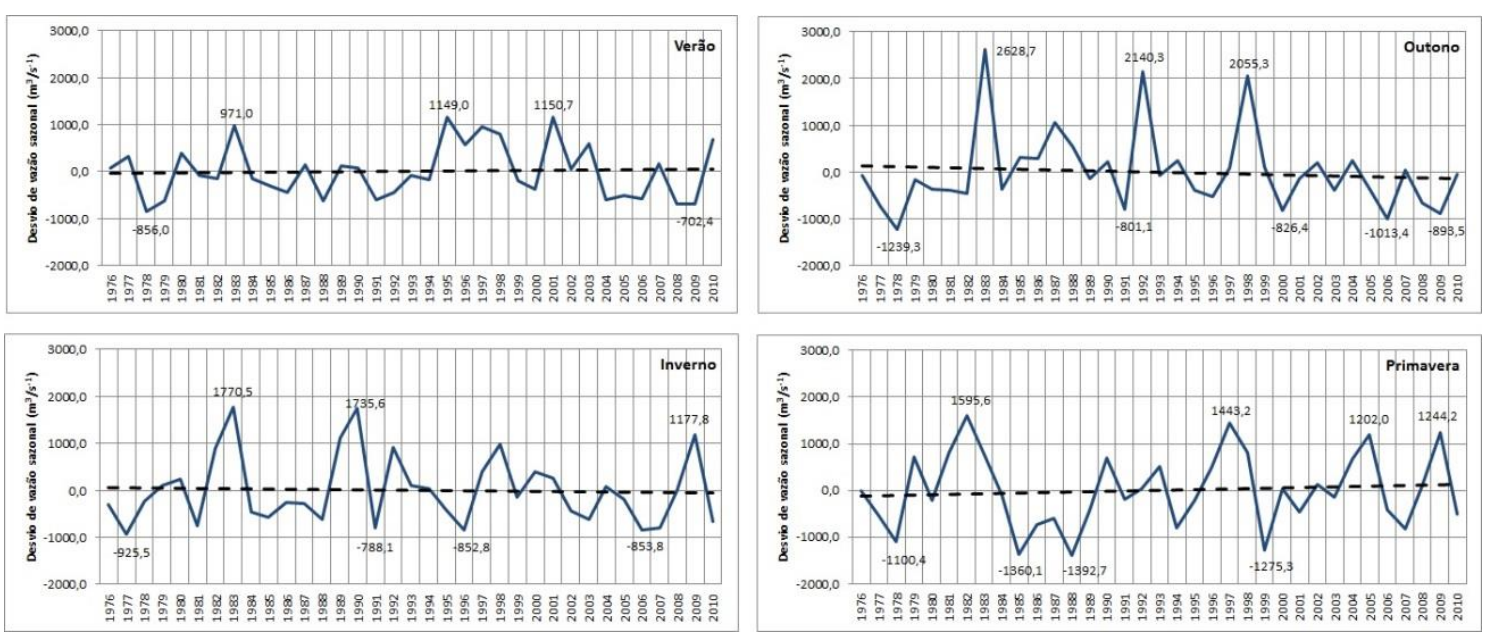

Figura 16: Desvio de vazão sazonal e linha de tendência sazonal para o posto Balsa Sta. Maria da bacia hidrográfica do rio Piquiri-PR.

Org.: Márcio Greyck Guimarães Correa, 2017.

A figura 17 mostra os desvios mensais da vazão fluvial para o posto Balsa Sta. Maria, nota-se que uma maior amplitude entre os desvios positivos e negativos nos meses de maio, junho e outubro e uma menor amplitude para março, julho e agosto.

A linha de tendência indica aumento significativo da vazão para outubro e tendência de diminuição da vazão nos meses de maio, junho e dezembro. 

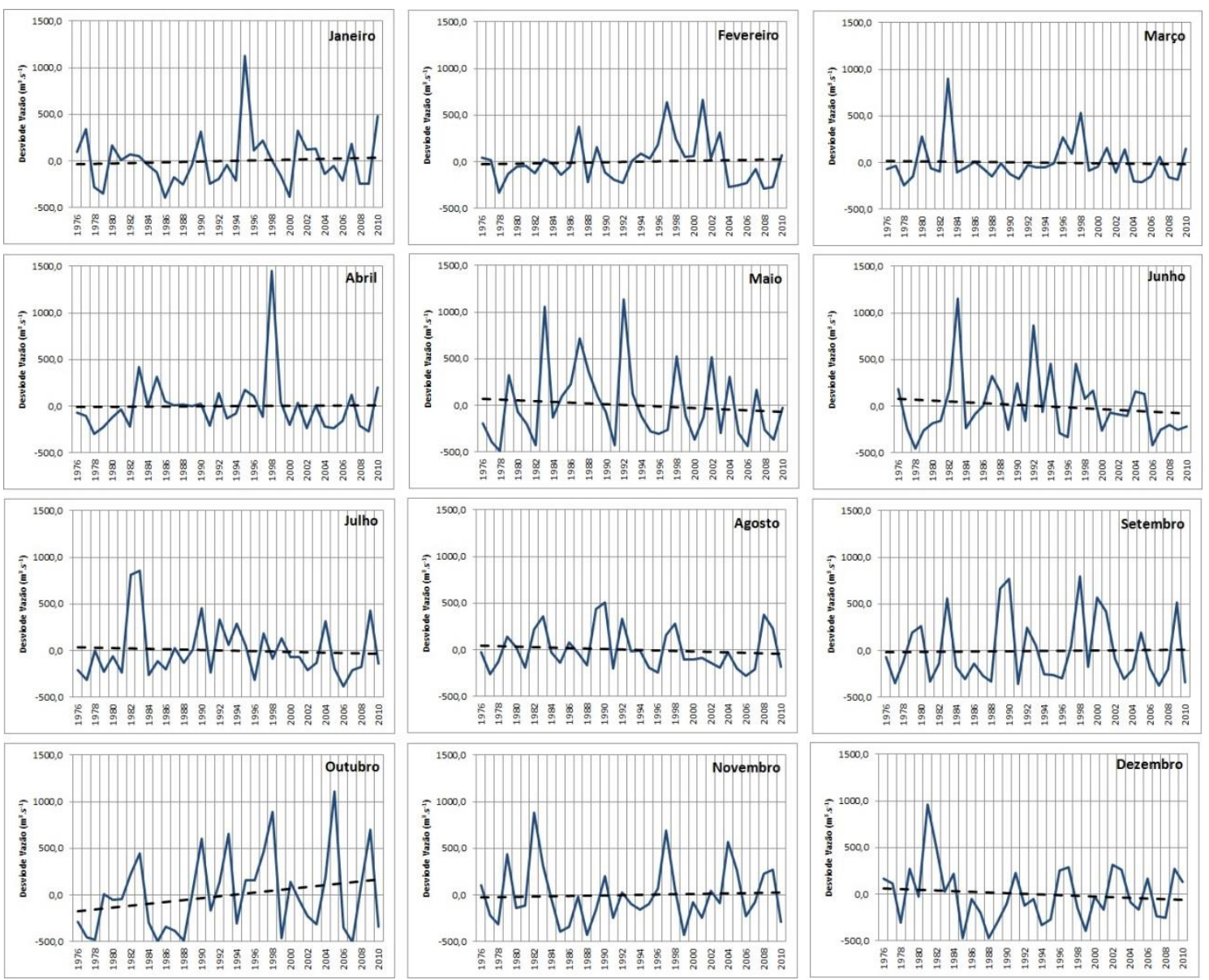

Figura 17: Desvio de vazão mensal e linha de tendência mensal para o posto Balsa Sta. Maria da bacia hidrográfica do rio Piquiri-PR.

Org.: Márcio Greyck Guimarães Correa, 2017.

\subsection{Considerações sobre a vazão fluvial}

A vazão fluvial mensal mostra linearidade entre os três postos, com destaque para os meses entre fevereiro e junho de 1978 e maio e agosto de 2006 como um período de vazões mínimas registradas ao longo da série histórica, e os meses entre março e julho de 1983 com as maiores vazões, indicando períodos de meses consecutivos de vazões máximas e mínimas.

Outubro apresenta-se como o mês de maior ocorrência de precipitação e vazão, agosto é o mês com menor precipitação e março com menor vazão, importante ressaltar que essa diferença entre agosto com menor precipitação contrapondo março com a menor vazão média mensal pode ser explicada através dos processos hidrológicos que envolvem o ciclo da água. 
Os meses de fevereiro e março apresentam maior suscetibilidade à deficiências hídricas, isso porque durante essa época do ano a elevada radiação, temperatura média do ar e a diminuição das chuvas em março, podem aumenta os valores médios de evapotranspiração, diferente de agosto, que apesar de ter uma diminuição considerável nas medias pluviométricas com relação aos outros meses, a temperatura média do ar ainda é baixa e os valores de evapotranspiração tendem a ser menores. 


\section{PARTE III - CORRELAÇÃO ENTRE PRECIPITAÇÃO E VAZÃO NA BACIA HIDROGRÁFICA DO RIO PIQUIRI}

\subsection{Introdução}

As respostas de eventuais anomalias (catastróficas ou não) no sistema natural servem como um importante indicador da vulnerabilidade da sociedade frente às intempéries da natureza, como alagamentos, baixa produtividade agrícola, transtornos de mobilidade urbana devido alagamento, vazão de rios, entre outros.

Estudos que integram a relação da precipitação e a vazão dos rios vêm sendo discutida no âmbito acadêmico há certo tempo, nos Estados Unidos Hewlett e Hibbert (1966) estudaram os processos hidrológicos de vazão em pequenas bacias hidrográficas relacionando-os a precipitação, assim como Yoshimoto e Suetsugi (1990) ressaltaram a importância dos processos de urbanização e alterações na descarga de bacias hidrográficas em áreas urbanas do Japão.

A precipitação pluviométrica é o principal dispositivo de entrada de energia e matéria na bacia hidrográfica, nesta parte do trabalho será dada especial atenção às interações hidroclimáticas que ocorrem entre a precipitação e a vazão fluvial.

\subsection{Procedimentos metodológicos: Correlação precipitação e vazão}

Inicialmente realizou-se um teste de correlação linear de Pearson (equação 3) entre a precipitação média anual, sazonal e mensal de toda a bacia hidrográfica com a vazão fluvial de cada posto fluviométrico, com a finalidade de mostrar um panorama geral da dinâmica hidroclimática da bacia. 


$$
r=\frac{c_{X, Y}}{s_{X} s_{Y}}
$$

Equação 3

\section{$\mathrm{C}_{\mathrm{X}, \mathrm{Y}}$ - Covariância ou variância conjunta das variáveis $\mathrm{X}$ e $\mathrm{Y}$}

$S_{X}$ - Desvio padrão da variável $X$

$\mathrm{S}_{\mathrm{Y}}$ - Desvio padrão da variável Y

Após o teste de correlação preferiu-se determinar a área de captação de cada posto fluviométrico. Determinou-se assim a Área 1(A1) que abrange uma área de $1690 \mathrm{~km}^{2} \mathrm{e}$ integra a área de drenagem do posto Guampará e mais 3 postos pluviométricos, a Área 2 (A2) com $4160 \mathrm{~km}^{2}$ com a área de drenagem do posto Pto. Guarani e mais 6 postos pluviométricos e a Área 3 (A3) com $20900 \mathrm{~km}^{2}$ abrangendo a área de drenagem do posto de Balsa Sta. Maria e 36 postos pluviométricos, é a área mais representativa da bacia, figura 18.

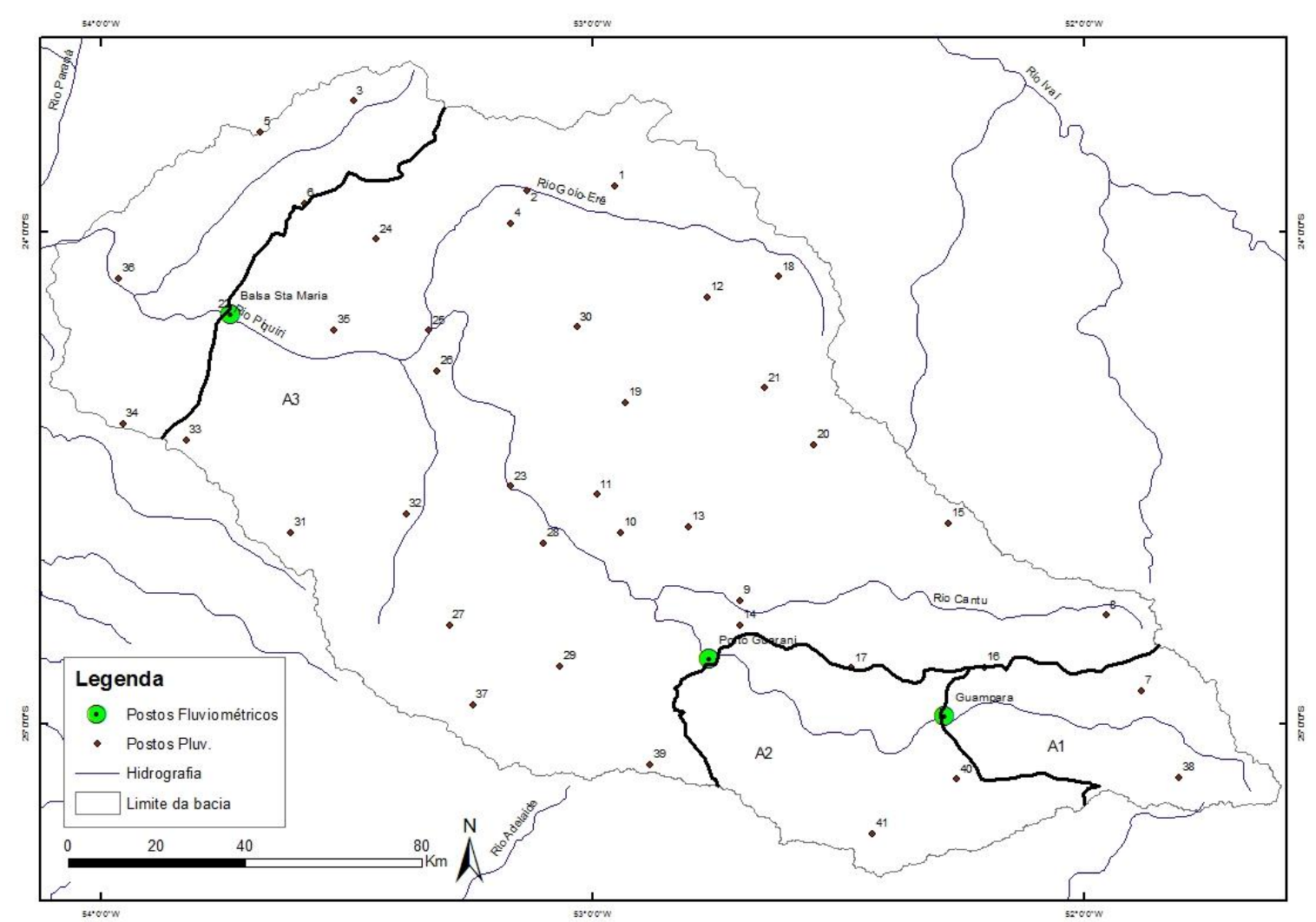

Figura 18: Área de captação determinada pela área de drenagem de cada posto fluviométrico na bacia hidrográfica do rio Piquiri.

Org.: Márcio Greyck Guimarães Correa, 2017. 


\subsubsection{Estatística para a análise de série temporal}

Nesta parte da pesquisa a análise estatística foi realizada com base no uso de boxplots para representar os dados das três áreas de captação (A1, A2 e A3). De acordo com Andrade e Ogliari (2007) esta é uma maneira eficiente de representar medidas de dispersão, além de mostrar as médias e o desvio padrão, o boxplot também apresenta a mediana e os quartis, que indicam a forma, o valor representativo a dispersão e os valores discrepantes da distribuição de dados.

De acordo com Box e Jenkens (1970), Morettin e Toloi (2006), a autocorrelação parcial é útil na identificação da ordem de um modelo autoregressivo, ou seja, são medidas de associação entre valores de séries atuais e anteriores e indicam quais valores de série anteriores são mais úteis para prever valores futuros.

\subsubsection{Técnicas para determinação da ETP e C}

A partir dos dados de precipitação e vazão realizou-se o balanço hídrico, segundo Tucci e Beltrame (2001), o balanço hidrológico objetiva o cálculo da evapotranspiração (ETP) e apresenta maior confiabilidade em uma série de dado de longa duração, por isso optou-se em fazer o referido balanço hídrico na escala anual. Segundo os autores o balanço hidrológico de bacias hidrográficas envolve a quantificação de ETP a partir da diferença entre P e Q e é expresso em milímetros (mm), equação 4.

$$
\mathbf{E T P}=\mathbf{P}-\mathbf{Q}
$$

(Equação 4) 
Para realizar o cálculo do balanço hidrológico os valores de vazão foram transformados em (mm), para isso utilizou-se a metodologia proposta por Tucci (2001) a partir de um fator de conversão:

$$
Q(m m)=\frac{31536 . Q}{A}
$$

Para fins de comparação, a ETP calculada através de Q foi confrontada com a ETP calculada através da metodologia de Thortnwaite (1948), como esse procedimento de cálculo de ETP é baseado na precipitação e temperatura do ar, os dados foram fornecidos pelo Instituto Agronômico do Paraná (IAPAR), a estação utilizada foi a de Palotina (PR).

Além do cálculo de ETP, também se realizou o cálculo do coeficiente de escoamento superficial (C), que determina em porcentagem quanto da chuva precipitada transformou-se em vazão fluvial, a partir da seguinte equação:

$$
C=\frac{Q}{P} \cdot 100
$$

Segundo Tucci (2001) este coeficiente varia de uma média anual de $25 \%$ a $45 \%$ para as regiões úmidas brasileiras, quando os valores são muito baixos, inferior a $10 \%$ ou muito alto, superior a $60 \%$ (para áreas agrícolas, como é o caso predominante da bacia hidrográfica do rio Piquiri) significa que os dados podem apresentar algum erro. 


\subsection{Análise e discussão dos resultados da correlação entre precipitação e a vazão}

Anualmente o coeficiente de correlação entre a precipitação média anual e a vazão média anual para cada posto fluviométrico é menor no posto Guampará e aumenta em direção ao posto Balsa Sta. Maria, tabela 10, isso ocorre devido à abrangência da área de drenagem de cada posto fluviométrico não refletir diretamente a precipitação distribuída ao longo de toda área da bacia hidrográfica. Para ambos os postos a correlação linear é moderada a forte, ou seja, a vazão responde diretamente às variações de precipitação.

Sazonalmente a correlação entre precipitação e vazão diminuiu especialmente nos postos Guampará e Pto. Guarani, apresentando uma correlação moderada a fraca, no posto Balsa Sta. Maria a correlação continua forte.

O coeficiente de correlação entre precipitação e vazão mensal para Guampará e Pto. Guarani aumenta com relação à escala sazonal porém a correlação continua de moderada a fraca, para Balsa Sta. Maria diminui para uma correlação moderada.

Tabela 10 - Correlação (r) entre precipitação média (P) e vazão (Q) anual, sazonal e mensal.

\begin{tabular}{c|c|c|c}
\hline Posto Fluv. & r anual & r sazonal & r mensal \\
\hline \hline Guampará & 0,79 & 0,32 & 0,42 \\
\hline Pto. Guarani & 0.92 & 0.53 & 0,56 \\
\hline Balsa Sta. Maria & 0,93 & 0,80 & 0,70
\end{tabular}

Org.: Márcio Greyck Guimarães Correa, 2017.

Obs.: Estes testes de correlação não levaram em consideração as áreas de drenagem de cada posto fluviométrico, e sim a precipitação média para toda a bacia.

\subsubsection{Boxplots e autocorrelação de precipitação e vazão para as três áreas de drenagem}

Observando a Figura 19 nota-se que a precipitação para os três postos fluviométricos, apresenta uma grande variabilidade, com decrescimento na precipitação mediana nos meses 
de março a agosto, com exceção de maio. Nas três áreas a maior amplitude e variabilidade é observada no mês de maio, e a menor amplitude no mês de março, mesmos valores já identificados na Parte I desta pesquisa.

Os valores discrepantes (outliers) se repetem nos meses de maio, junho e julho para as três áreas, e aumentam em quantidade conforme se direciona da A1 para A3.

No gráfico da função de autocorrelação, Figura 19, observa-se que apesar da correlação da precipitação em um determinado mês com a dos meses anteriores no período de um ano ser significativa para algumas defasagens ( 1 mês, 7 meses, 11 meses e 12 meses), o valor encontrado é muito baixo (menor que 10\%), indicando a defasagem 0 meses a mais confiável.

Para a vazão fluvial, Figura 19, a variabilidade é maior que a observada na precipitação, Nas três áreas a maior amplitude e variabilidade é observada no mês de maio e outubro, e a menor amplitude e variabilidade no mês de março.

Os outliers variam entre 15-16 para as três áreas, sendo o extremos observados nos meses de abril, maio e outubro (especialmente na A3).

A função de autocorrelação na Figura 20 mostra que a correlação da vazão em um determinado mês com a dos meses anteriores no período de um ano foi significativa para algumas defasagens, principalmente para A2 e A3, sendo que a defasagem de 1 mês para A3 apresentou $50 \%$, porém a mais confiável continua sendo a defasagem de 0 meses. 
Área 1 - Guampará

Boxplots Precipitação

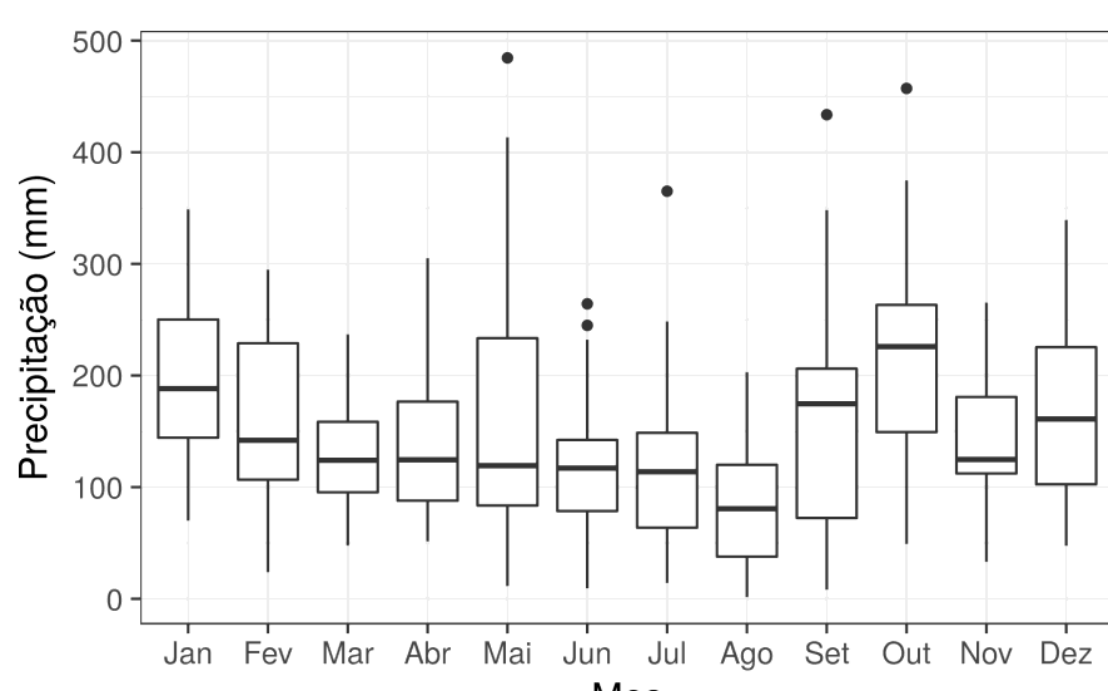

Mes

Função de autocorrelação da precipitação

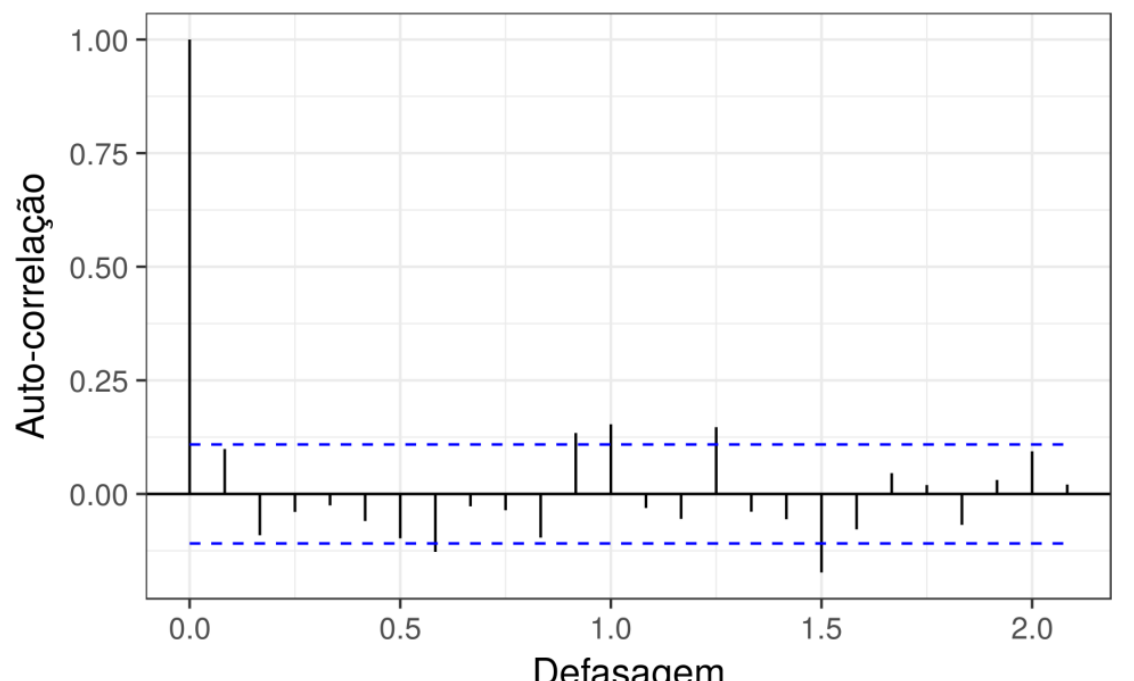

Área 2 - Pto. Guarani

Boxplots Precipitação

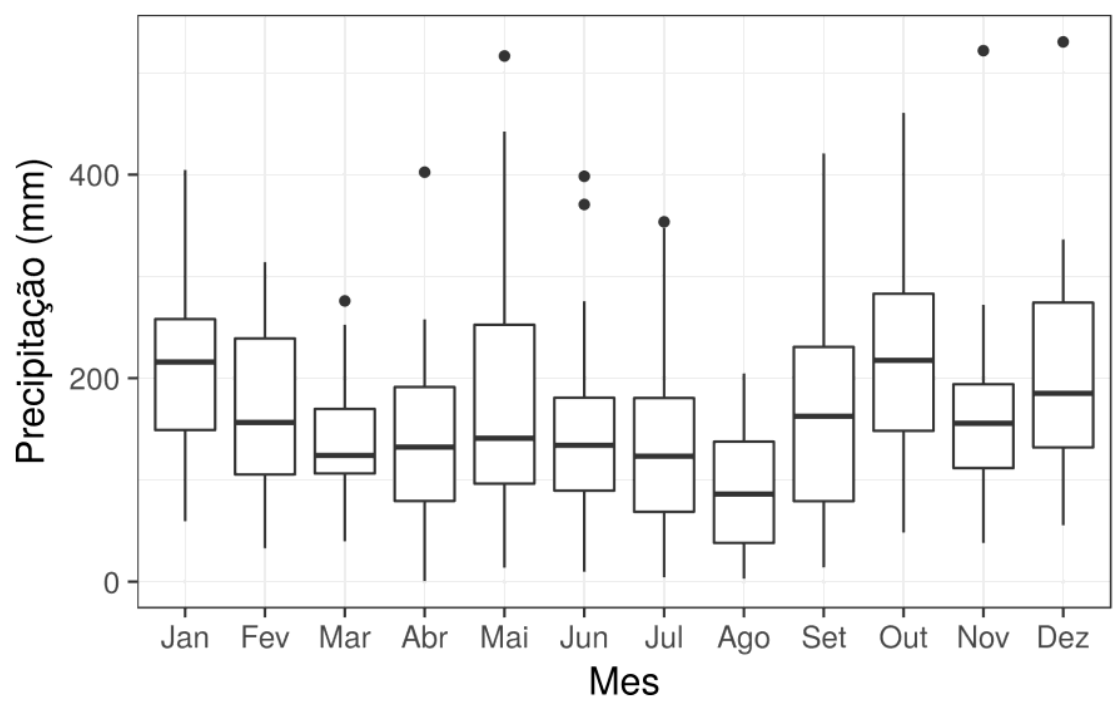

Função de autocorrelação da precipitação

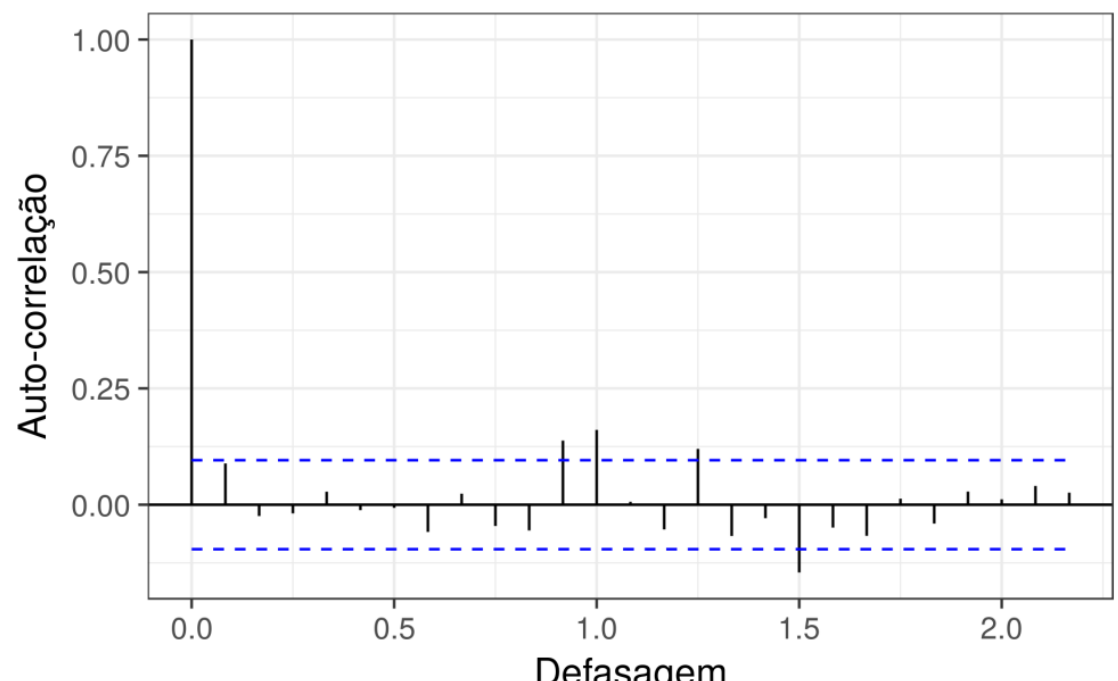

Área 3 - Balsa Santa Maria

Boxplots Precipitação

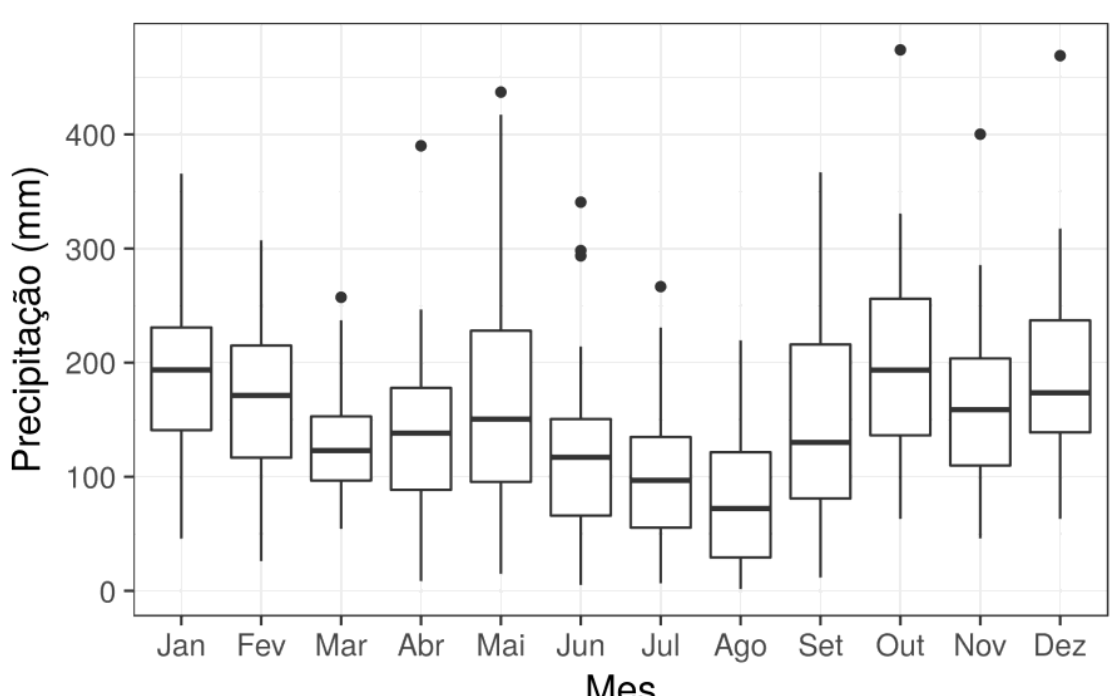

Mes

Função de autocorrelação da precipitação

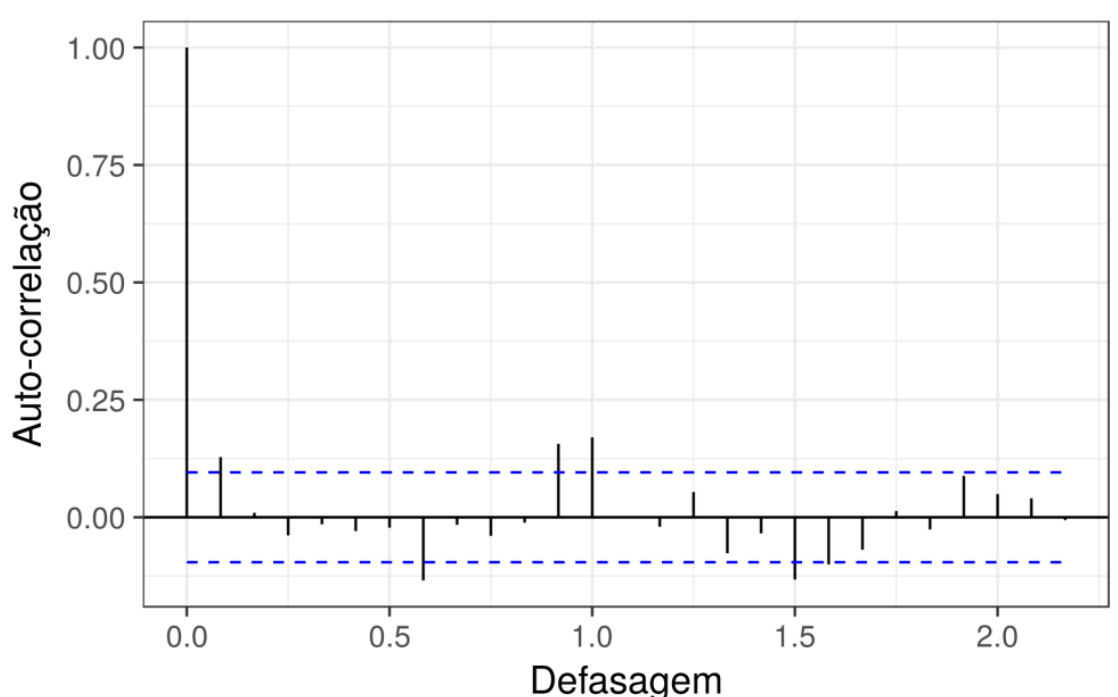

Figura 19: Boxplots e autocorrelação da precipitação pluviométrica para as três áreas de drenagem da bacia hidrográfica do rio Piquirì. Org.: Márcio Greyck Guimarães Correa (Com base no relatório desenvolvido por Alencar et al., 2016). 
Área 1 - Guampará

Boxplots Vazão

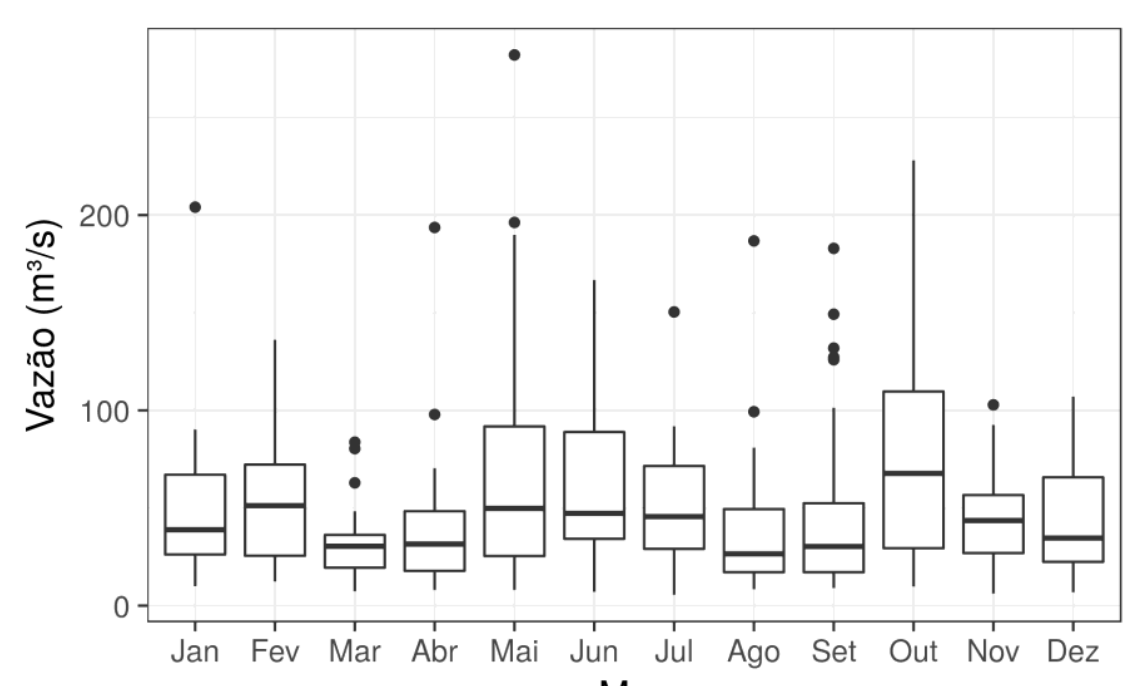

Mes

Função de autocorrelação da vazão

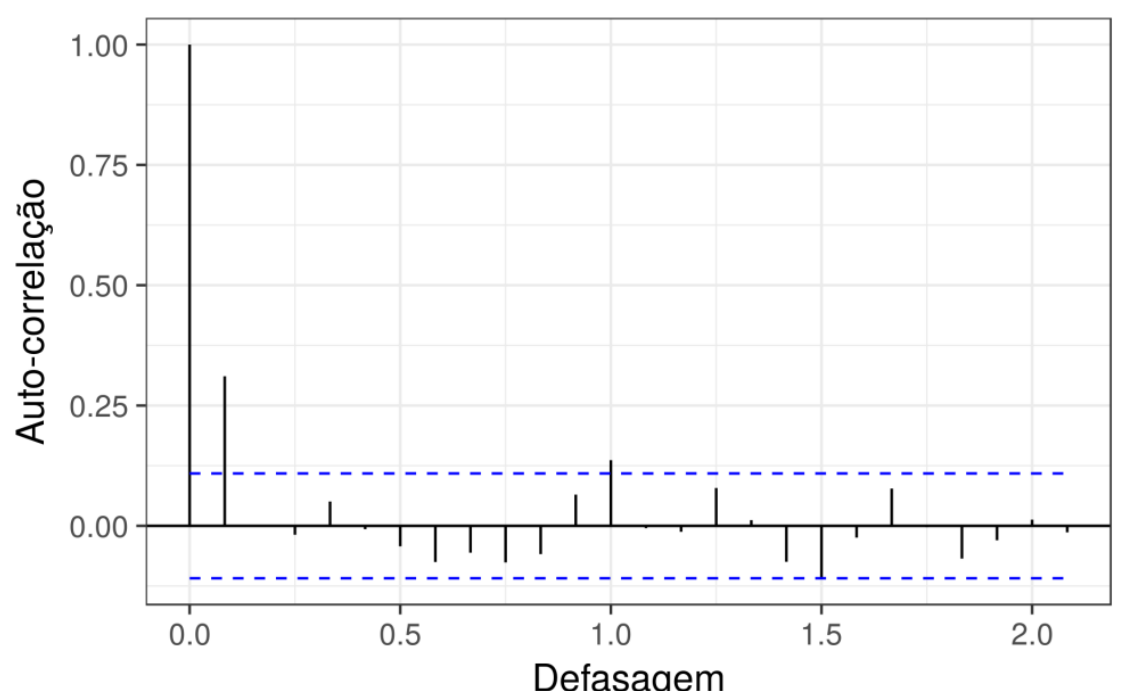

Área 2 - Pto. Guarani

Boxplots Vazão

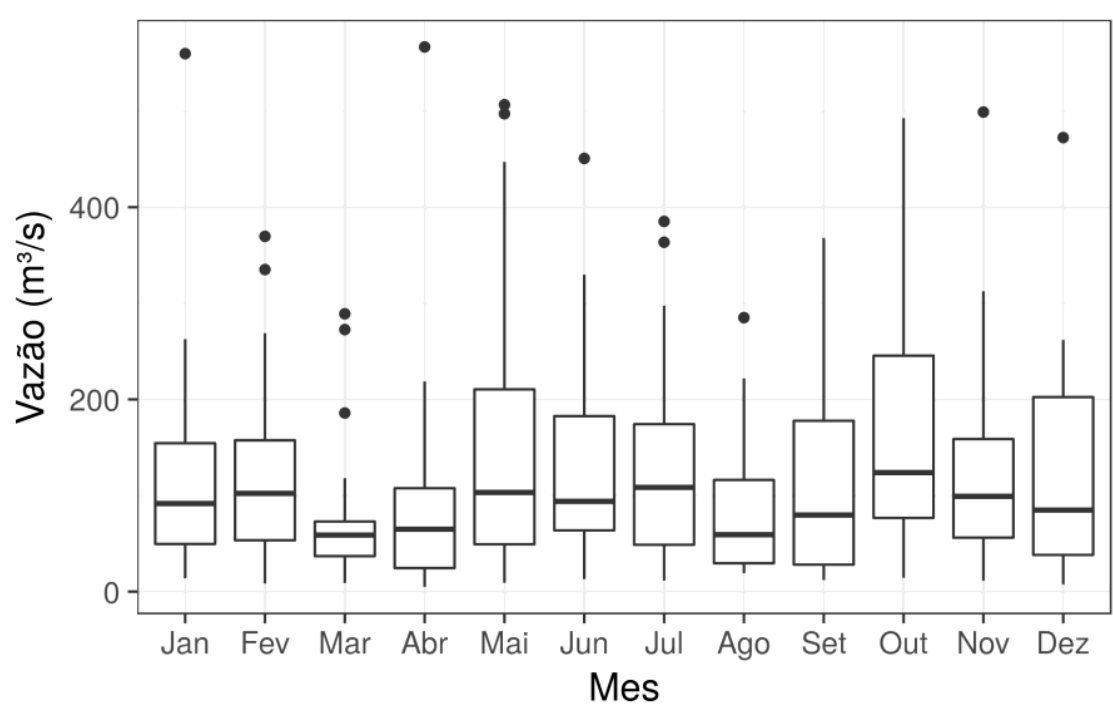

Função de autocorrelação da vazão

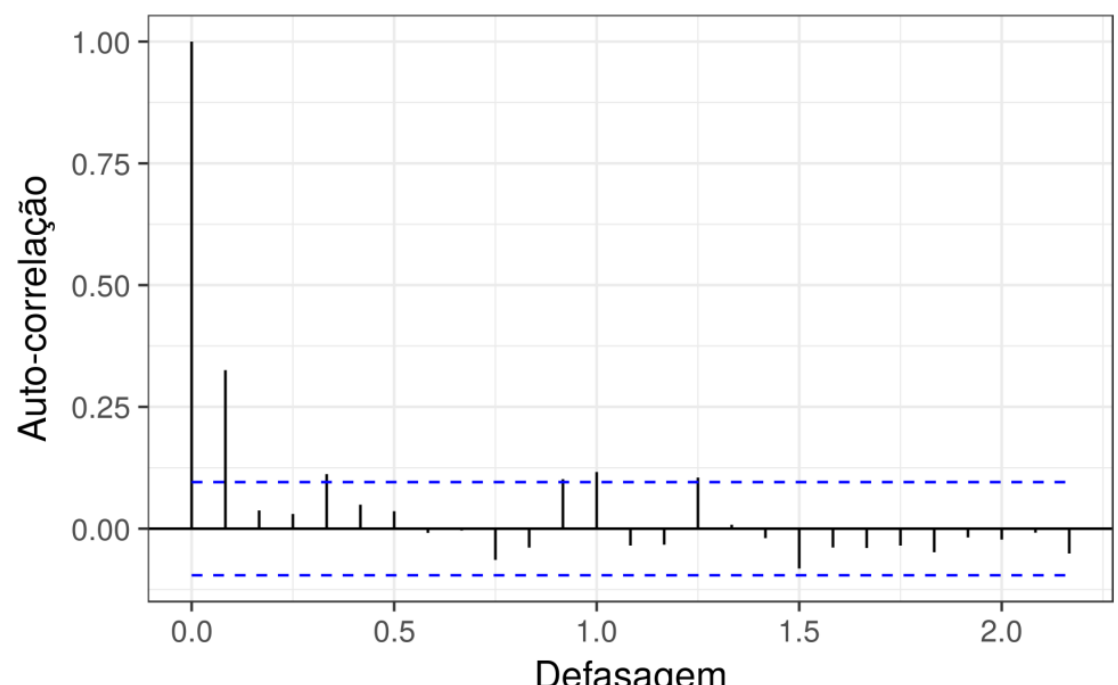

Área 3 - Balsa Santa Maria

Boxplots Vazão

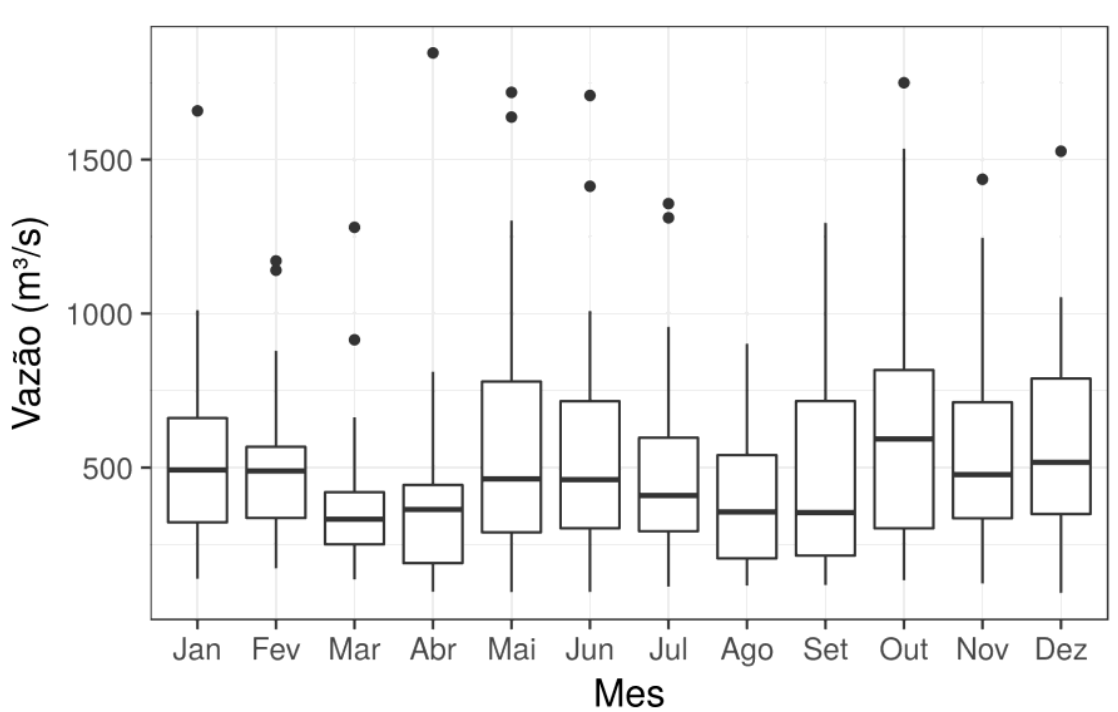

Função de autocorrelação da vazão

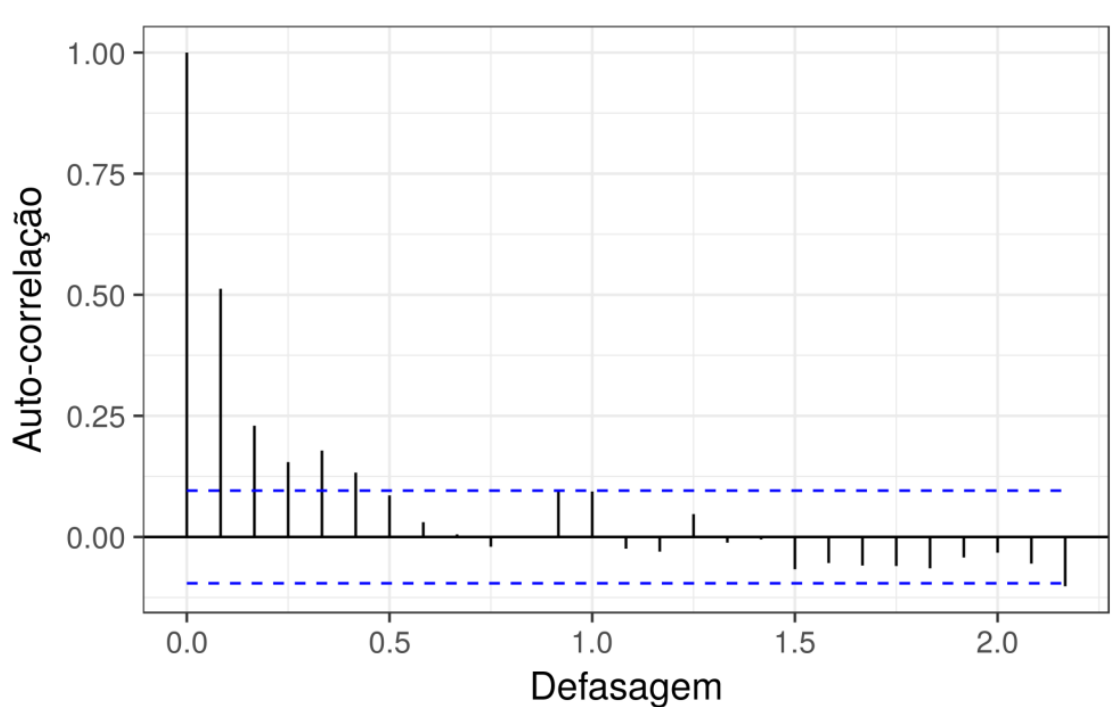

Figura 20: Boxplots e autocorrelação parcial da vazão fluvial para as três áreas de drenagem da bacia hidrográfica do rio Piquirì

Org.: Márcio Greyck Guimarães Correa (Com base no relatơrio desenvolvido por Alencar et al., 2016). 
Observa-se que na Figura 21, os gráficos de dispersão da vazão e da precipitação mensal para cada área de drenagem, devido a prováveis pontos influentes, não é possível saber se estas variáveis apresentam uma relação linear ou quadrática, porém é notável que independente do valor de IOS (usado aqui apenas para mostrar a não dependência direta da precipitação e da vazão à esta variável, assunto que será abordado com maior detalhes na parte IV), à medida que a precipitação aumenta a vazão também aumenta, pois a água presente na bacia não é utilizada para fins externos, como geração de energia elétrica, de tal forma que este fator não precisa ser considerado.

Ao observar as correlações para A1, A2 e A3 nota-se correlação com 1 mês de defasagem, porem as correlações com zero defasagem foram superiores, 0,$75 ; 0,80$ e 0,70 respectivamente. 
Área 1 - Guampará

Gráfico de dispersão entre Vazão e Precipitação mensal

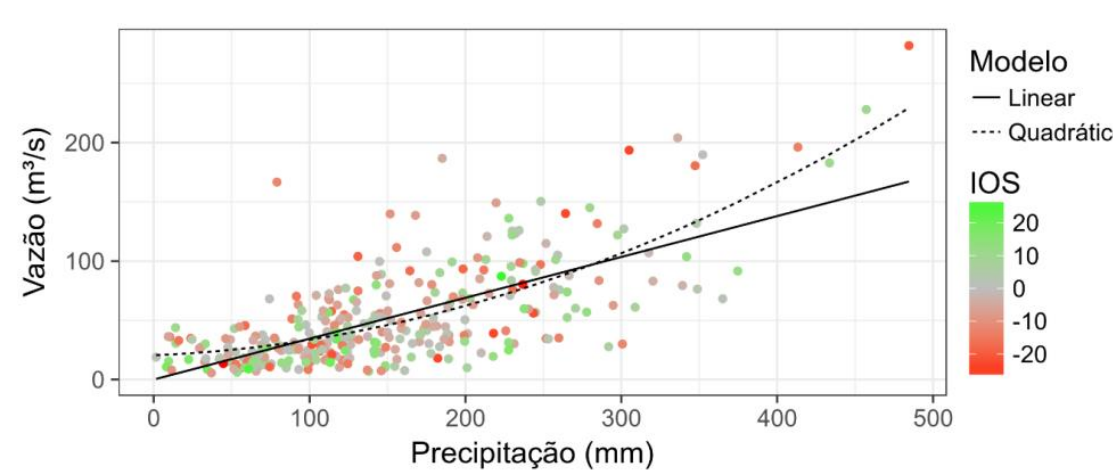

Correlação cruzada entre Vazão em determinado mês e Precipitação em mês defasado

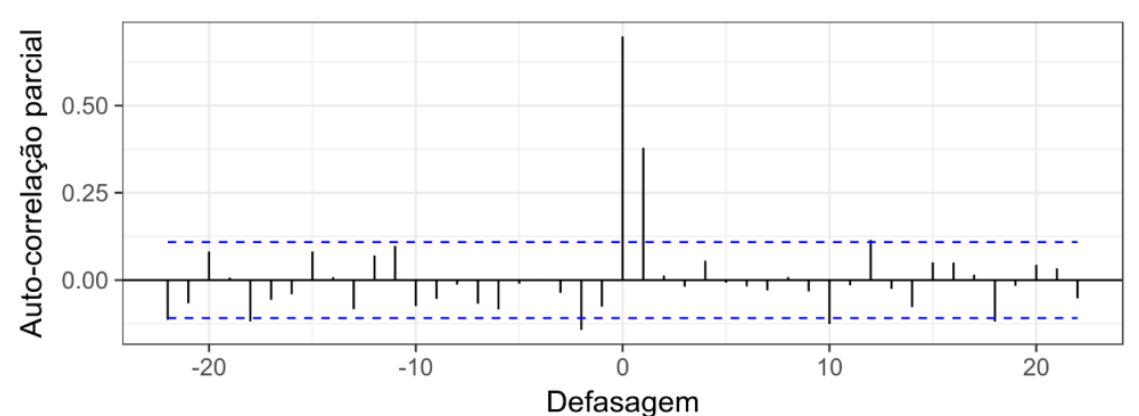

Área 2 - Pto. Guarani

Gráfico de dispersão entre Vazão e Precipitação mensal

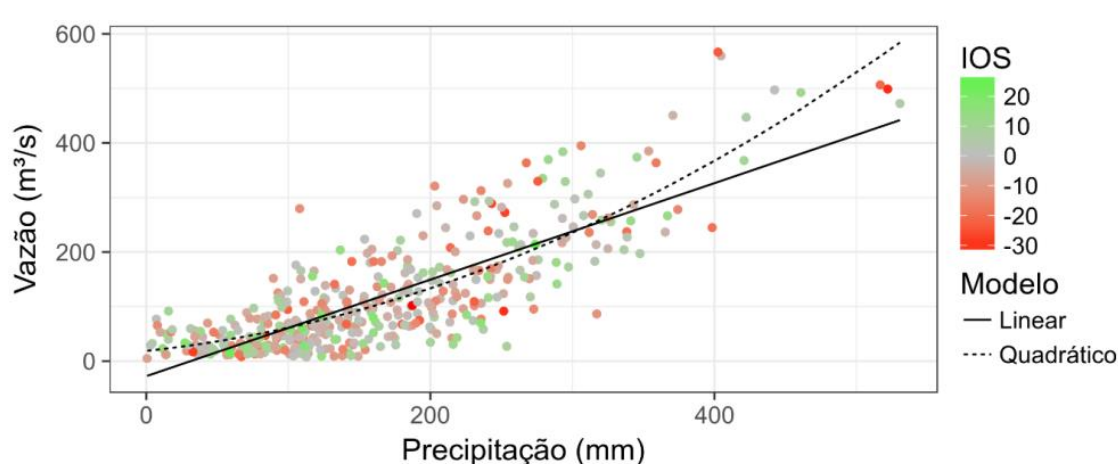

Correlação cruzada entre Vazão em determinado mês e Precipitação em mês defasado

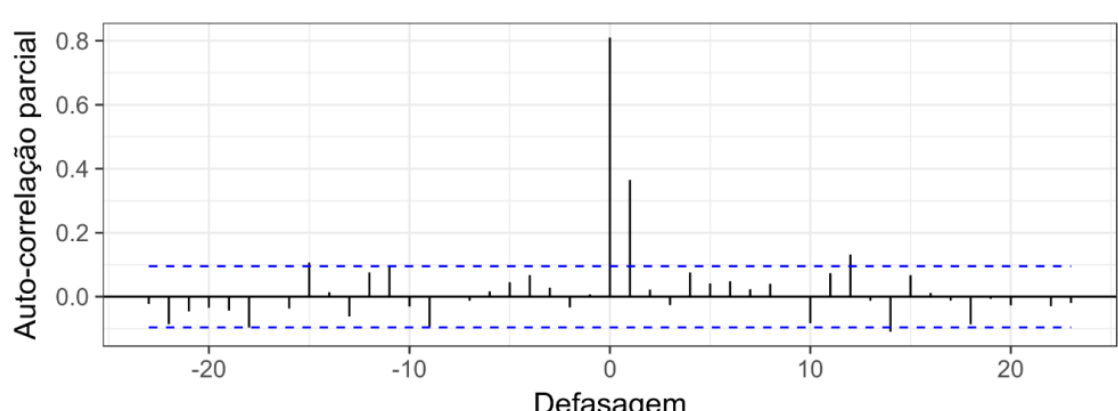

Área 3 - Balsa Sta Maria

Gráfico de dispersão entre Vazão e Precipitação mensal

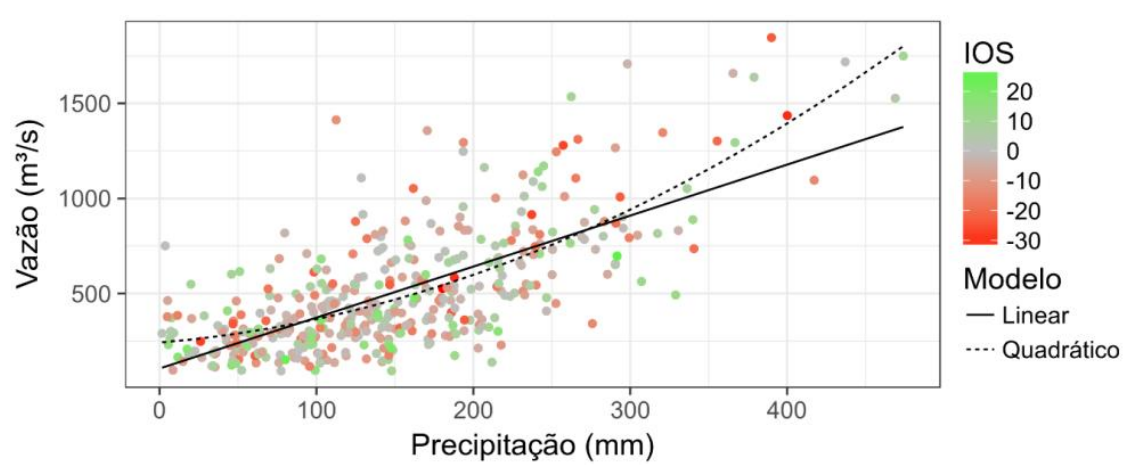

Correlação cruzada entre Vazão em determinado mês e Precipitação em mês defasado

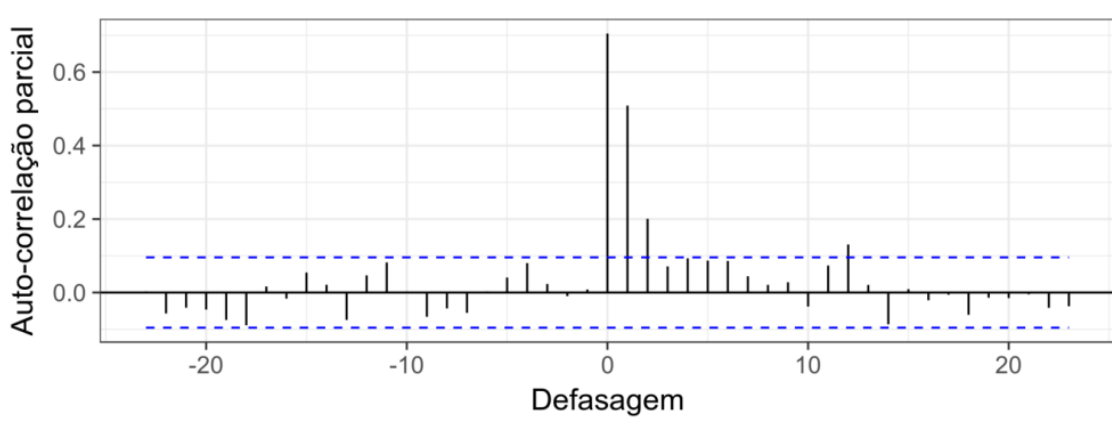

Figura 21: Gráficos de dispersão e autocorrelação cruzada entre precipitação e vazão na bacia hidrográfica do rio Piquiri-PR Org.: Márcio Greyck Guimarães Correa (Com base no relatório desenvolvido por Alencar et al., 2016). 
Devido a fatores intrínsecos a bacia, o escoamento da água nas estações fluviométricas não acontece no mesmo instante de tempo em que é medida a quantidade de chuva no pluviômetro. Baseando-se nesse pressuposto, realizou-se um teste de defasagem entre a precipitação e a vazão, por meio de uma correlação cruzada, figura 22.

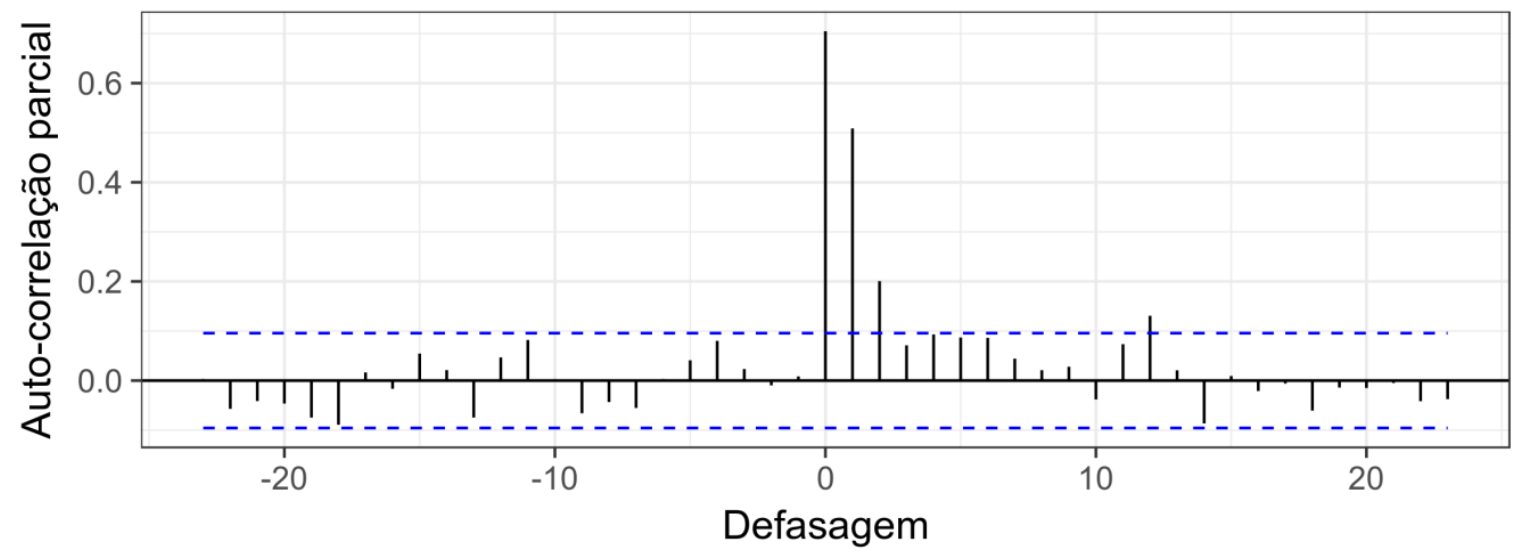

Figura 22: Autocorrelação cruzada entre Vazão e Precipitação com defasagem para o posto de Balsa Sta. Maria A3.

Org.: Márcio Greyck Guimarães Correa (Com base no relatório desenvolvido por Alencar et al., 2016).

Verifica-se que a vazão também possui uma correlação não desprezível com a precipitação do mês anterior. Contudo, analisando a Figura 23, com a defasagem da precipitação em 1 mês, para o posto de Balsa Sta. Maria, essa associação pode ser questionada por conta da alta dispersão dos pontos do gráfico. 


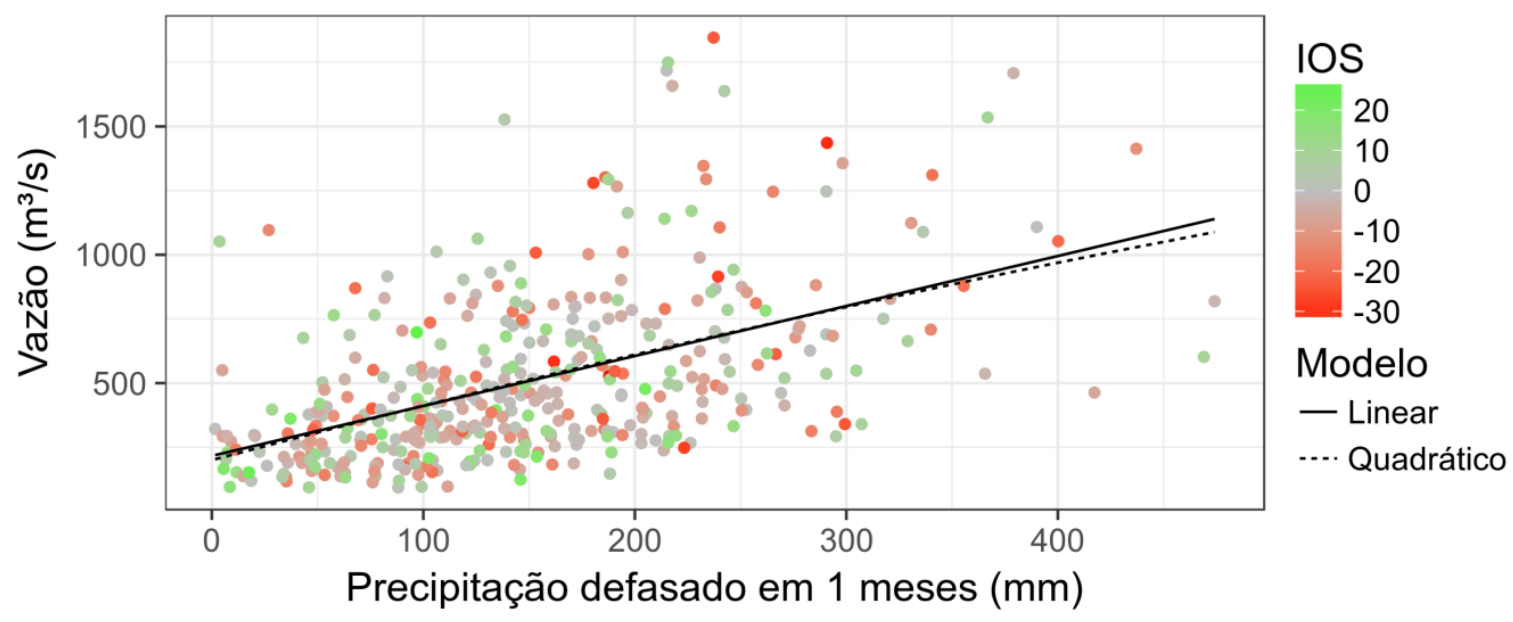

Figura 23: Gráfico de dispersão entre Vazão e Precipitação defasada em um mês para o posto de Balsa Sta. Maria A3.

Org.: Márcio Greyck Guimarães Correa (Com base no relatório desenvolvido por Alencar et al., 2016).

Observa-se que há associação expressiva, medida por uma correlação 0,7 entre a vazão e a precipitação sem defasagem para A3, um aumento da precipitação implica em um aumento simultâneo na média da vazão. Existe uma associação menor da vazão com a precipitação defasada em um mês, mas a dispersão pode indicar que a correlação 0,5 encontrada possa ser não conclusiva. A defasagem entre a precipitação e a vazão deve ser menor que 1 mês, na ordem temporal de semanas ou dias, o que não é detectável na escala mensal utilizada nesta pesquisa.

Analisando a figura 24 observa-se a distribuição anual da precipitação e da vazão, sem defasagem, sendo os anos de 1983 e 1998 com os maiores valores de precipitação e vazão enquanto os anos de 1978 e 1985 apresentaram as menores precipitações, as menores vazões foram nos anos de 1978 e 2006 (para ambos os postos, exceto o ano de 1978 em Guampará que não teve medidas). 


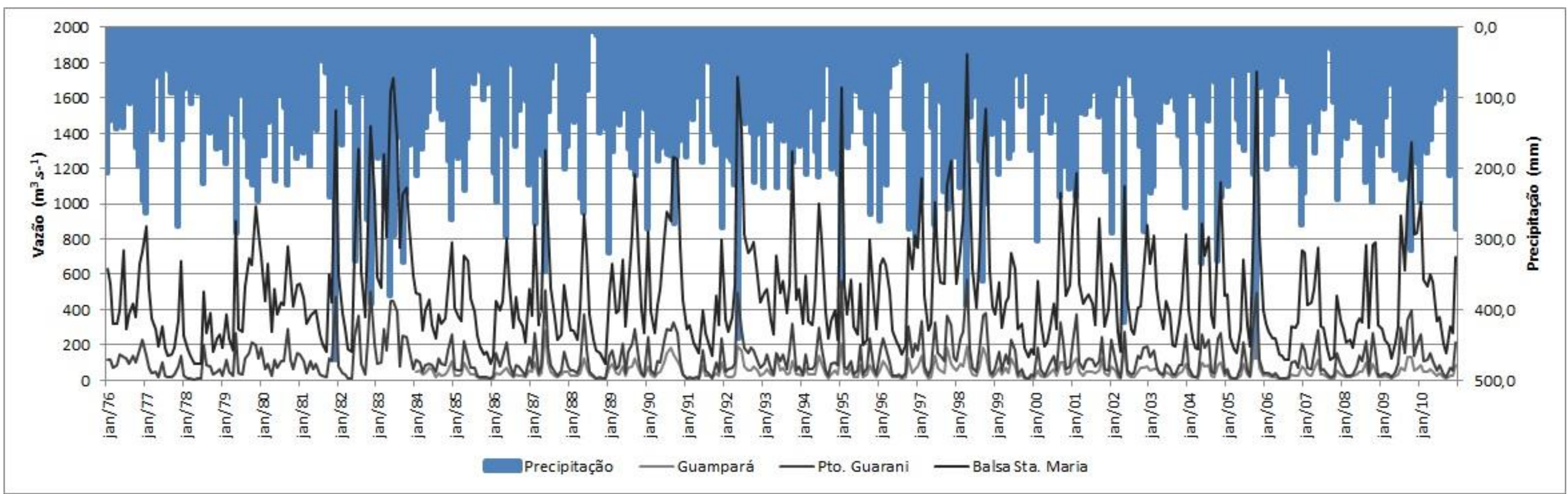

Figura 24: Distribuição temporal da precipitação pluviométrica e da vazão fluvial para a bacia do rio Piquiri-PR

Org.: Márcio Greyck Guimarães Correa, 2017. 


\subsubsection{Processos de evapotranspiração (ETP) e coeficiente de escoamento (C)}

Analisando a tabela 11 observa-se o balanço hidrológico anual para a bacia hidrográfica do rio Piquiri, ao longo da série histórica analisada a evapotranspiração (ETP) varia entre 754, 7 mm em 1988 à 1262,0 mm em 2000 apresentando uma ETP média de 990,4 mm.

Comparando-se a ETP obtida com a ETP calculada pelo método de Thortnwaite (1948) nota-se que o segundo apresenta-se mais constante, isso porque o cálculo é baseado na temperatura do ar, a média anual da ETP por essa metodologia é de 1048,7 mm. O desvio absoluto do método de Thortnwaite (1948) apresenta ETP em média 58,3 mm maior que a metodologia de cálculo de ETP baseada na precipitação e vazão.

O coeficiente de escoamento (C) varia entre $26 \%$ e $60 \%$, e os cálculos de ETP indicam que de acordo com a metodologia de diferença entre $\mathrm{P}$ e Q, em média, 56,2\% da precipitação que cai sobre na bacia hidrográfica do rio Piquiri é revertida para o sistema como evapotranspiração e 43,8\% é transportada pela vazão fluvial e outros processos, pela metodologia de Thortnwaite (1948) a ETP corresponde por 59,5\% dos processos de saída de água do sistema hidrográfico e a vazão e outros processos é responsável por 40,5\%.

Tabela 11 - Balanço hídrico climatológico anual para o período de 1976 a 2010 para bacia hidrográfica do rio Piquiri-PR

\begin{tabular}{c|c|c|c|c|c}
\hline Ano & P (mm) & Q (mm) & ETP $(\mathbf{m m})$ & $\begin{array}{c}\text { ETP-Thornthwaite } \\
(\mathbf{m m})\end{array}$ & $\mathbf{C}$ \\
\hline \hline 1976 & 1730,4 & 727,8 & 1002,7 & 976,7 & $42 \%$ \\
\hline 1977 & 1519,0 & 527,7 & 991,3 & 1130,8 & $35 \%$ \\
\hline 1978 & 1268,5 & 334,8 & 933,6 & 1099,5 & $26 \%$ \\
\hline 1979 & 1868,8 & 771,3 & 1097,5 & 1027,0 & $41 \%$ \\
\hline 1980 & 1738,6 & 774,4 & 964,1 & 1051,5 & $45 \%$ \\
\hline 1981 & 1773,2 & 712,8 & 1060,4 & 1049,8 & $40 \%$ \\
\hline 1982 & 2028,5 & 1003,4 & 1025,1 & 1043,1 & $49 \%$ \\
\hline
\end{tabular}




\begin{tabular}{|c|c|c|c|c|c|}
\hline 1983 & 2558,7 & 1519,3 & 1039,3 & 1027,3 & $59 \%$ \\
\hline 1984 & 1599,5 & 620,4 & 979,1 & 1087,5 & $39 \%$ \\
\hline 1985 & 1285,6 & 526,0 & 759,6 & 1103,1 & $41 \%$ \\
\hline 1986 & 1804,9 & 607,2 & 1197,8 & 1062,4 & $34 \%$ \\
\hline 1987 & 1811,3 & 955,5 & 855,9 & 1022,6 & $53 \%$ \\
\hline 1988 & 1256,7 & 501,9 & 754,7 & 1053,9 & $40 \%$ \\
\hline 1989 & 1932,6 & 863,0 & 1069,6 & 995,6 & $45 \%$ \\
\hline 1990 & 2068,0 & 1109,9 & 958,1 & 1061,7 & $54 \%$ \\
\hline 1991 & 1511,3 & 478,4 & 1032,9 & 1075,9 & $32 \%$ \\
\hline 1992 & 2087,1 & 1097,1 & 990,0 & 1033,1 & $53 \%$ \\
\hline 1993 & 1815,2 & 830,0 & 985,2 & 1028,2 & $46 \%$ \\
\hline 1994 & 1729,5 & 690,6 & 1038,8 & 1060,6 & $40 \%$ \\
\hline 1995 & 1719,7 & 781,9 & 937,8 & 1036,5 & $45 \%$ \\
\hline 1996 & 1817,0 & 726,7 & 1090,3 & 1015,3 & $40 \%$ \\
\hline 1997 & 2114,9 & 1125,1 & 989,8 & 1049,8 & $53 \%$ \\
\hline 1998 & 2244,9 & 1350,2 & 894,7 & 1033,0 & $60 \%$ \\
\hline 1999 & 1398,7 & 575,7 & 823,0 & 1028,2 & $41 \%$ \\
\hline 2000 & 1933,2 & 671,3 & 1262,0 & 1031,0 & $35 \%$ \\
\hline 2001 & 1707,3 & 864,5 & 842,7 & 1053,3 & $51 \%$ \\
\hline 2002 & 1809,5 & 762,6 & 1046,9 & 1103,0 & $42 \%$ \\
\hline 2003 & 1728,3 & 694,2 & 1034,2 & 1009,1 & $40 \%$ \\
\hline 2004 & 1771,8 & 827,6 & 944,2 & 1008,7 & $47 \%$ \\
\hline 2005 & 1738,0 & 794,0 & 944,0 & 1070,1 & $46 \%$ \\
\hline 2006 & 1568,9 & 416,6 & 1152,4 & 1067,5 & $27 \%$ \\
\hline 2007 & 1534,9 & 597,7 & 937,2 & 1083,6 & $39 \%$ \\
\hline 2008 & 1555,2 & 609,2 & 946,0 & 1025,1 & $39 \%$ \\
\hline 2009 & 1969,2 & 871,0 & 1098,2 & 1070,9 & $44 \%$ \\
\hline 2010 & 1687,5 & 702,4 & 985,1 & 1029,9 & $42 \%$ \\
\hline Média & 1762,5 & 772,1 & 990,4 & 1048,7 & $43 \%$ \\
\hline
\end{tabular}

Org.: Márcio Greyck Guimarães Correa, 2017.

\subsection{Considerações}

Os gráficos boxplots mostraram que maio apresenta uma grande variabilidade da precipitação e outubro é o mês com maior variabilidade para a vazão. Os outliers mais expressivos na precipitação foram observados nos meses de maio, na vazão foram nos meses de abril, maio e outubro. As funções de autocorrelação indicam que para a precipitação e a vazão sem defasagem tem-se maior confiabilidade indicando que a defasagem entre 
precipitação e vazão fluvial na bacia hidrográfica do rio Piquiri deve ser inferior a 1 mês, na escala de semanas ou dias.

Com relação à dinâmica hidroclimática nota-se que a chuva precipitada na bacia hidrográfica do rio Piquiri em média $43 \%$ é transformada em vazão, o restante $57 \%$ é estimado entre evapotranspiração e infiltração.

Esta parte da pesquisa apresentou uma análise sistêmica-funcional dos elementos hidroclimáticos na bacia hidrográfica do rio Piquiri. A água representada pela precipitação, vazão e evapotranspiração funcionam como elemento dinamizador dos fenômenos físicos. A interação destes fenômenos é complexa e abre uma infinidade de possibilidades de estudos futuros. 


\section{PARTE IV - EL NIÑO OSCILAÇÃO SUL E A BACIA HIDROGRÁFICA DO RIO PIQUIRI}

\subsection{Introdução}

A atmosfera terrestre sempre despertou a curiosidade dos pesquisadores nas áreas de meteorologia e climatologia devido à sua dinamicidade, o quente contrapondo o frio, o chuvoso em contraposição ao seco, estes fenômenos sempre estiveram na pauta das pesquisas climáticas. Ao longo dos anos os estudos aprimoraram o conhecimento sobre a atmosfera e explicações plausíveis sobre tais fenômenos auxiliaram na evolução do conhecimento climático do planeta.

Os estudos climáticos evoluíram com o passar do tempo, Heymann (2010) discute que o desenvolvimento científico dos últimos séculos proporcionou uma visão mecanicista e reducionista do clima e que a partir de meados do século $\mathrm{XX}$ a análise físico-geográfica do clima passou a contemplar questões de interesse social e econômico.

É com a noção de ritmo climático introduzida por Max Sorre, tipos de tempo por Pierre Pédelaborde e mais tarde a análise rítmica de Carlos Augusto de Figueiredo Monteiro que houve um impulso nos estudos sobre a dinâmica climática, e os estudos da climatologia estática baseada nas médias climatológicas, passaram a receber menos atenção no meio acadêmico.

Mendonça e Danni-Oliveira (2007) destacam que os estudos climáticos tiveram um grande avanço quando a análise da dinâmica atmosférica passou a priorizar os eventos episódicos e não apenas as condições médias dos elementos atmosféricos, pois estes fenômenos eventuais são os responsáveis pelos maiores impactos na sociedade, na economia e 
no ambiente. Os autores discutem o fato de que a Climatologia é um estudo científico do clima responsável por explicar as interações das atividades humanas e os padrões atmosféricos ao longo do tempo.

A partir de 1970 muitos estudos abordaram a variabilidade climática por meio da análise rítmica ou da dinâmica atmosférica, principalmente com vistas ao planejamento agrícola e urbano, dentre os quais pode-se citar os trabalhos de Monteiro (1971), Conti (1975) Zavatini (1990) e Sant'Anna Neto (1995).

Além da dinâmica atmosférica, a escala climática também passou a receber atenção nas pesquisas, da escala espacial macroclimática até o microclima perpassando pela escala temporal diária (horária) até séries históricas de trinta anos, tornaram-se importante para a compreensão dos fenômenos climáticos.

O desenvolvimento das técnicas de observação do tempo meteorológico proporcionou um grande avanço para a climatologia como um todo, Ferreira (2006) aponta que desde a década de 1960 os satélites meteorológicos estão em órbita terrestre, fornecendo uma vasta quantidade de dados observacionais. $\mathrm{O}$ aumento das estações meteorológicas e das observações atmosféricas auxiliou na identificação e compreensão de fenômenos como ENOS (El Niño Oscilação Sul).

\subsection{Referencial Teórico - El Niño Oscilação Sul}

\subsubsection{As teleconexões}

Baseando-se nas concepções da dinâmica dos fluidos, termodinâmica e da dinâmica atmosférica, pesquisadores como Carl-Gustaf Rossby e Vilhelm Bjerknes foram precursores nas ciências atmosféricas moderna. A contribuição da teoria sistêmica no campo das ciências 
atmosféricas nos remonta à obra de Lorenz $(1963 ; 1968 ; 1969)$ e seus estudos acerca da previsão do tempo meteorológico baseado em teorias sistêmicas, este, um dos grandes pensadores da Teoria do Caos. Segundo o autor o sistema climático é matematicamente um objeto caótico, isso devido às inúmeras variáveis responsáveis pelo seu funcionamento, tornando mais fácil matematicamente a previsão do tempo para poucos dias.

Ångström (1935) foi o pioneiro a mencionar os efeitos das teleconexões ao estudar a Oscilação do Atlântico Norte. Os estudos de Jacob Bjerknes, filho do norueguês Vilhelm Bjerknes, foram essenciais para a consolidação e compreensão da dinâmica envolvendo as oscilações e a interação entre o oceano e a atmosfera. Bjerknes (1969) foi responsável por disseminar o termo teleconexões ao estudar os impactos do fenômeno ENOS em várias regiões do globo.

De acordo com Ambrizzi et al. (2014, p. 138) “A palavra "teleconexão" significa conexão a distância." Segundo Liu e Alexander (2007) as teleconexões se referem à vinculação entre anomalias climáticas aparentemente sem nenhuma relação e que estão a grandes distâncias.

Dentre as principais teleconexões conhecidas atualmente, Reboita e Santos (2014) apontam as principais: ENOS (El Niño Oscilaçao Sul), PSA (modo do Pacífico - América do Sul), MAS (Modo Anular Sul), a ODP (Oscilação Decadal do Pacífico), e SAJI (dipolo de temperatura da superfície do mar no oceano Índico e o dipolo de temperatura da superfície do mar no oceano Atlântico Tropical).

Silva e Silva (2012) explicam que a variabilidade climática, compreendida como os desvios em torno da média climática regional, é regulada em boa parte pela interação oceano- 
atmosfera e fazem uma análise das principais interações que influenciam o clima na América do Sul por meio das teleconexões, destacando ENOS.

A interação entre a temperatura da superfície do mar e diferenças barométricas em distintas regiões do globo é considerada a principal forçante da variabilidade climática global, Ambrizzi (2003) destaca que essa dinâmica é responsável por produzir trens de ondas capazes de interferir na variabilidade climática de áreas distintas do globo terrestre.

Ao estudar a influência das teleconexões na precipitação do norte e nordeste brasileiro, Reboita e Santos (2014) utilizaram o fenômeno ENOS e anomalias da TSM no Atlântico Tropical para averiguar tal correlação e perceberam que o acoplamento desses fenômenos resultou em situações de ocorrência de precipitação diferenciada para as regiões estudadas, trazendo um novo entendimento sobre os efeitos do El Niño e La Niña sobre o norte e nordeste do Brasil.

\subsubsection{El Niño Oscilação Sul}

O fenômeno El Niño Oscilação Sul (ENOS) é caracterizado pelo aquecimento das águas superficiais e sub-superficiais do Oceano Pacífico Equatorial próximo à costa do Peru e do Equador como aponta Trenberth (1997). A interação entre as águas aquecidas do oceano com a baixa atmosfera gera alterações nos padrões gerais de circulação da atmosfera (Célula de Walker).

Oliveira (1999) comenta que o fenômeno ENOS apresenta complexidade no que diz respeito a estas interações e que representa de forma mais genérica um fenômeno de interação atmosfera-oceano que está associado a alterações dos padrões normais da Temperatura da 
Superfície do Mar (TSM) e dos ventos alísios na região do Pacífico Equatorial e que pode ser quantificado pelo Índice de Oscilação Sul (IOS).

A anomalia de TSM é um dos principais indicadores de ocorrência de ENOS. Segundo Trenberth (1997) a anomalia positiva de TSM observada por ao menos três meses consecutivos indica a ocorrência de El Niño. Existem regiões do Pacifico que são consideradas como parâmetros para a determinação e correlação das variações climáticas globais associadas ao fenômeno ENOS, a região mais utilizada nas pesquisas é a chamada Niño 3.4, quando apresenta anomalias maiores ou superiores a $0,5^{\circ} \mathrm{C}$ em relação a média da TSM. Pode-se observar a localização das regiões sobre o oceano Pacifico na Figura 25.

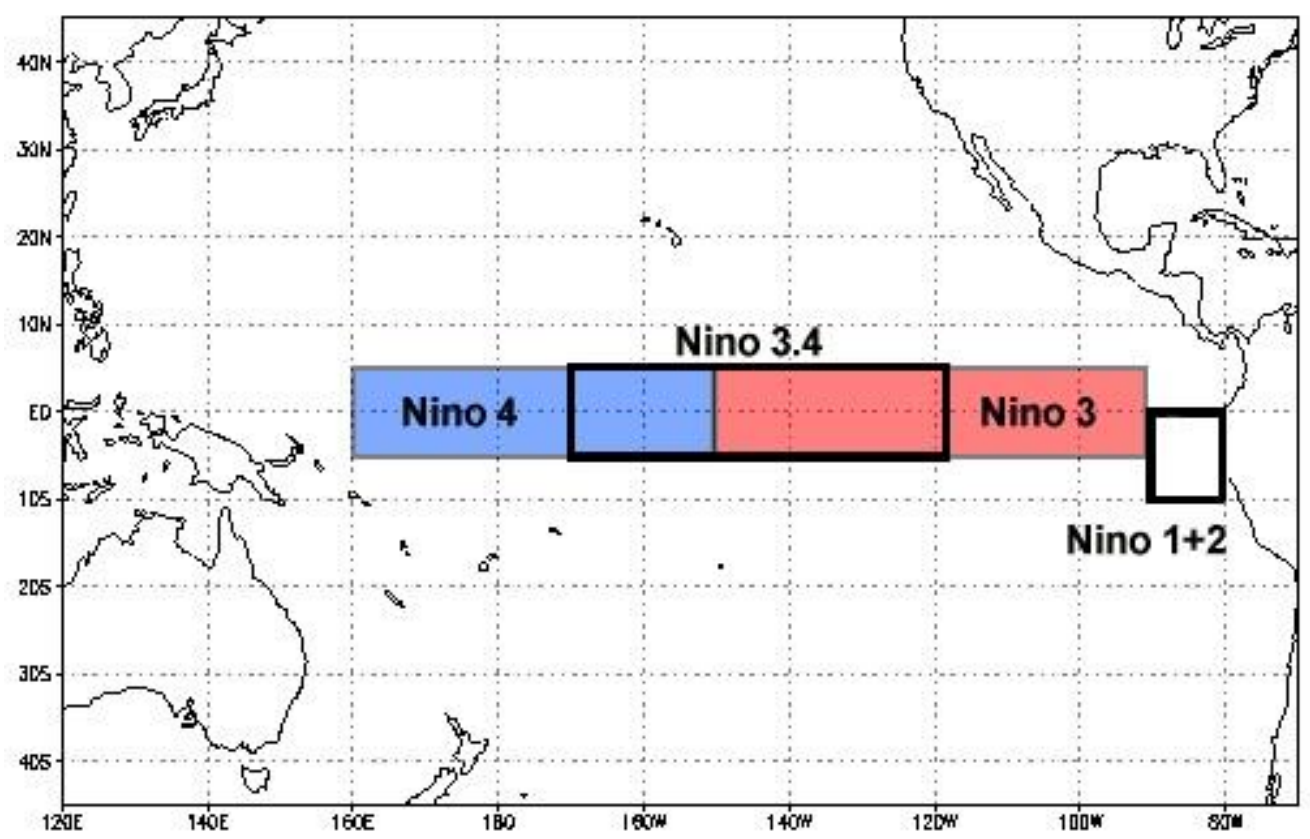

Figura 25: Regiões consideradas para determinação de anomalias de temperatura da superficie do mar (TSM) no oceano Pacífico.

Fonte: National Centers for Environmental Information (NOAA), 2017.

O Índice de Oscilação Sul (IOS) também fornece evidências de ocorrência do fenômeno ENOS, de acordo com Berlato e Fontana (2003), esse índice representa a "gangorra barométrica", ou seja, a correlação inversa entre a pressão atmosférica no extremo leste e oeste do oceano Pacífico. O (IOS) é definido pela diferença entre os desvios normalizados da 
pressão observada no Taiti (Polinésia Francesa) e em Darwin (norte da Austrália), Figura 26, valores negativos do índice estão associados a ocorrência de El Niño, enquanto valores positivos de IOS à ocorrência de La Niña.

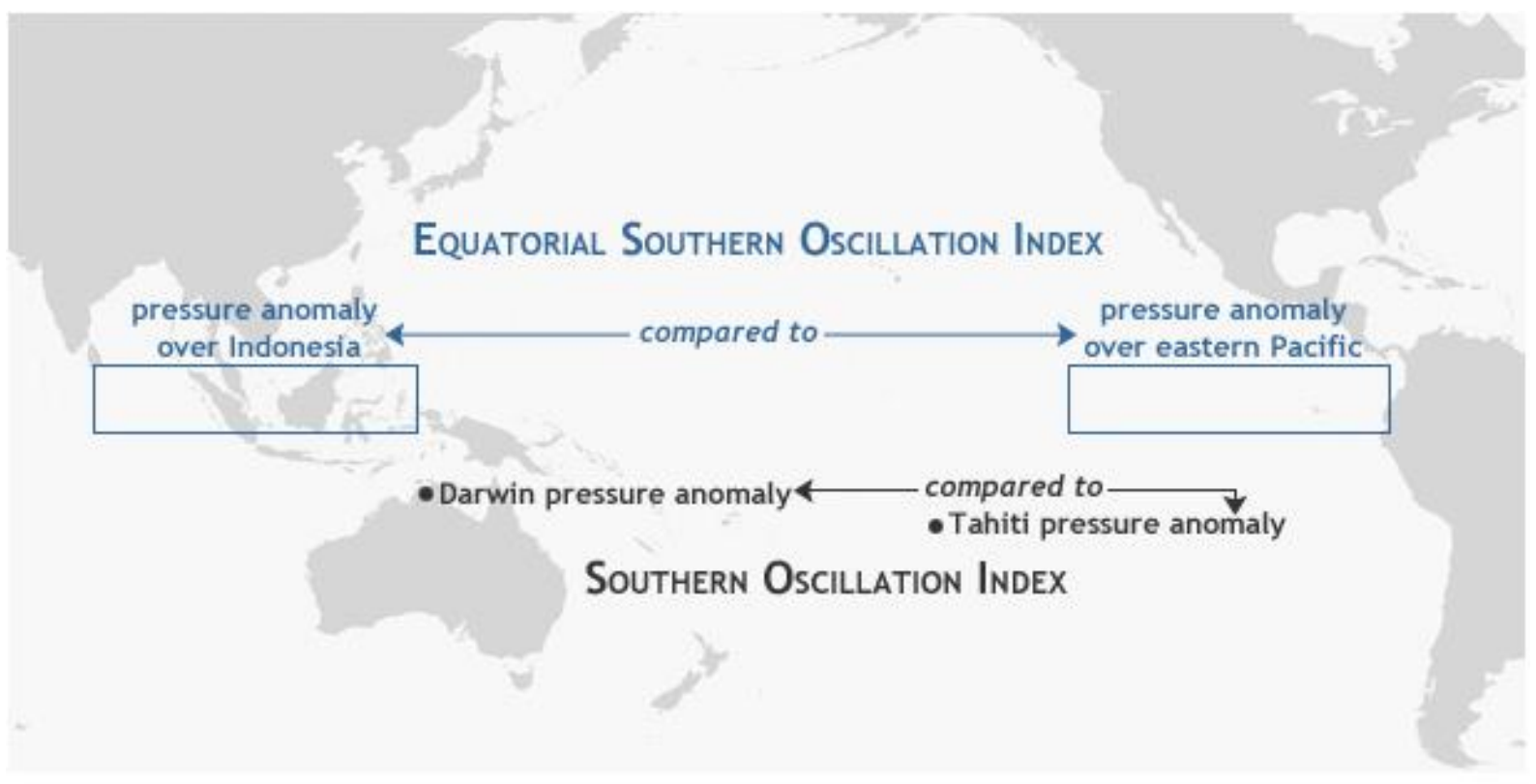

Figura 26: Localização das áreas consideradas para a mensuração do Índice de Oscilação Sul (IOS). Fonte: National Centers for Environmental Information (NOAA), 2017.

A TSM e o IOS são inversamente proporcionais, a Figura 27 mostra a relação entre as variáveis no período entre 1970 e 1995, em períodos em que a TSM é positiva consequentemente o IOS é negativo, caracterizando período de El Niño, quando a TSM é negativa e o IOS positivo caracteriza período de La Niña. 


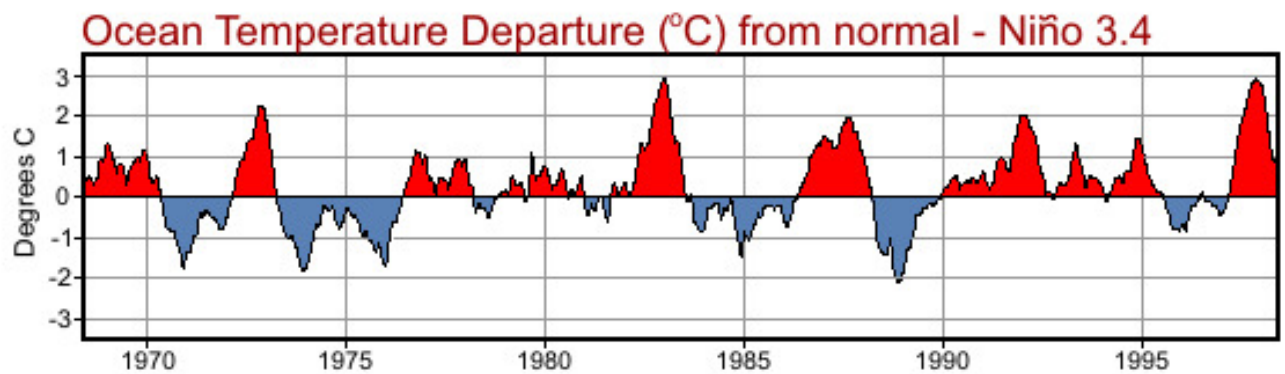

Tahiti-Darwin SOI (3-month running average)

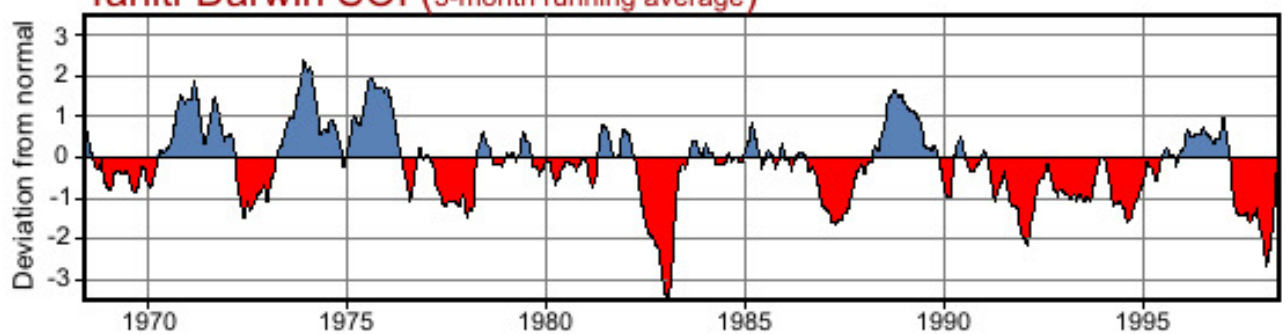

Figura 27: Comparação entre anomalias de TSM (Região Niño 3.4) e IOS.

Fonte: National Centers for Environmental Information (NOAA), 2017.

Observando a Figura 28 nota-se que sobre o Pacífico em condições normais favorece a formação de chuvas devido à convecção intensa sobre o oceano, as águas próximas a costa da América do Sul são mais frias (representados pela termoclina). Numa situação de El Niño as águas mais quentes se direcionam para a proximidade da costa sul americana e a célula de circulação de Walker se divide, a termoclina suaviza-se e as temperaturas do oceano na costa do Peru se aquecem mais. Durante a fase negativa do ENOS, o que de fato ocorre é um aumento na intensidade dos ventos alísios, isso promove um alongamento da célula de Walker para oeste e a ressurgência de águas mais frias na costa da América do Sul com a maior inclinação da termoclina.

O que Ambrizzi et al. (2004), Freitas e Ambrizzi (2012) observaram em episódios quentes de ENOS, é que as anomalias da TSM (Temperatura da Superfície do Mar) influenciam anomalias de convecção e subsidência do ar em grande escala, ligada ao ramo descendente da circulação de Hadley, gerando perturbações nas ondas estacionárias globais e correntes de jatos relacionados. 


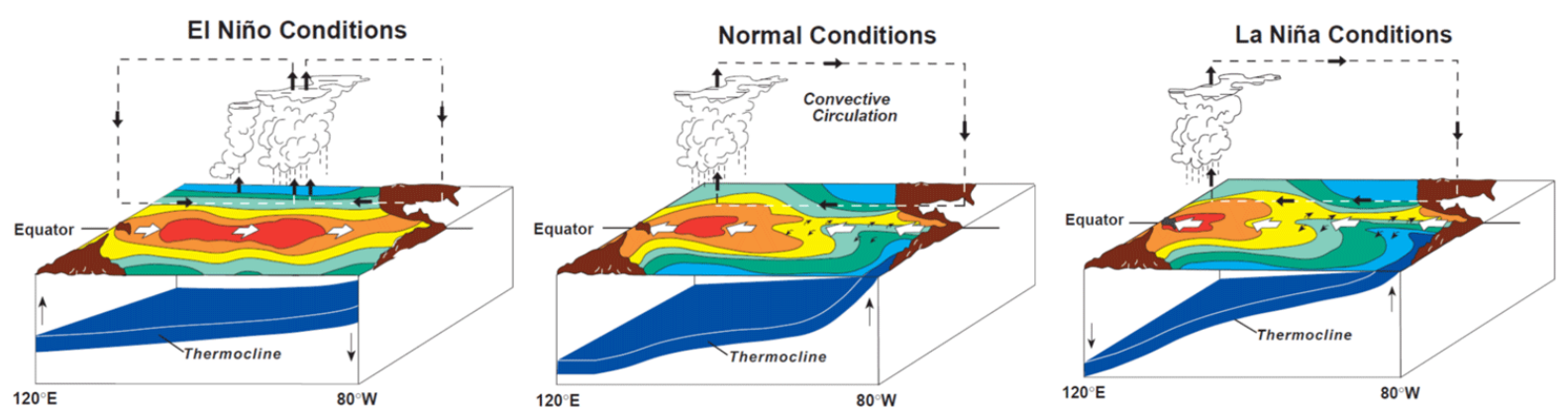

Figura 28: Modelo explicativo da ocorrência do ENOS em sua fase positiva e negativa sobre o Oceano Pacífico Equatorial.

Fonte: National Centers for Environmental Information (NOAA), 2017.

Os reflexos do ENOS nos padrões de tempo da América do Sul são diversos, o fenômeno é responsável por provocar alterações importantes na distribuição das chuvas sobre o continente. Rao e Hada (1990) e Stoeckenius (1981), realizaram estudos pioneiros sobre as relações entre fenômenos globais e a variabilidade da precipitação na faixa tropical do globo, inclusive o Brasil, e destacaram a sazonalidade do clima tropical brasileiro e a forte correlação das chuvas de primavera com fenômenos de Oscilação Sul, porém na época ainda havia muitas dúvidas sobre tais fenômenos e suas decorrências no território brasileiro.

Grimm et al. (2000) caracterizaram no sul da América do Sul oito regiões pluviométricas influenciadas por El Niño e seis regiões pelo La Niña e diagnosticaram mudanças nos padrões de circulação atmosférica durante os vários estágios da anomalia. Britto et al. (2008) estudaram a variabilidade espacial e temporal da chuva no estado do Rio Grande do Sul e associaram-na com a ocorrência de El Niño e La Niña, estudos dessa natureza foram realizados por Nery (2005) ao evidenciar a dinâmica climática do sul do país.

Os resultados de fenômenos dessa magnitude interferem no cotidiano das pessoas, pois alteram mesmo que temporariamente, a dinâmica atmosférica, excessos ou escassez de chuva expõe a vulnerabilidade que a sociedade se encontra frente a situações que fogem do padrão de funcionamento esperado da natureza. 
Segundo Vandenberghe (2003) os eventos climáticos mais intensos e sua regularidade sazonal são os grandes responsáveis naturais por promover mudanças significativas nos sistemas fluviais, como erosão e transporte de matéria pelos rios.

Amarasekera et al. (1997) estudaram a influência do fenômeno ENOS na descarga anual de "rios tropicais" (Amazonas, Congo, Paraná e Nilo) e perceberam que há menor correlação entre a vazão dos rios Amazonas e Congo com o fenômeno atmosférico de escala global, mas analisando a vazão dos rios Paraná e Nilo (abrangem áreas subtropicais) notaram que a correlação é maior, e o rio Paraná tem relação direta com as variações da TSM. Em média 20-25\% de variação anual na descarga dos rios Paraná e Nilo explicam-se por meio do ENOS. Camilloni e Barros (2003) também estudaram a relação entre o EN e LA na vazão do rio Paraná e diagnosticaram que cerca de dois terços das principais anomalias de descarga no rio ocorrem em períodos de El Niño (região 3.4), principalmente entre a primavera e o outono.

\subsection{Procedimentos Metodológicos: Correlação ENOS, Precipitação e Vazão fluvial}

Analisou-se a ocorrência de ENOS por meio do Índice de Oscilação Sul (IOS), com os dados disponibilizados pelo National Climate Centre da Austrália. O critério adotado para a classificação dos meses se fez baseado na metodologia (Troup SOI) do Serviço de Meteorologia da Austrália.

De acordo com essa metodologia de análise do IOS, consideram-se os meses de ocorrência de IOS negativo (El Niño) inferior a -7 e IOS positivo (La Niña) superior a +7. Os valores de IOS apresentados pelo órgão responsável foram multiplicados por 10 (por 
convenção) e tem valores máximos variando entre -35 e +35 . O cálculo para a obtenção dos valores normalizados de IOS é apresentado na equação 7.

(Equação 7)

$$
S O I=10 . \frac{(\text { Pdiff }- \text { Pdiffav })}{S D(\text { Pdiff })}
$$

$S O I=$ Índice de Oscilação Sul (IOS)

Pdiff $=$ Diferença entre a pressão atmosférica medida no Taiti e Darwin para o mês.

Pdiffav = Média de Pdiff para o mês em questão.

$S D($ Pdiff $)=$ Desvio padrão de Pdiff para o mês em questão.

Segundo Lanna (2001) a precipitação e a vazão são variáveis hidrológicas aleatórias, o que dificulta conhecer a evolução destes fenômenos ao longo do tempo e do espaço, estatisticamente a correlação entre essas variáveis será feita por meio de correlação linear de Pearson, assim como os valores do IOS. Esse tipo de análise estatística permite observar a intensidade da correlação entre as variáveis estudadas, equação 8.

(Equação 8)

$$
r=\frac{\sum\left(x_{i}-\bar{x}\right)\left(y_{i}-\bar{y}\right)}{\sqrt{\left(\sum\left(x_{i}-\bar{x}\right)^{2}\right)\left(\sum\left(y_{i}-\bar{y}\right)^{2}\right)}}
$$

Em que: $x_{i}$ e $y_{i}$ indicam as duas variáveis observadas em cada passo de tempo i, $\overline{\mathbf{x}}$ e $\overline{\mathbf{y}}$, a média aritmética de cada série temporal; $\sqrt{\left(\sum\left(\mathrm{x}_{\mathrm{i}}-\overline{\mathrm{x}}\right)^{2}\right)\left(\sum\left(\mathrm{y}_{\mathrm{i}}-\overline{\mathrm{y}}\right)^{2}\right)}$ corresponde ao desvio padrão de x e y. 
Sabe-se que existe um atraso entre a ocorrência de fenômenos sobre os oceanos e suas decorrências na precipitação e na vazão fluvial no continente, esse lag foi considerado nos estudos realizados, para isso realizou-se o teste de correlação linear para averiguar qual a melhor correlação entre as variáveis consideradas, e foram apresentadas em um gráfico de autocorrelação cruzada.

\subsubsection{Modelagem GAMLSS}

Para caracterizar o efeito de IOS na bacia hidrográfica do rio Piquiri, utilizou-se modelos de regressão para modelar a média e, em algumas situações, a variância das variáveis respostas vazão e precipitação, sendo assim buscou-se um procedimento que priorizasse em identificar o impacto do IOS na precipitação média e o impacto do IOS na vazão média quando controlada por variações da precipitação, um modelo de diagnóstico e não de previsão.

Optou-se por utilizar o modelo GAMLSS (Modelos Aditivos Generalizados para Posição, Escala e Forma), de acordo com Stasinopoulos e Rigby (2007) GAMLSS é um tipo de modelo de regressão semi-paramétrico, ele surge como uma abordagem para superar algumas limitações dos Modelos Lineares Generalizados (MLG) e dos Modelos Aditivos Generalizados (MAG).

O funcionamento deste modelo é descrito por Milhorança (2014, p. 12).

"Com o GAMLSS podemos modelar diretamente todos os parâmetros da distribuição condicional de $y$, e não somente a média (localização). Para a maioria das distribuições os parâmetros são: média, variância, assimetria e curtose. Isso permite que possamos explicar a heteroscedasticidade ${ }^{3}$ por

\footnotetext{
${ }^{3}$ É um fenômeno estatístico que ocorre quando o modelo de hipótese matemático apresenta variâncias para Y e X(X1, X2, X3,..., Xn) diferentes para todas as observações. A heterocedasticidade apresenta-se como uma forte dispersão dos dados em torno de uma reta de regressão, o contrário de homocedasticidade.
} 
meio de variáveis explicativas, porém não permite ter parâmetros para a autocorrelação."

Com o modelo proposto esperou-se encontrar alguma resposta por meio das variáveis (precipitação e vazão) a influência do IOS na bacia hidrográfica do rio Piquiri. Os resíduos do modelo, ou seja, “a diferença entre o valor observado, e o valor esperado”, Milhorança (2014, p. 13) foram transformados estatisticamente para terem distribuição normal padrão.

Primeiro partiu-se de um modelo simples, como por exemplo uma regressão linear normal unidimensional ou múltipla. A partir do ajuste desse modelo, verificou-se se as suposições utilizadas eram satisfatórias e, em caso positivo, considerou-se que a explicação do fenômeno observado foi suficiente. O Modelo aplicado para a precipitação pode ser observado na equação 9:

(Equação 9)

$$
\begin{gathered}
P_{t} \sim G G\left(\mu_{t}, \sigma_{t}, v\right) \text { independentes } \\
\log \left(\mu_{t}\right)=\log \left(E\left[P_{t}\right]\right)=\mu+\alpha_{M e s_{t}}+\beta \operatorname{IOS}_{t-1}, \\
\log \left(\sigma_{t}\right)=\tau+\gamma_{M e s_{t}}+\beta_{2} \operatorname{IOS}_{t-1} \\
\operatorname{Var}\left[P_{t}\right]=\left(\mu_{t} \times \sigma_{t}\right)^{2} .
\end{gathered}
$$

$P_{t}$ : Precipitação da t-ésima observação.

$\mu$ : Parâmetro que representa a Precipitação média associada dos meses de janeiro.

$\alpha_{\text {Mest }_{t}}$ : Parâmetro que representa a diferença entre a Precipitação média dos meses correspondentes ao mesmo mês da t-ésima observação e a Precipitação média dos meses de janeiro.

$\beta$ : Parâmetro que representa a variação na média da Precipitação proporcionada pelo aumento de uma unidade de IOS.

Para a vazão a escolha das covariáveis foi feita com base nas conclusões da análise descritiva (Parte III). Justifica-se a inclusão da precipitação e suas defasagens, onde as 
maiores correlações aparecem até a terceira defasagem de precipitação. De maneira análoga, a justificativa para a inclusão do IOS defasado é obtida analisando o gráfico de correlação cruzada e verificando que a maior correlação acontece quando o IOS é defasado em um mês (resultados apresentados na análise e discussão dos resultados a seguir). A equação 10 mostra o procedimento estatístico adotado para a obtenção dos resultados esperados.

(Equação 10)

$$
\begin{gathered}
V_{t}=\mu+\alpha_{\text {Mes }_{t}}+\beta I O S_{t-1}+\rho_{0} P_{t}+\rho_{1} P_{t-1}+\rho_{2} P_{t-2}+\epsilon_{t} \\
\epsilon_{t}=\phi v_{t-1}+v_{t} \\
v_{t} \sim N\left(0, \sigma^{2}\right) \text { independentes e identicamente distribuídas } \\
t=1, \ldots, 420 .
\end{gathered}
$$

$V_{t}$ : Vazão da t-ésima observação.

$\mu$ : Parâmetro que representa a média das Vazão dos meses de janeiro.

$\alpha_{\text {Mest }_{t}}$ : Parâmetro que representa a diferença entre a média da Vazão dos meses correspondentes ao mesmo mês da t-ésima observação e a média da Vazão dos meses de janeiro.

$\beta$ : Parâmetro que representa a variação na média da Vazão proporcionada pelo aumento de uma unidade de IOS.

$\rho_{0}$ : Parâmetro que representa a variação na média da Vazão proporcionada pelo aumento de uma unidade da Precipitação da t-ésima observação.

$\rho_{1}$ : Parâmetro que representa a variação na média da Vazão proporcionada pelo aumento de uma unidade da Precipitação da (t-1)-ésima observação.

$\rho_{2}$ : Parâmetro que representa a variação na média da Vazão proporcionada pelo aumento de uma unidade da Precipitação da (t-2)-ésima observação.

$\phi$ : Parâmetro que representa a correlação entre os resíduos da regressão usual $\epsilon_{t}, t=$ $2, \ldots, 420$, e a sua versão defasada $\epsilon_{t-1}, t=2, \ldots, 420$.

O modelo GAMLSS foi aplicado para a precipitação e a vazão das três áreas de drenagem A1, A2 e A3 e produzido os gráficos com os resíduos resultantes da modelagem. 
Nos gráficos de resíduos espera-se que a dispersão dos pontos fique alinhada à reta, dentro da área cinza, e que nos demais gráficos de dispersão os pontos estejam dispersos com amplitude constante em torno de zero, pois isso significa que o modelo ajusta-se aos dados, de acordo com Paiva et al. (2008, p. 298) a interpretação dos gráficos de resíduos deve ser feita da seguinte maneira:

"Assim, se um modelo se ajustar bem aos dados, os seus resíduos verdadeiros deverão apresentar distribuição aproximadamente normal padrão, ou seja, média próximo de zero, variância próximo de 1, coeficiente de assimetria próximo de 0 e coeficiente de curtose próximo de $3 . .$.

... A normalidade dos resíduos também poderá ser verificada pela interpretação dos gráficos de dispersão dos resíduos contra a variável explanatória ou contra valores ajustados e transformados, de tal forma que se tenha uma variância constante para a distribuição utilizada. O padrão nulo desses gráficos é uma distribuição dos resíduos em torno de zero com amplitude constante. A análise gráfica residual permite verificar afastamentos da normalidade dos resíduos."

As tabelas com o resultado da estatística do modelo GAMLSS apresentam a estimativa, erro padrão, estatística t, valor-p e efeito para cada parâmetro utilizado na modelagem. Para a interpretação do modelo é essencial as colunas estatística t, valor-p e efeito. 


\subsection{Análise e discussão dos resultados da correlação entre ENOS, precipitação e vazão fluvial}

De todos os 420 meses da série histórica estudada (1976-2010), foram identificados 132 meses com IOS negativo menor ou igual que -7 (31,4\% do total de meses) enquanto 89 meses obtiveram IOS positivo maior ou igual que +7 ( $21,1 \%$ do total de meses), isso significa que $47,5 \%$ dos meses foram considerados neutros com relação ao IOS.

A influência do IOS não ocorre instantaneamente, existe uma defasagem de tempo para que os efeitos dessas teleconexões sejam perceptíveis no clima de uma região. Silva (2012) verificou a correlação entre a vazão dos rios do centro-norte do Pantanal e a TSM do Pacífico, e concluiu que a defasagem mais confiável foi de até 4 meses, baseando-se nesse pressuposto realizou-se as correlações entre IOS e precipitação e IOS e vazão com defasagens

As correlações com defasagem apresentadas nas figuras 28,29 e 30 (A1, A2 e A3 respectivamente) mostram que os valores da correlação são baixos em todas as defasagens, e a maior correlação encontrada foi de um mês (aproximadamente -0,1) para a precipitação, enquanto para a vazão a maior correlação observada considerada foi de um e dois meses. Com defasagens maiores que 10 meses também observou-se correlações próximos de 0,1 , porém com pouca significância.

Com um mês de defasagem os gráficos de dispersão mostram que a reta ajustada aos pontos é mais íngreme do que nos gráficos sem defasagem e os pontos apresentam-se mais agrupados em torno da reta (Figura 29)

Pode-se observar o mesmo padrão de correlação e dispersão para a A2 - Porto Guarani e A3-Balsa Santa Maria, Figura 30 e Figura 31. A defasagem de um mês entre IOS e 
precipitação é a mais confiável, a exceção é na vazão, a correlação com defasagem de dois meses pode ser considerada, apesar da defasagem de um mês ainda assim não ser descartada.

Essa diferença na defasagem entre a vazão e o IOS para A2 e A3 pode ser explicada pelo fato de que a vazão é uma variável resultante do processo da precipitação pluviométrica e escoamento, o tempo e ocorrência do evento de precipitação e a área de captação do rio principal influenciam na defasagem dos postos fluviométricos mais à jusante. Isso é perceptível com o aumento da significância da defasagem de 2 meses de A1 para A3. Importante destacar que a partir do décimo mês de defasagem as correlações mudam de sinal, porém poucos meses apresentaram resultados confiáveis. Neste caso há de se considerar a persistência das correlações negativas de até sete meses, e maior confiança até o terceiro mês, o que corrobora ainda mais para a confiabilidade dos testes.

As correlações negativas podem ser consideradas mais confiáveis porque a maioria dos meses analisados apresentaram desvios de IOS negativos, indicando aquecimento das águas superficiais do Pacifico e configuração da fase quente do fenômeno (El Niño), oque resultaria em maiores desvios positivos de chuva e vazão, grandezas inversamente proporcionais, isso fica ainda mais evidente nos gráficos de dispersão para as três áreas consideradas (A1, A2 e A3 - Figura 29Figura 30Figura 31)

A dispersão dos pontos mostra que a precipitação e o IOS tem maior variabilidade do que as correlações entre vazão e IOS, isso é válido para as três áreas de drenagem, os pontos ficam mais concentrados e próximos à reta nos gráficos com um mês de defasagem, e isso é mais evidente para a vazão. 


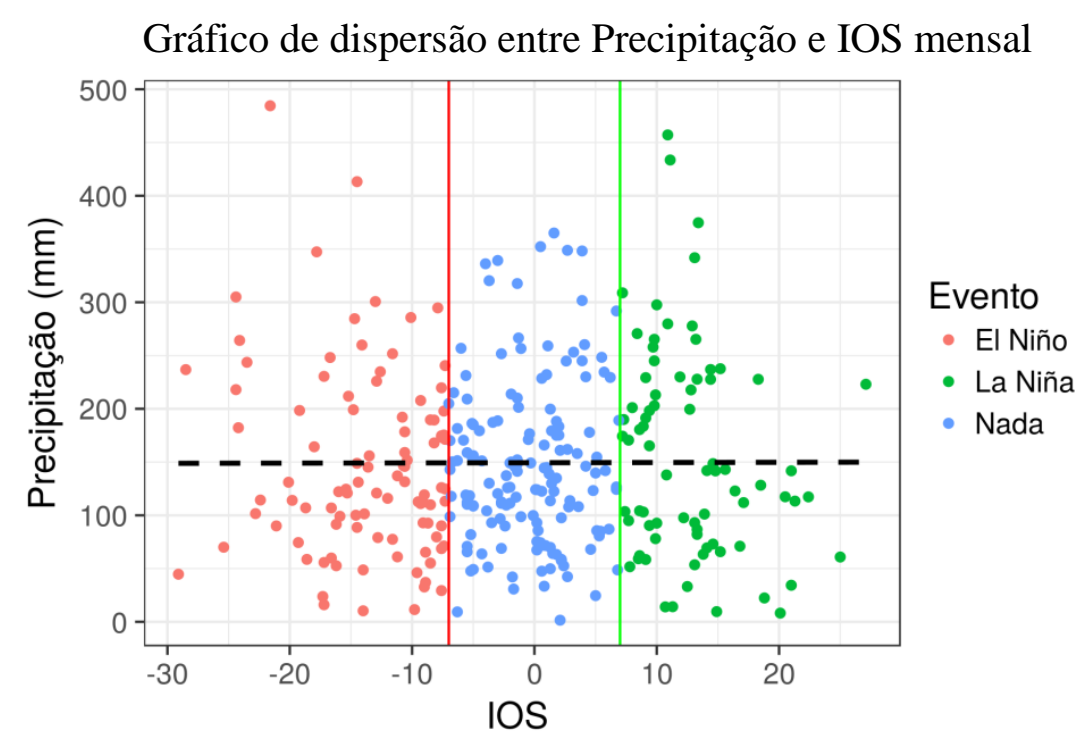

Autocorrelação com defasagem entre Precipitação e IOS

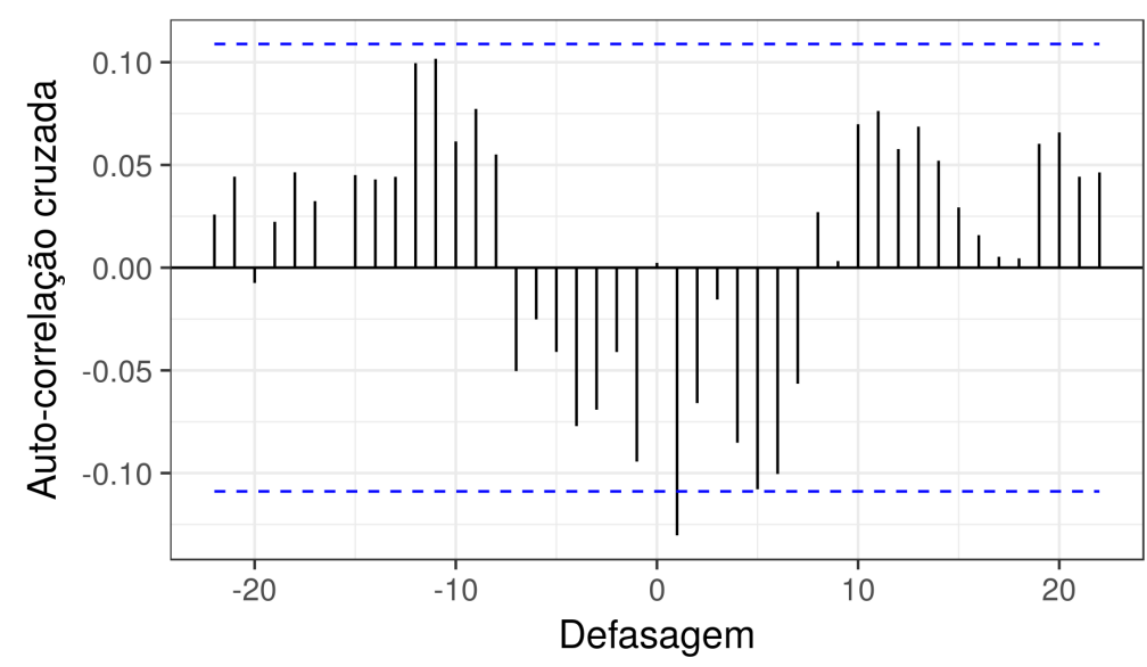

Gráfico de dispersão entre Precipitação e IOS defasagem de 1 mês

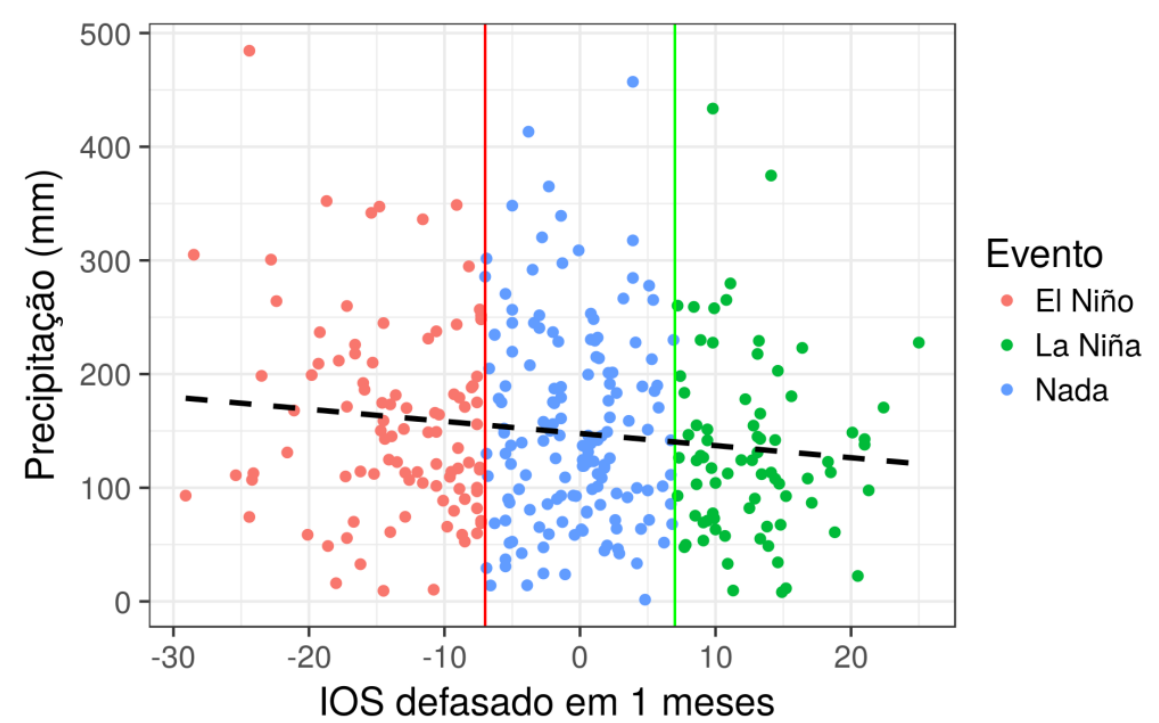

Gráfico de dispersão entre Vazão e IOS mensal

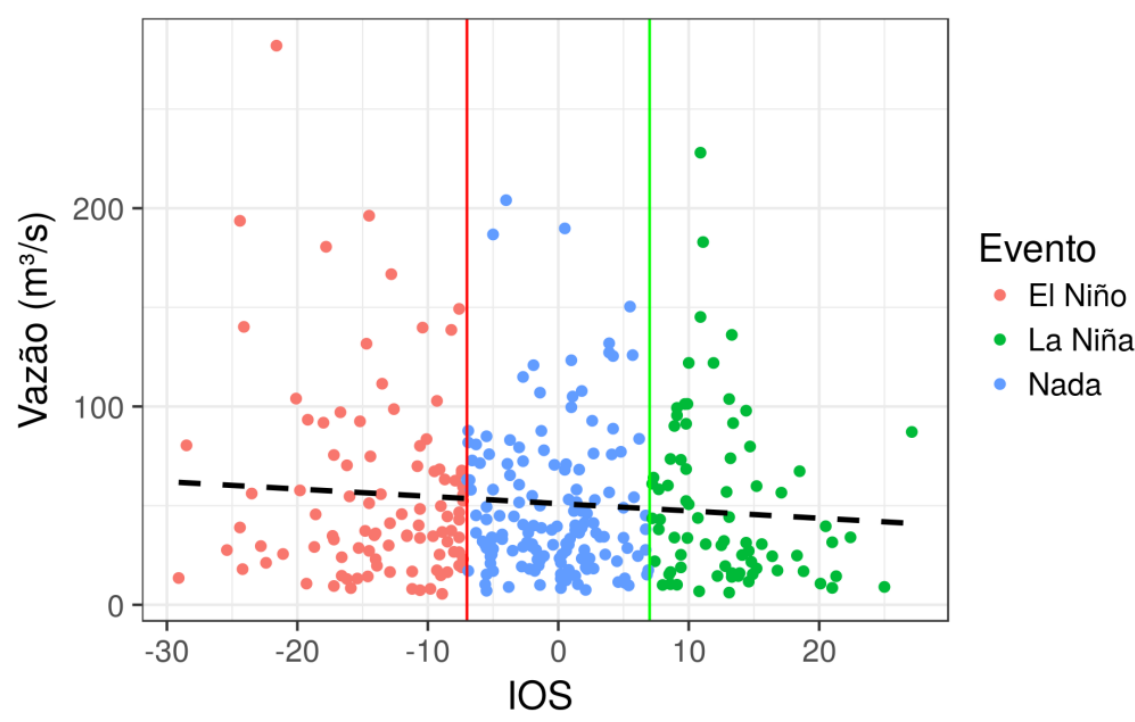

Autocorrelação com defasagem entre Vazão e IOS

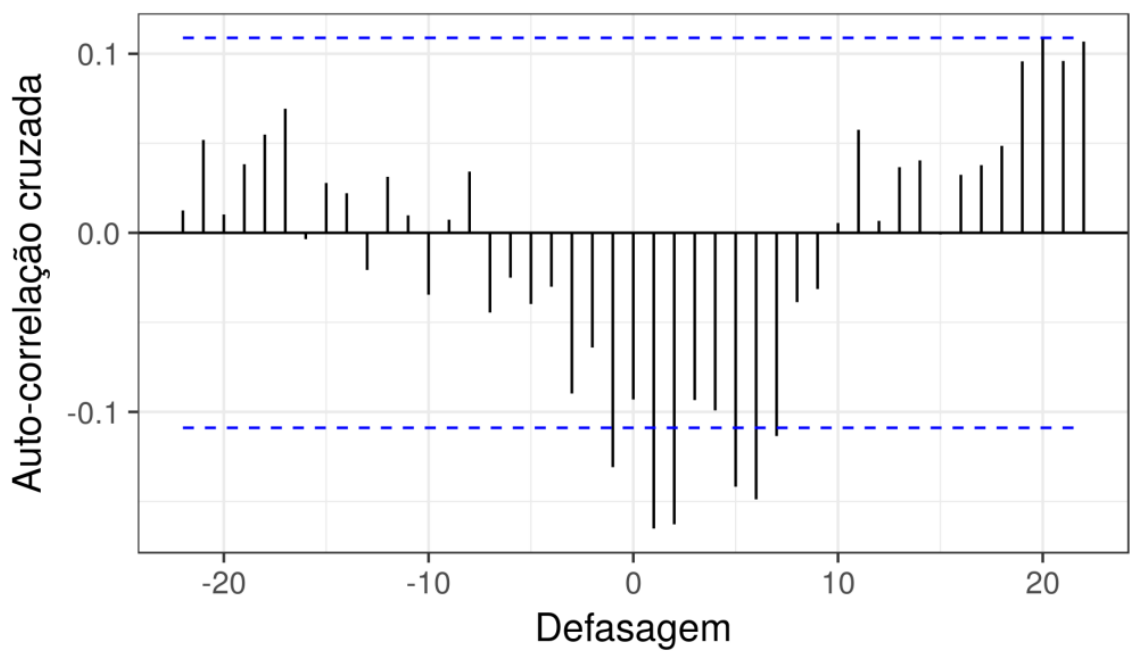

Gráfico de dispersão entre Vazão e IOS defasagem de 1 mês

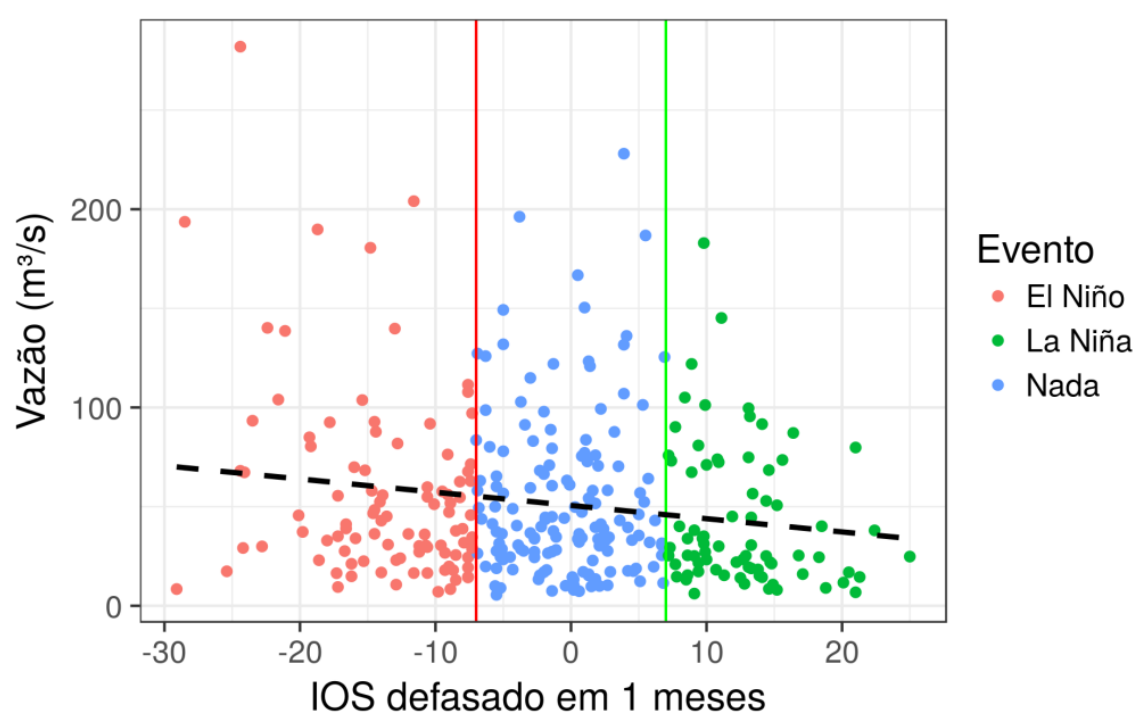

Figura 29: Gráficos de dispersão e autocorrelação com defasagem entre precipitação, vazão e IOS Para Área 1- Guampará na bacia hidrográfica do rio Piquiri-PR

Org.: Márcio Greyck Guimarães Correa (Com base no relatório desenvolvido por Alencar et al., 2016). 


\section{Área 2 - Porto Guarani}

Gráfico de dispersão entre Precipitação e IOS mensal

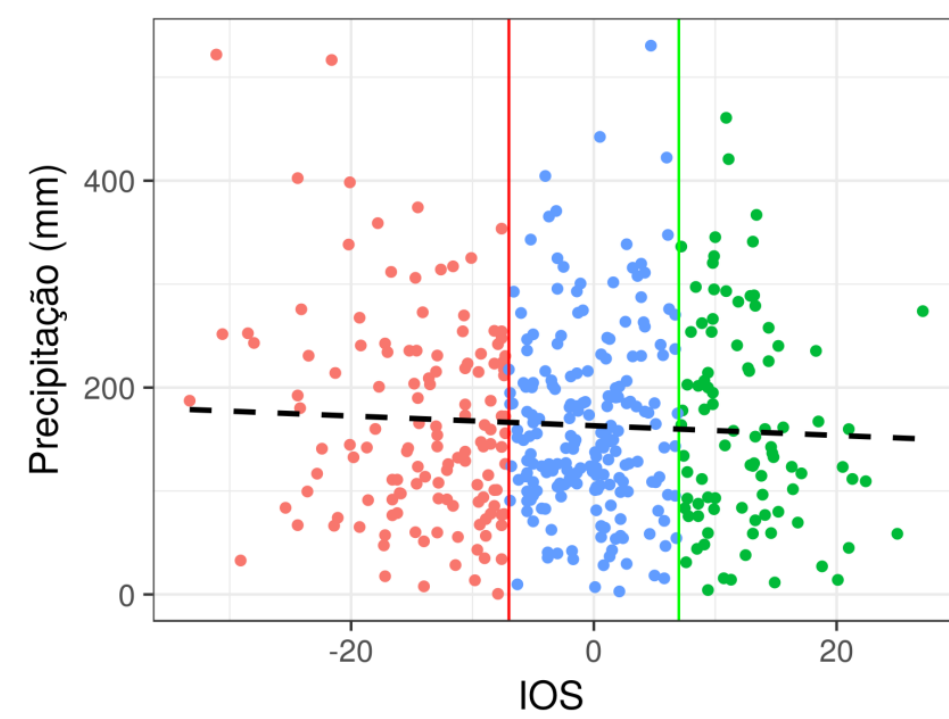

Autocorrelação com defasagem entre Precipitação e IOS

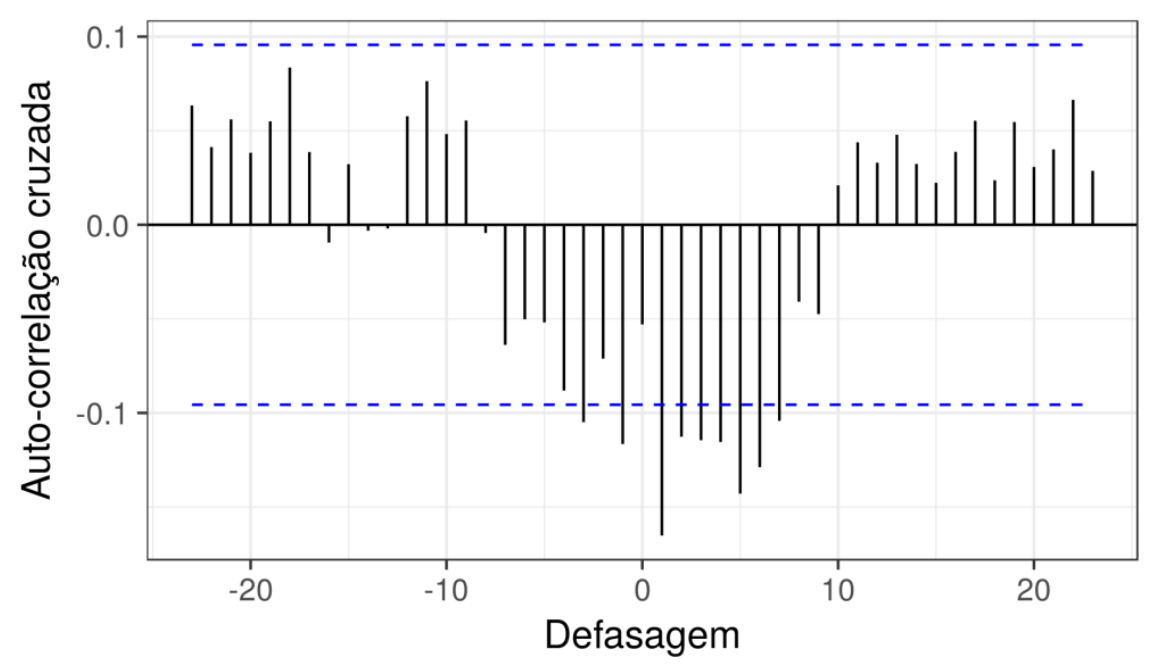

Gráfico de dispersão entre Precipitação e IOS defasagem de 1 mês

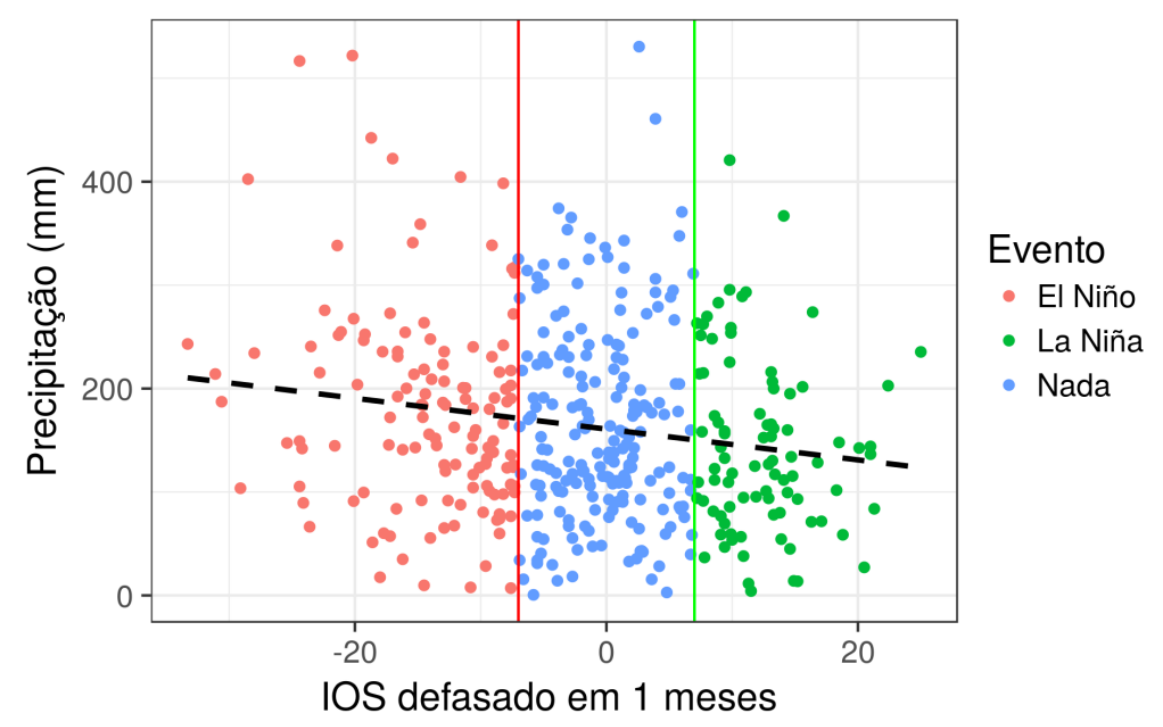

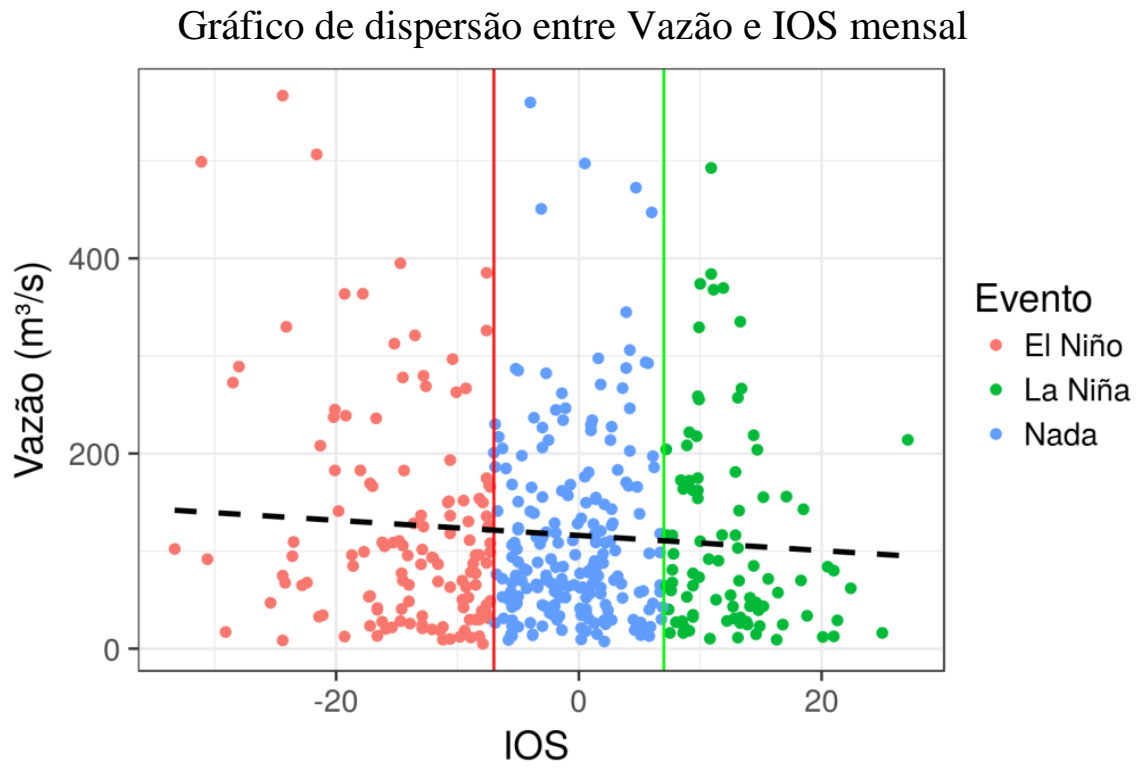

Autocorrelação com defasagem entre Vazão e IOS

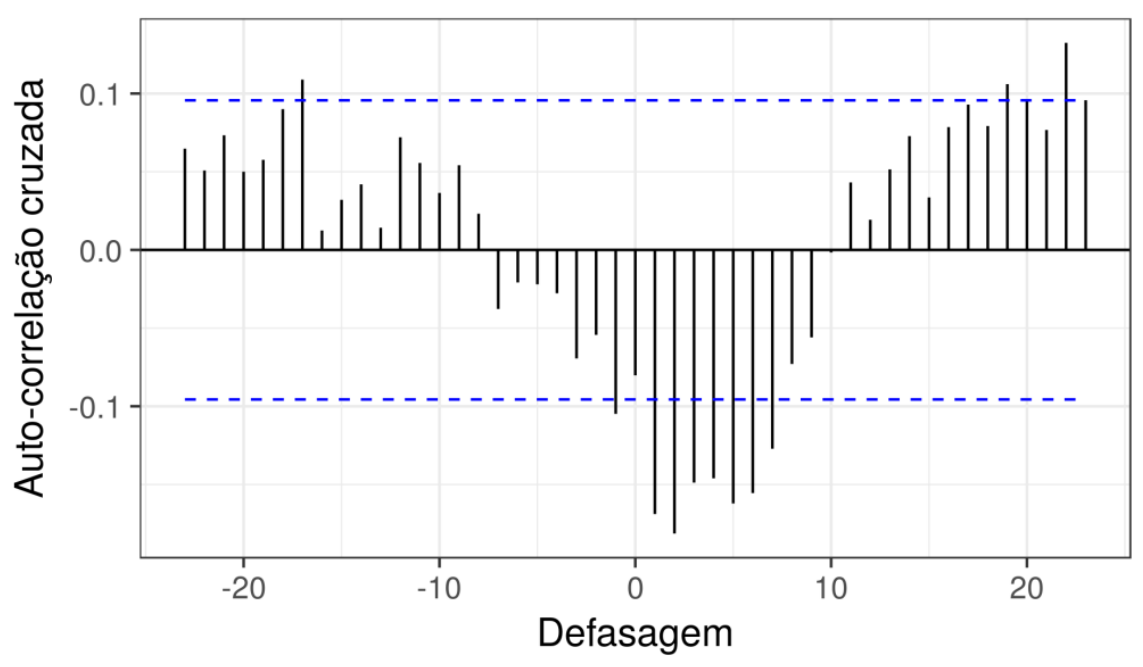

Gráfico de dispersão entre Vazão e IOS defasagem de 1 mês

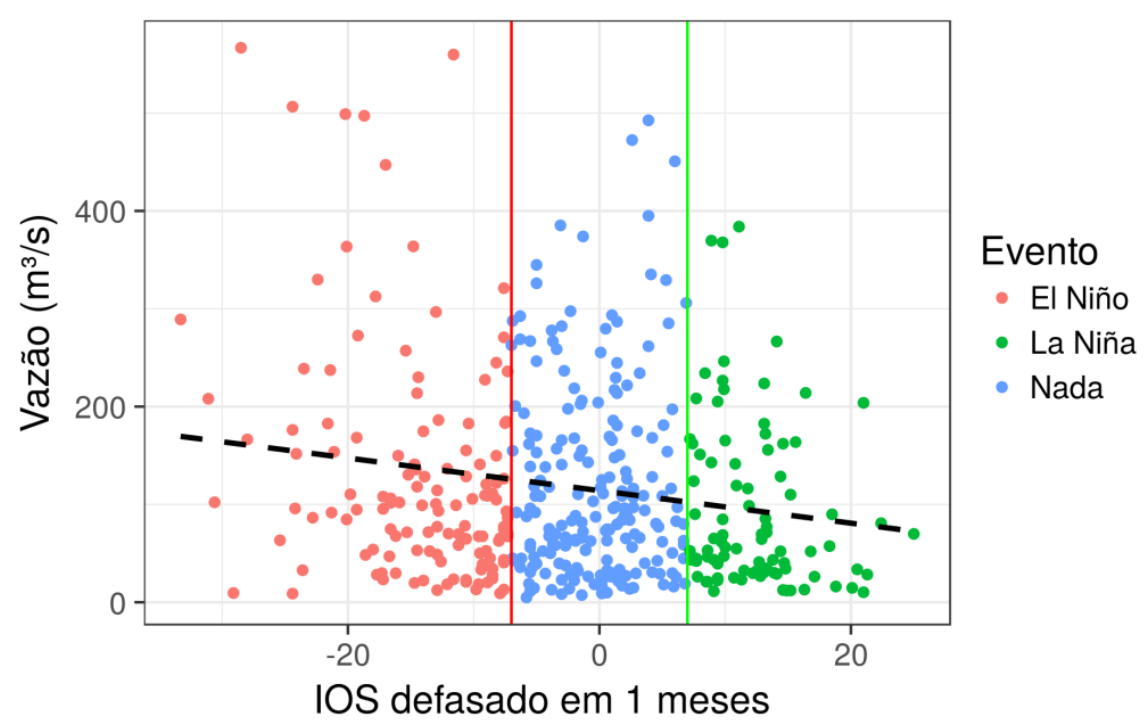

Figura 30: Gráficos de dispersão e autocorrelação com defasagem entre precipitação, vazão e IOS Para Área 2- Porto Guarani na bacia hidrográfica do rio Piquiri-PR Org.: Márcio Greyck Guimarães Correa (Com base no relatório desenvolvido por Alencar et al., 2016). 


\section{Área 3 - Balsa Santa Maria}

Gráfico de dispersão entre Precipitação e IOS mensal

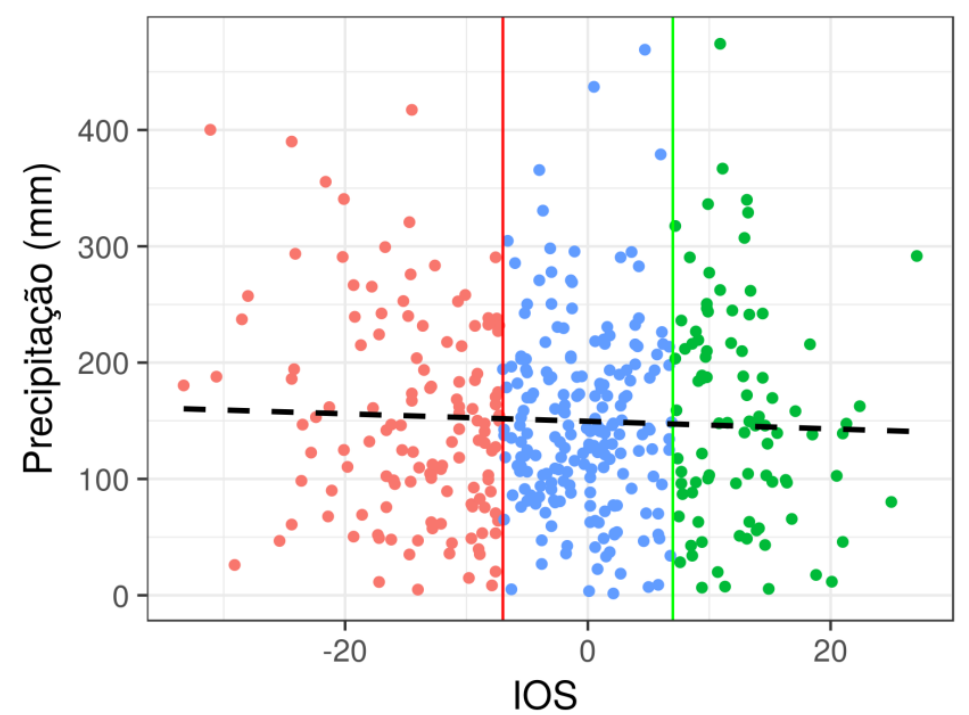

Autocorrelação com defasagem entre Precipitação e IOS

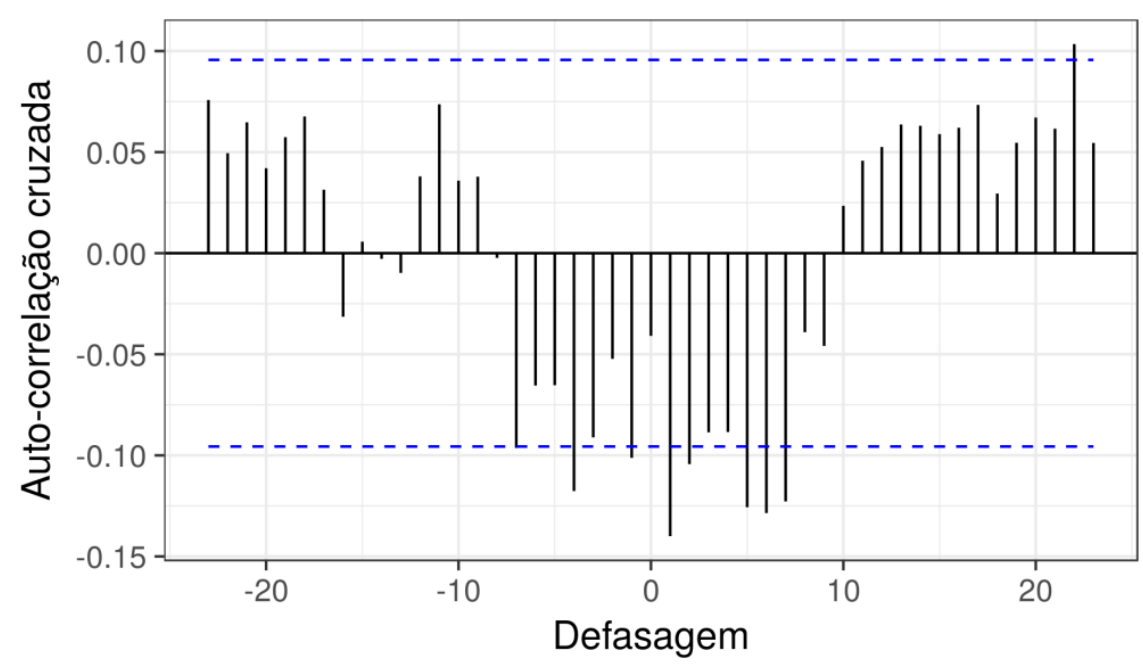

Gráfico de dispersão entre Precipitação e IOS defasagem de 1 mês

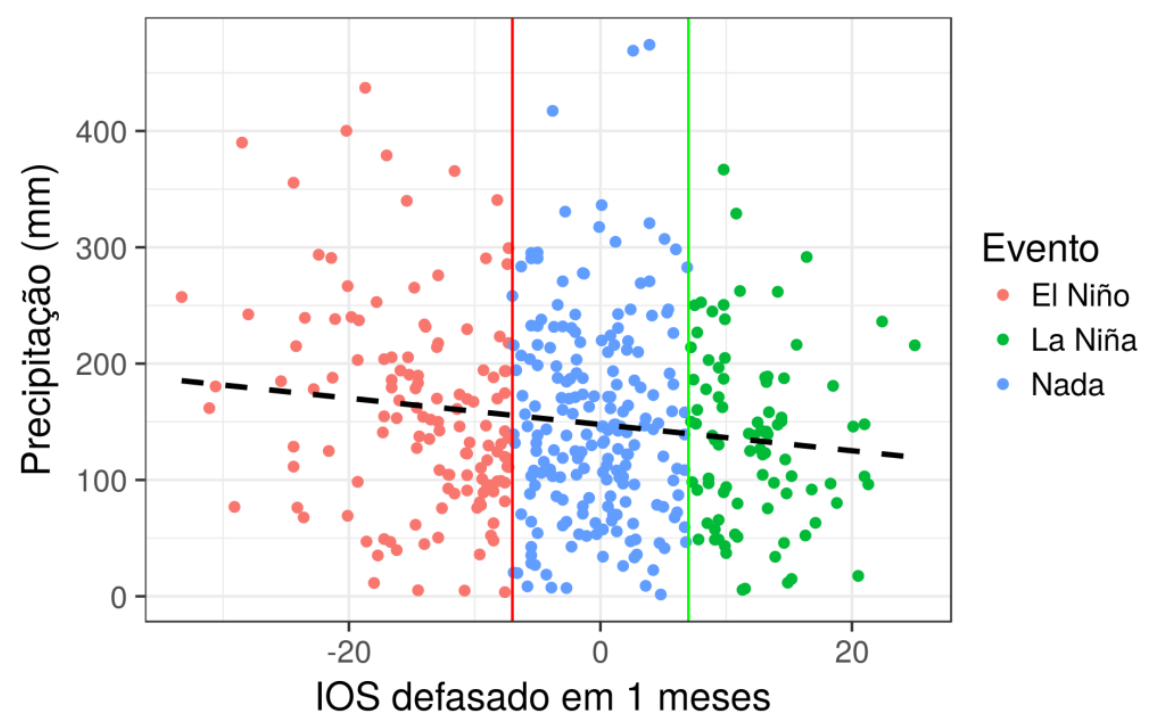

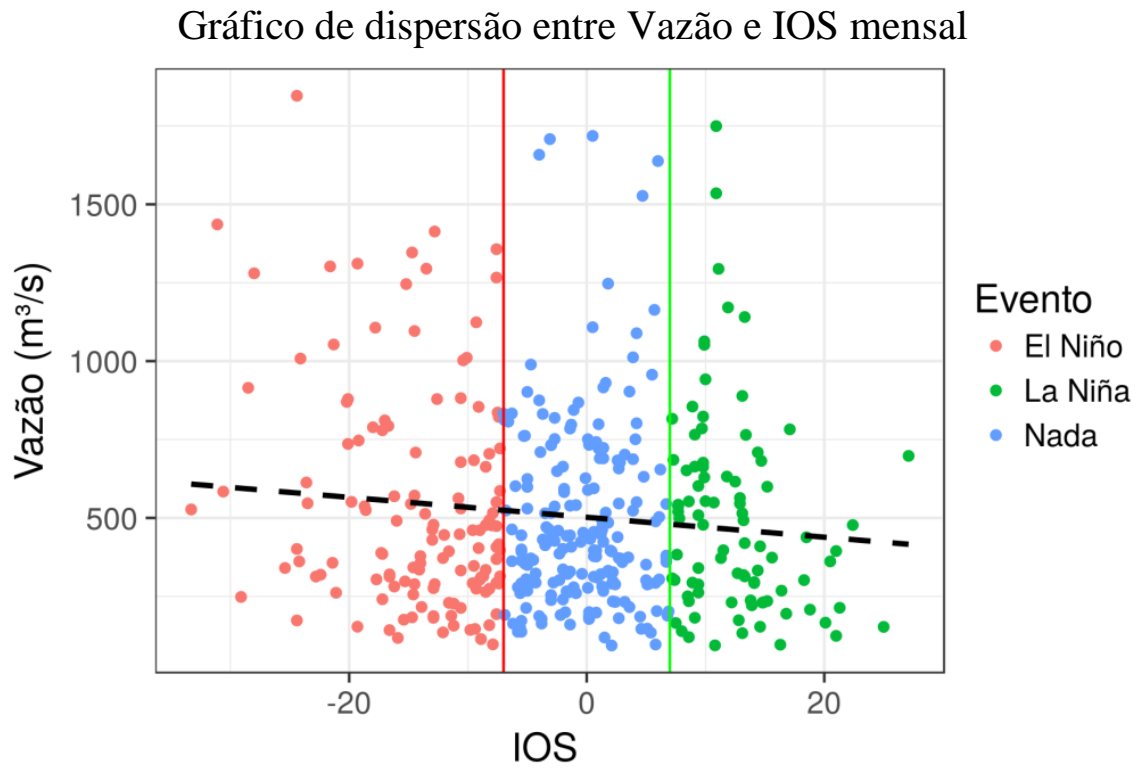

Autocorrelação com defasagem entre Vazão e IOS

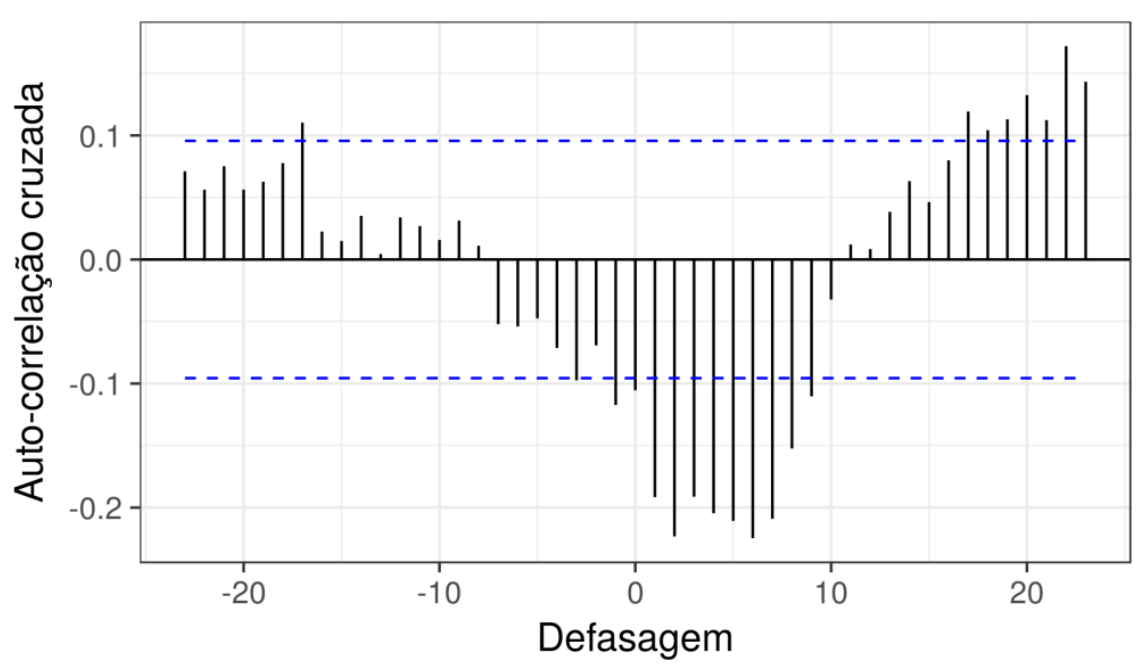

Gráfico de dispersão entre Vazão e IOS defasagem de 1 mês

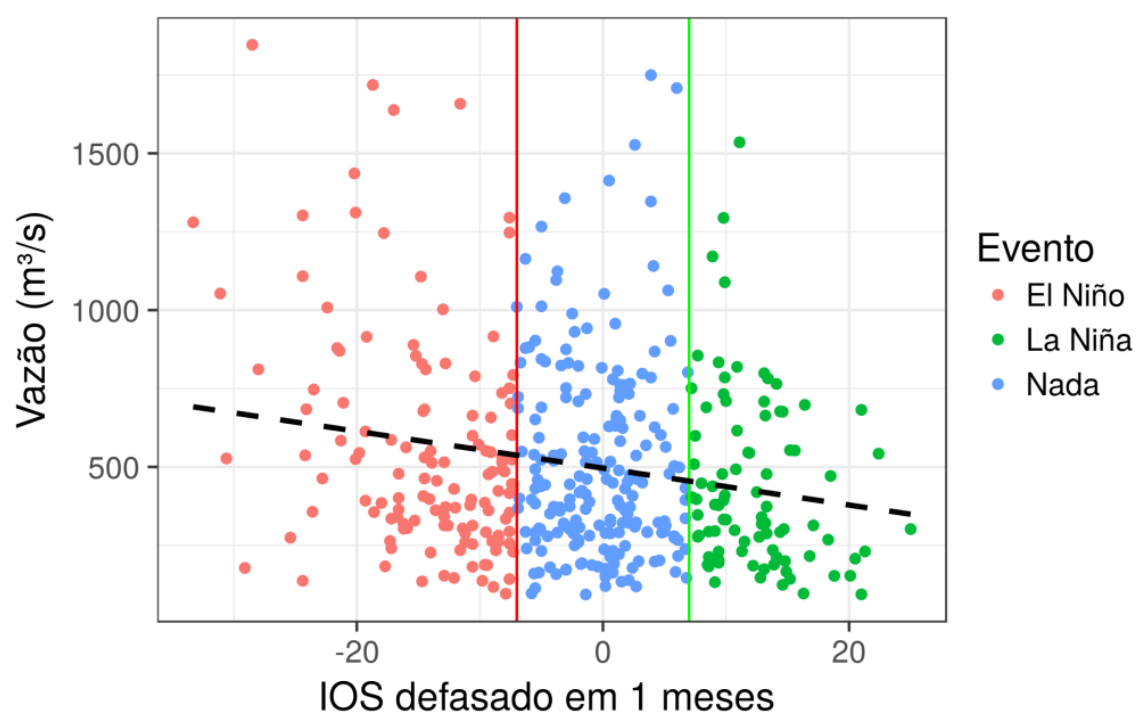

Figura 31: Gráficos de dispersão e autocorrelação com defasagem entre precipitação, vazão e IOS Para Área 3- Balsa Santa Maria na bacia hidrográfica do rio Piquiri-PR Org.: Márcio Greyck Guimarães Correa (Com base no relatório desenvolvido por Alencar et al., 2016). 


\subsubsection{Modelo inferencial para Precipitação}

Observando as Figura 32, Figura 33 e Figura 34 nota-se que as medidas de diagnóstico obtidas para esse modelo são satisfatórias, os resíduos padronizados estão normalmente distribuídos (dentro da área cinza), a dispersão dos dados se alinha à reta, demonstrando homocedasticidade, para A1 - Guampará, A2 - Porto Guarani e A3-Balsa Santa Maria.
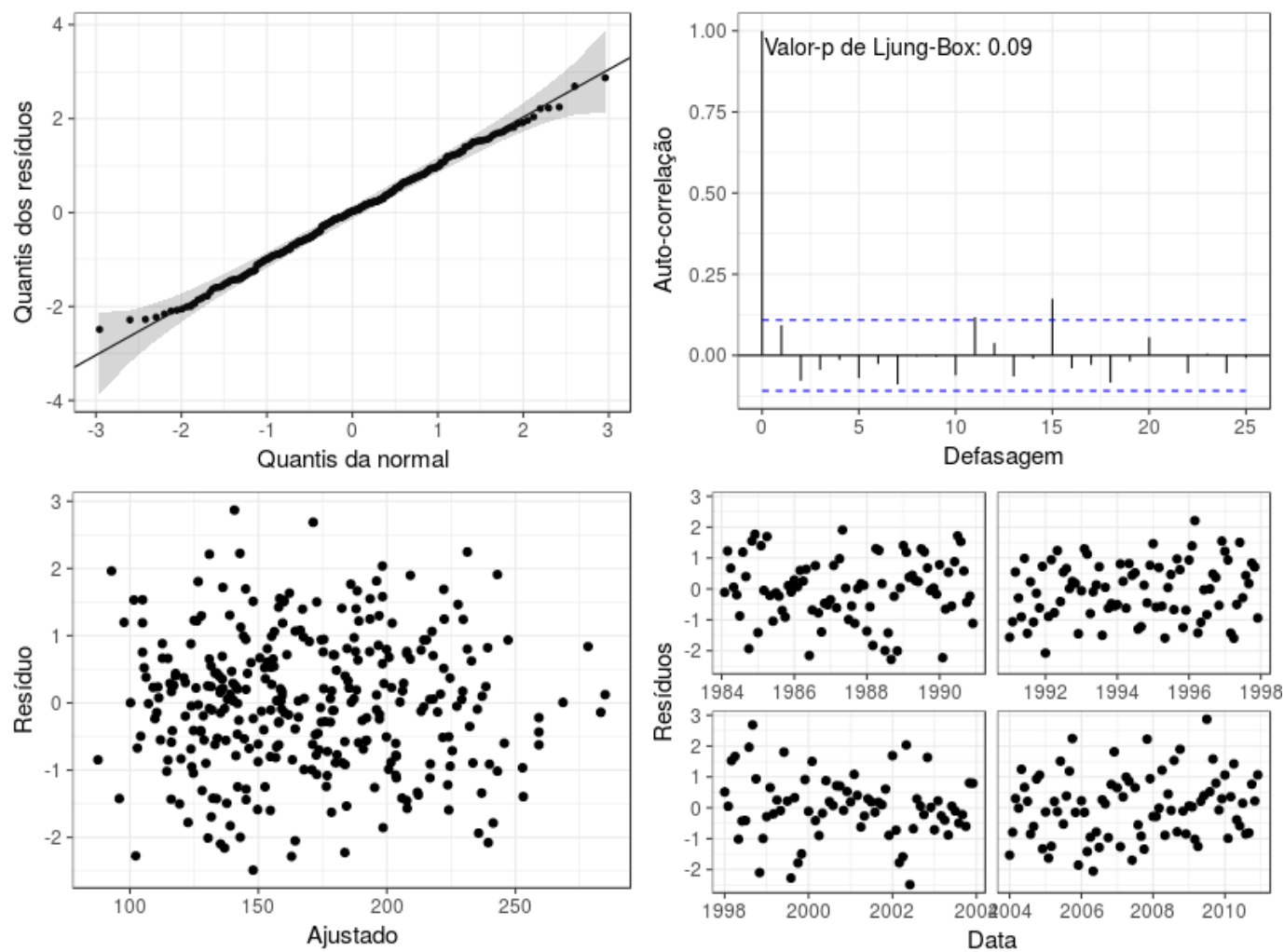

Figura 32: Análise de resíduos do modelo GAMLSS duplo com resposta gama generalizada ajustado para a variável precipitação em A1 - Guampará.

Org.: Márcio Greyck Guimarães Correa (Com base no relatório desenvolvido por Alencar et al., 2016). 

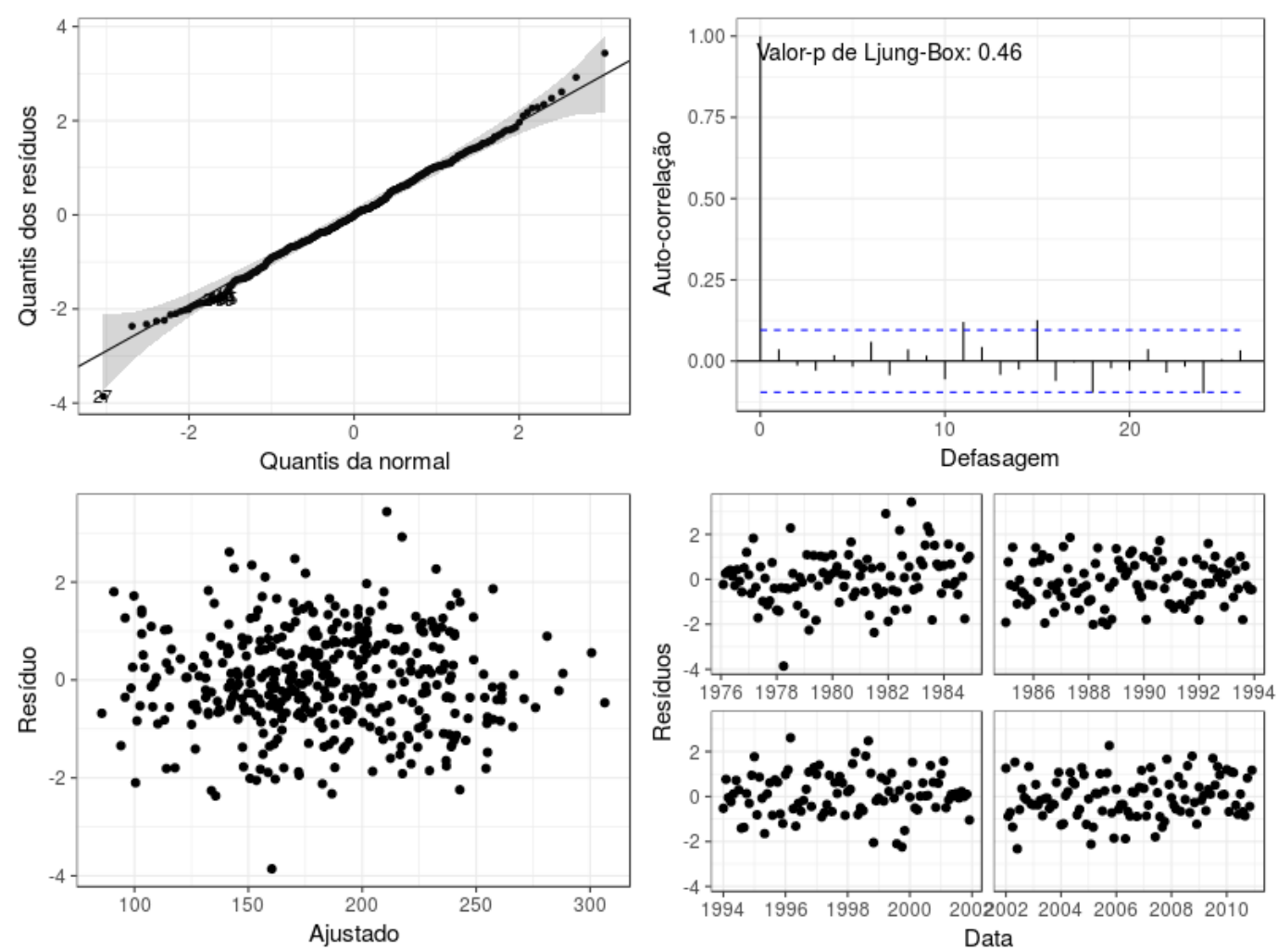

Figura 33: Análise de resíduos do modelo GAMLSS duplo com resposta gama generalizada ajustado para a variável precipitação em A2 - Porto Guarani.

Org.: Márcio Greyck Guimarães Correa (Com base no relatório desenvolvido por Alencar et al., 2016).
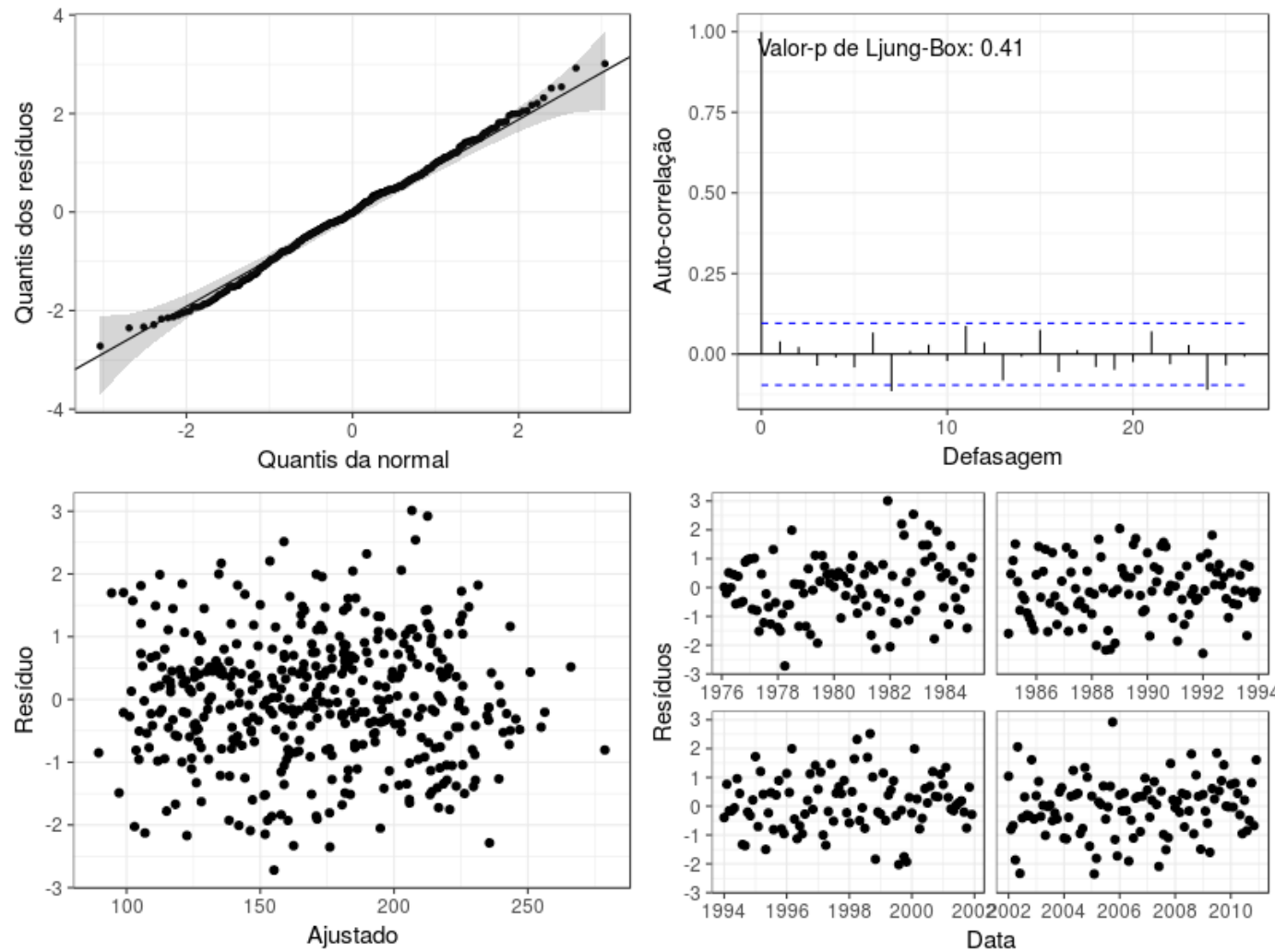
Figura 34: Análise de resíduos do modelo GAMLSS duplo com resposta gama generalizada ajustado para a variável precipitação em A3 - Balsa Santa Maria.

Org.: Márcio Greyck Guimarães Correa (Com base no relatório desenvolvido por Alencar et al., 2016).

As Tabelas 12, 13 e 14 mostram os parâmetros ajustados para a modelagem da média da precipitação no modelo GAMLSS com resposta Gama Generalizada para as três áreas de drenagem consideradas na pesquisa. Verifica-se uma redução estatisticamente significativa de $0,99 \%$ para A1, de $1,01 \%$ para A2 e de $0,89 \%$ para A3 na média da quantidade de chuvas para o aumento de uma unidade de IOS, ou seja, conforme aumenta uma unidade no IOS (tende a ser positivo - indicador da fase fria) a precipitação média diminui.

Com relação aos meses, verifica-se que os meses de março e abril e de junho a agosto tem média de precipitação entre $30 \%$ e $40 \%$ menor com relação à média da precipitação observada nos meses de janeiro. Para os demais meses, a variação identificada não foi significativa ao nível de $5 \%$.

Tabela 12 - Parâmetros ajustados para a modelagem da média da Precipitação no modelo GAMLSS com resposta Gama Generalizada para A1 - Guampará.

\begin{tabular}{crrrcc}
\hline Parâmetro & Estimativa & Erro padrão & Estatística t & Valor-p & Efeito \\
\hline$\mu$ & 5,3133 & 0,0722 & 73,5664 & $<0,0001$ & - \\
$\beta$ & $-0,0099$ & 0,0024 & $-4,0611$ & $<0,0001$ & $-00.99 \%$ \\
$\alpha$ Fev & $-0,1113$ & 0,1165 & $-0,9553$ & 0,3402 & $-10.53 \%$ \\
$\alpha$ Mar & $-0,4278$ & 0,0986 & $-4,3393$ & $<0,0001$ & $-34.81 \%$ \\
$\alpha$ Abr & $-0,3561$ & 0,1074 & $-3,3157$ & 0,0010 & $-29.96 \%$ \\
$\alpha$ Mai & $-0,0613$ & 0,1335 & $-0,4590$ & 0,6465 & $-05.95 \%$ \\
$\alpha$ Jun & $-0,4597$ & 0,1231 & $-3,7338$ & $<0,0001$ & $-36.85 \%$ \\
$\alpha$ Jul & $-0,3895$ & 0,1285 & $-3,0315$ & 0,0026 & $-32.26 \%$ \\
$\alpha$ Ago & $-0,6383$ & 0,1509 & $-4,2311$ & $<0,0001$ & $-47.18 \%$ \\
$\alpha$ Set & $-0,0729$ & 0,1321 & $-0,5522$ & 0,5812 & $-07.03 \%$ \\
$\alpha$ Out & 0,1690 & 0,1130 & 1,4959 & 0,1357 & $18.41 \%$ \\
$\alpha$ Nov & $-0,2984$ & 0,1052 & $-2,8377$ & 0,0048 & $-25.80 \%$ \\
$\alpha$ Dez & $-0,0492$ & 0,1115 & $-0,4410$ & 0,6595 & $-04.80 \%$ \\
\hline
\end{tabular}

Org.: Márcio Greyck Guimarães Correa (Com base no relatório desenvolvido por Alencar et al., 2016). 
Tabela 13 - Parâmetros ajustados para a modelagem da média da Precipitação no modelo GAMLSS com resposta Gama Generalizada para A2 - Porto Guarani.

\begin{tabular}{crrrcc}
\hline Parâmetro & Estimativa & Erro padrão & Estatística t & Valor-p & Efeito \\
\hline$\mu$ & 5,3687 & 0,0703 & 76,3253 & $<0,0001$ & - \\
$\beta$ & $-0,0102$ & 0,0022 & $-4,6665$ & $<0,0001$ & $-01,01 \%$ \\
$\alpha \mathrm{Fev}$ & $-0,1437$ & 0,1047 & $-1,3714$ & 0,1710 & $-13,39 \%$ \\
$\alpha \mathrm{Mar}$ & $-0,4043$ & 0,0914 & $-4,4222$ & $<0,0001$ & $-33,26 \%$ \\
$\alpha \mathrm{Abr}$ & $-0,3509$ & 0,1172 & $-2,9932$ & 0,0029 & $-29,59 \%$ \\
$\alpha \mathrm{Mai}$ & $-0,0663$ & 0,1244 & $-0,5332$ & 0,5942 & $-06,41 \%$ \\
$\alpha \mathrm{Jun}$ & $-0,2869$ & 0,1239 & $-2,3157$ & 0,0211 & $-24,94 \%$ \\
$\alpha \mathrm{Jul}$ & $-0,3418$ & 0,1252 & $-2,7300$ & 0,0066 & $-28,95 \%$ \\
$\alpha$ Ago & $-0,7099$ & 0,1361 & $-5,2153$ & $<0,0001$ & $-50,83 \%$ \\
$\alpha \mathrm{Set}$ & $-0,1307$ & 0,1185 & $-1,1031$ & 0,2706 & $-12,25 \%$ \\
$\alpha$ Out & 0,1195 & 0,1006 & 1,1884 & $0 ., 2354$ & $12,69 \%$ \\
$\alpha$ Nov & $-0,2236$ & 0,0982 & $-2,2776$ & 0,0233 & $-20,04 \%$ \\
$\alpha$ Dez & 0,0398 & 0,1045 & 0,3812 & 0,7033 & $04,06 \%$ \\
\hline
\end{tabular}

Org.: Márcio Greyck Guimarães Correa (Com base no relatório desenvolvido por Alencar et al., 2016).

Tabela 14- Parâmetros ajustados para a modelagem da média da Precipitação no modelo GAMLSS com resposta Gama Generalizada para A3 - Balsa Santa Maria.

\begin{tabular}{crrrcc}
\hline Parâmetro & Estimativa & Erro padrão & Estatística t & Valor-p & Efeito \\
\hline$\mu$ & 5,3141 & 0,0694 & 76,5497 & $<0,0001$ & - \\
$\beta$ & $-0,0089$ & 0,0021 & $-4,3253$ & $<0,0001$ & $-00,89 \%$ \\
$\alpha \mathrm{Fev}$ & $-0,1276$ & 0,1005 & $-1,2689$ & 0,2052 & $-11,98 \%$ \\
$\alpha \mathrm{Mar}$ & $-0,4029$ & 0,0878 & $-4,5908$ & $<0,0001$ & $-33,16 \%$ \\
$\alpha \mathrm{Abr}$ & $-0,3214$ & 0,1078 & $-2,9817$ & 0,0030 & $-27,49 \%$ \\
$\alpha \mathrm{Mai}$ & $-0,0360$ & 0,1187 & $-0,3032$ & 0,7619 & $-03,54 \%$ \\
$\alpha \mathrm{Jun}$ & $-0,3527$ & 0,1238 & $-2,8488$ & 0,0046 & $-29,72 \%$ \\
$\alpha \mathrm{Jul}$ & $-0,5403$ & 0,1183 & $-4,5666$ & $<0,0001$ & $-41,74 \%$ \\
$\alpha$ Ago & $-0,6370$ & 0,1415 & $-4,5002$ & $<0,0001$ & $-47,11 \%$ \\
$\alpha \mathrm{Set}$ & $-0,1593$ & 0,1143 & $-1,3936$ & 0,1642 & $-14,73 \%$ \\
$\alpha$ Out & 0,0796 & 0,0990 & 0,8043 & 0,4217 & $08,29 \%$ \\
$\alpha$ Nov & $-0,1560$ & 0,0938 & $-1,6618$ & 0,0973 & $-14,44 \%$ \\
$\alpha$ Dez & 0,0401 & 0,0989 & 0,4061 & 0,6849 & $04,09 \%$ \\
\hline
\end{tabular}

Org.: Márcio Greyck Guimarães Correa (Com base no relatório desenvolvido por Alencar et al., 2016).

As tabelas 15, 16 e 17 mostram os parâmetros ajustados para a modelagem da variância da precipitação no modelo GAMLSS com resposta Gama Generalizada para as três 
áreas de drenagem, observa-se que a variabilidade da precipitação nos meses de maio a setembro é maior do que a variabilidade da precipitação dos meses de janeiro.

Tabela 15- Parâmetros ajustados para a modelagem da variância da precipitação no modelo GAMLSS com resposta Gama Generalizada para A1 - Guampará

\begin{tabular}{crrrcc}
\hline Parâmetro & Estimativa & Erro padrão & Estatística t & Valor-p & Efeito \\
\hline$\tau$ & $-0,9996$ & 0,1274 & $-7,8453$ & $<0.0001$ & - \\
$\beta 2$ & 0,0001 & 0,0033 & 0,0222 & 0.9823 & $00,01 \%$ \\
$\gamma$ Fev & 0,2543 & 0,1751 & 1,4526 & 0.1473 & $28,96 \%$ \\
$\gamma$ Mar & $-0,0539$ & 0,1791 & $-0,3010$ & 0.7636 & $-05,25 \%$ \\
$\gamma$ Abr & 0,1134 & 0,1771 & 0,6401 & 0.5226 & $12,01 \%$ \\
$\gamma$ Mai & 0,4598 & 0,1721 & 2,6711 & 0.0080 & $58,38 \%$ \\
$\gamma$ Jun & 0,3392 & 0,1740 & 1,9492 & 0.0522 & $40,38 \%$ \\
$\gamma$ Jul & 0,4034 & 0,1731 & 2,3302 & 0.0204 & $49,69 \%$ \\
$\gamma$ Ago & 0,6253 & 0,1696 & 3,6859 & 0,0003 & $86,88 \%$ \\
$\gamma$ Set & 0,4445 & 0,1723 & 2,5792 & 0.0104 & $55,97 \%$ \\
$\gamma$ Out & 0,2031 & 0,1758 & 1,1554 & 0.2488 & $22,52 \%$ \\
$\gamma$ Nov & 0,0762 & 0,1775 & 0,4295 & 0.6678 & $07,92 \%$ \\
$\gamma$ Dez & 0,1798 & 0,1762 & 1,0202 & 0.3084 & $19,70 \%$ \\
\hline
\end{tabular}

Org.: Márcio Greyck Guimarães Correa (Com base no relatório desenvolvido por Alencar et al., 2016).

Tabela 16- Parâmetros ajustados para a modelagem da variância da precipitação no modelo GAMLSS com resposta Gama Generalizada para A2 - Porto Guarani

\begin{tabular}{crrrrc}
\hline Parâmetro & Estimativa & Erro padrão & Estatística t & Valor-p & Efeito \\
\hline$\tau$ & $-0,8897$ & 0,1113 & $-7,9929$ & $<0,0001$ & - \\
$\beta 2$ & 0,0021 & 0,0029 & 0,729 & 0,4664 & $00,21 \%$ \\
$\gamma$ Fev & 0,1131 & 0,1549 & 0,7303 & 0,4657 & $11,97 \%$ \\
$\gamma$ Mar & $-0,1666$ & 0,1578 & $-1,0557$ & 0,2917 & $-15,35 \%$ \\
$\gamma$ Abr & 0,3083 & 0,1525 & 2,0210 & 0,0439 & $36,11 \%$ \\
$\gamma$ Mai & 0,3984 & 0,1514 & 2,6319 & 0,0088 & $48,94 \%$ \\
$\gamma$ Jun & 0,3901 & 0,1513 & 2,5777 & 0,0103 & $47,71 \%$ \\
$\gamma$ Jul & 0,4074 & 0,1512 & 2,6939 & 0,0074 & $50,29 \%$ \\
$\gamma$ Ago & 0,5220 & 0,1496 & 3,4891 & 0,0005 & $68,54 \%$ \\
$\gamma$ Set & 0,3248 & 0,1523 & 2,1331 & 0,0335 & $38,38 \%$ \\
$\gamma$ Out & 0,0377 & 0,1557 & 0,2422 & 0,8088 & $03,84 \%$ \\
$\gamma$ Nov & $-0,0075$ & 0,1562 & $-0,0479$ & 0,9619 & $-00,75 \%$ \\
$\gamma$ Dez & 0,1097 & 0,1549 & 0,7083 & 0,4792 & $11,59 \%$ \\
\hline Org M M
\end{tabular}

Org.: Márcio Greyck Guimarães Correa (Com base no relatório desenvolvido por Alencar et al., 2016). 
Observando a tabela 17 que representa uma maior área de drenagem para a bacia hidrográfica do rio Piquiri, nota-se que para o parâmetro de dispersão da Precipitação $\left(\sigma_{t}\right)$, associado ao aumento na variância, não se verifica influência significativa proporcionada pelo IOS (valor- $p=78 \%$ ). Por outro lado, são significativos ao nível de $5 \%$ os aumentos de variabilidade identificados nos meses de maio a setembro.

A partir de maio observa-se um aumento de $40 \%$ na variabilidade da quantidade de chuvas com relação a variabilidade das chuvas nos meses de janeiro, mas este número chega a atingir $80 \%$ em agosto, com uma diminuição dessa discrepância no mês de setembro, último mês com variação significativa e em que o aumento estimado foi de 33,08\%.

Tabela 17 - Parâmetros ajustados para a modelagem da variância da precipitação no modelo GAMLSS com resposta Gama Generalizada para A3 - Balsa Santa Maria

\begin{tabular}{crrrcc}
\hline Parâmetro & Estimativa & Erro padrão & Estatística t & Valor-p & Efeito \\
\hline$\tau$ & $-0,9049$ & 0,1094 & $-8,2735$ & $<0,0001$ & - \\
$\beta 2$ & 0,0008 & 0,0029 & 0,2691 & 0,7880 & $00.08 \%$ \\
$\gamma$ Fev & 0,0620 & 0,1527 & 0,4057 & 0,6852 & $06.40 \%$ \\
$\gamma$ Mar & $-0,2387$ & 0,1560 & $-1,5298$ & 0,1268 & $-21023 \%$ \\
$\gamma$ Abr & 0,1895 & 0,1511 & 1,2540 & 0,2105 & $20,86 \%$ \\
$\gamma$ Mai & 0,3446 & 0,1491 & 2,3114 & 0,0213 & $41,14 \%$ \\
$\gamma$ Jun & 0,4067 & 0,1482 & 2,7446 & 0,0063 & $50,19 \%$ \\
$\gamma$ Jul & 0,3395 & 0,1491 & 2,2765 & 0,0233 & $40,42 \%$ \\
$\gamma$ Ago & 0,5912 & 0,1459 & 4,0510 & 0,0001 & $80,62 \%$ \\
$\gamma$ Set & 0,2858 & 0,1498 & 1,9073 & 0,0572 & $33,08 \%$ \\
$\gamma$ Out & 0,0331 & 0,1530 & 0,2160 & 0,8291 & $03,37 \%$ \\
$\gamma$ Nov & $-0,0766$ & 0,1543 & $-0,4961$ & 0,6201 & $-07,37 \%$ \\
$\gamma$ Dez & 0,0294 & 0,1531 & 0,1923 & 0,8476 & $02,98 \%$ \\
\hline
\end{tabular}

Org.: Márcio Greyck Guimarães Correa (Com base no relatório desenvolvido por Alencar et al., 2016). 


\subsubsection{Modelo inferencial para Vazão}

Conforme se verifica nas Figura 35Figura 36Figura 37, com a análise de resíduos do modelo de regressão linear ajustado para a vazão com transformação logarítmica na variável resposta e auto-correlação nos resíduos para as três áreas de drenagem, o modelo satisfaz todas as suposições com exceção da homocedasticidade.

Para as três áreas (A1, A2 e A3) observa-se na dispersão do canto inferior esquerdo que alguns valores ajustados maiores do que 7 sistematicamente apresentam resíduos negativos. Entretanto, a interpretação desse gráfico como um indício de heterocedasticidade não é confirmada pelo teste de Breusch-Pagan, que atribui à hipótese de homocedasticidade o nível descritivo de $78,13 \%$, indicando que não existe evidência suficientemente grande para rejeitar essa hipótese. O ajuste do modelo para a vazão não é tão eficiente como para a precipitação, porém como descrito anteriormente isso não anula o procedimento. 

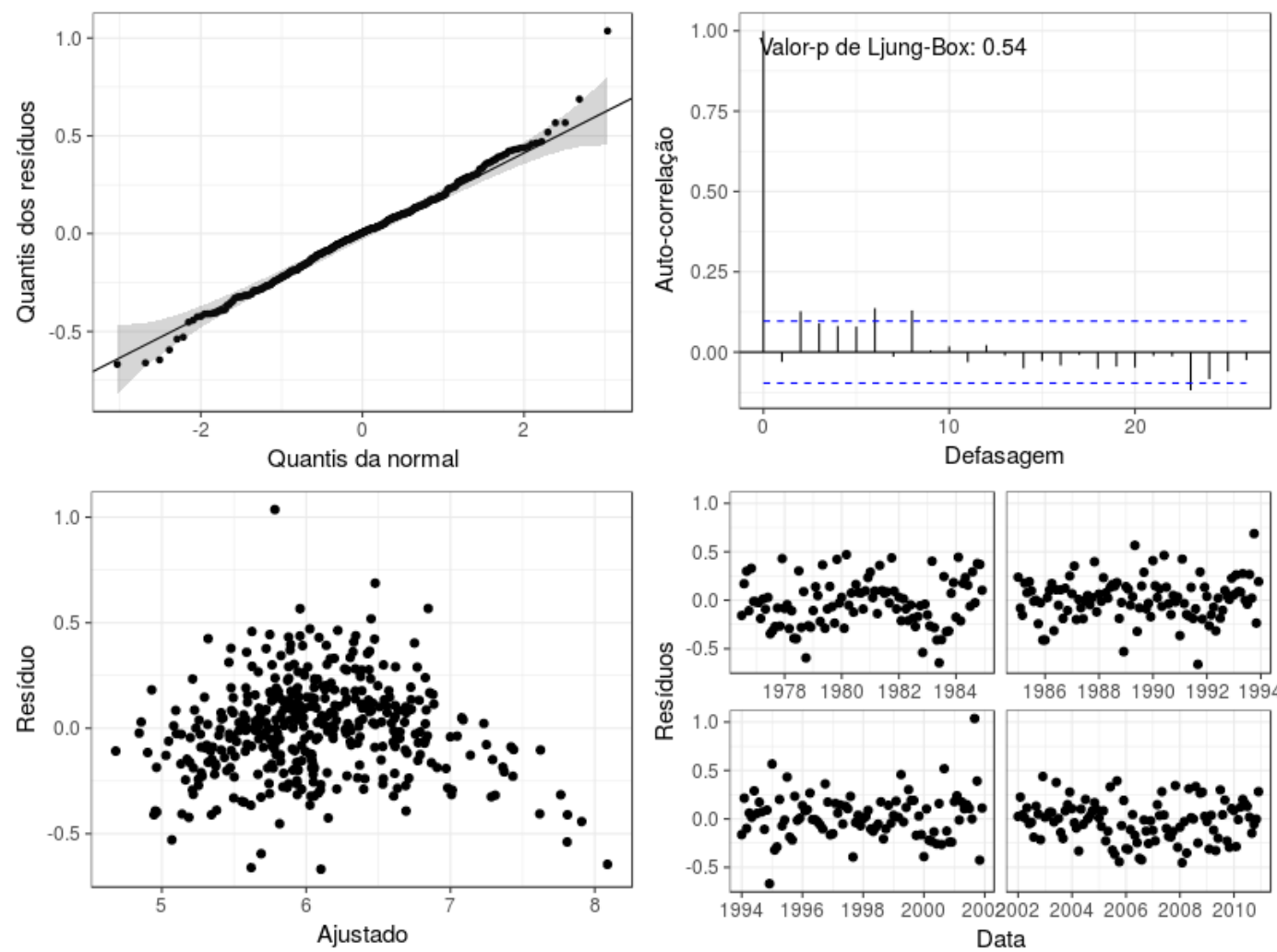

Figura 35: Análise de resíduos do modelo de regressão linear ajustado para a vazão com transformação logarítmica na variável resposta e auto-correlação nos resíduos para A1-Guampará.

Org.: Márcio Greyck Guimarães Correa (Com base no relatório desenvolvido por Alencar et al., 2016).
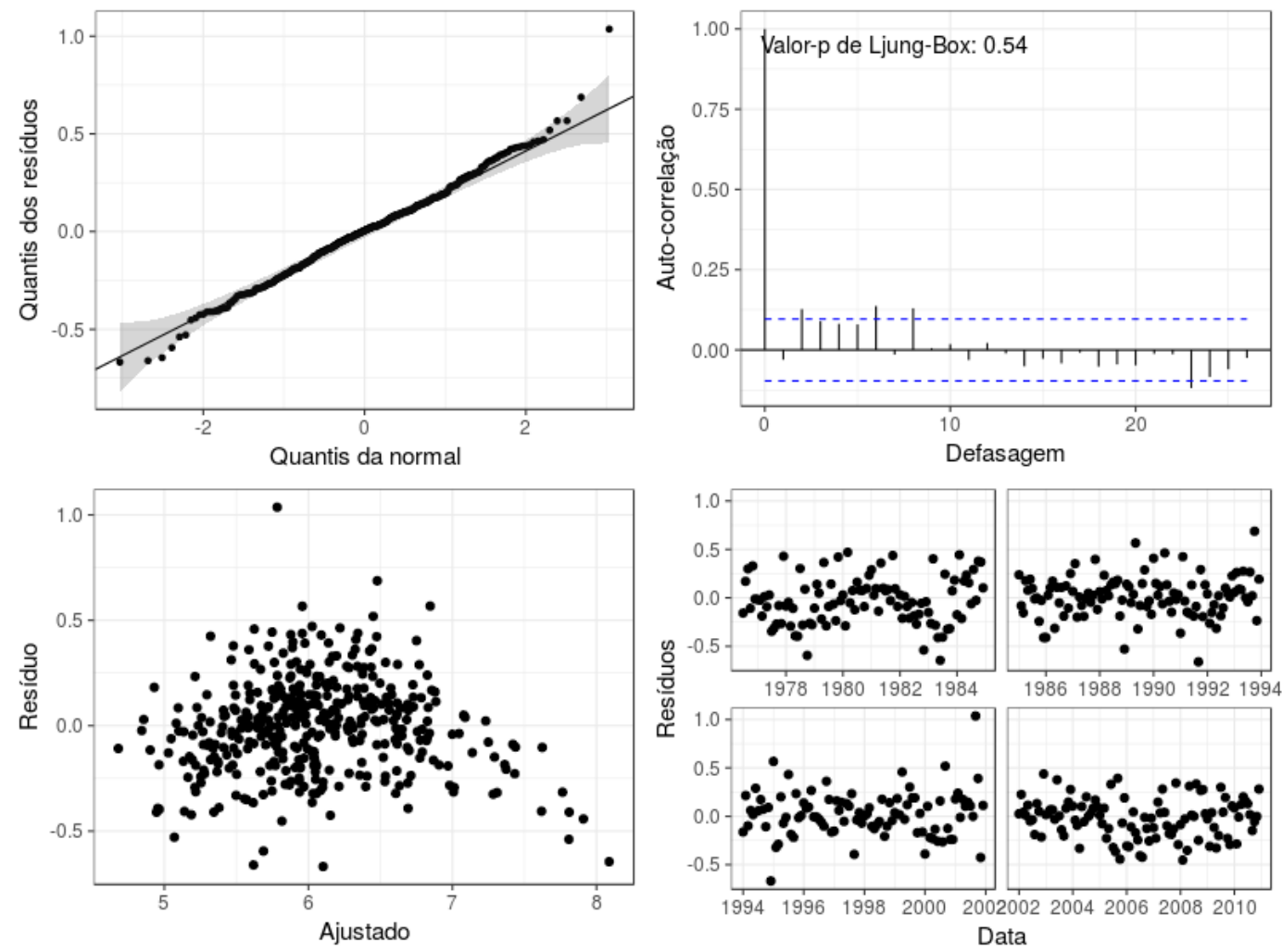

Figura 36: Análise de resíduos do modelo de regressão linear ajustado para a vazão com transformação logarítmica na variável resposta e auto-correlação nos resíduos para A2-Porto Guarani. 
Org.: Márcio Greyck Guimarães Correa (Com base no relatório desenvolvido por Alencar et al., 2016).
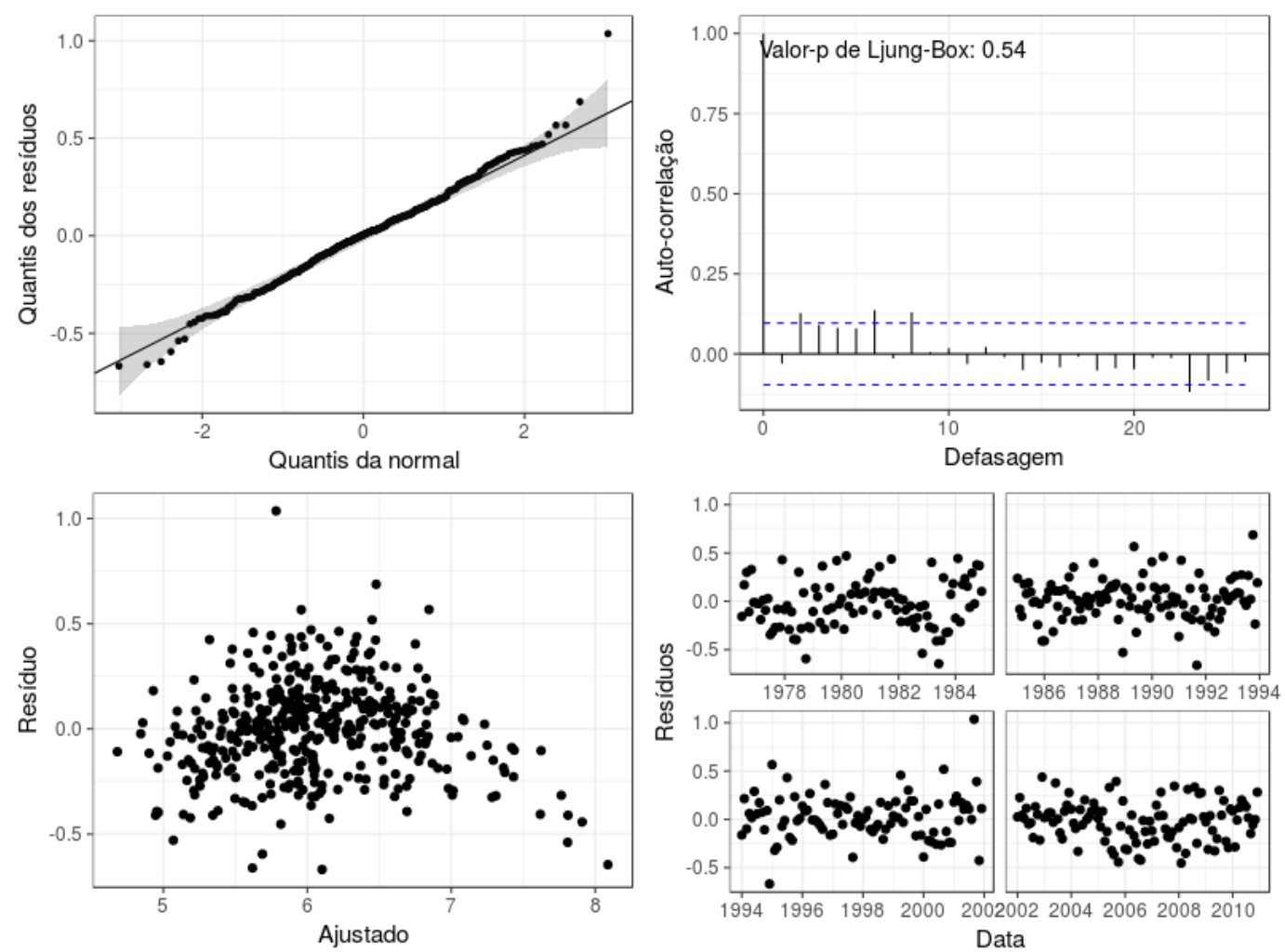

Figura 37: Análise de resíduos do modelo de regressão linear ajustado para a vazão com transformação logarítmica na variável resposta e auto-correlação nos resíduos para A3-Balsa Santa Maria.

Org.: Márcio Greyck Guimarães Correa (Com base no relatório desenvolvido por Alencar et al., 2016).

Analisando a Figura 38, é possível verificar que, embora a evidência a favor de heterocedasticidade não seja estatisticamente significativa, os pontos discrepantes do gráfico do canto inferior esquerdo das Figuras 34, 35 e 36 normalmente ocorrem ao mesmo tempo em que ocorrem as vazões mais intensas, indicando que ainda pode restar algo a ser explicado sobre essas ocorrências. De toda forma, do ponto de vista estatístico o modelo satisfaz os prérequisitos para produzir inferências. 


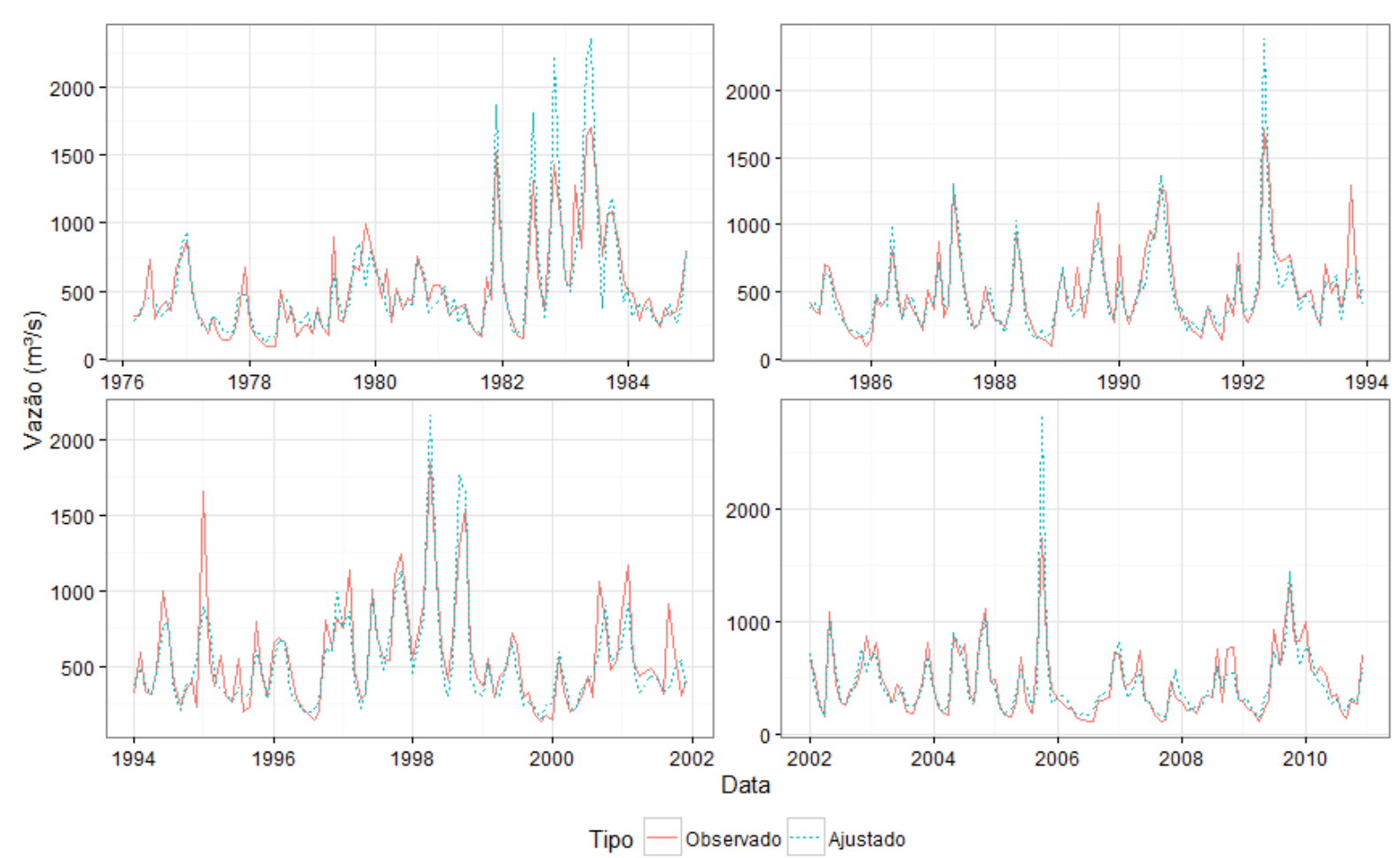

Figura 38: Valores ajustados preditos e valores observados pelo modelo de regressão com resíduos auto correlacionados para vazão para A3 - Balsa Santa Maria.

Org.: Márcio Greyck Guimarães Correa (Com base no relatório desenvolvido por Alencar et al., 2016).

As tabelas 18, 19 e 20 mostram os parâmetros ajustados para o modelo de regressão linear com erros correlacionados para vazão nas três áreas de drenagem (A1, A2 e A3), a interpretação dos parâmetros ajustados é compatível com os resultados esperados. A intepretação do impacto de cada variável é mais simples quando analisa-se os valores da coluna "Efeito", de onde conclui-se, por exemplo, que o aumento de uma unidade do IOS proporciona a redução da vazão média do mês seguinte em 0,21\% para A3 - Balsa Santa Maria (Tabela 20).

Observando ainda Tabela 20 para A3-Balsa Santa Maria, nota-se o contrário do que foi observado para precipitação, nos meses centrais do ano observa-se um aumento crescente da vazão até o mês de agosto, com declínio até o mês de dezembro, quando se estabiliza até começar a subir novamente em abril. 
Com relação aos coeficientes associados à precipitação $(\rho 0, \rho 1$ e $\rho 2)$, temos que esses parâmetros são significativamente diferentes de 0 , indicando que o controle da variável vazão por essa quantidade foi bem sucedido e que os demais efeitos podem ser considerados independentemente de suas associações com a variável precipitação.

Nos modelos de vazão, a inferência sobre a influência do IOS nas variáveis respostas muda de acordo com a bacia em estudo. Nas bacias de Guampará e Porto Guarani, Tabelas 18 e 19, conclui-se que não há efeito significativo de IOS na vazão controlada pela precipitação dos meses anteriores, pois os valores-p obtidos são $18 \%$ e $23 \%$, respectivamente. Já na bacia de Santa Maria, conforme mencionado anteriormente, o valor-p associado a essa quantidade foi de $3 \%$, abaixo do limiar de $5 \%$ usualmente adotado.

Tabela 18 - Parâmetros ajustados para o modelo de regressão linear com erros correlacionados para vazão da A1 - Guampará com transformação logarítmica.

\begin{tabular}{lrrrrc}
\hline Parâmetro & Estimativa & Erro padrão & Estatística t & Valor-p & Efeito \\
\hline$\varphi$ & 0,3715 & 0,0528 & 7,0416 & $<0.0001$ & $44,99 \%$ \\
$\mu$ & 1,6097 & 0,1332 & 12,0835 & $<0.0001$ & - \\
$\alpha$ Fev & 0,1434 & 0,0961 & 1,4929 & 0.0339 & $15,42 \%$ \\
$\alpha \mathrm{Mar}$ & 0,0065 & 0,1129 & 0,0579 & 0.2385 & $00,65 \%$ \\
$\alpha \mathrm{Abr}$ & 0,2549 & 0,1184 & 2,1522 & 0.0078 & $29,03 \%$ \\
$\alpha \mathrm{Mai}$ & 0,4697 & 0,1192 & 3,9419 & $<0.0001$ & $59,95 \%$ \\
$\alpha \mathrm{Jun}$ & 0,6956 & 0,1211 & 5,7427 & $<0.0001$ & $100,5 \%$ \\
$\alpha \mathrm{Jul}$ & 0,6742 & 0,1224 & 5,5089 & $<0.0001$ & $96,25 \%$ \\
$\alpha$ Ago & 0,6114 & 0,1251 & 4,8875 & $<0.0001$ & $84,30 \%$ \\
$\alpha$ Set & 0,3647 & 0,1221 & 2,9859 & 0,0007 & $44,01 \%$ \\
$\alpha$ Out & 0,2466 & 0,1174 & 2,1009 & 0.0089 & $27,97 \%$ \\
$\alpha$ Nov & 0,0340 & 0,1122 & 0,3031 & 0.1904 & $03,46 \%$ \\
$\alpha$ Dez & 0,0142 & 0,0971 & 0,1464 & 0.2209 & $01,43 \%$ \\
$\rho 0$ & 0,0065 & 0,0003 & 21,9005 & $<0.0001$ & $00,65 \%$ \\
$\rho 1$ & 0,0039 & 0,0003 & 13,0749 & $<0.0001$ & $00,39 \%$ \\
$\rho 2$ & 0,0013 & 0,0003 & 4,3420 & $<0.0001$ & $00,13 \%$ \\
$\beta$ & $-0,0009$ & 0,0027 & 0,3198 & 0.1873 & $-00,09 \%$ \\
\hline
\end{tabular}

Org.: Márcio Greyck Guimarães Correa (Com base no relatório desenvolvido por Alencar et al., 2016). 
Tabela 19 - Parâmetros ajustados para o modelo de regressão linear com erros correlacionados para vazão da A2 - Porto Guarani com transformação logarítmica.

\begin{tabular}{lrrrll}
\hline Parâmetro & Estimativa & Erro padrão & Estatística t & Valor-p & Efeito \\
\hline$\varphi$ & 0,431 & 0,0452 & 9,5407 & $<0.0001$ & $53,88 \%$ \\
$\mu$ & 1,9364 & 0,1247 & 15,5269 & $<0.0001$ & - \\
$\alpha \mathrm{Fev}$ & 0,1988 & 0,0836 & 2,3780 & 0.0044 & $21,99 \%$ \\
$\alpha \mathrm{Mar}$ & 0,0886 & 0,1004 & 0,8822 & 0.0944 & $09,26 \%$ \\
$\alpha \mathrm{Abr}$ & 0,2399 & 0,1077 & 2,2272 & 0.0065 & $27,11 \%$ \\
$\alpha \mathrm{Mai}$ & 0,4678 & 0,1093 & 4,2814 & $<0.0001$ & $59,65 \%$ \\
$\alpha \mathrm{Jun}$ & 0,7096 & 0,1098 & 6,4596 & $<0.0001$ & $103,3 \%$ \\
$\alpha \mathrm{Jul}$ & 0,8025 & 0,1113 & 7,2093 & $<0.0001$ & $123,1 \%$ \\
$\alpha$ Ago & 0,8156 & 0,1146 & 7,1183 & $<0.0001$ & $126,0 \%$ \\
$\alpha$ Set & 0,6061 & 0,1128 & 5,3722 & $<0.0001$ & $83,33 \%$ \\
$\alpha$ Out & 0,3782 & 0,1069 & 3,5393 & 0,0001 & $45,97 \%$ \\
$\alpha$ Nov & 0,2323 & 0,0991 & 2,3437 & 0.0048 & $26,15 \%$ \\
$\alpha$ Dez & 0,0875 & 0,0838 & 1,0440 & 0.0741 & $09,14 \%$ \\
$\rho 0$ & 0,0076 & 0,0002 & 32,3378 & $<0.0001$ & $00,76 \%$ \\
$\rho 1$ & 0,0040 & 0,0002 & 16,0473 & $<0.0001$ & $00,40 \%$ \\
$\rho 2$ & 0,0009 & 0,0002 & 4,0097 & $<0.0001$ & $00,09 \%$ \\
$\beta$ & $-0,0002$ & 0,0025 & 0,0682 & 0.2364 & $-00,02 \%$ \\
\hline
\end{tabular}

Org.: Márcio Greyck Guimarães Correa (Com base no relatório desenvolvido por Alencar et al., 2016).

Tabela 20 - Parâmetros ajustados para o modelo de regressão linear com erros correlacionados para vazão da A3 - Balsa Santa Maria com transformação logarítmica.

\begin{tabular}{lrrrrc}
\hline Parâmetro & Estimativa & Erro padrão & Estatística t & Valor-p & Efeito \\
\hline$\varphi$ & 0,3902 & 0,0490 & 7,9702 & $<0,0001$ & $47,73 \%$ \\
$\mu$ & 4,2717 & 0,0817 & 52,2622 & $<0,0001$ & - \\
$\alpha \mathrm{Fev}$ & 0,0770 & 0,0528 & 1,4579 & 0,0362 & $08,00 \%$ \\
$\alpha \mathrm{Mar}$ & 0,0457 & 0,0626 & 0,7294 & 0,1164 & $04,68 \%$ \\
$\alpha \mathrm{Abr}$ & 0,1185 & 0,0668 & 1,7745 & 0,0190 & $12,58 \%$ \\
$\alpha \mathrm{Mai}$ & 0,3069 & 0,0676 & 4,5388 & $<0,0001$ & $35,92 \%$ \\
$\alpha \mathrm{Jun}$ & 0,4311 & 0,0680 & 6,3376 & $<0,0001$ & $53,89 \%$ \\
$\alpha \mathrm{Jul}$ & 0,5769 & 0,0698 & 8,2621 & $<0,0001$ & $78,05 \%$ \\
$\alpha \mathrm{Ago}$ & 0,5844 & 0,0727 & 8,0405 & $<0,0001$ & $79,39 \%$ \\
$\alpha \mathrm{Set}$ & 0,4775 & 0,0716 & 6,6709 & $<0,0001$ & $61,20 \%$ \\
$\alpha$ Out & 0,3090 & 0,0672 & 4,5974 & $<0,0001$ & $36,21 \%$ \\
$\alpha \mathrm{Nov}$ & 0,1287 & 0,0618 & 2,0829 & 0,0093 & $13,73 \%$ \\
$\alpha \mathrm{Dez}$ & 0,0745 & 0,0526 & 1,4153 & 0,0392 & $07,73 \%$ \\
$\rho 0$ & 0,0050 & 0,0002 & 29,453 & $<0,0001$ & $00,50 \%$ \\
$\rho 1$ & 0,0036 & 0,0002 & 19,987 & $<0,0001$ & $00,36 \%$ \\
$\rho 2$ & 0,0015 & 0,0002 & 8,0094 & $<0,0001$ & $00,15 \%$
\end{tabular}




\begin{tabular}{llllll}
$\beta$ & $-0,0021$ & 0,0015 & 1,4164 & 0,0392 & $-00,21 \%$ \\
\hline
\end{tabular}

Org.: Márcio Greyck Guimarães Correa (Com base no relatório desenvolvido por Alencar et al., 2016).

\subsection{Considerações sobre ENOS na bacia hidrográfica do rio Piquiri}

As correlações mostraram que o IOS influencia a precipitação e a vazão na bacia hidrográfica do rio Piquiri, com maior confiança, de um a três meses de defasagem. Os gráficos de dispersão indicaram menor variação da vazão com um mês de defasagem, fato que também pode ser observado pela maior inclinação da reta, e a precipitação apresentou maior variação e dispersão dos dados.

O modelo GAMLSS se mostrou satisfatório para a determinação da influência do IOS nas variáveis precipitação e vazão. A análise dos resíduos apresentou-se dentro do esperado, e para a precipitação conclui-se que conforme aumenta uma unidade no IOS (tende a ser positivo - indicador da fase fria) a precipitação média diminui $1 \%$.

Para a vazão o modelo apresentou-se menos eficiente, isso porque o impacto do fenômeno ENOS na vazão média acontece apenas através da sua influência na precipitação média, porém não há necessidade de descartá-lo, apesar dos resíduos não apresentarem a homocedasticidade esperada, os resíduos discrepantes normalmente ocorrem ao mesmo tempo em que ocorrem as vazões mais intensas, do ponto de vista estatístico o modelo satisfaz os pré-requisitos para produzir inferências.

Os coeficientes mostraram alta dependência da vazão com relação à precipitação. A área de drenagem A3 - Balsa Santa Maria apresentou resultados mais significativos na influência do IOS na vazão controlada pela precipitação dos meses anteriores, indicando que o aumento de uma unidade do IOS proporciona a redução da vazão média do mês seguinte em $0,21 \%$. 


\section{CONCLUSÃO}

O desenvolvimento da tese proporcionou alcançar os objetivos propostos. A análise estatística da precipitação e da vazão corroborou para a descrição das condições hidroclimáticas da bacia hidrográfica em questão, sobre esses aspectos é importante ressaltar:

- Precipitação média anual de $1762,5 \mathrm{~mm}$, tendo como o ano mais chuvoso 1983 e o ano menos chuvoso foi 1988. A primavera e o verão apresentam-se como os mais chuvosos enquanto outono e inverno como menos chuvosos e com maior coeficiente de variação, desvio padrão e amplitude. Outubro é o mês mais chuvosos e agosto o menos chuvoso. A variabilidade mensal da precipitação é maior que a variabilidade sazonal e anual.

- A vazão média anual é de $6101,1 \mathrm{~m}^{3} \cdot \mathrm{s}^{-1}$. O outono e a primavera apresentam as maiores vazões médias e o verão e o inverno as menores. Outubro é o mês com maior vazão e março com menor vazão média. Assim como ocorre na precipitação, a variabilidade mensal da vazão é maior que a variabilidade sazonal e anual.

- Os gráficos boxplots mostraram que maio apresenta uma grande variabilidade da precipitação e outubro é o mês com maior variabilidade para a vazão. As funções de autocorrelação indicaram que a defasagem entre precipitação e vazão fluvial na bacia hidrográfica do rio Piquiri deve ser inferior a um mês, na escala de semanas ou dias.

- O coeficiente de escoamento mostrou que de toda a chuva precipitada na bacia hidrográfica do rio Piquiri, em média, $43 \%$ é transformada em vazão, o restante, $57 \%$ pode ser estimado entre evapotranspiração e infiltração. 
A diferença entre o mês com menor precipitação e o mês com menor vazão (agosto e março respectivamente) pode ser explicada pelo fato de que durante março (final do verão) a elevada radiação, temperatura média do ar e a diminuição das chuvas aumentam os valores médios de evapotranspiração (ETP), diferente de agosto, que apesar de ter uma diminuição considerável nas medias pluviométricas com relação aos outros meses, a temperatura média do ar ainda é baixa (final do inverno) e os valores de ETP tendem a ser menores.

A vazão não é apenas resultante da precipitação, mas os processos de evapotranspiração e infiltração também influenciam na sua variabilidade. O funcionamento hidroclimático da bacia hidrográfica do rio Piquiri evidencia essa inter-relação entre as variáveis.

Com relação à influência do fenômeno ENOS, as correlações mostraram que o IOS influencia a precipitação e a vazão na bacia hidrográfica do rio Piquiri, com maior confiança, de um a três meses de defasagem.

O modelo GAMLSS se mostrou satisfatório para a determinação da influência do IOS nas variáveis precipitação e vazão. Para a precipitação conclui-se com maior confiabilidade que conforme aumenta uma unidade no IOS a precipitação média diminui 1\%, para a vazão o aumento de uma unidade do IOS proporciona a redução da vazão média do mês seguinte em $0,21 \%$.

A determinação da influência do IOS na vazão apresentou-se mais difícil de constatar, novamente, há de se considerar que esta variável é resultante de processos que não envolvem apenas a precipitação, e os processos de evapotranspiração e infiltração não foram considerados na modelagem estatística utilizada. Contudo pode-se concluir que o fenômeno ENOS exerce influência sobre a dinâmica hidroclimática da bacia hidrográfica do rio Piquiri. 


\section{REFERÊNCIAS}

AGÊNCIA NACIONAL DE ÁGUAS. Orientações para elaboração do relatório de instalação de estações hidrométricas. Brasília: ANA, SGH, 2011.

AGUIAR, A. M. Análises hidrogeomorfológicas e hidrossedimentológicas para comparação de duas bacias hidrográficas contribuintes do reservatório de Itaipu. 2009. Dissertação (Mestrado em Geografia Física) - Faculdade de Filosofia, Letras e Ciências Humanas, Universidade de São Paulo, São Paulo, 2009.

ALENCAR, A. P., CORRÊA, F. P. T., ALBARRACIN, O. Y. E. e CAMPOS, R. H. Análise Estatística sobre o Projeto: "Dinâmica hidroclimática e o fenômeno ENOS na bacia hidrográfica do Rio Piquiri - PR”. São Paulo, IME-USP. 2016.

AMARASEKERA, K. N.; LEE, R. F.; WILLIAMS, E. R; ELTAHIR, A. B. ENSO and the natural variability in the flow of tropical rivers. Journal of Hydrology. n.200. 1997.

AMBRIZZI, T. El Niño/La Niña; Teleconexão Atmosférica. Livre-docência. IAG/USP, 2003.

AMBRIZZI, T.; SACCO, M. A. L.; FERRAZ, S. E. T. A importância das teleconexões para a previsão sazonal. Ciência e Natura, v. 36, p. 137-148, 2014.

AMBRIZZI, T.; SOUZA, E. B.; PULWARTY, R. S. The Hadley and Walker regional circulations and associated ENSO impacts on the South American Seasonal Rainfall. In: HENRY, F. D.; RAYMOND S. B. (Orgs.). The Hadley Circulation: Present, Past and Future. 1ed. Netherlands: Kluwer Academic Publishers, 2004, v. 21, p. 203-235.

ANDRADE, D. F.; OGLIARI, P. J. Estatística para ciências agrárias e biológicas com noções de experimentações. Florianópolis: Ed. Da UFSC, 2007, 432 p.

ÅNGSTRÖM, A. Teleconnections of climate changes in present time. Geography Annals, v. 17, p 242- 258, 1935.

AZEVEDO, L.C. Análise da Precipitação Pluvial da Bacia do Rio Iguaçu - Paraná. 2006. 123f. Dissertação (Mestrado). Programa de Pós-Graduação em Geografia. Universidade Estadual de Maringá, Maringá, 2006.

BALDO, M.C. Variabilidade Pluviométrica e a Dinâmica Atmosférica da Bacia do Rio Ivaí. 2006. 153 f. Tese (Doutorado). Programa de Pós-Graduação em Geografia. Universidade Estadual Paulista "Júlio de Mesquita Filho", Presidente Prudente, 2006.

BERLATO, M. A.; FONTANA, D. C. EI Niño e La Niña: impactos no clima, na vegetação e na agricultura do Rio Grande do Sul; aplicações e previsões climáticas na agricultura. Porto Alegre: Editora da UFRGS, 2003. 
BERTONI, J. C.; TUCCI, C. E. M. Precipitação. In: TUCCI, C. E. M. Hidrologia: Ciência e aplicação. Porto Alegre: Ed. da Universidade - UFRGS, ABRH, 2001.

BERTRAND, G.; BEROUTCHACHVILI, N. Le géosystéme ou système territorial naturel (1978). Une géograpnie traversière: l'environment à travers territoires et temporalités. Paris: Éditions l'Arguments, 2002.

BJERKNES, J. Atmospheric teleconnections from the equatorial Pacific. Monthly Weather Review, v. 97, n. 3, p. 163-172, 1969.

BOX, G.E.P.; JENKINS, G.M. Time Series Analysis: Forecasting and Control. San Francisco: Holden-Day, 1970.

BRITTO, P. F.; BARLETTA, R.; MENDONÇA, M. Variabilidade especial e temporal da precipitação pluvial no Rio Grande do Sul: Influencia do fenômeno El Niño Oscilação Sul. Revista Brasileira de Climatologia, v. 3, 2011.

CAMILLONI, I. A.; BARROS, V. R. Extreme discharge events in the Paraná River and their climate forcing. Journal of Hydrology, n. 278. 2003.

CHEVAlLIER, P. Aquisição e processamento de dados In: TUCCI, C. E. M. Hidrologia: Ciência e aplicação. Porto Alegre: Ed. da Universidade - UFRGS, ABRH, 2001.

CHORLEY, R. J. Geomorphology and General Systems Theory. General Systems, 9, p. 45$56,1964$.

CHRISTOFOLETTI, A. A aplicação da abordagem em sistemas na geografia física. Revista Brasileira de Geografia. Rio de Janeiro, v. 52, n. 2, 1990.

CHRISTOPHERSON, R. W. Geossistemas: uma introdução à geografia física. Porto Alegre: Bookman, 2012.

COELHO, C. A. S.; UVO, C. B.; AMBRIZZI, T. Exploring the impacts of the Tropical Pacific SST on the precipitation patterns over South America during ENSO periods. Theoretical and Applied Climatology, Austria, v. 71, p. 185-197, 2002.

CONTI, J. B. Circulação secundária e o efeito orográfico na gênese das chuvas na região lesnordeste paulista. 1975. Tese (Doutorado em Geografia) - Faculdade de Filosofia, Letras e Ciências Humanas, Universidade de São Paulo, São Paulo, 1975.

CONTI, J. B. Desertificação nos trópicos: proposta de metodologia de estudo aplicada ao nordeste brasileiro. 1995. Livre Docência. Faculdade de Filosofia, Letras e Ciências Humanas, Universidade de São Paulo, São Paulo, 1995.

CORREA, M. G. G. Distribuição espacial e variabilidade da precipitação pluviométrica na bacia do rio Piquiri-PR. 2013. Dissertação (Mestrado em Geografia) - Faculdade de Filosofia, Letras e Ciências Humanas, Universidade de São Paulo, São Paulo, 2013. 
CORREA, M. G. G.; GALVANI, E. Evaluation de l'effet orographique dans le bassin versant du Piquiri - Paraná/Brésil. In: XXIX Colloque de l'Association Internationale de Climatologie. Besançon: Climat et pollution de l'air, 2016.

DOWNING, D.; CLARK, J. Estatística Aplicada. São Paulo: Editora Saraiva, 2000.

EHLERS, R.S. Análise de Séries Temporais. Departamento de Estatística, UFPR. 2005. Disponível em http://www.each.usp.br/rvicente/AnaliseDeSeriesTemporais.pdf. Acesso em 10 de maio de 2017.

ESPINOZA VILLAR, J. C.; RONCHAIL, J.; GUYOT, J. L.; COCHONNEAU, G.; NAZIANO, F.; LAVADO, W.; DE OLIVEIRA, E.; POMBOSA, R.; VAUCHEL, P. Spatiotemporal rainfall variability in the Amazon basin countries (Brazil, Peru, Bolivia, Colombia, and Ecuador). Int. J. Climatol. n.29. 2009.

FERREIRA, A. G. Meteorologia prática. São Paulo: Oficina de Textos, 2006.

FREITAS, A. C. V.; AMBRIZZI, T. Changes in the Austral Winter Hadley Circulation and the Impact on Stationary Rossby Waves Propagation. Advances in Meteorology, v. 2012, p. $1-15,2012$.

GALVANI, E. Estatística descritiva em sala de aula. In: VENTURI, L. A. B. Geografia: Práticas de campo, laboratório e sala de aula. São Paulo: Editora Sarandi, 2011.

GOOSSENS, C.; BERGER, A. Annual and seasonal climatic variations over the northem hemisphere and Europe during the last century. Annales Geophysicae, Berlin, v.4, n.B4, 1986.

GRIMM, A.M.; BARROS, V.R.; DOYLE, M.E. Climate variability in Southern South America associated with El Niño and La Niña events. Journal of Climate, v.13, p.35-58, 2000 .

HARZALLAH, A.; ROCHA DE ARAGÃO, J. O.; SADOURNY, R. Interannual rainfall variability in North-East Brazil: Observation and model simulation. Int. J. Climatol., 16: 861-878, 1996.

HEWLETT, J.D.; HIBBERT, A.R. Factors affecting the response of small watersheds to precipitation in humid areas. In: SOPPER, W.E.; LULL, H.W. Forest hydrology. New York: Pergamon Press. 1967.

HEYMANN, M. The evolution of climate ideas and knowledge. Wiley Interdisciplinary Reviews: Climate Change. v.1, 2010.

KAROLY, D.J. Southern Hemisphere circulation features associated with El Niño-Southern Oscillation events. Journal Climate. v. 2, 1239-1252. 1989.

KÖPPEN, W. Climatologia: com un estúdio de los climas de la tierra. México. Ed. Fondo de Cultura Econômica, 1948. 
LANGBEIN, W. G. Hydroclimate. In: The Encyclopedia of Atmospheric Sciences and Astrogeology, ed. R. W. Fairbridge. New York, NY: Reinhold, pp. 447-51, 1967.

LANNA, A. E. Elementos de Estatística e probabilidades. In: TUCCI, C. E. M. Hidrologia: Ciência e aplicação. Porto Alegre: Ed. da Universidade - UFRGS, ABRH, 2001.

LIMBERGER, L.; SILVA, M. E. S. Precipitação na bacia amazônica e sua associação à variabilidade da temperatura da superfície dos oceanos Pacífico e Atlântico: uma revisão. GEOUSP: Espaço e Tempo. São Paulo, v. 20, n. 3, p. 657-675, 2016.

LIU, Z.; ALEXANDER, M. Atmospheric bridge, oceanic tunnel, and global climatic teleconnections. Reviews of Geophysics, v. 45, 2007.

LORENZ, E. N. Deterministc nonperiodic flow. Journal of the Atmospheric Science, 20, 130-141, 1963.

LORENZ, E. N. Climatic determinism. Meteorological Monographs American Meteorological Society, 25, 1-3, 1968.

LORENZ, E. N. Three approach to atmospheric predictability. Bulletin of the American Meteorological Society. 50, 345-351, 1969.

MAACK. R. Geografia física do estado do Paraná. 2 ed. Rio de Janeiro: Livraria José Olympio Editora, 1981.

MENDONÇA, F.; DANNI-OLIVEIRA, I. M. Climatologia: noções básicas e climas do Brasil. São Paulo: Oficina de Textos, 2007.

MILHORANÇA, I. A. Modelos paramétricos para séries temporais de contagem. 2014. Dissertação (Mestrado em Estatística) - Instituto de Matemática e Estatística, Universidade de Sâo Paulo, Sâo Paulo, 2014.

MOLION, L.C.B.; BERNARDO, S. O. Dinâmica das chuvas no Nordeste brasileiro. In: XI Congresso Brasileiro de Meteorologia. Rio de Janeiro: Anais do XI CBMET, 2000.

MONTEIRO, C. A. F. Clima. In: INSTITUTO BRASILEIRO DE GEOGRAFIA E ESTATÍSTICA. Geografia do Brasil: Grande Região Sul. Rio de Janeiro, v.4, n.18,Tomo I, 1968, p.114-166.

MONTEIRO, C. A. F. A frente polar atlântica e as chuvas de inverno na fachada Suloriental do Brasil: Contribuição metodológica à análise rítmica dos tipos de tempo no Brasil. 1969. Tese. (Doutorado em Geografia), Universidade de São Paulo, São Paulo, 1969.

MONTEIRO, C.A.F. Análise Rítmica em Climatologia. Climatologia 1: São Paulo. IGEOG/USP, 1971.

MONTEIRO, C. A. F. O nível de resolução para a análise da paisagem sob o enfoque de organização sistêmica. Material didático, 1974. 
MONTEIRO, C. A. F. Geossistema: a história de uma procura. São Paulo: Contexto, 2001.

MORETTIN, P. A.; TOlOI, C. M. C. Análise de Séries Temporais. 2. ed. São Paulo: Edgard Blucher, 2006.

NERY, J. T. Dinâmica climática da região sul do Brasil. Revista Brasileira de Climatologia. São Paulo, v.1, n. 1. 2005.

NIMER. E. Climatologia do Brasil. Rio de Janeiro: IBGE, 1979.

NUNES, L. H. - "Mudanças climáticas, extremos atmosféricos e padrões de risco a desastres hidrometeorologicos" In: HOGAN, D. J. \& MARANDOLA JR, E. (org.) Populações e mudanças climáticas: dimensões humanas das mudanças ambientais globais. Campinas: NEPO/ Unicamp; Brasília: UNFPA, 2009.

OLIVEIRA, G. S. El Niño e você: o fenômeno climático. São José dos Campos: Transtec, 1999.

PAIVA, C. S. M.; FREIRE, D. M. C.; CECATTI, J. G. Modelos aditivos generalizados de posição, escala e forma (GAMLSS) na modelagem de curvas de referência. Revisa Brasileira de Ciências da Saúde, v. 12, n. 3, p. 289-310, 2008.

RAMPAZZO, L. Metodologia científica. São Paulo: Edições Loyola, 2010.

RAO, V. B.; HADA, K. Characteristics of Rainfall over Brazil: Annual variations and connections with the Southern Oscillation. Theoretical and Applied Climatology. v. 42. 1990.

REBOITA, M.S.; GAN, M.A.; ROCHA, R.P. \& AMBRIZZI, T. Regimes de precipitação na América do Sul: uma revisão bibliográfica. Revista Brasileira de Meteorologia: v. 25, n. 2 185-204, 2010.

REBOITA, M. S.; SANTOS, I. A. Influência de alguns padrões de teleconexões na precipitação do Norte e Nordeste do Brasil. Revista Brasileira de Climatologia, v.15, 2014.

RODRIGUES, C.; ADAMI, S. Técnicas de hidrografia. In: VENTURI, L. A. B. Geografia: Práticas de campo, laboratório e sala de aula. São Paulo: Sarandi, 2011.

ROWELL, D. P.; FOLLAND, C. K.; MASKELL, K.; WARD, M. N. (1995), Variability of summer rainfall over tropical north Africa (1906-92): Observations and modelling. Q.J.R. Meteorol. Soc., 121: 669-704.

SANT'ANNA NETO, J. L. As chuvas no Estado de São Paulo. 1995. Tese (Doutorado em Geografia Física) - Faculdade de Filosofia, Letras e Ciências Humanas, Universidade de São Paulo, São Paulo, 1995.

SANT'ANNA NETO, J. L . Clima e Organização do Espaço. Boletim de Geografia, v.15, no 01, p. $119-131,1998$. 
SECRETARIA DE ESTADO DO MEIO AMBIENTE E RECURSOS HÍDRICOS. Bacias hidrográficas do Paraná: Série histórica. Governo do Estado do Paraná, 2010.

SHELTON, M. L. Hydroclimatology: Perspectives and applications. Cambridge: Cambridge University Press, 2009.

SILVA, C. B. da. Variabilidade climática nos oceanos e a vazão fluvial no Planalto Brasileiro. 2012. Dissertação (Mestrado em Geografia Física) Faculdade de Filosofia, Letras e Ciências Humanas, Universidade de São Paulo, São Paulo, 2012.

SILVA, M. E. S.; SILVA, C. B. Variabilidade climática - Processos físicos e dinâmicos nos oceanos e atmosfera. Revista do Departamento de Geografia (USP), v. 2, 2012.

SILVEIRA, A. L. L. Ciclo hidrológico e bacia hidrográfica. In: TUCCI, C. E. M. Hidrologia: Ciência e aplicação. Porto Alegre: Ed da Universidade - UFRGS, ABRH, 2001.

SORRE, M. Les Fondements de la Géographie Humaine. Paris: Armand Colin, 1951.

SOTCHAVA, V. B. O estudo de geossistemas. São Paulo: Ed. Lunar, 1977.

STASINOPOULOS, D. Mikis et al. (2007). Generalized additive models for location scale and shape (GAMLSS) in R. Journal of Statistical Software, v. 23, n. 7, p. 1-46.

STOECKENIUS, T. Interannual variations of tropical precipitation patterns. Mon. Wea. Rev. n. 109. 1981.

STRAHLER, A. N. Dynamic basis of geomorphology. Geological Society of America Bulletin. N. 63, p. 923-938, 1952.

TERASSI, P.M.B. Variabilidade pluviométrica e a erosividade na unidade hidrográfica Pirapó, Paranapanema III e IV, Paraná. Dissertação (Mestrado). Maringá, Universidade Estadual de Maringá, 2015.

THOMPSON, J. W.; The Organismic Conception in Meteorology. General Systems, 6, p. 45-49, 1961.

THORNTHWAITE, C. W. An approach toward a rational classification of climate. Geographical Review. v.38, p.55- 94, 1948.

TRENBERTH, K. E. The Definition of El Niño. Bulletin of the American Meteorological Society. v.78, 1997.

TRICART, J. Ecodinâmica. Rio de Janeiro: IBGE/SUPREN, 1977.

TUCCI, C. E. M. Fundamentos do escoamento não-permanente. In: TUCCI, C. E. M. Hidrologia: Ciência e aplicação. Porto Alegre: Ed. da Universidade - UFRGS, ABRH, 2001. 
TUCCI, C. E. M. Escoamento Superficial. In: TUCCI, C. E. M. Hidrologia: Ciência e aplicação. Porto Alegre: Ed. da Universidade - UFRGS, ABRH, 2001.

TUCCI, C. E. M. Controle de enchentes. In: TUCCI, C. E. M. Hidrologia: Ciência e aplicação. Porto Alegre: Ed. da Universidade - UFRGS, ABRH, 2001.

TUCCI, C. E. M.; BELTRAME, L> F. S. Evaporação e Evapotranspiração. In: TUCCI, C. E. M. Hidrologia: Ciência e aplicação. Porto Alegre: Ed. da Universidade - UFRGS, ABRH, 2001.

TUNDISI, J. G. Ciclo hidrológico e gerenciamento integrado. Ciência e Cultura. São Paulo: v. 55, n. 4, p. 31-33, 2003.

VANDENBERGHE, J. Climate forcing of fluvial system development: an evolution of ideas. Quaternary Science Reviews, v.22. 2003.

VAREJÃO-SILVA, M. A. Meteorologia e Climatologia. Recife: Versão digital 2, 2006.

VON BERTALANFFY, L. Teoria geral dos sistemas. 5 ed. Petropolis: Vozes, 2010.

WINTER, T. C. The concept of hydrological landscapes. Journal of the American Water Resources Association. V.37, 2001.

WORLD METEOROLOGICAL ORGANIZATION. Guide to Hydrological Practices, Data Acquisition and Processing, Analysis, forecasting and other Applications. Geneva: 5 ed. $n$ 168, 1994.

YOSHIMOTO, T.; SUETSUGI, T. Comprehensive flood disaster prevention measures in Japan. Hydrological Processes and Water Management in Urban Areas: IAHS Publ. n. 198, 1990.

ZANDONADI, L. As chuvas da bacia do rio Paraná, Brasil: Um estudo do ritmo climático e algumas considerações sobre a vazão hídrica. 2013. 206f. Tese (Doutorado). Programa de Pós-Graduação em Geografia, Universidade Estadual Paulista "Júlio de Mesquita Filho", Rio Claro, 2013.

ZAVATINI, J.A. A Dinâmica Atmosférica e a Distribuição das Chuvas no Mato Grosso do Sul. Tese de Doutorado. FFLCH/USP, 1990. 